
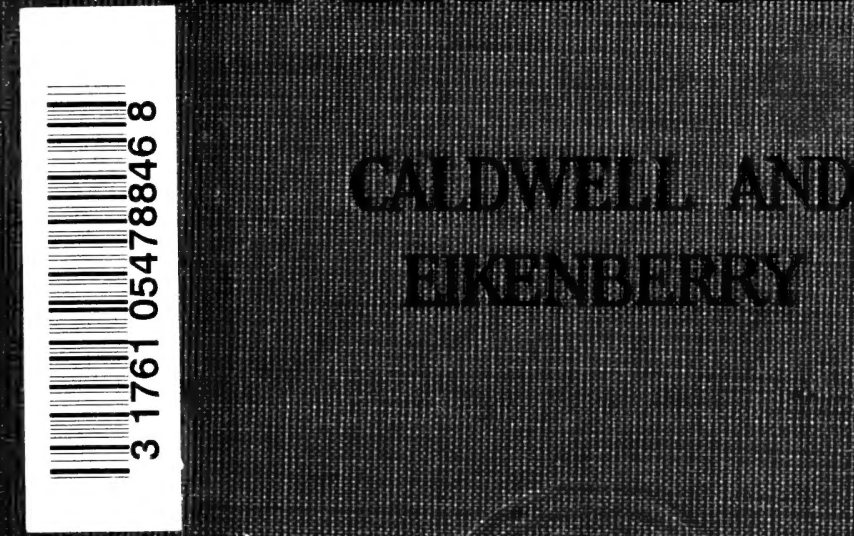
Digitized by the Internet Archive in 2007 with funding from . Microsoft Corporation 


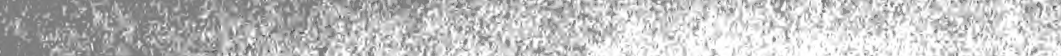

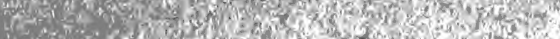

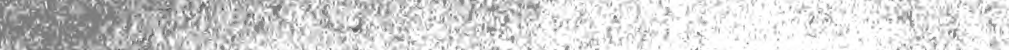

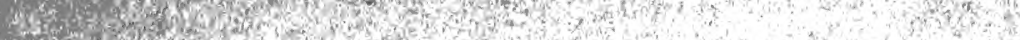

7.

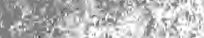

tif

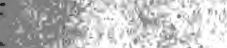

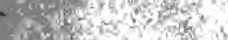

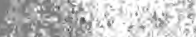

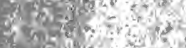

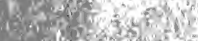

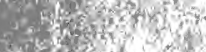

20132 in

the 180

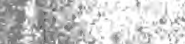

$-71230.2$

Shoteres

* $x_{0}$

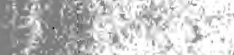

in $6 x x^{2}$

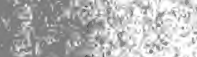

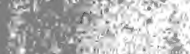

+

(19)

$f^{2}=7$ in -2

2.:

o 15 y

(f) on

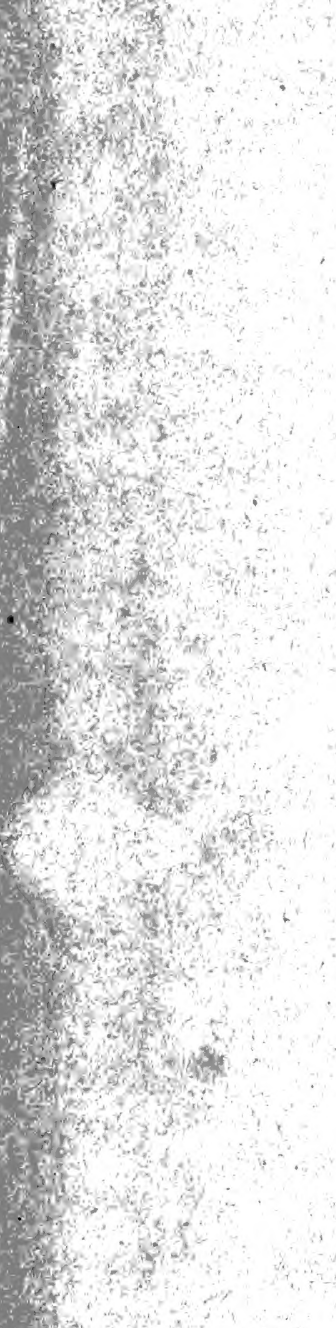

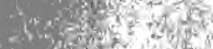

3.

3.

3.

3.

The

Pons

3)

Afr

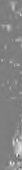

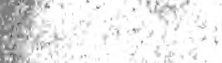

$200+2+2$

20

nei

$3_{0}, \quad 48$

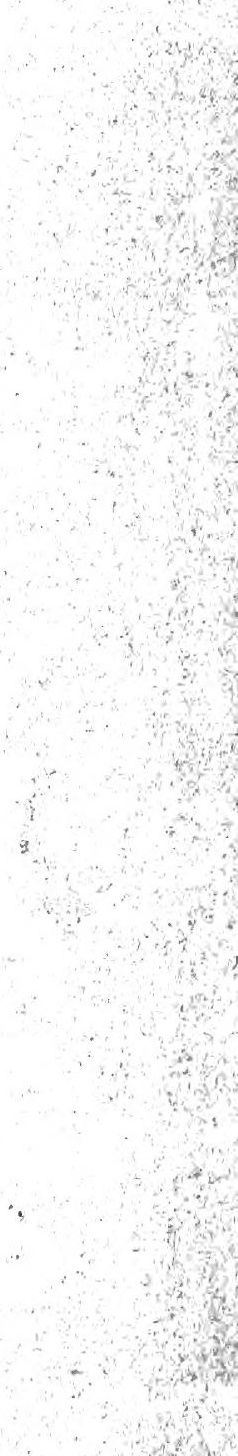




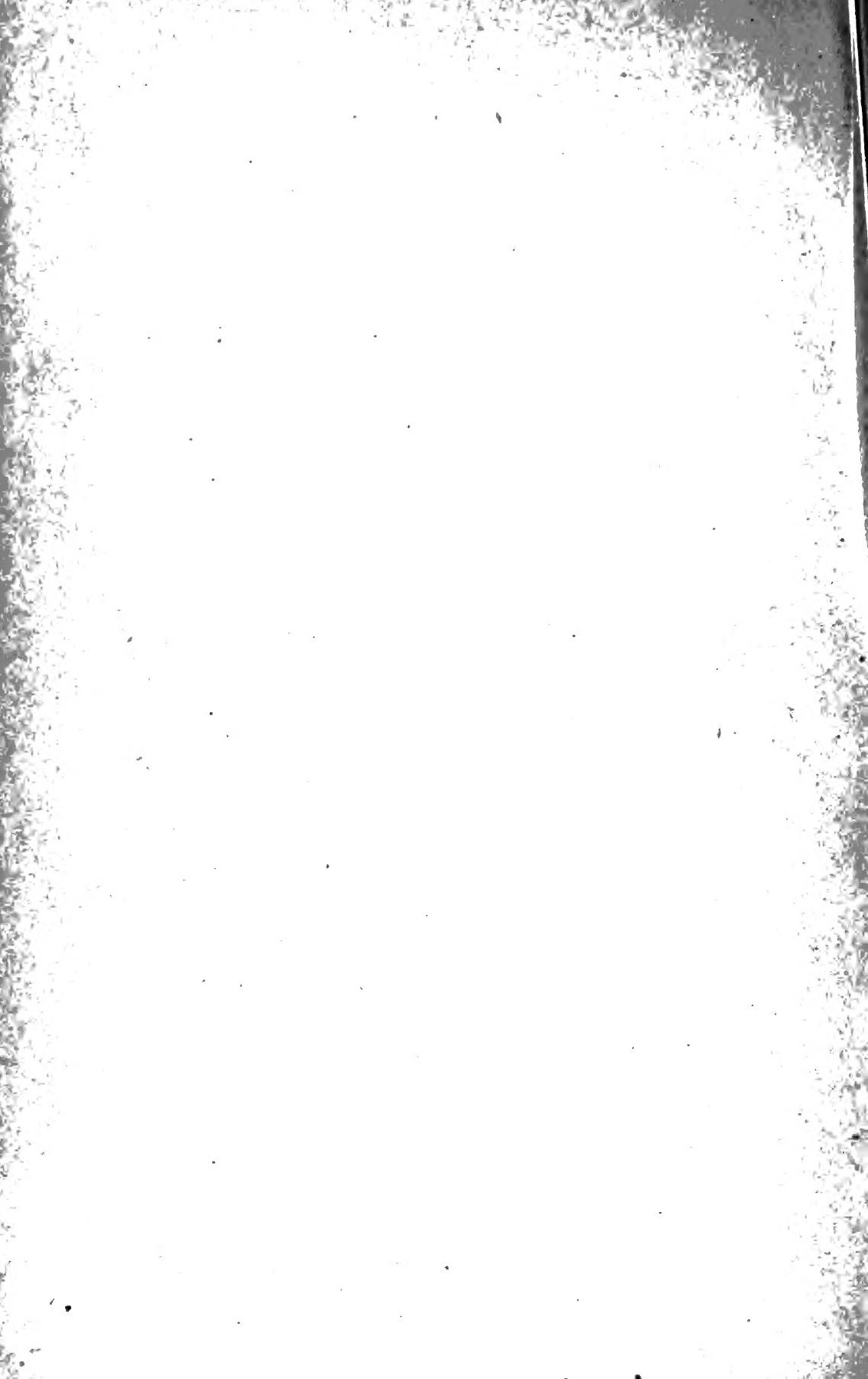




\section{ELEMEN'TS OF}

\section{GENERAL SCIENCE}

BY

OTIS WILLIAM CALDWELL, Рн.D.

HEAD OF THE DEPARTMENT OF NATURAL SCIENOE

SCHOOL OF EDUCATION IN THE UNIVERSITY OF CHICAGO

AND

WILLIAM LEWIS EIKENBERRY, B.S.

INSTRUCTOR IN THE UNIVERSITY HIGH SCHOOL

SOHOOL OF EDUCATION IN THE UNIVERSITY OF CHICAGE

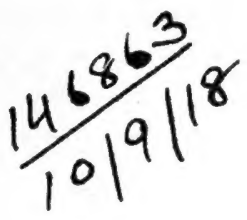

\section{GJNN AND COMPANY}

BOSTON - NEW YORK - CHICAgO - LONDON

atlanta - Dallas - columbus - san francisco 
COPYRIGHT, 1914, BY OTIS W. CALDWELL

AND WILLIAM L. EIKENBERRY

ALL RIGHTS RKSERVED

8136 


\section{PREFACE}

Science instruction in the first year of the high school has presented one of the most serious problems in secondaryschool work. First-year pupils usually do not possess a large fund of information about the common phenomena of nature, or they may not attempt a scientific interpretation of these phenomena. This lack in abundant, concrete, and rationalized experience has made it extremely difficult to secure the desired results from the first science course through presentation of any one of the differentiated sciences. Experiments have been under way in different parts of the United States for several years with the purpose of securing an organization of science materials and a method of presentation which shall prove more educative. It has been the object of these experiments to develop a more usable fund of knowledge about common things and a more scientific attitude in interpreting common problems, and to discover and to utilize interest and ability in such ways that more effective and more profitable work may thereafter be done in the differentiated sciences. These experiments have shown uniformity in their attempt to use the point of view of the relatively uninformed pupil, and while they have followed several lines of effort, in the main they have come to use a similar body of knowledge.

The course presented in this book is the result of six years of experiment with a number of pupils, averaging about one hundred per year. During this time several persons have assisted in teaching the course and have made contributions to it. Teachers of subjects other than science, and particularly the administrative officers who are studying the efficiency of the whole high-school curriculum, have been constant observers and 
critics of the experiment. The success of the course has been such as to justify its presentation, with the hope that it may prove helpful in increasing the efficiency of science teaching.

The unity which is essential to any worthy study of science is here secured by means of the logical connections between the topies which compose the course, no attempt being made to maintain the unity of any one of the different sciences from which materials are taken. These topics are readily arranged under five major headings. Within these major topics the subtopics, which are further divided into sections, are arranged so that there is constant coherence, thus giving progression in the nature of the work.

The difficulties which arise in the selection of material for a general science course are largely those of elimination. Even after the exclusion of all materials which are obviously unsuited for elementary presentation, the richness of the field is embarrassing. At the same time any such selection must be definite and limited if it is to be useful. The authors have made choice of the materials here indicated upon grounds of pedagogical value and after extended classroom use.

The topics considered are those of general significance. Apparatus suggested for use in experiments should be the most simple available. Apparatus from the community and home may often be more educative than that which is complex and costly. In general, each pupil should work out his own experimental problems, but in many cases a single demonstration to all the class by the teacher or by a small group of pupils is preferable to individual experiments.

The authors wish particularly to express their appreciation for the advice and criticism given in various ways by Director Charles H. Judd, Principal F. W. Johnson, Dr. Mary Blount, Mr. George J. Miller, Dr. E. S. Bishop, Mr. C. J. Pieper, and Professors C. R. Mann and R. A. Millikan. 


\section{CONTENTS}

\section{PART I. THE AIR}

CHAPTER I. SOME CHARACTERISTICS OF THE AIR . . .

PAGF

Air as material. Working under water. The weight of air. Air pressure. Measurement of air pressure. Graduation of the barometer. Altitude and air pressure. Effect of temperature. Thermometers. Some effects of expansion. Convection currents. Hot-air furnaces. Chimneys. Importance of air temperature.

CHAPTER II. TEMPERATURE CHANGES AND THE SEASONS

Seasonal changegs of temperature. Relation of the seasons to the sun. Effects of changes in sun's altitude. Length of day and night. How the air is warmed.

CHAPTER III. THE WATER OF THE AIR . . . . . . .

Evaporation. Amount of water in the atmosphere. Absolute humidity and relative humidity. Some examples. Determination of relative humidity. Variations in relative humidity. Humidity in houses. Total amount of water in the air.

CHAPTER IV. THE WEATHER

General statement. Air pressure and winds. Pressures as shown by weather maps. Procession of high and low pressures. Winds about a "low"-cyclones. Temperature in a cyclone. Humidity in a cyclone. Passage of a cyclone. Weather in anticyclones. Hot and cold waves. Hurricanes. Thunderstorms. Tornadoes. General circulation of air on the earth. Rainfall in the United States. The United States Weather Bureau.

CHAPTER V. STRUCTURE OF AIR: MOLECULAR THEORY Compressibility of air. Expansion of gases. Diffusion of gases. Some questions regarding gases. A theory about the air. Molecular theory applied to air. Gas pressures. Heat and molecular movement. Gas mixtures. Liquids and solids.

CHAPTER VI. COMPOSITION OF AIR: ATOMIC THEORY . . The air not a simple substance. The flame and the air. A burning candle. Products of the flame. Water produced by a flame. The 
composition of water. The molecule of water. Explanation of some chemical terms. Formation of water in the flame. Other products from the flame. Carbon dioxide formed by the flame. Some further facts about carbon dioxide. The gases of the air. More about oxygen. Nitrogen and argon. Summary.

CHAPTER VII. RELATION OF AIR TO FOOD MANUFACTURE

Sources of our food. Source of plant food. Food of plants. The place where food is made. Some problems. Structure of the leaves. Structure of the epidermis. Structure of the leaf interior. Entrance of materials into the leaf. Manufacture of carbohydrates. The waste material. The source of energy. Importance of chlorophyll. Photosynthesis. Sugar and starch in the leaf. Comparison with a factory. Importance of photosynthesis.

CHAPTER VIII. DUSTS, MOLDS, AND BACTERIA OF THE AIR 79

Dust in the air. Dust is everywhere. The nature of dust. Living dust. Dependent plants. Bacteria. Bacteriology. Relation of bacteria to decay. Bacteria and disease. Useful bacteria. Bacteria in cultivation.

CHAPTER IX. DISTRIBUTION OF BACTERIA AND OTHER DISEASE GERMS .

Distribution of bacteria. Bacteria upon carelessly handled bread. Transmission of typhoid bacteria. Importance of pure milk and water. Results of improved hygienic conditions. Typhoid carried by flies. The life history of house flies. How flies carry bacteria. Disposal of house files. Cleanliness and disease. Practical questions. Mosquitoes and malaria. Malaria caused by an animal organism. The life history of the mosquito. How mosquitoes carry malaria. How to destroy mosquitoes. Different kinds of mosquitoes. Disease germs distributed by other insects.

\section{PART II. IVATER AND ITS USES}

CHAPTER X. ICE, WATER, AND STEAM .

The three states of matter. When water freezes. Changing water to steam. Other facts about steam. Distillation. Boiling and melting points. Evaporation. Laws of evaporation. Cooling effects. Ice machines and cold storage. Perspiration. Amount of water evaporated by the air. Evaporation from plants : transpiration. Refrigerators. Freezing mixtures. 
Importance of water. The siphon. The lift pump. Why the water rises in the pump. The problems of water pressure. Pressure on horizontal surfaces in general. Pressure on the sides of a tank. Upward pressure in a liquid. Relation to size of a tank. Effect of the shape of a tank. Pressure in other liquids. Calculation of fluid pressure. Transmission of pressure in liquids. The principle of the hydraulic press. Air pressure. Pressure in other fluids. Dams. Buoyancy. Floating objects. Submarines and balloons. Densities.

ChAPTER XII. ClimATIC INFLUENCES OF BODIES OF WATER . . . . . . . . . . . . .

Importance of lakes and oceans. The Great Lakes. The lakes and summer temperatures. The lake breeze. Cause of the lake breeze. Causes of unequal heating of land and water. Cooling of land and water. Effects of Lake Michigan on temperature. Reason for difference between east and west shores. Some general conclusions. Some effects of lake climate.

CHAPTER XIII. COMMERCIAL RELATIONS: THE GREAT LAKES

Commercial importance of the Great Lakes. Advantages of water transportation. Origin of lake cities : Chicago as a type. Extension and improvement of waterways. The railroads. Harbors. Lights, buoys, and life-saving stations. Other ports.

CHAPTER XIV. WATER SUPPLY AND SEWAGE DISPOSAL

Sources of water supply. Importance of pure water. Kinds of impurities. Sources of bacteria in lakes and rivers. Methods of securing pure water. The problem of sewage disposal. Sewers. A problem in sewage disposal. The sanitary canal. Sewage treatment and disposal. Rural water supplies. Disposal of wastes in rural districts.

\section{PART III. WORK AND ENERGY}

CHAPTER XV. WORK BY RUNNING WATER .......

The power of running water. Work done by Niagara Falls. Utilization of running water. Undershot water wheels. Overshot water wheels. Turbines. 
CHAPTER XVI.WORK . . . . . . 170

About work in general. Different methods of working. A problem in work. Decreasing friction by the use of rollers. Some facts about pulleys. Mechanical advantage of pulleys. Work and pulley systems. Work defined. Measurement of work. Calculation of work in pulley systems. Efficiency. Summary.

CHAPTER XVII. MECHANICAL ENERGY AND HEAT .

Capacity for doing work. Examples of bodies possessing energy. Kinds of energy. Measurement of energy. Work against friction produces heat. Energy transformed into heat. Work done by heat. The steam engine. Transformations of energy. Loss of energy. The source of energy. Amount of energy from the sun. Energy and work in living things.

\section{PART IV. THE EARTH'S CRUST}

CHAPTER XVIII. NATURAL FORCES UPON THE SURFACE OF THE EARTH .

The surface of the earth. The surface and water. Work by freezing water. Other changes due to water. Glaciers and the earth's crust. Effect of plants and animals. The soil and its significance.

CHAPTER XIX. PHYSICAL STRUCTURE OF THE SOIL .

Kinds of soil. The structure of the soil. Size of soil particles. Plants and animals as soil formers. Raw materials for plant food.

CHAPTER XX. SOIL WATER, DRAINAGE, AND IRRIGATION

Amount of water in the soil. Soil water and soil temperature. A mount of water used by crops. Soil water as affected by tillage. Natural drainage of the soil water. Artificial drainage of soil water. Irrigation. Source of water for irrigation. Dry farming. Reclamation of swamp lands.

\section{CHAPTER XXI. EROSION AND SEDIMENTATION}

Removal of the soil : erosion. Loss from water erosion. Vegetation and erosion. Deposit of soil from erosion. Erosion by wind.

CHAPTER XXII. LIFE IN THE SOIL

Living things in the soil. Interrelationship of living things in the soil. Bacteria of the soil. Soils and man. 


\section{PART V. LIFE UPON THE EARTH}

CHAPTER XXIII. THE PLANT COVERING OF THE EARTH

Abundance of plants. Variety among plant formations. Value of wild plants. Cultivated plants.

CHAPTER XXIV. ABSORPTION FROM THE SOIL BY PLANTS

The problem. Loss of water from the soil. Osmosis. Root structure. Root surface. Water-carrying tissues. Solids absorbed only when in solution. Root surface and transplanting. Summary.

CHAPTER XXV. THE WORLD'S FOOD SUPPLY

The demand for food. The source of food. Composition of foods. Protein manufacture. Loss of nitrogen from soil. The supply of nitrogen. The value of the soil. Summary.

CHAPTER XXVI. UTILIZATION OF FOOD IN THE PLANT

Need of food in the plant. Where food is used. The method of transfer. Digestion of starch. Digestion of other substances. Transference in the plant. Food storage. Use of food by plants. Assimilation and respiration.

CHAPTER XXVII. NUTRITION OF ANIMALS

Plants and animals. Processes of animal nutrition. Mastication: teeth. Structure of the teeth. Mastication: the saliva. Mastication: use of the saliva. Digestion in the stomach and intestines. Circulation. The heart as a force pump. Transportation and assimilation of food. Respiration. Proper nutrition.

CHAPTER XXVIII. HYGIENIC ASPECTS OF NUTRITION

The purpose of food. The body a machine. Prolonged mastication. Heavy eating. Variety of food. Contaminated food. Food and filth. Circulation and nutrition. Breathing and nutrition.

CHAPTER XXIX, REPRODUCTION IN PLANTS AND ANIMALS

Meaning of reproduction. Reproduction of the yeast plant. Reproduction of pond scum. The frog's egg. Development of the egg. The tadpole. Reproduction in birds and mammals. Reproduction in seed plants: the flower. The pistil. The stamen. The embryo plant. The seedling. Vegetative reproduction. 
CHAPTER XXX. THE STRUGGLE FOR EXISTENCE

The meaning of the term. Overproduction among plants. Overproduction among animals. Not food enough for all. Climatic dangers. Destruction by disease. The balance of life. Types of disturbance of nature's balance of life.

CHAPTER XXXI. PAREN' $\Lambda$ ND OFFSPRING

Which plants and animals are to live. The nature of variation. Hybrids. Natural and artificial selection. Changes in environment. Results of natural selection. Artificial selection. Progressive results of artificial selection. The weakness of the artificially selected types. Inheritance. Heredity and the future of the race. Controlling humaı environment. 


\section{INTRODUCTION}

Science instruction in high schools and in elementary schools is in difficulty. Within the last generation we have seen a remarkable series of phenomena in this matter of science teaching in the schools. Following the example of higher institutions of learning, and of society at large, the schools began, about a generation ago, to manifest a keen interest in the laws and facts of nature. The schools took up nature study, physiography, botany, physics, and some chemistry and zoölogy. Popular sentiment demanded the introduction of physiology, and a miscellaneous body of science was already in the elementary schools under the head of geography. No one thought for a moment that there could be the slightest question about the value of science courses in the schools. What has happened? First and most striking is the fact that science courses are not yet properly placed or in any definite way established in the schools. Second is the impressive fact that in an age when science has the right of way everywhere else, - in business, in popular thought, and in our higher institutions of learning, - the number of students pursuing science in our high schools is in many departments relatively less than it was ten, and even twenty, years ago, and in the elementary schools the so-called nature-study courses are loudly called in question by teachers and supervisors.

It would perhaps be ungracious for a layman to dwell upon this inhibition of science if it were not such a grave fact in school organization. The school administrative officer looks on with wonder and consternation while science specialists fall upon one another in vicious assault. College and university teachers of science, with a curious lack of logical acumen, 
repudiate their own students and their own examples by roundly vituperating science as taught in the lower schools. They tell us it would be better that the boy should not take physics in the high school and that the girl should come to college without any of the chemistry or botany with which she has been misled in elementary courses. If we go to the high schools and ask what science the sophomore or the junior should study, we hear a clamor of tongues telling discordant tales. Finally, there are few, and these are for the most part the outlaws of science, who deal with elementary-school problems.

Perhaps it would be well to follow the advice of some scientific specialists and close all the science courses for a time. To be sure, there are many future citizens who would then never have the opportunity of knowing nature as she is expounded by the apostles of the pure thought and undiluted research. There would be more probability that unsound views about nature would pass current among the untutored populace. On the other hand, the scientists might have time during their cloistered association with one another to realize that they need the world quite as much as the world needs them.

If we decide not to close the science courses, there is the obvious alternative that we discover what has been the matter and reform the courses so as to fit them to the real situation. Experience does not seem to justify any expectation that the expert chemist, physicist, geologist, or biologist will always be wise in regard to the minds of students. Experience does show that the minds of students constitute part of the problem of science teaching. In fact, so important is the mind of the student that to neglect it seems to the lay thinker to be a cardinal error symptomatic of a lack of scientific breadth. Hence the enthusiasm of the lay observer when the scientist is seen actually experimenting with the problem of teaching.

In this matter of experiments in teaching, the instructor in science is a newcomer, a veritable amateur, as contrasted with 
the instructor in the humanities and languages. When one studies the history of methods of teaching reading or of teaching Latin, one realizes how much experimenting has been done. One understands, too, how the elementary courses in these subjects have been perfected by many trials and errors. Why did not science begin at once conserving its own interests by a higher method than the method of trial and error? For the reason that human nature has always begun its studies with things remote. As the ancients studied the stars before they studied the earth, as chemistry developed before anatomy, so to-day the student of the atom is so much absorbed in the thing remote that he overlooks his child's needs and the homely facts of human development. The result of this attention to far-away things is that science teaching is in difficulty even while science flourishes.

There is a science of science teaching. This new science is young. It is not recognized as yet by many who profess themselves to be hospitable to every form of research. But the new science can afford to be patient. The greatest conquests of which the older sciences are so proud are all matters of a century, at most, and many of these conquests fall within the memory of our own generation. There are men now working in biology who remember well the beginnings of the modern period in that science. So it will be with the science of teaching. Once we realize the value of experimentation, once we take seriously the problem of adapting intellectual material to real needs, we may look for a rapid and satisfactory growth in this our new science.

This book is a contribution to science teaching conceived in the spirit of science and elaborated under the critical scrutiny of those who wish to do more than merely mourn over the difficulties in which science teaching finds itself. As an ex. periment it has been successful enough to justify putting it forth as a working hypothesis. Verification or emendation will follow in due order. Its authors and their colleagues have the 
same type of enthusiasm for it as the physician has for his report of successful methods of treating a difficult case.

Our enthusiasm for the course is tempered by the knowledge that many a wise head will be shaken in doubtful negation. The course itself probably will not be accepted in some colleges as suitable preparation for the type of work which these institutions administer. The knowledge that it will thus knock in vain at certain academic cloors moves us, to be quite frank, only in the direction of a firmer belief that the course is needed. So we hold to our enthusiasm, confident that many a co-worker in the science of teaching will take from the book, not alone material about air and water, but also new encouragement to fit air and water and all nature to human needs and to students' needs.

CHARLES H. JUDD

The Univergity of Chicago 


\section{ELEMENTS OF GENERAL SCIENCE}

\section{PART I. THE AIR}

\section{CHAPTER I}

\section{SOME CHARACTERISTICS OF THE AIR}

1. Air as material. Most of the time we are quite unconscious of the air with which we are surrounded. In fact, we usually igiore the existence of the air, for if there is a glass tumbler on the table before us and this does not contain either a liquid or a solid, we say that it is empty. It is not empty, for it is filled with air, but since air is not visible, we ordinarily do not recognize its presence (fig. 1). Similarly, we often say, when we look out over the louses, tree tops, and open fields, that "there is nothing there," but if we go out of doors on a windy day

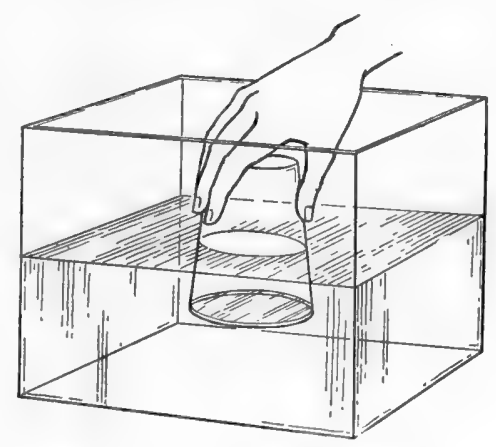

Fig. 1. An experiment with air

If an inverted drinking glass is forced downward into water, the air within the glass keeps the water from entering the glass we may be very forcibly reminded that there $i s$ something there.

If we examine a bicycle tire or a football empty of everything but air, we may find proof that air does really fill things, for everyone knows that when you attempt to flatten out an inflated football or tire, it resists and shows evidence of being 
filled. All of these common experiences, and many others, teach us that air is a very real substance, even though it is invisible, and that it occupies space as do other substances. This space-occupying property of air is useful to man in many ways.

2. Working under water. In laying the foundations of bridge piers and other structures which must rest below water level (fig. 2), it is common for the laborers to work in a

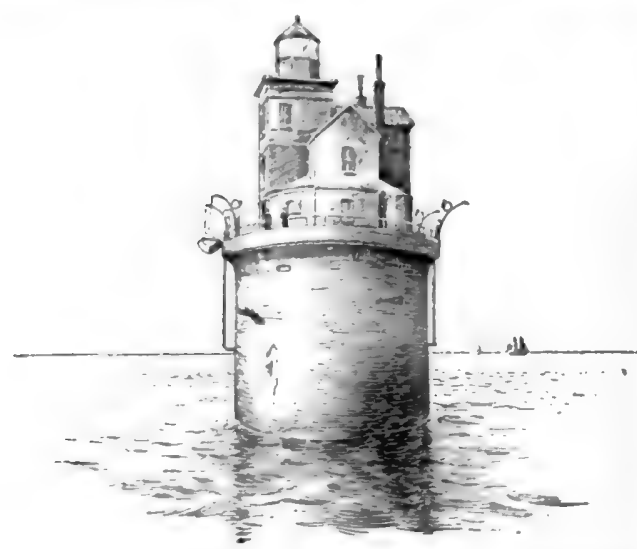

Fig. 2. A lighthouse upon a submerged foundation The foundation was constructed by men who worked under water large steel chamber which has no flocr and which rests upon the bottom of the lake or river (fig. 3). This is called a caisson. The water is kept out of the caisson by the use of air pumps which force air into it with sufficient pressure to overcome the pressure of the water. The entrance and exit of

workmen without allowing the escape of the air in the caisson is made possible by means of a shaft and air lock. The shaft, which contains a ladder, is a large, vertical, metal tube reaching from above the surface of the water down to the caisson. Within the shaft is a chamber, or air lock, with upper and lower doors, the lower opening into the caisson.

In case a workman wishes to enter the caisson, he first enters the air lock through the upper doors, which are closed after his entrance. Air is then forced into the air lock until its pressure is equal to that in the caisson. He then opens 
the doors leading to the caisson and enters, closing the doors behind him. When he emerges from the caisson the process is reversed. In practice it is found necessary to allow a man to remain in the intermediate chamber, or air lock, for some time, while the air pressure is slowly increased or decreased in order that he may not suffer from too sudden change of pressure.

Compressed air is used also for excluding water in excavating tunnels beneath water level. The principles involved in excavating tunnels are similar to those of the caisson. Diving bells are another form of apparatus in which air is used to exclude water from the working space when men work under water.

\section{The weight of air.} Not only is air like other substances in occupying space, but, like them, it has weight. The best way to show

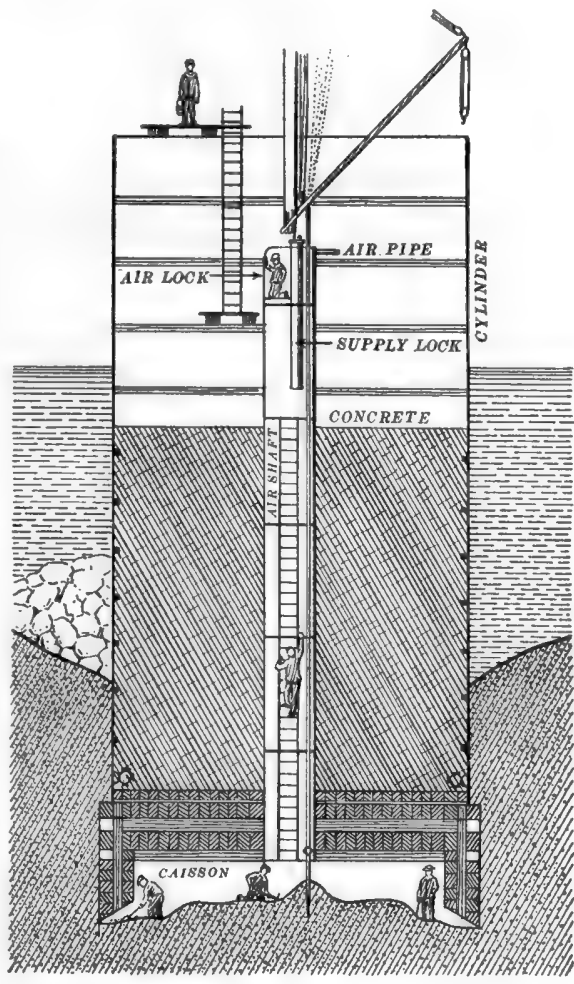

Fig.3. Working under water by means of an air chamber, or caisson

A sectional view of the caisson used in sinking the foundation for the lighthouse shown in figure 2. Note the men working in the air chamber below; also the three men in different stages of passing into the air chamber through the air lock. After a drawing by the United States Bureau of Lighthouses that air has weight is to weigh a quantity of it, as may be done in the following manner: The air (almost all of it) 
may be pumped from a brass globe or glass flask which is so constructed that it may be closed after the air has been

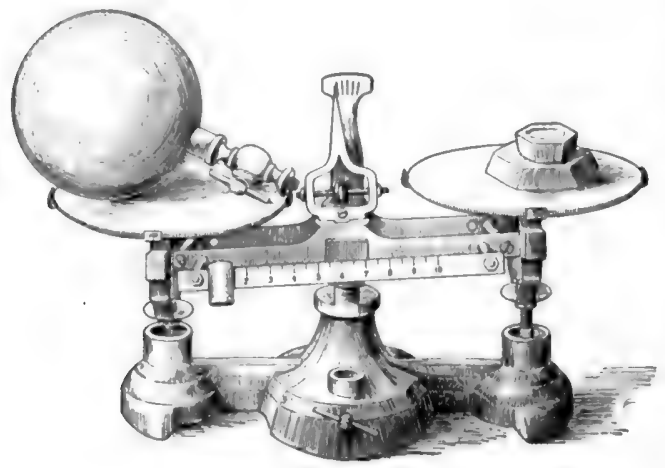

F1G. 4. Weight of air

'The glole, which was balanced after part of the air had been pumped from it, was found to be heavier when the air was again allowed to enter it removed. The closed vessel may then be placed upon a balance (see fig. 4) and weighed. If the vessel is opened (thus allowing air to enter it) and again weighed, any difference in weight that is found will be due to the air which luas come into the vessel. Supposing all the air was pumped out in the first place, the increase in weight would be precisely the weight of the air the vessel contains. Therefore we may measure the vessel used and calculate the cubic contents, and thus find out the weight of the air per cubic foot or meter, as shown by the experiment. This result will not be quite correct, since not all the air can be removed from the vessel by the pump, and therefore we include part of the air in both weights. Is our result greater or less than the true weight of air?

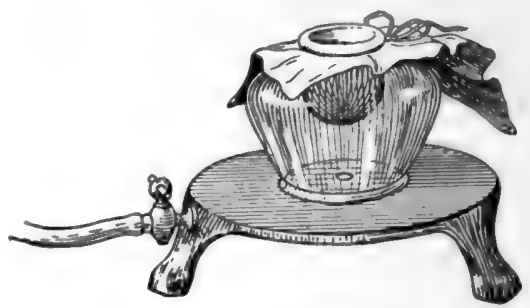

F1G. 5. Air pressure

When air is pumped from within the glass jar, the sheet of rubber tied over the upper. open end of the jar is forced downward by the weight, or pressure, of the outside air 
By attaching a barometer (sect. 5) to the air pump it is possible to find out what fraction of the air was left in the vessel, and this enables us to tell exactly what relation the amount of air removed by the pump bears to the whole amount of air in the flask. By this means we may ascertain the necessary corrections and discover the true weight of air. This has been

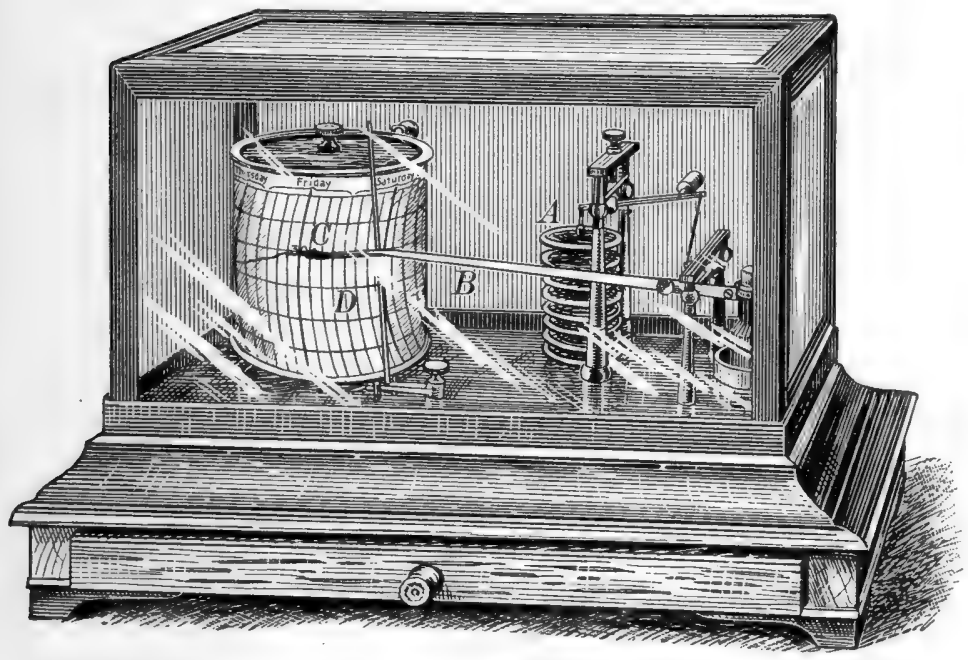

FiG. 6. An aneroid barometer (barograph)

This instrument automatically records the air pressure. $A$, metal boxes; $B$, pointer, at the tip of which is $C$, the pen; $D$, paper-covered cylinder which is rotated by a clock contained within it. As the pressure changes, the pen moves up or down, thus tracing its course upon the rotating cylinder of paper

done many times. The actual weight of air varies from time to time, because of changes in temperature, moisture, and pressure, but at $60^{\circ} \mathrm{F}$. it is about 533 grains, or 34.5 grams, per cubic foot.

4. Air pressure. If air has weight, it ought to press down upon the surface of the earth just as other objects do when they rest upon the earth, and it ought to rest upon us and other objects on the earth's surface with considerable weight. 
The truth of this may be tested in the following manner: A bladder glass (fig. 5) may be placed upon the stand of an air pump, with a sheet of rubber tied over the open top. If

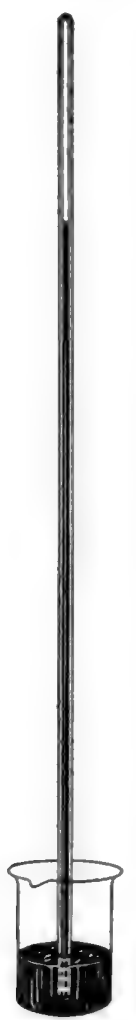

Frg. 7. A simple barometer

The weight of the air forces the mercury into the hollow glass tube. Any change in the weight of the air changes the height of the column of mercury there is any pressure upon the top, due to the weight of air, it does not push the rubber downward, because the air within the glass resists, as it does in the football or the tire. If, however, the air is partially removed from the interior of the glass by the use of a pump, the resistance from within is reduced and the rubber is pressed downward and may even be broken. It is plain that there is pressure upon the upper side of the rubber, but that so long as the air was allowed to remain in the glass the pressure upon the two sides was equal.

5. Measurement of air pressure. The pressure of the air is measured by use of instruments known as barometers. There are two principal types of barometers - the aneroid barometer and the mercurial barometer.

Let us consider the aneroid first (fig. 6). The part of this instrument which is sensitive to the air pressure is a small, thin-walled metal box shaped somewhat like the case of a watch. The air is exhausted from this metal box and it is sealed air tight. The pressure of the air tends to press the flat top and bottom of the metal box inward, as it did with the rubber top of the bladder glass, but the metal does not yield nearly so much as the rubber did. In fact, the metal bends so little that it is not easy to see the change taking place: For this reason an arrangement of levers or gear wheels which will magnify the motion is attached to the box and operates a pointer 
which moves up or down as the pressure increases or decreases. A still larger movement is secured in a compound barometer of this type, which is constructed by joining six or eight of the metal boxes (fig. 6 ).

The mercurial barometer is quite a different instrument. Indeed, at first it appears to have no resemblance to the aneroid. A simple mercurial barometer may be constructed in the following manner: Secure a glass tube about three feet long, with one end closed. Fill it with mercury, close the open end with the finger, invert the tube, and place the open end in a cup of mercury. When the finger is removed the mercury in the tube will not continue to fill the whole tube, but will fall so that the top of the mercury column is about 30 inches above the mercury in the dish (fig. 7). If this column of mercury is observed from time to time for several days, it will be found to slowly rise or fall. The change in height of the column is due to the change in pressure of the air.

6. Graduation of the barometer. In order to be an efficient instrument, a barometer must be graduated; that is, a scale of some kind must be attached to it in such a way that the movements of the pointer or of the top of the mercury column may be easily read and recorded. This scale might be marked in pounds pressure per square inch, and this would seem a very natural thing to do, but it is not the common method. Mercury

F1G. 8. A standard barometer

A mercurial barometer with thermometer and scales. The graduations allow both barometer and thermometer to be read. This is the standard form of barometer used by the United States Weather Bureau

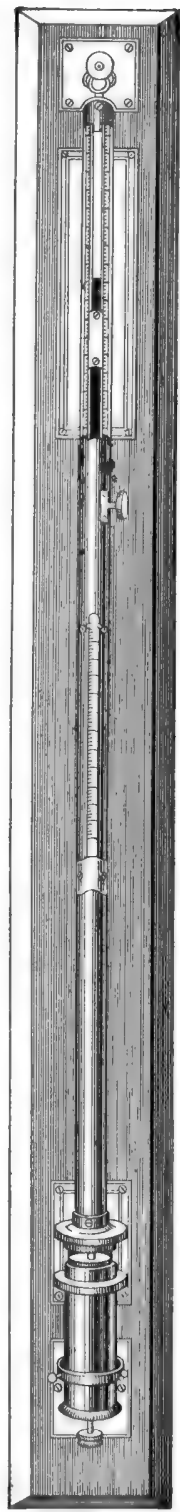


barometers were the first used, and usually we express the air pressure by stating the height of the column in a mercury barometer. 'These barometers are therefore graduated in inches or centimeters, and a scale of this sort will be found upon any practical instrument for measuring air pressure (fig. 8). An aneroid is commonly given a scale so graduated that the

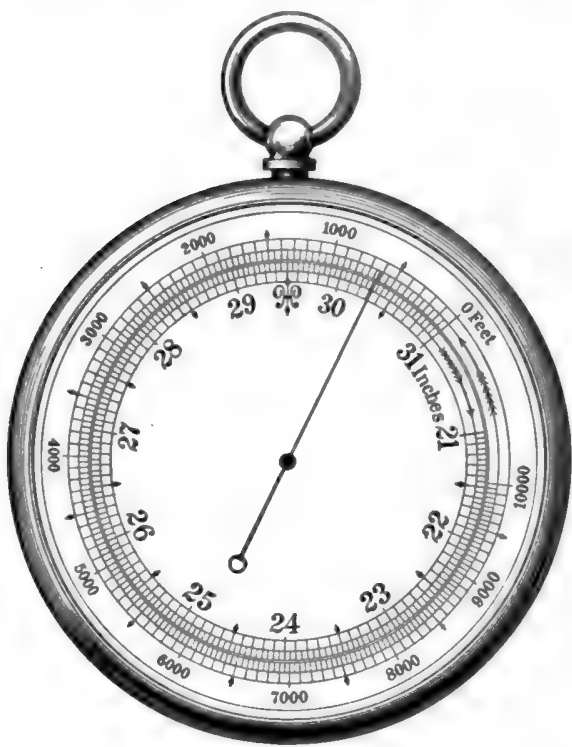

Fı. 9. A pocket aneroid barometer

This pocket type of barometer is graduated so as to show both the pressure and the elevation at which a reading is taken

numbers correspond with the readings of the mercury barometer. The readings of the two are therefore identical.

Since the air pressure decreases with increase of elevation, barometers may also be graduated to read in terms of the elevation above sea level. Aneroids are frequently so graduated, since their small size makes it possible to carry them conveniently (fig. 9). They may be used to ascertain the approximate height of mountains and the elevations reached by balloons or aëroplanes. Some aneroids are so constructed that a pen attached to the pointer is caused to write on a piece of paper which is kept moving by means of a clock in such a manner as to make a record of the readings. Such an instrument is called a barograph (fig. 6).

7. Altitude and air pressure. It was stated in the preceding paragraph that the pressure of the air is due to the weight of 
the air above. It must be plain that if we ascend in a balloon, we are leaving some of the air below us, and the pressure of the air at our elevation will be less by a proportionate amount. In the case of our bladder-glass experiment, if the experiment were conducted at a place 1000 feet up in the air, as in a balloon, the rubber would be pressed down by a force equal to the weight of the air above it; but there would be 1000 feet

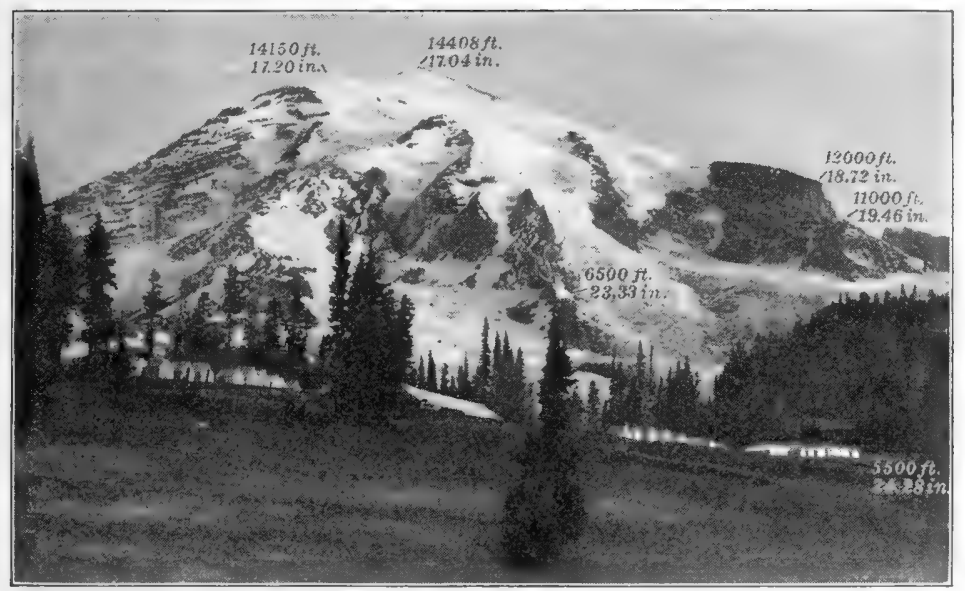

Fig. 10. Air pressures at different elevations

The illustration shows Mt. Rainier from 5500 feet to the summit. Figures are placed on the illustration to show the elevations at different points and the air pressures at these points. Note the decrease of air pressure with the increase of elevation

less depth of air above it than there would be if it were at the earth's surface, and the pressure would be correspondingly less. The same thing would be true on a mountain 1000 feet high, as has been noticed by those who have ascended mountains. It is this fact which makes it possible to use the barometer to measure altitudes (fig. 10).

It is not possible to state any exact rule as to the pressure which will be found at any given altitude, but at elevations of less than a mile above sea level the pressure decreases by 
an inch for each 900 to 1000 feet increase in altitude. The average pressures for various elevations are shown in the following table:

Euevarion
Sea level

8. Effect of temperature. It is often noticed that a pneu. matic tire which is only moderately firm in the morning, when the bicycle or automobile is first taken out upon the road, may be much harder by noon, as if more air had been put into it. The same thing will occur if the machine is allowed to stand in the sun. The additional pressure may indeed become so great as to burst the tire. Of course, it is very clear that no air has been added to that which was in the tire in the morning, for if the rubber will retain the air which is in the tire, it will be equally effective in preventing more from entering. Since such an increase of pressure as we have been describing occurs only when the tire has been heated by contact with the hot road or by direct exposure to the sun, it is fair to conclude that when the air is heated it has greater tendency to expand, and that it therefore presses harder against the walls of the tire and would expand if it were not confined by the tire.

The notion that air expands when heated ought to be tested before we accept it finally. This may be done in many ways. 
For instance, an empty bottle may be inverted and its mouth placed under water, and the bottle warmed by holding it between the hands (fig. 11) or by using a flame. The air will soon be warmed, and if it expands, bubbles of air will overflow from the mouth of the bottle and rise to the surface of the water. What other ways can you devise to test the notion that air expands when heated?

9. Thermometers. Air expands when heated and contracts when cooled. It is possible to arrange apparatus in such a way that this expansion may be observed and measured. An instrument by means of which such measurements could be made would give us some idea of the degree of heat. It would, in fact, be an air thermometer. Such thermometers have been constructed and used, but only for special purposes. For ordinary purposes much more satisfactory thermometers are made from other substances.

Thermometers such as are in common use depend upon the expansion and contraction of a liquid. The liquid most commonly used is mercury, though alcohol which has been colored red or blue is sometimes used. Each thermom-

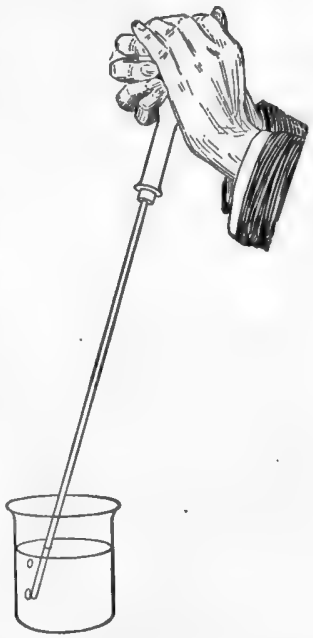

FiG. 11. Expansion of air When heated by the hands the air in the flask expands and bubbles of air appear at the open end of the tube under the water eter is furnished with a scale of degrees by means of which the temperature may be read. There are two sorts of scales in use in this country (fig. 12). The one in most common use is called the Fahrenheit scale, after the man who designed it. On this scale the freezing point of water is $32^{\circ}$ and the boiling point is $212^{\circ}$. The centigrade scale, which is the one used in all scientific work the world over, places the zero mark at the freezing point of water and the $100^{\circ}$ mark at the boiling point 
of water. Because there are two scales, it is always necessary, when we write temperatures, to indicate which scale is used, and thus we say that the boiling point is at $100^{\circ} \mathrm{C}$. or $212^{\circ} \mathrm{F}$. Since both types of thermometers are in use, it is important to be familiar with both of them and to be able to determine

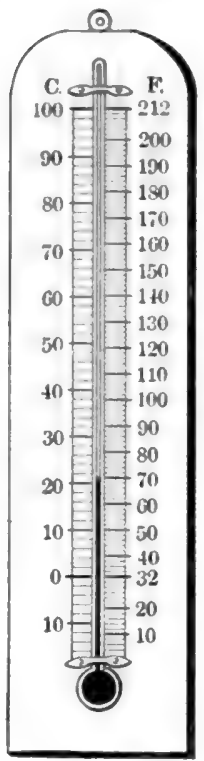

Fra.12. A mercurial thermometer

Both Fahrenheit and centigrade scales are shown the equivalent of a given reading of one thermometer in terms of the other type of thermometer.

In the Fahrenheit scale the freezing temperature is $32^{\circ}$ above zero and the boiling temperature is $212^{\circ}$ above zero. Therefore there are $180^{\circ}$ between freezing and boiling, according to the Fahrenheit system. In the centigrade system the freezing temperature is zero and the boiling temperature is $100^{\circ}$. Therefore 100 divisions on the centigrade scale equal 180 divisions on the Fahrenheit scale. One centigrade degree equals 1.8 Fahrenheit degrees. A temperature of $80^{\circ} \mathrm{C}$. is equivalent to $80 \times 1.8+32$, or $176^{\circ} \mathrm{F}$.

10. Some effects of expansion. It was learned in a previous experiment that if the air in a bottle is heated, the mouth of the bottle remaining open, the air will expand and some of it will escape. The air that remains fills all the space that the whole amount originally occupied, but plainly it cannot weigh the same, for only a part of the original air is in the bottle, and a part cannot weigh as much as the whole. Careful measurement and weighing will show that the weight of the bottle is less by exactly the weight of the air which has escaped. We usually express this by saying that heated air is lighter than cold air. We must remember, however, that this is true only under certain conditions. For instance, if we put a stopper in the bottle so that there can be 
no expansion and therefore no escape of air, after heating the bottle we shall have all the air that was in it at first, and it will weigh exactly the same. As stated before, if we allow the bottle to remain open, some of the air will escape, owing to expansion, and at the second weighing we shall be weighing only a part of the air that we had at the first, and hence the weight will be less. It would be better to say that heated air is lighter than cool air if we take equal volumes under the same pressure.

11. Convection currents. The fact that warm air of a given volume and pressure is lighter than cold air of the same volume and pressure explains many common occurrences. Almost everyone has noticed ascending currents of air over a radiator or stove. These currents are strong enough to carry upward light objects, such

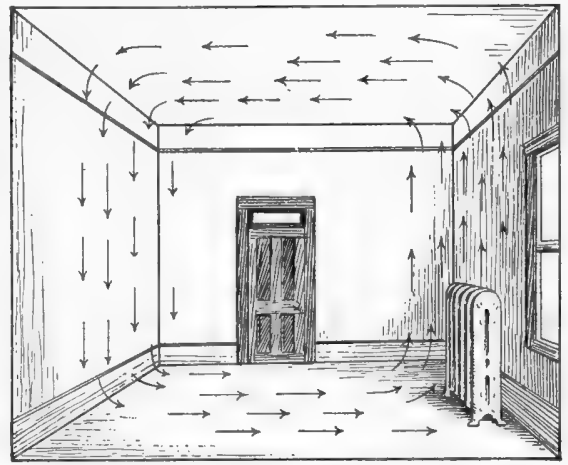

Fig. 13. The circulation of air

Diagrammatic representation of the circulation of air in a closed room heated by a radiator as bits of paper, and to cause pinwheels to revolve. When the air reaches the top of the room, it flows along the ceiling toward the more distant parts of the room, and as it becomes cooler it may descend again (fig. 13). Its course may be easily traced if it is mingled with smoke. Less commonly we notice that air is flowing along the bottom of the room from all sides toward the source of heat (radiator or stove). One may find these bottom currents very easily if he will hold a burning match or candle near the floor in the vicinity of a heated stove or radiator and note the direction in which the flame is blown. Their course also can be traced by adding smoke to the air. The air is always in circulation 
in a room containing a heated stove or radiator. Since the air in the vicinity of the source of heat is lighter, volume for volume, than that in the other parts of the room, it follows that the lower air near the stove does not have so much weight resting upon it as does that in other parts of the room. It is therefore pushed upward and finally reaches the ceiling, when it spreads out, is cooled, and descends slowly in the cooler parts of the room, only to flow across the floor toward the source of heat, where it will again be warmed and be pushed up. Thus the circulation continues. Currents of air that are caused by differences of temperature, such as the currents of which we have been speaking, are called convection currents.

12. Hot-air furnaces. The circulation of air in hot-air heating apparatus such as is commonly used in private houses is maintained by convection currents. The heater is located in the lowest part of the house, usually the basement, and is surrounded by a jacket which incloses a heating chamber. Cold air is admitted to this chamber from outdoors through a large pipe, is expanded by heating, is pushed up through the pipes leading from the top (why?) of the air chamber to the various rooms of the house, and escapes out of doors through available openings. In some cases the apparatus is so arranged as to take cold air from within the house, as from the front hall, instead of from without, but this arrangement is not desirable, as in this case the same air is passed through the rooms repeatedly, while by the other arrangement fresh air from outdoors is supplied continually. It will also be found of interest in this connection to determine the reason for the circulation of water in the pipes of hot-water heating plants.

13. Chimneys. The main purpose of a chimney is to supply a draft; that is, to cause the air to pass rapidly through the fire and make it burn more vigorously. The chimney must also remove the smoke. Since the air in the chimney is heated, it is not so heavy as the outside air. The outside air, therefore, 
pushes through the furnace into the chimney and crowds the warmer air upward with sufficient current to enable it to carry the smoke with it. But the incoming cold air is heated as it passes through the fire, so that it is lighter than the outside air and is in turn forced upward. The movement of the air is therefore continuous.

14. Importance of air temperature. The temperature of the air is a matter of importance to us all. It has much influence in determining whether our sports shall be tennis, golf, and baseball or coasting and snowballing; it decides for us whether the water shall invite us to swim or to skate; it even settles pretty largely the kind of clothing we shall wear, the food we shall eat, and the social activities in which we shall engage. It levies a tax upon us for coal at one time and for ice and electric fans at another. Our whole round of activities in business and pleasure is very largely regulated by the temperature of the air and the seasonal changes. 


\section{CHAPTER II}

\section{TEMPERATURE CHANGES AND THE SEASONS}

15. Seasonal changes of temperature. The change of temperature that comes with the seasons is to many of us the most notable and striking difference between the seasons. Why should there be such a difference? The sun still shines as brightly as ever, and its heat has not decreased in the winter. We are no farther away from the sun. Why are not our homes warmed as well by the sun in winter as in summer? In discussing this question it will be supposed that the reader remembers from his study of geography the main elementary facts about the sun and the earth. In any event it would be well to review the subject of the earth's orbit, its revolution and rotation, and its inclination upon its axis.

16. Relation of the seasons to the sun. All apparent changes in the sun's position are due to the movement of the earth around the sun, and to the inclination of the earth's axis (fig. 14). We often say that the sun rises and sets, when we know that these appearances are due to the motion of the earth. In the same way we say that the sun is higher in the heavens in summer than in winter, meaning that we have changed our position so that the sun appears higher. It is also noted that daylight lasts longer in summer than in winter.

We therefore know that as the seasons change there is also a change in the apparent altitude of the sun and in the length of day and night. It is to these changes that the seasons are due.

17. Effects of changes in sun's altitude. Why should it make any difference in the heat that we get whether the sun is high up in the heavens or lower down near the horizon? 
We all know that it does make a difference, for we readily feel that the heat which we receive at noon in the winter and at noon in the summer are not the same. Also, we notice the same thing when we compare the morning or evening effect of the sun with the effect at noon.

The reason for this difference in the effect of the sun's rays is not difficult to understand if we make use of a simple experiment. Suppose in the morning, when the sun is not very

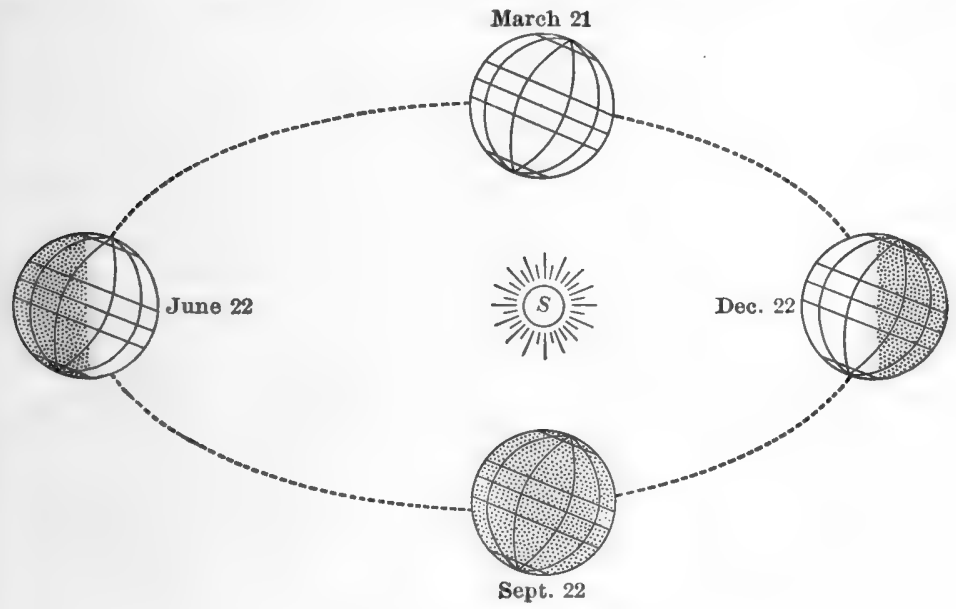

FIG. 14. The earth's orbit

A diagram showing the position of the earth with reference to the sun on four dates of the year

high, we hold a piece of paper with a large hole in it squarely facing the sun and notice the size of the spot of light on the ground. At noon we do the same. It will be seen that the spot of light observed in the morning experiment was larger; that is, in the morning, when the rays of the sun were more aslant than at noon, the rays of light and heat that came through the hole covered a larger space on the surface of the earth than at noon, when the rays were more nearly at right angles with the earth's surface (fig. 15). The light and heat 
coming through the hole might be the same in both experiments, but in the morning it is distributed over more surface and is therefore less intense. If you spread your butter over a larger piece of bread, it will be spread thinner.

Of course, the difference that you have discovered between morning and noon exists between winter and summer. Can you make a drawing showing exactly how large a space will be covered by a beam of sunlight one inch square if it comes to the earth at an angle of $65^{\circ}$ ? of $18^{\circ}$ ? In which case

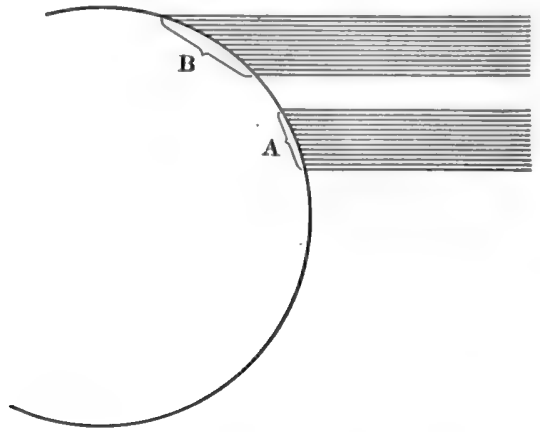

FIG. 15. Heating effects of sun's rays

Diagram showing the difference in inclination of the earth's surface to the sun's rays. A sunbeam of the given size would cover more area at $B$ than at $A$ would the earth's surface receive more heat to the square inch? How much more? Which corresponds to summer? to winter?

18. Length of day and night. In summer, when the sun is higher in the heavens, it is also visible more hours in the day. The difference between the longest day and the shortest one is not the same at all places. It is least at the equator and greatest at the poles. At intermediate places the difference corresponds to the distance from the equator. In the central part of the United States (central from north to south) the longest daylight, in the latter part of June, is about fifteen hours, and the shortest, in the latter part of December, is about nine and one-half hours (fig. 16).

The angle of the sun's rays and the number of hours during which it shines upon us work together to make the earth and the air warmer in summer than in winter. From an almanac it is possible to find out the length of day on the first 
of each month and to make a chart which shows the change in length of day during the year.

19. How the air is warmed. The air does not get much warmth directly from the sun's rays, even though the rays pass through it. The air is relatively transparent, and both heat and light pass through it with very little hindrance. This may be illustrated better by the more familiar case of the sun's rays passing through glass. If the glass of a window is perfectly clean and transparent, the sunshine will pass through it and warm the room within, but the glass is not much warmed. If it is covered with dust and other substances which hinder the passage of the sunshine, the window is somewhat warmed and the room is heated and lighted less. In the same way the transparent air gets little warmth from the sun's

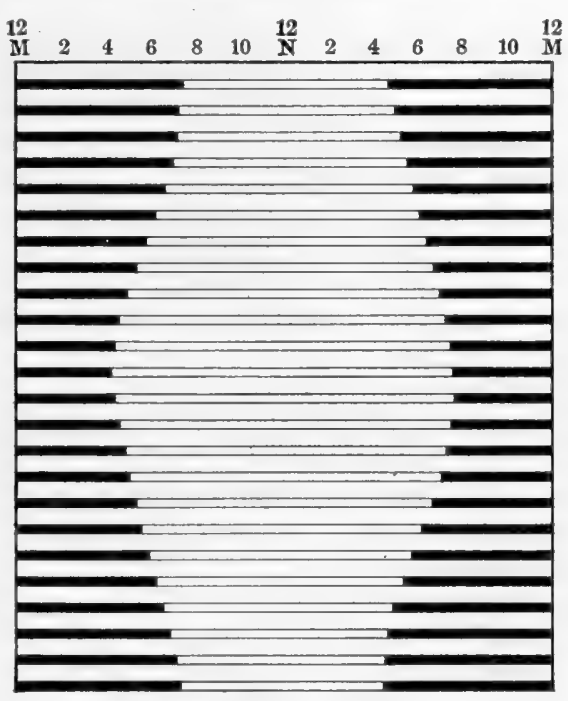

Fig. 16. Yearly distribution of hours of light and darkness

Diagram showing the length of time the sun is above the horizon on the first and fifteenth of each month at latitude $40^{\circ} \mathrm{N}$ rays which are passing through it, excepting as the heat is absorbed by dust, clouds, and water vapor. When the earth has been warmed, the air in contact with the earth is warmed by the earth. Being lighter, it is replaced by cold air, the whole body of air being warmed more or less in this way. The temperature of the air, therefore, depends principally upon the temperature of the area over which it is moving, whether this area is land or water. 
This explains why it is that in summer a wind which is coming across a large body of water is cooler than one which comes across the land, for in summer the land is warmer than the water. In the winter the reverse is true. In the same way, a wind from the north is likely to be colder than one from the south.

When the sun is not shining directly upon a part of the earth, as at night or on a cloudy day, the earth's surface is continually losing heat to the surrounding space and therefore becoming cooler. The heat which passes off from objects upon the earth warms any transparent medium through which it passes much more than it does when the sun's rays pass through such a medium. This is well illustrated by a greenhouse. Here the rays of the sun pass through the glass with little loss, but the heat which is given off by the objects in the greenhouse, after they have been warmed by the sun, does not easily pass through.the glass. The heat is therefore retained in the greenhouse. 


\section{CHAPTER III}

\section{THE WATER OF THE AIR}

20. Evaporation. It is a matter of common observation that if water is left exposed to the air, it soon disappears. We say that it has evaporated. That does not mean that it has gone out of existence. It has only changed into the form in which it is invisible and can pass off into the air. It has become a gas. The same thing is true of the surface of every pond, lake, river, sea, and ocean - indeed, of any water that is exposed to the air. There is, therefore, always considerable water in the atmosphere, and so long as it remains in the form of a gas (water vapor) it is invisible, just as is true of the remainder of the atmosphere.

21. Amount of water in the atmosphere. The amount of water in the atmosphere in the form of vapor, or gas, varies greatly at different times and places. These differences are significant in many ways, for the amount of water in the air is an important factor in such things as cloudy and clear days, rain, dew, fog, snow, and the discomfort that we have upon warm, muggy days in summer.

In order to learn what controls the amount of water vapor present in our atmosphere, let us use the following illustration: Suppose that a small quantity of water is placed in a dish within an air-tight chamber. We know that the water will immediately begin to evaporate, but it will not all evaporate. The space in the chamber will soon contain all the water vapor that it is able to contain under existing conditions, and evaporation will therefore cease. The space within the chamber is said to be saturated with water vapor when it contains all that it is able to contain. If the chamber is 
warmed, however, an additional amount of water will evaporate, while if it is cooled, some of the water vapor will return to the liquid form and may be seen upon the walls in the form of drops.

It thus appears that water evaporates into the adjacent space until the space is saturated, and that the amount of water which is needed to saturate a given amount of space depends upon the temperature. The exact amounts of water in grains per cubic foot of space are given in the table (sect. 22).

It should be added that the amount of air in the space has no influence on the amount of water vapor which the space is able to contain.

22. Absolute humidity and relative humidity. The space about us is not often saturated with water vapor. Among the reasons for this may be mentioned the fact that in many parts of the world there is not much water exposed, and therefore not much opportunity for water to evaporate. Even where there is much water exposed, as at the surface of lakes and oceans, the space above the water is not usually saturated, though containing a large amount of water. For instance, a space to-day may contain one half as much moisture as would be possible at the present temperature, while to-morrow it may contain only one third as much as would be needed to saturate it without changing temperature; that is, in the first case the space may be said to be one-half saturated, and in the second case one-third saturated. These relations are usually expressed in percentages. When saturated, the space contains 100 per cent of the moisture that it is able to contain without change of temperature; if only half the possible amount is present, the percentage is 50 ; and similarly for other values. This percentage expresses the relation between the water actually present and the amount which the space would be able to contain. This relation is called the relative humidity.

The actual amount of water present in a given space is known as its absolute humidity and may be measured in grains 
per cubic foot. Thus, when a cubic foot of space contains, besides the air, 7 grains (absolute humidity) of water vapor, and is able to contain at that temperature 14 grains (saturation) of water vapor, it has 50 per cent (relative humidity) of all that it is able to contain.

The following table shows the amount of water per cubic foot of space which is present at saturation at the different temperatures given. The temperatures stated are Fahrenheit, and the amount of water is given in grains per cubic foot.

Grains per cu. ft.

Grains per cu, ft.

\begin{tabular}{|c|c|c|c|c|c|c|c|c|c|c|c|}
\hline $20^{\circ} \mathrm{F}$. & • & & $\bullet$ & • & . $\quad 1.235$ & $60^{\circ} \mathrm{F}$. & $\bullet$ & & • & - & 5.745 \\
\hline $22^{\circ} \mathrm{F}$. & - & $\cdot$ & • & - & . 1.355 & $62^{\circ} \mathrm{F}$ & - & - & • & . & 6.142 \\
\hline $24^{\circ} \mathrm{F}$. & - & • & - & $\cdot$ & - $\quad 1.483$ & $64^{\circ} \mathrm{F}$ & - & $\cdot$ & $\cdot$ & • & 6.563 \\
\hline $26^{\circ} \mathrm{F}$. & - & . & • & - & - $\quad 1.623$ & $66^{\circ} \mathrm{F}$ & - & $\cdot$ & - & - & 7.009 \\
\hline $28^{\circ} \mathrm{F}$. & - & . & . & * & 1.773 & $68^{\circ} \mathrm{F}$. & - & - & $\bullet$ & • & 7.480 \\
\hline $30^{\circ} \mathrm{F}$. & . & - & - & • & 1.935 & $70^{\circ} \mathrm{F}$ & - & - & * & . & 7.980 \\
\hline $32^{\circ} \mathrm{F}$. & - & . & • & . & 2.113 & $72^{\circ} \mathrm{F}$ & - & 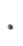 & • & - & 8.505 \\
\hline $34^{\circ} \mathrm{F}$. &. & - & . & • & 2.279 & $74^{\circ} \mathrm{F}$. & - & $\theta$ & - & - & 9.066 \\
\hline $36^{\circ} \mathrm{F}$. & . & • & • & - & 2.457 & $76^{\circ} \mathrm{F}$ & - & $\bullet$ & - & . & 9.655 \\
\hline $38^{\circ} \mathrm{F}$. & - & - & - & - & - $\quad 2.646$ & $78^{\circ} \mathrm{F}$ & - & $\bullet$ & • & • & . 10.277 \\
\hline $40^{\circ} \mathrm{F}$. & - & . & • & * & 2.849 & $80^{\circ} \mathrm{F}$ & • & $\bullet$ & ${ }^{*}$ & - & . 10.934 \\
\hline $42^{\circ} \mathrm{F}$. & . & • & - & - & 3.064 & $82^{\circ} \mathrm{F}$ & - & $\cdot$ & - & · & . 11.626 \\
\hline $44^{\circ} \mathrm{F}$. & . & $\cdot$ & • & • & . $\quad 3.294$ & $84^{\circ} \mathrm{F}$ & • & & $\bullet$ & . & . 12.356 \\
\hline $46^{\circ} \mathrm{F}$. & - & - & • & - & 3.539 & $86^{\circ} \mathrm{F}$ & - & 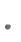 & * & . & . 13.127 \\
\hline $48^{\circ} \mathrm{F}$. & . & - & - & • & 3.800 & $88^{\circ} \mathrm{F}$ & . & 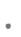 & • & . & . 13.937 \\
\hline $50^{\circ} \mathrm{F}$. & - & - & - & $\cdot$ & 4.076 & $90^{\circ} \mathrm{F}$ & - & - & $\bullet$ & . & . 14.790 \\
\hline $52^{\circ} \mathrm{F}$. & . & • & - & " & 4.372 & $92^{\circ} \mathrm{F}$. & . & • & $\bullet$ & . & . 15.689 \\
\hline $54^{\circ} \mathrm{F}$. & - & • & • & $\theta$ & 4.685 & $94^{\circ} \mathrm{F}$ & - & * & & - & . 16.63 \\
\hline $56^{\circ} \mathrm{F}$. & - & - & $\bullet$ & * & . $\quad 5.016$ & $96^{\circ} \mathrm{F}$ & - & • & & - & . 17.62 \\
\hline $8^{\circ} \mathrm{F}$ & . & - & $\cdot$ & $\cdot$ & . $\quad 5.370$ & $98^{\circ} \mathrm{F}$ & - & • & • & . & . 18.67 \\
\hline
\end{tabular}

23. Some examples. If the temperature falls below that at which the contained vapor saturates the space, some of the water will condense into the liquid form. For instance, if the space in a room is at a temperature of $70^{\circ} \mathrm{F}$. and contains 3.8 grains of water vapor to the cubic foot, the air will appear rather dry, for it would be able to contain over 4 grains more without being saturated (see table in section 22). If, 
however, the room were cooled to $40^{\circ} \mathrm{F}$., its capacity would be decreased to less than 3 grains per cubic foot. Some of the water would therefore condense into liquid form and settle upon surrounding objects. In the case supposed, how much would condense?

The temperature at which a given space would be saturated by the water that it contains and below which the water will begin to condense is called the dew point. What was the dew point in the above example?

In the example used above, when the air was at the temperature of $70^{\circ}$ and there were 3.8 grains of water per cubic foot, what part did the room actually contain of the total amount that it would have been able to contain? Ex. press your result in the form of a fraction; also in the form of a percentage. ${ }^{1}$ Is this relative or absolute humidity? If the room contained all the water that it could contain without a change in temperature, what would be the relative humidity? If it contained no moisture, what would be the relative humidity? What is the relative humidity at the dew point?

Relative humidity is of much more interest to us than absolute humidity. Whether the atmosphere feels dry or moist or whether clouds are seen (fig. 17) depends upon what proportion it has of the water it is able to contain (that is, upon how near the relative humidity is to 100 per cent), and we are much more concerned with the way the atmosphere feels and the probability of moisture condensing in the form of rain than we are with the number of grains of water in a cubic foot.

24. Determination of relative humidity. Relative humidity is the relation, expressed in percentage, of the amount of water per unit volume actually constituting part of the air to the amount of water per unit volume necessary to produce

1 There is a slight error in this method, since no allowance is made for contraction due to cooling. Exact work would require that the proper correction be applied, but the error is so slight that it is immaterial for present purposes and will be disregarded. 
saturation at the observed temperature. In the problems and illustrations which we have discussed in the two preceding sections both of these factors have been given, but if we were to attempt to ascertain the relative humidity experimentally, we should have to ascertain both of them for ourselves.

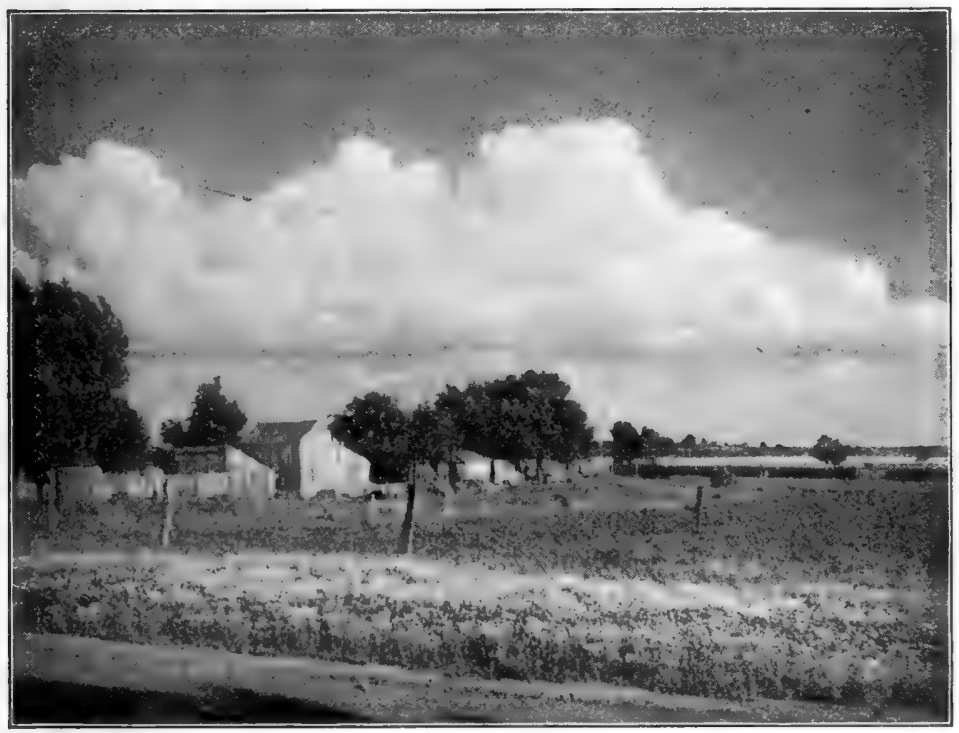

Fig. 17. A cumulus cloud

This kind of cloud is formed by the condensation of moisture in columns of rising air. Note the characteristic lower edge of the cloud, indicating the level at which the dew point is reached

A common experimental procedure for ascertaining the amount of water in the air is as follows: Water is placed in a bright metal cup, ice is added, and the whole is stirred in order that the water may be evenly cooled. In a short time water will be deposited on the outer surface of the cup in a thin film, and as time passes it may accumulate in drops, as it does more familiarly on a pitcher containing ice water. This water has been deposited from the air because the space about 
the cup is cooled by the cold metal until its capacity for water vapor is less than the amount of such vapor present. Some of the water vapor therefore condenses into the liquid form and is seen on the surface of the cup. At the moment when the first trace of moisture appears upon the surface of the cup the adjacent space is evidently saturated; that is, the temperature near the cup is that at which the water vapor present saturates the space. By reference to the table (sect. 22)

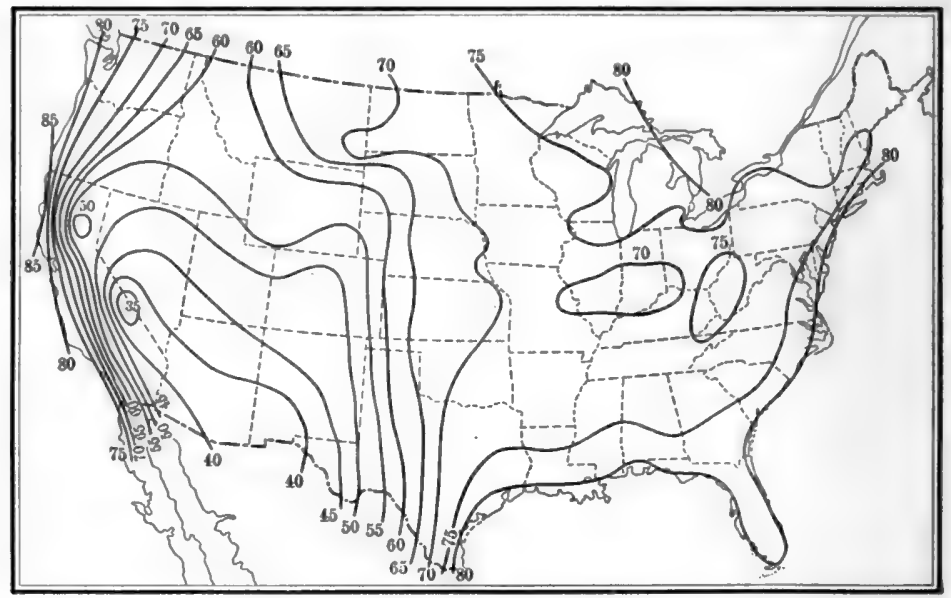

FIG. 18. Average relative humidity in the United States

The figures show relative humidity in percentages. After diagram by H. J. Cox the amount of water vapor present at saturation may be ascertained when the temperature corresponding to the dew point is known. In this case the temperature is secured by observation of a thermometer which is used to stir the water during the progress of the experiment.

Having determined the dew point and the temperature of the air, it is necessary only to refer to the table in order to learn both the amount of water present in the air and the amount required for saturation. From these figures the relative humidity may be calculated as in the preceding problems. 
25. Variations in relative humidity. If the temperature changes, the relative humidity changes also. For instance, you have found that space which is saturated at $48^{\circ} \mathrm{F}$. may have a relative humidity of less than 50 per cent if it is warmed to $70^{\circ} \mathrm{F}$. In the same way the relative humidity changes during the day as the temperature rises and falls. It also changes because of difference in the actual amount of water present - absolute humidity. In most parts of the United States (fig. 18) where it is not desert the relative humidity in summer averages not less than 65 per cent; in the desert region of the southwest it may average below 30 per cent; and there is a record of relative humidity as low as 3 per cent at Yuma, Arizona, though this very low humidity did not last more than a few hours.

26. Humidity in houses. In the winter the air of our houses is heated so that it is much warmer than the air out of doors. Usually no water, or very little, is added, and therefore the air seems very dry; that is, the relative humidity is very low. It is usually below 50 per cent and sometimes as low as 20 per cent. It is seen, therefore, that during the winter those persons who spend most of their time in the house are really living in a desert climate so far as atmospheric moisture is concerned. It is believed that we should be much healthier if we could keep the air of our rooms more moist.

27. Total amount of water in the air. Determine the relative humidity of the room. Measure the room and calculate its cubic contents. By means of the table given in section 22 find out the number of grains of water in a cubic foot and calculate the amount of water in the entire room.

It has been estimated that the amount of water in the atmosphere of the earth would, if condensed into liquid water, make a layer of liquid water at least an inch deep over the whole surface of the globe. 


\section{CHAPTER IV}

\section{THE WEATHER}

28. General statement. The winds and the weather are perpetually interesting in connection with our study of the air. The wind changes so frequently and apparently so aimlessly that it has become a symbol of fickleness, and we say of a changeable person that he is as "changeable as the wind." The rains come and go in an irregular way that makes it very difficult for us to feel any confidence in our plans if they are subject to disturbance by the weather. Weather signs are numerous. Many of these are the result of the experience of many years and frequently come true, while others are only the crudest superstition. In either case the people who believe in them cannot explain why things should happen as the sign indicates, so the matter is as great a mystery as ever to many persons.

We have rain when there is a cause for rain, and the wind blows this way or that when the appropriate causes are at work. If we are able to discover and understand the causes of all things connected with the weather, it will no longer be mysterious, and probably we shall be able to foretell it with certainty. Men have not yet been able to discover all the causes which are at work in the production of our weather, but enough have been discovered to make the weather much less mysterious. In this chapter an account will be given of some of the most important facts that are known at present.

29. Air pressure and winds. The first thing we must find out about is the winds, for most other features of the weather depend upon winds. Winds are merely air in motion, and of course the faster the motion the harder the wind is said to blow. 
In order to explain the cause of winds we must go back to the subject of air pressure and barometers. Anyone who has watched a barometer for several days knows that even if it remains in one place, its indicator goes up and down, thus showing that the pressure is constantly changing. If we should secure a record of the readings of barometers at a great many places in the United States at the same time, we should find that they would not be the same. The readings would show that in some parts of the country the pressure is high, while in others it is low. We might find, for instance, that the barometers read 29.8 inches in Iowa but only 29.5 inches in Indiana. If we should do this for several days, we should find that the pressure is never the same all over the country, and that it does not long remain stationary at any place.

If the pressure of the air is high in Iowa and relatively low in Indiana, we can see that the air next to the ground in Iowa will tend to flow away toward places of less pressure. It will move from Iowa toward Indiana across the intervening state of Illinois, and Illinois will, therefore, have a wind from the west. If the difference of pressure between Iowa and Indiana were only 0.1 inch, the wind would be light; if the difference were as much as 0.5 inch, the wind would be much stronger. What has been said about these three states is only an example of what is actually happening in the country all the time.

In general it may be said that there are always differences of pressure between various parts of the country, and that the air is always flowing from regions of high pressure to regions of low pressure.

30. Pressures as shown by weather maps. A good idea of the distribution of high and low pressures (figs. 19, 20, and 21) throughout the country may be obtained by looking at a weather map. On such a map many things are represented, but we shall give our attention just now to the air pressures only. These are represented on the maps by heavy black lines. These lines are drawn in such a way that all places 
which have the same air pressure are shown on one line, and the figure which represents this pressure is marked upon the map close to the line. These lines are called isubars.

The map is made in the following manner: Each morning at eight o'clock (Washington time), at every weather-bureau station in the United States, the barometer is read and the

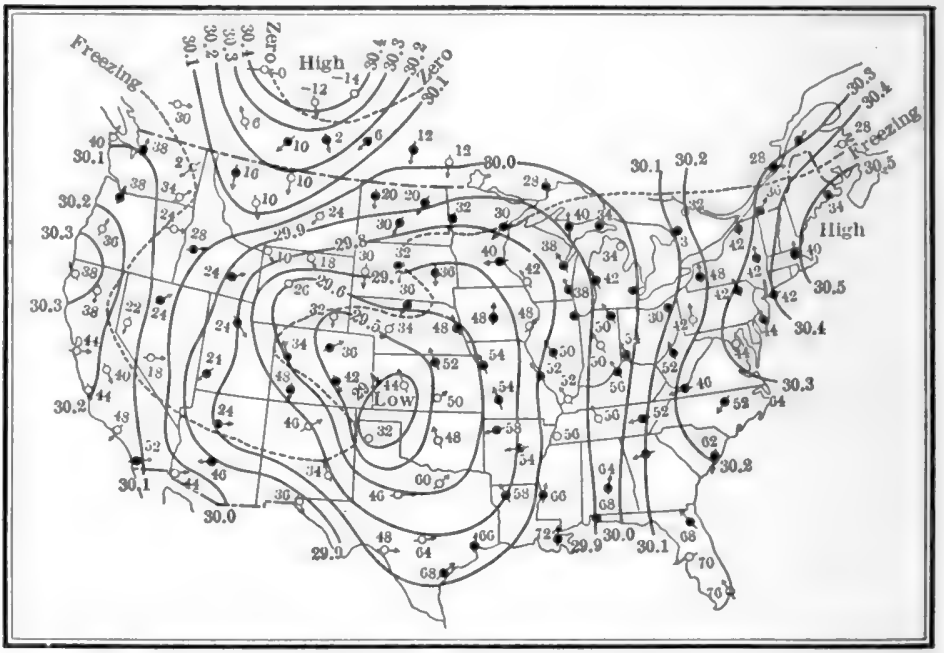

FIG. 10. Weather map for March 13, 1913

The three maps for successive days (figs. 19, 20, and 21) should be compared, to show the promress of the storm and changes in weather conditions. The unbroken lines are the isolars; the arrows fly with the wind; the blackened circles indicate cloudy weather at the time of observation; figures near the arrows show temperature; broken lines are isotherms of zero and freezing temperatures. These figures

are from the United States Weather Bureau

reading is telegraphed to Washington. There the readings are placed upon a map, each at the location of the city from which it was telegraphed. The lines are then drawn through places having the same pressures. These lines thus make it possible to see very easily where the high-pressure and lowpressure centers are located. Usually a map will show several well-defined areas of this kind. Each pupil should examine 


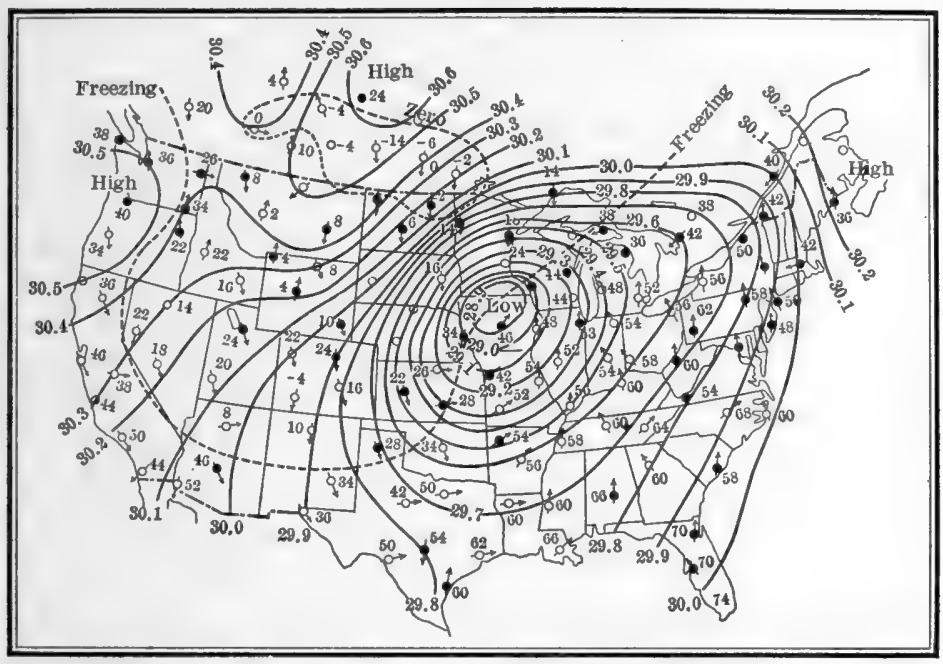

Fig. 20. Weather map for March 14, 1913

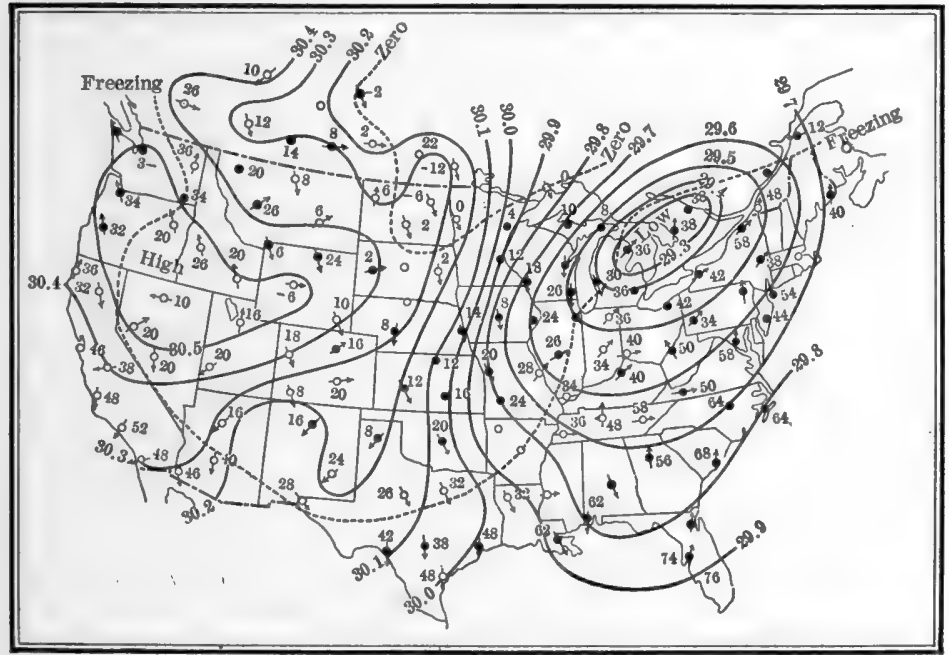

Fig. 21. Weather map for March 15, 1913 
several such maps and note the size of the areas included within the low-pressure and high-pressure regions.

31. Procession of high and low pressures. Observation of maps on successive days will disclose the fact that a "low," for instance, does not remain in the same place. It moves eastward across the country at the rate of several hundred miles per day, and often several of them may be on the map at once. "The centers of the "lows" commonly cross the

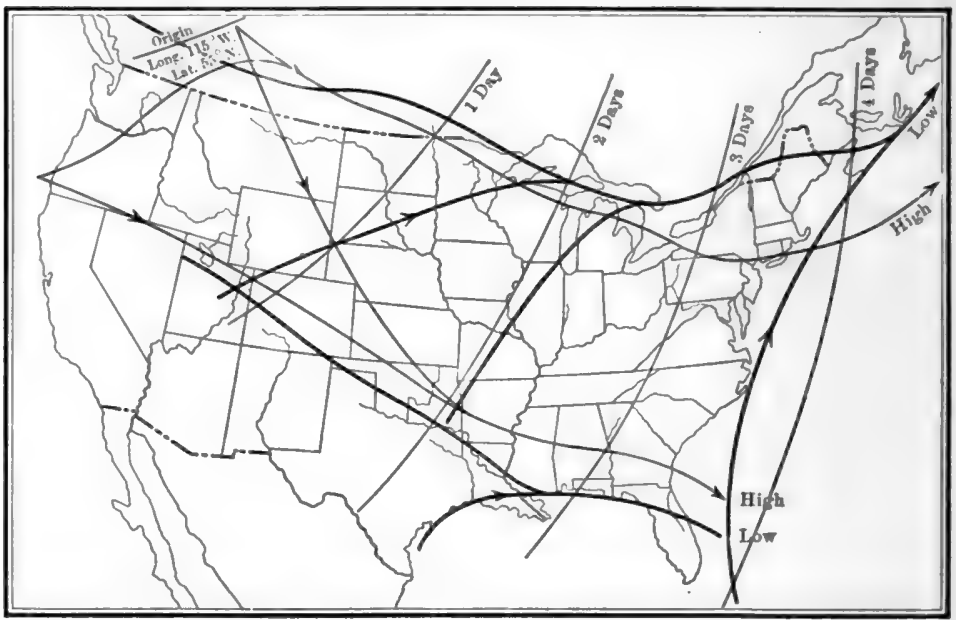

FiG. 22. Average courses of "highs" and "lows" in the United States

After the United States Weather Bureau

northern part of the United States and almost invariably pass down the St. Lawrence River valley (fig. 22). The " highs" occupy the spaces between the "lows" and also proceed eastward across the continent, but their course is usually inclined toward the southeast, and their progress is not as regular as that of the "lows." Both " highs" and "lows" are commonly elongated in a north-and-south direction and are often compared to a series of great waves in which the "highs" are the crests and the "lows" are the troughs. 
32. Winds about a "low"-cyclones. Since a low area is usually more or less nearly circular in form and surrounded by higher pressures, it follows that the air will tend to move into the low area from all sides. If there were nothing to direct the course of the wind except its tendency to blow toward the lowest pressure, the wind would blow from all directions straight across the isobars toward the center of low pressure. It takes only a very slight examination of the weather maps, in which the wind direction is indicated by arrows, to show that, while the wind does blow into the low areas, it does not blow straight toward the center of the "low." Instead of moving as we should expect, the air turns a little to its right. That is, at a point north of the "low" the air is moving not south but southwesterly; at a point east of the "low" it may be moving northwest instead of west; and so likewise for other places in the vicinity of the "low."

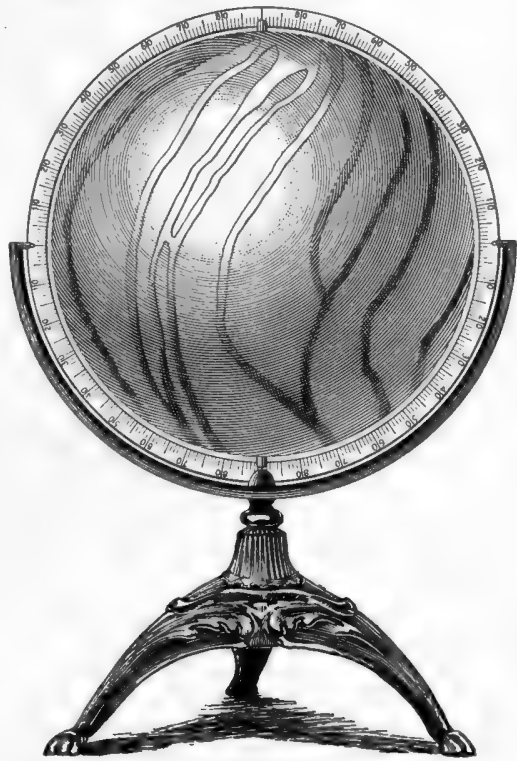

FIG.23. Deflection on a rotating globe

Water was poured upon the top of the globe while it was rotating from left to right. The direction of water is reversed after crossing the equator

The reason for this deviation of the wind from the expected direction lies in the rotation of the earth on its axis. The rotation does not cause the wind to blow, but it does affect the direction of the wind. The effect of rotation upon moving bodies may be illustrated by pouring water upon a rotating globe. If the globe (which should be a smooth one) is placed 
with the pole which represents the north pole of the earth pointing upward, and rotated while the water is poured upon it, the paths which the drops of water mark on the surface of the globe will not run directly from pole to pole, like meridians (fig. 23). They will be curved to right or left. If the globe is rotated in the same direction as the earth is rotating, the paths of the water will curve to the right (westward) in the northern hemisphere, but as soon as the drops cross the equator they begin to curve to the left (eastward). Precisely the
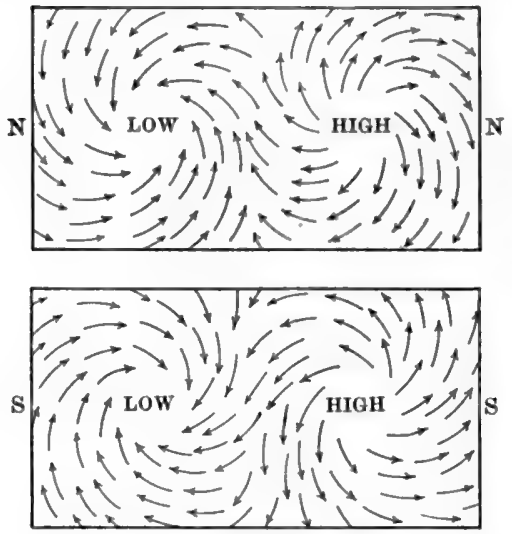

Fig. 24. Deflection of air currents

Diagram of air currents as affected by rotation of the earth. Both northern $(\mathbf{N})$ and southern (S) hemispheres are shown same thing occurs on the surface of the earth. It is a general law that anything moving on the surface of the earth will tend to follow a curving path. In the northern hemisphere this path curves to the right, and the direction of rotation of cyclones and other storms is opposite to the direction which is followed by the hands of a clock, or counterclockwise. In the southern hemisphere deflection is to the left and the rotation is clockwise (fig. 24).

Having now learned this new law, we should no longer expect the air to blow at right angles to the isobars and therefore straight toward the center of the "lows." There are at least two factors controlling the movement of the wind. One of these is the result of differences of pressure, and it causes the air to move across the isobars toward places of lower pressure; the other is the rotation of the earth, and this deflects the moving air always a little to the right of the course which it would otherwise follow. Since the effect of the earth's rotation 
is the same, regardless of whether the air is moving east, west, north, south, or in some intermediate direction, the air about a "low" will all circle about it before reaching the center. Each mass of air will travel in a spiral direction, and the whole body of air about the "low" will rotate. The action of the air is like that of water when it is running through a hole in the bottom of the vessel containing it. We must therefore think of a "low" as a great whirlpool of air sometimes as much as a thousand miles in diameter and moving slowly eastward. Such a great spiral whirl is called a cyclone. The cyclone must not be confused with a very destructive storm that sometimes occurs in our country and is often called a cyclone, although the proper name is tornado (see sect. 40).

The air about a " high" will be deflected to the right and thus will circulate spirally outward. This is called an anti-cyclone.

33. Temperature in a cyclone. When warm winds blow to a cooler part of the country, they cause it to become warmer, as when a south wind blows over the northern states and produces higher temperature. Likewise a wind from the cold plains of the northwest in winter may carry a freezing temperature all the way to the gulf coast. Since, as we have seen, the winds come into a cyclone from all directions, it follows that there must be parts of it in which cool air is going southward and cooling warmer places, and other parts of the storm in which warm air from the south is carrying warm weather northward. Let us take for the moment the case of the warm air from the south and its effects on temperatures in the cyclone. If we refer to any of our diagrams of cyclones or to the weather maps, we see that the spiral course of the air which comes into the "low" from the south carries it a little to the east of the center of the "low." This means, of course, that the eastern part of the storm will have southerly and warm winds. The western part, on the contrary, will consist of air which is coming from the north or northwest and 
is comparatively cool. We may therefore expect to find that the temperature rises as a "low" approaches any given region, and falls as it passes. On weather maps places of equal temperature are connected by dotted lines, just as places of equal pressure are connected by continuous lines. The lines representing equal temperature are called isotherms. Examination of the maps will show that the isotherms are usually bent northward in front of a storm and southward in its rear.

34. Humidity in a cyclone. We are probably as much concerned about the humidity of the air and about clouds and rain as we are about the wind or temperature. It will be recalled that in a previous chapter we learned that the relative humidity varies when the temperature varies. Air which appears moderately dry (has a low relative humidity) when it is hot may appear to be very moist when cooled, and some of the moisture may condense. When air from the south is moving northward and warming the country over which it passes, it is itself losing heat and becoming cooler. As it becomes cooler the relative humidity becomes greater, until finally, at some distance above the earth, saturation may be reached and moisture may be condensed in the form of clouds. If condensation continues, rain will fall. As pointed out before, the warm southern winds are blowing northward in the front part of the storm (the eastern half), and it is here that clouds and rain are found.

In the western half of the storm the winds are coming from northern and cooler places and are being warmed. Capacity for moisture is increasing, and there is no condensation in this part of the storm area. The air in the western part of a cyclone is usually clear, dry, and relatively cool.

It should be noted in this connection, however, that large bodies of water and great irregularities of the earth's surface, such as mountain ranges, may cause marked local variations in the character of the weather which accompanies the passage of cyclones. 
35. Passage of a cyclone. On the average, several cyclones pass eastward over the United States each week. Cyclones and anticyclones commonly follow so closely upon one another that we are practically always in one or the other. Most of the winds which we experience are cyclonic winds, and most of the rainfall in the Mississippi Valley is produced by these cyclonic winds. The events that occur in connection with the passage of a cyclone have been described as follows in a pamphlet issued by the United States Weather Bureau :

When the wind sets in from points between south and southeast, and the barometer falls steadily, a storm is approaching from the west or northwest, and its center will pass near or to the north of the observer within twelve to twenty-four hours, with winds shifting to northwest by way of southwest and west. When the wind sets in from points between east and northeast, and the barometer falls steadily, a storm is approaching from the south or southwest, and its center will pass near or to the south or east of the observer within twelve to twenty-four hours, with winds shifting to northwest by way of north. The rapidity of the storm's approach, and its intensity, will be indicated by the rate and amount of the fall in the barometer.

36. Weather in anticyclones. The air which flows into a cyclone usually rises when it reaches the center of the storm, and thus the circulation is kept up. An anticyclone is an area in which the cooler air of the upper regions is settling to the surface and flows away in all directions as described. Since this air at the surface of the earth has come from the cooler regions above, it is getting warmer, and as it flows away from the center of the "high" most of it is still going to warmer regions. Since it is becoming warmer, it is relatively dry. For these reasons the weather in a region covered by a high-pressure area is usually cool, clear, and dry, with a west or northwest wind. Most of us have no difficulty in recalling the bracing air of the pleasant days which follow a period of clouds and rain, and this is typical anticyclone weather.

37. Hot and cold waves. A large low-pressure area some. times draws so much air from the south into the northern part 
of the country that the temperature of the north rises unseasonably high, producing a period of very warm weather which in this country is usually called a hot wave. In the western part of the Mississippi Valley the crops are sometimes seriously damaged by hot winds coming off the deserts of the southwestern part of the United States. Such a hot and dry wind is often called a sirocco, though in this country it is more usually referred to as a hot wind.

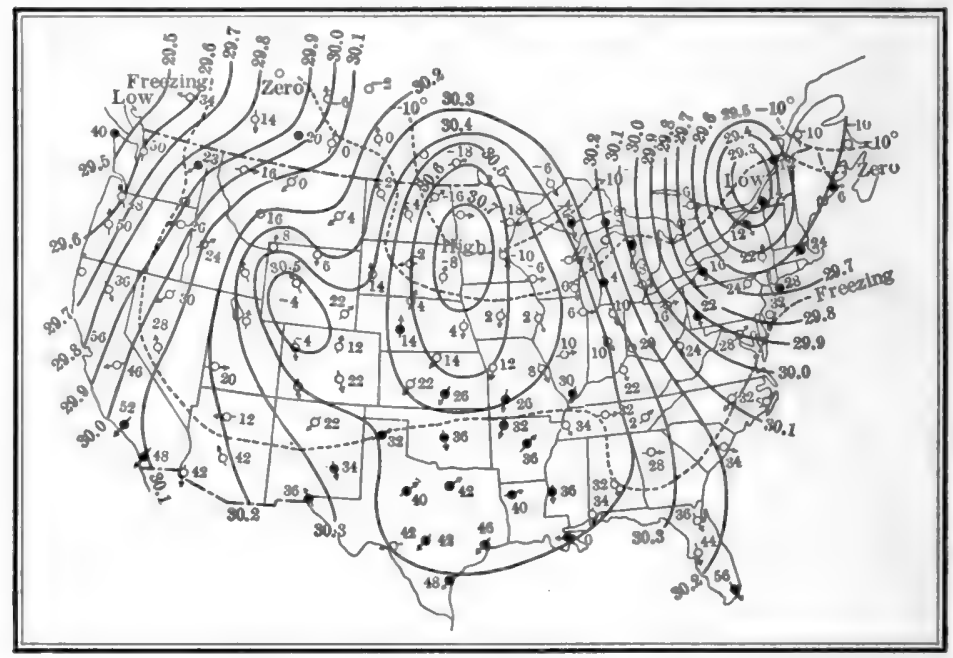

Fia. 25. An unusually large " high" area

Note the low temperatures throughout the country. United States Weather Map for January 12, 1914

If a high-pressure area remains for a while in the northwest, the cold air which comes from it may spread over the greater part of the country (fig. 25); and if the fall in temperature is rapid and of considerable amount, it is called a cold wave (figs. 26 and 27). The presence of low pressure over the Gulf of Mexico or over the Atlantic Ocean near our southern coast will usually assist in the progress of the cold wave. It occasionally happens that the freezing temperatures reach the 


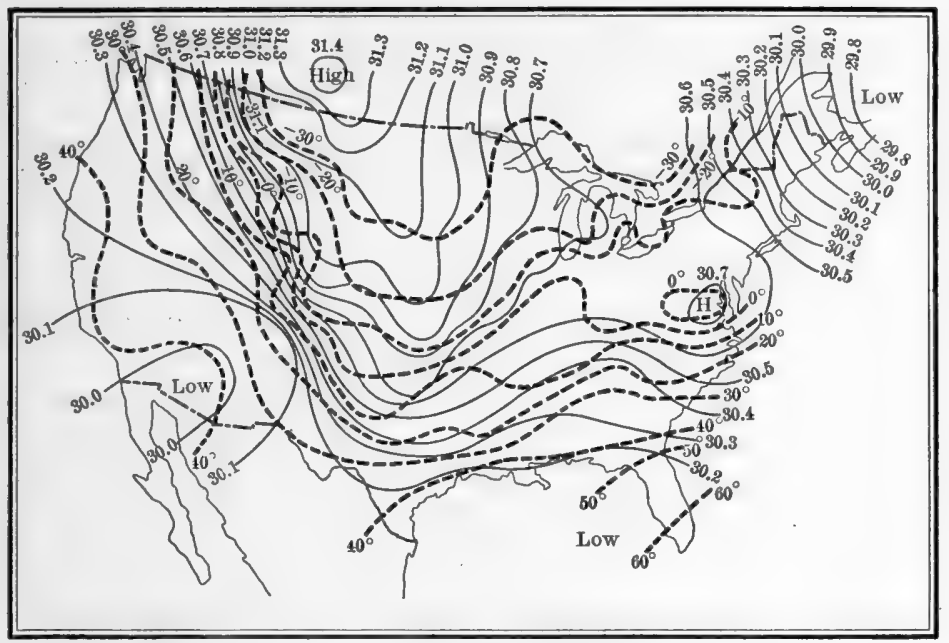

Fig. 26. Beginning of cold wave, February 11, 1899

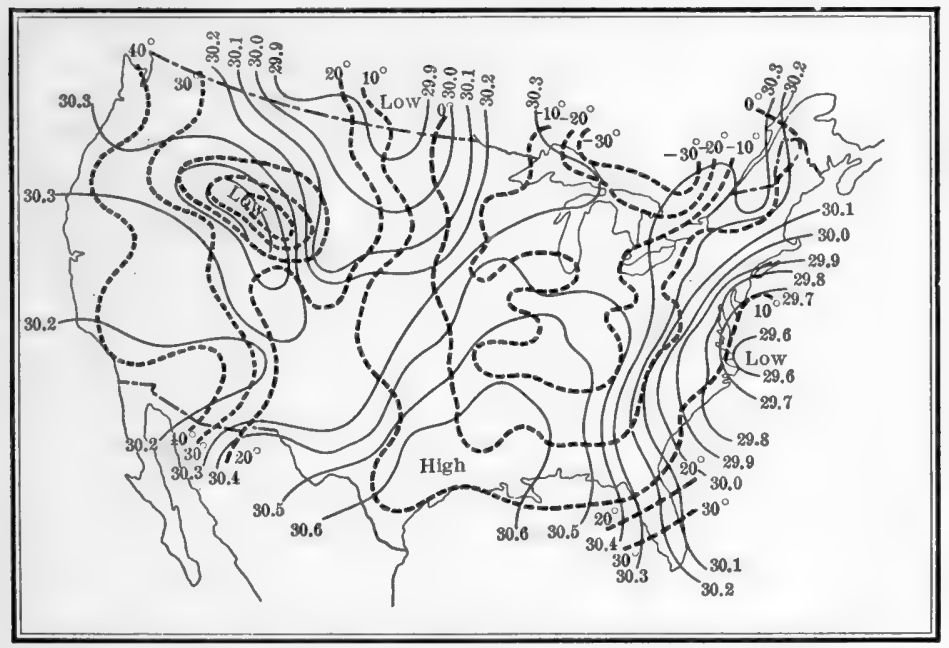

Fig. 27. Cold wave at greatest intensity, February 13, 1899

At many points in the southern part of the United States this was the coldest period recorded. After United States Weather Bureau 
Gulf Coast and even extend far down the Florida peninsula. In these cases there is great loss resulting from the freezing of orange trees and the crops of early vegetables. On the great plains of the $W$ est the cold wave may be accompanied by a strong wind and considerable driving snow. In this case it is called a blizzard. It frequently happens that people who are caught out in a blizzard are unable to find their way

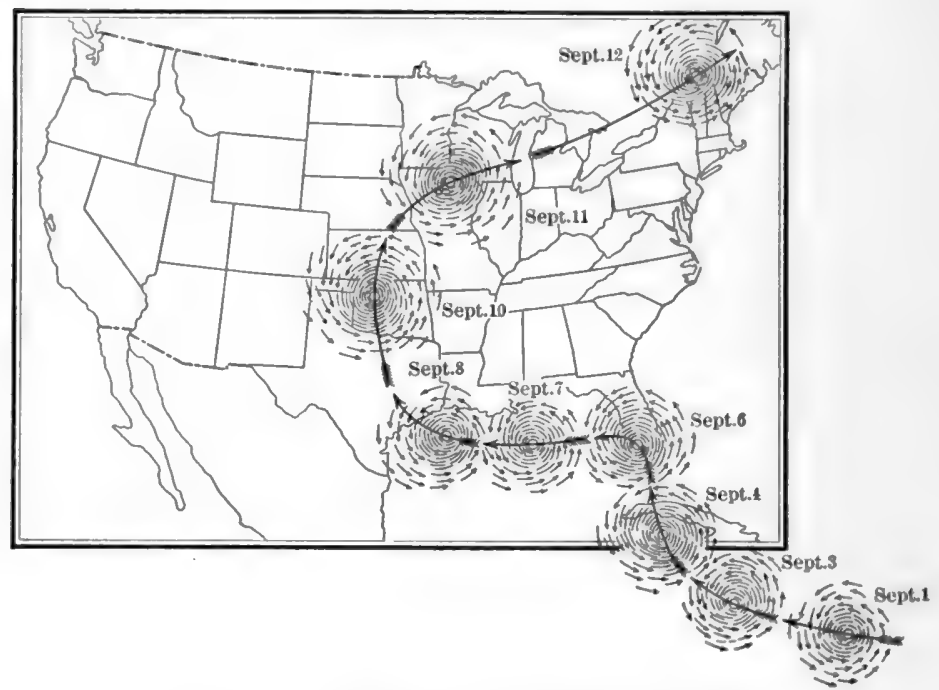

Fig. 28. The path of the Galveston hurricane

Diagrammatic representation of the position of the storm on several successive days. Its intensity was much decreased after it left the Gulf of Mexico. After United States Weather Burean

home and are frozen to death. Almost every winter great numbers of cattle and other live stock perish in the blizzards which, under the name of northers, may reach as far south as Texas (fig. 27).

38. Hurricanes. Hurricanes are storms of the same general character as the cyclones, but they originate only over the oceans. Those which affect the United States have their 
origin near the West Indies. They usually move westward toward the coast of the southern United States and then gradually curve northward and northeastward and pass out across the Atlantic Ocean with decreasing severity (fig. 28). It is very "common for them to pass almost parallel to our eastern coast and to do a great deal of damage to shipping. Occasionally one of them goes far enough west to enter the Gulf of Mexico. In the year 1900 the city of Galveston was destroyed by a hurricane which had taken this unusual course.

These storms are of very much greater severity than the cyclones and often do a great deal of damage in the West Indies and occasionally upon the mainland.

39. Thunderstorms. In the warmer parts of the year the layers of air next to the surface of the earth may become much warmer than the air higher up, and this difference may become so great that the lower layers are distinctly lighter than the upper layers. If this is the case, the lower air begins to rise through the upper air in ascending currents somewhat like the ascending currents of air over a heated stove. At a height of several thousand feet the ascending air may be sufficiently cooled to cause the condensation of some of the water and the formation of the dome-shaped white clouds which are such familiar objects in summer skies. They are called cumulus clouds (fig. 17).

If the conditions are such as to cause very vigorous movements of the air, and if there is a good deal of water in the lower air, the clouds may grow until they become heavy and dark and rain begins to fall. The fall of rain is accompanied by lightning and thunder, as well as by considerable wind. After it has passed, the temperature is cooler because the warm air has flowed away upward and has been replaced by cooler air from above.

Thunderstorms usually occur in the southerly part of a cyclone during warm weather and in the warmer part of the day, but they may occur even in the winter. Thunderstorms 
move eastward across the country at a rate of from 20 to 50 miles per hour and may affect a region many miles wide, or they may be restricted to a width of a fraction of a mile. They also vary greatly in severity but are not commonly destructive.

40. Tornadoes. In the United States, particularly in the central part, there are occasional storms of very great severity over a limited area. These are frequently called cyclones, but the correct name is tornadoes. Like the thunderstorms, they

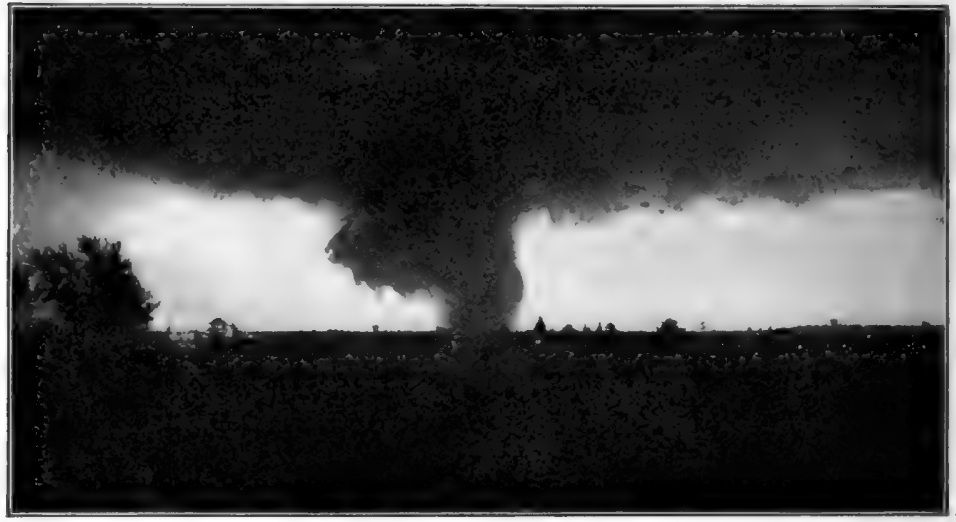

Fig. 29. A tornado cloud

Note the "funnel" reaching from the upper clouds to the earth. Mount Morris, Illinois, May 18, 1898

are due to the excessive heating of lower air, which is also nearly saturated with water vapor. They differ from the thunderstorms in that the ascending current is very strong and has a rotary motion. The movement of the air in such a storm resembles that of water in a whirlpool (fig. 29).

A tornado commonly occurs within the southeast quarter of a cyclone and moves toward the northeast, the direction of the prevailing wind, at about the same rate as a thunderstorm moves. The condensation of water and the presence of dirt and dust which have been blown up by the whirl make the 
storm visible as a conical or funnel-shaped cloud which is whirling rapidly.

The path of a tornado is never wide and may not be more than 100 or 200 feet in width. Within this path the destruction is often so complete that all buildings, fences, trees, etc. are leveled to the earth or earried long distances.

The velocity of the wind within the central whirl is very great, but it has not been possible to measure it. From the character of the results which are produced, it is estimated that

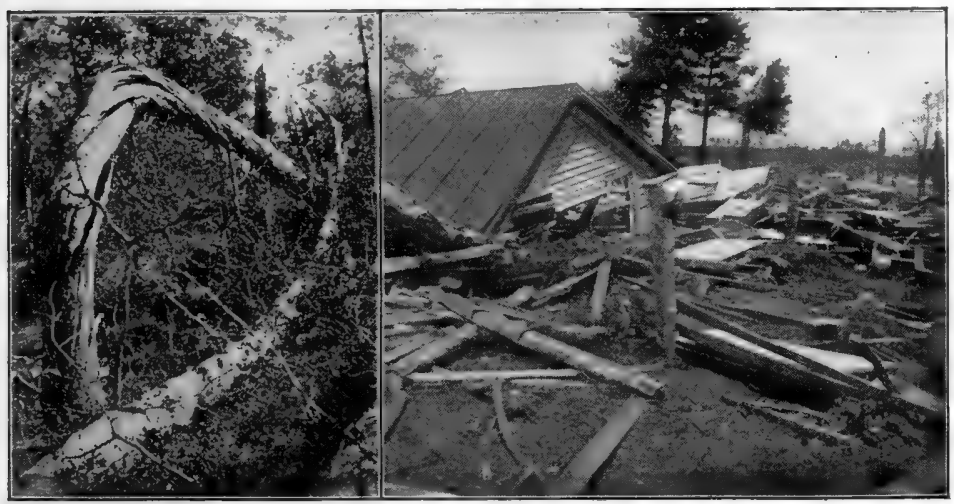

Fig. 30. Results of a tornado

These photographs were taken in the path of the tornado which is shown in figure 29. Note the twisted tree and wrecked house

the wind velocity may be as high as 500 miles per hour. The storm at Mount Morris, Illinois, on May 18, 1898, of which pictures are shown, "carried off heavy objects (such as stoves), destroyed buildings to the foundation (fig. 30), drove light sticks through or into boards and posts, plucked the feathers from living chickens, and did many other peculiar things.

Fortunately such storms cover such a small area and occur so rarely that the chance of any one place being visited by one of them is not great. Tornadoes sometimes occur at sea and are then known as waterspouts. 
41. General circulation of air on the earth. The various sorts of winds and storms which we have been considering are common to the United States and to other countries that are in the same latitude, but they do not occur in the tropics or in some other parts of the globe. In fact, the surface of the earth may be divided into zones, or belts, characterized by different sorts of winds. The belt which we have been discussing is called the belt of westerly winds, because the lower winds are from a westerly direction more frequently than from any other.

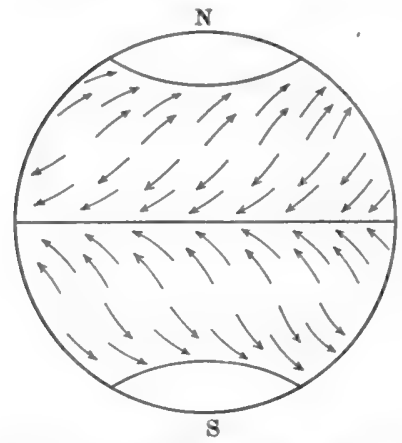

Fig. 31. Diagram of the general circulation of air upon the earth

These general currents are always more or less modified by local conditions

It is true also that the upper air currents in this region are from the west, as is shown by the movement of the higher clouds. This is always from the west. The winds of this belt are so much disturbed by the passage of the cyclones that it is difficult to see any regular eastward movement until one recalls that the cyclones themselves move eastward. This eastward movement is doubtless due to the fact that they are merely great whirls in the greater mass of eastward-moving air. It will also be recalled that thunderstorms and tornadoes move eastward, as indeed is true of practically all weather conditions. This general eastward movement is so universal that we are accustomed to look at the western sky to detect the approach of weather conditions. It is in the western sky that we see the first indication of the coming storm; the first lightning flashes are usually seen in the west; and it is in the west that the clearing of the sky begins after the storm.

This belt of westerly winds, with its cyclones and other phenomena, extends entirely around the earth in this latitude (fig. 31). Mountain ranges which cross the path of the 
westerly winds have much heavier rainfall on the western than on the eastern side, because the winds, as they ascend the western side, are cooled and some of the moisture condenses into clouds and rain, while on the eastern side the air is warming as it descends and becomes relatively dry. A good example of this will be found by comparing the rainfall on the west slope of the Cascade Mountains in Washington and Oregon with the rainfall on the east side of the same mountains (fig. 32).

In the tropical regions we have the belt of trade winds on each side of the equator. The great heat of the equatorial regions causes the air to expand and thus become less dense, and it is pushed upward in the region of greatest heat, - the heat equator, - which is near the true equator. In this region of rising air there is little wind at the surface of the earth, and it is known as the belt of calms. To the north and south of the belt of calms the air is rushing southward (or northward) toward the heat equator, but by the rotation of the earth these winds are turned from the direct course they would otherwise pursue, so that in the northern hemisphere they become northeast winds and in the southern hemisphere they blow from the southeast. These winds blow very steadily and are known as trade winds.

We have, then, three important wind regions on the earth's surface besides the winds of the polar regions, which are not well known and will not be discussed here. The three belts of which we have spoken are the belt of calms, the trade winds (northern and southern hemispheres), and the westerlies (in both the northern and the southern hemisphere).

42. Rainfall in the United States. Rainfall is very unequally distributed in the United States (fig. 32). It ranges in amount from 100 inches per year in northwestern Washington to 2 inches per year in southeastern California. While there are no very large regions in the United States which deserve to be called deserts, yet much more than a third of the country is arid and cannot be farmed successfully without irrigation 
or other special means. The eastern slope, the lake region, and the Mississippi Valley as far west as the middle of the Dakotas and Nebraska are well watered, but the great plains and mountains of the West have very scanty rainfall excepting on the westward slopes of mountains near the Pacific Ocean.

The rainfall on the Pacific coast is due mainly to the effect of the mountains upon the prevailing westerly winds. The scantiness of rainfall in the mountains and on the plains directly east of them is due to the same thing. The larger rainfall of the Mississippi Valley occurs principally in connection with the cyclones and is condensed from the air which is sweeping northward from the Gulf of Mexico into the cyclones. Farther east the Atlantic Ocean contributes in the same way.

43. The United States Weather Bureau. The importance of the weather to the people of the country is so great that the government has established a bureau for the purpose of studying the weather and forecasting it as far as possible. While it is not possible to foretell the weather with certainty, the predictions that are made are fairly accurate and have been of great value.

All forecasting of weather is based upon the weather map. The map is made up each lay from the reports telegraphed from the observing stations all over the country. The predictions are based almost wholly on knowledge of the character and actions of cyclones. The usual path of cyclones and the rate of motion have been carefully studied, and it is possible to estimate quite closely what a cyclone will do within the next twenty-four hours, and therefore how weather conditions will change. For instance, if it were found that within twentyfour hours a cyclone that is now in the West could be expected to approach to within a short distance of a certain place, it would be safe to predict clouds and rain for that place. On the other hand, the approach of a high-pressure area would justify the prediction of clear weather. 


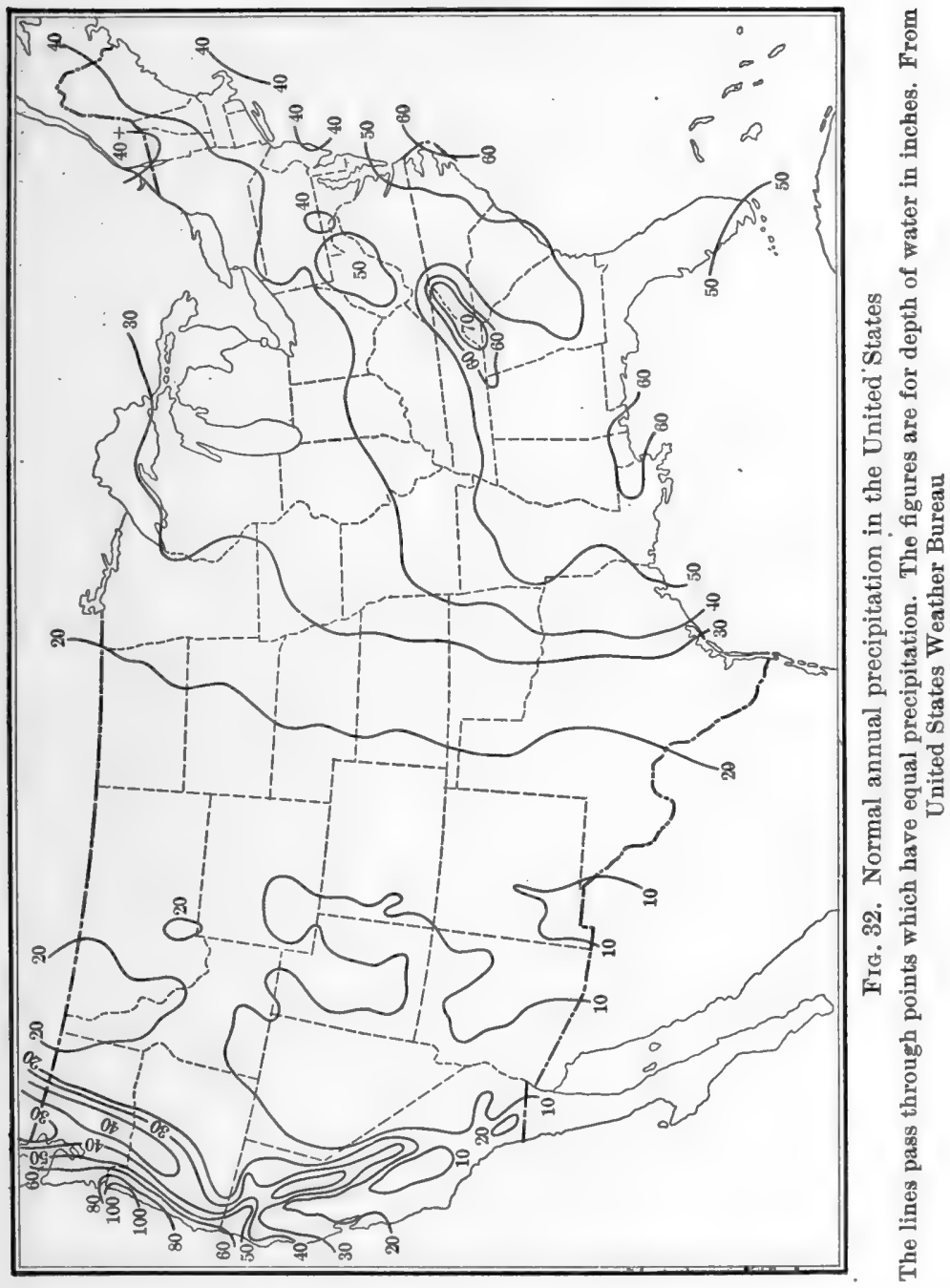


The difficulties in forecasting are many, and most of them arise from the irregularities in the behavior of cyclones. If all cyclones moved in the same path at the same rate and did not change in violence, we should be able to predict the weather with almost absolute certainty. But cyclones sometimes travel in unexpected directions or at unusual rates. Sometimes they disappear entirely, and sometimes new ones make their appearance without any warning. In spite of all these difficulties the art of forecasting the weather has been brought to a high degree of reliability.

The storm warnings at ports on the ocean and Great Lakes are the means of saving annually thousands of dollars' worth of property and many lives. The warnings of frosts have saved as much as $\$ 3,000,000$ worth of perishable property in the form of fruits and vegetables in a single year. Flood warnings are another important part of the work of the bureau. 


\section{CHAPTER V}

\section{STRUCTURE OF AIR: MOLECULAR THEORY}

44. Compressibility of air. We have already discussed the general nature and movements of the air. In the experience of everyone many questions and problems arise which can be explained only through a further discussion of the structure and composition of the air. In this chapter we shall consider some of the problems and their explanations.

If a pneumatic tire is filled with air so that it is fully expanded and also feels quite firm, we say that it is "filled" with air, and so it is. If it were filled with water in like manner, we should not expect to be able to get any more water into it, but we know very well that if we apply the pump, we can force in more air. As we continue to pump, the tire gets firmer and the pump works harder, showing that there is greater pressure in the tire. There seems scarcely any limit to the amount of air that can be forced in, so long as our strength endures and the tire does not burst. How can this additional amount of air get into the tire? Plainly the air that was in there before must have been forced to occupy less space than before, or else the old and the new have mingled within the space formerly occupied by the old. In either case they both together occupy less space than they would occupy if they had not been forced into the tire. In other words, the air has been compressed.

Instead of pumping air into the tire, we might have squeezed the tire together. We should then have forcer the tire and the air that it contains to occupy less space than they did before, again showing that it is possible to compress air into smaller space. 
From either of these experiments and from a great many of the experiences of life we get the notion that air, and other gases as well, may be compressed by applying force to them in the proper way, and that they resist the compressing force.

45. Expansion of gases. In experiments such as we have mentioned we notice that a gas resists a compressing force. It does not surprise us, therefore, that when the gas is released it expands again to just the volume it had before. When a tennis ball filled with air is compressed and then released, it illustrates this point.

Suppose, furthermore, we attach an air pump to a bottle and exhaust the air from it. When we have pumped one half of the air out of the bottle, it is then only half filled. Is one half of the bottle filled and the other half empty? By no means. The air is just as plentiful in one end of the bottle as in the other. Indeed, no matter how much we may remove, if there is any air left in the bottle, it expands so as to fill the whole bottle.

In the same way, if we inclose some air in a rubber bag and pull the sides of the bag outward so as to make more space in the inside of it, the bag will still be filled with air. No matter how much the bag is enlarged, the air will continue to expand and fill it.

Such experiments might be carried much farther, and we should find that the air seems to possess the power of indefinite expansion. A gas always expands so as to occupy the whole space that is open to it.

46. Diffusion of gases. If there is a leaking gas pipe in a closed room, the odor of gas can soon be noticed in any part of the room. The fact inat the odor can be found in all parts of the room indicates that the gas has spread to the most remote corners. How did it get there? If there were currents of air, it might be carried by the currents, but the same result is observed even if the air is quiet. It seems, therefore, that the small amount of gas that has been released 
from the pipe in one part of the room has somehow managed to distribute itself more or less evenly through the room without being much affected by the presence of the air. In other words, although the room was occupied by the gas which we know as the air, the gas which escaped from the pipe has spread itself through the room as if it were the only gas present.

If other gases are used, the same results follow, and careful tests show that when several gases are in a space at the same time, each one of them is soon evenly distributed throughout the space. This property that gases have of mingling with one another when in contact, even if not stirred, is called diffusion. The same property is shown in liquids also.

From these experiments it might appear that two or more substances (gases in this case) can occupy the same space at the same time. Do you think that this is really true? Is it true of solids? of liquids?

47. Some questions regarding gases. In the last section we learned certain facts which were not explained and which ought to give rise to many questions if we are interested in those facts. In the first place, how can one substance pass through another substance, as when illuminating gas diffuses through the air from one part of the space to another part? It seems unlikely that the air and the illuminating gas really occupy the same space at the same time. Certainly two persons or two books cannot occupy the same space at the same time.

Furthermore, how may a substance be made to occupy less space, as it does when air is compressed? When a sponge, which is porous, is compressed, the pores are made smaller, but the substance of the sponge is not really compressed. Such a substance as iron does not appear to be porous, and we do not find it easy to compress iron into smaller space. May it be true that the air is really porous? If so, that might also explain how the illuminating gas passed through the air and how it is possible for air and other gases to expand. 
48. A theory about the air. In the attempt to answer the questions that we have been asking about the air, and also to explain many other matters, scientists who study these things have formed a theory which seems to account for a great many facts in nature. The theory is that the air is not a perfectly continuous substance, but that it is formed of a great many particles, each a little distance from the other particles. These particles, called molecules, are believed to be extremely small. It is believed that they are in rapid motion, and that one molecule moves in a straight line until it strikes another, when it rebounds and again moves in a straight line. It is supposed that molecules are continually moving and striking one another at very short intervals. This theory of the structure of the air and of other substances is called the molecular theory. As the question is more thoroughly investigated, more evidences are found that agree with the theory, and as yet nothing has been found that is opposed to it. All scientific men have come to accept it as a reasonable explanation and one that is probably true.

49. Molecular theory applied to air. The molecular theory will help us to answer some of our questions. In the case of the diffusion of illuminating gas through the air of the room, the molecules of the gas simply passed through the spaces between the molecules of air.

According to this explanation, gases are compressible because they are porous. Perhaps it may illustrate the condition of a gas if we imagine both the molecules and the spaces to be greatly magnified. If the molecules should be magnified to the size of baseballs, they would have to be about two feet apart to preserve the proportion. That is, a gas consists of material particles with spaces between them, and when the gas is compressed, the particles are forced together. The force with which air or any other gas resists compression makes it appear that in some way the particles resist being pressed together and are ready to fly apart again, as they do, in fact, when the pressure is removed and the gas expands. 
50. Gas pressures. If you strike a blow upon a punching bag, it is pushed to one side and immediately returns, but if you hit it again as it starts to return, and continue to strike one blow after another very rapidly, the bag will remain pushed to one side as long as you continue to strike. The molecules are believed to be doing something very similar to this. They not only strike against each other, but they also strike against the walls of the containing vessel if the gas is inclosed. Since they are so small, each blow is very insignificant indeed, but there are so many of them that they strike innumerable blows every second upon each square inch of the containing surface. Each of these blows is very small, but the sum of them is very great. The result of all these small blows is that the gas exerts pressure against the walls which confine it, for instance, against the inside of the rubber tire.

51. Heat and molecular movement. As the temperature of a gas increases, the speed with which its molecules move increases. Since they move faster, they strike harder when they hit the walls of the tire or other container, and the pressure is greater. This agrees with our observation, for we find that pressure exerted by a confined gas always increases with the temperature.

52. Gas mixtures. According to this theory, when two or more gases are mixed, their molecules are intermingled, but each kind of molecule remains unchanged. If some means of sorting the two kinds of molecules is available, the two gases may be recovered unchanged. A gas like the air may be made up of a mixture of molecules of several different kinds of gases, just as a swarm of gnats may be made up of several kinds of gnats.

53. Liquids and solids. It may be more difficult to believe that liquids and solids are composed of molecules, but it is believed to be the case. It is not very difficult when we recall the fact that gases can be condensed into liquids, as when steam becomes liquid water or in the formation of liquid air. 
Likewise, liquids may be frozen into solid form. It follows, then, that if gases are made of molecules, the same must be true of solids and liquids.

There are some differences, however. The molecules of a liquid seem to move about readily - almost as readily as they do in a gas, but they do not have the same tendency to fly apart. Thus the liquid changes form, but it remains the same in volume. It does not readily expand and is not easily compressed. The solid also is not easily compressible, since its molecules do not readily shift their positions. It has a permanent shape. The spaces between molecules in a liquid or a solid are much smaller than in a gas, but there must be some space, else we could not dissolve substances in water. Even so compact a substance as gold will absorb certain other substances, and we believe that the molecules of the dissolved substance find their way into the spaces between the molecules of gold.

If alcohol, which is lighter than water, is carefully poured into a test tube which has been half filled with water, at first most of the alcohol will float upon the water, but after some time it will be found that the two liquids have become evenly mixed. In a similar manner a lump of salt or sugar which may be dropped into a vessel of water will dissolve and diffuse throughout the water. Diffusion occurs in liquids as it does in gases. 


\section{CHAPTER VI}

\section{COMPOSITION OF AIR: ATOMIC THEORY}

54. The air not a simple substance. When you consider what we have learned about the air in connection with preceding chapters, you may recall several facts which have shown that the air is not composed of one substance only. For instance, we found that water vapor is often a very considerable part of the air. The air is in fact a mixture of several gases, of which water vapor is one. We should get some acquaintance with at least the more important of these, and learn how they act. As a means of securing such acquaintance we shall study the flame of a candle.

55. The flame and the air. If a candle is thrust into a lamp chimney which is held in an upright position, the flame will burn more brightly and steadily than in the open air; but if the lower end of the chimney is closed by the hand, the flame becomes smoky, flickers, and possibly is extinguished. In the first case the heat of the flame warmed and expanded the air in the chimney, thus causing an upward current of air (sect.11), so that the flame was better supplied with air than when it was in the open. When the hand was placed across the bottom of the chimney, however, the upward current of air was interrupted and the supply to the flame was so much reduced that burning was no longer possible.

It is clear that air has much to do with burning and with flames. Just what part air takes in the burning, or combustion, and what are the effects upon both the air and the candle, we shall study at some length; but first we must become familiar with the flame. 
56. A burning candle. When a candle is lighted, the flame burns at the top of the wick but does not come down the wick to the solid part of the candle (fig. 33 ). 'The heat soon forms a cup in the top of the candle by melting the center of it. 'This cup is filled with melted tallow or wax. The melted wax is absorbed by the wick and travels upward in it, just as

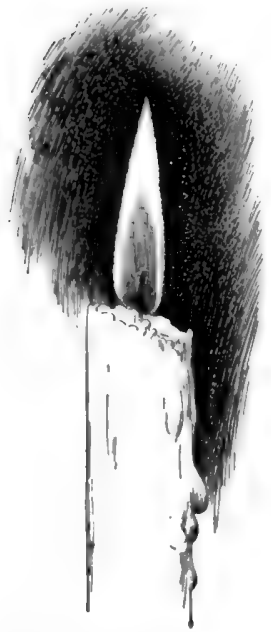

Fig. 33. The candle flame

Note the general form of the flame, the light outer part, and the dark center ink is absorbed by blotting paper and spreads through it. As the melted wax goes up the wick and gets closer to the flame, it gradually becomes hotter and finally begins to burn. The point at which it gets hot enough to burn is marked by the bottom of the flame.

The melted wax or oil really gets so hot before it burns, that it changes from a liquid into a gas and burns as it is passing away from the wick. By looking closely at a flame one may observe that the burning is not taking place immediately at the surface of the wick. It is apparent that there are several parts to the flame, as shown in the figure. The burning occurs chiefly in the outer part of the flame.

That there is a gas in the flame may be easily proved. Place a small tube so that the end shall be in the center of the flame, and try to light the other end (fig. 34). If this is properly done, we shall have a small gas flame burning at the end of the tube, some distance from the candle flame. If the end of the tube is not placed in the center of the flame, but at the surface, gas that can be burned does not enter the tube. This is because gas is burning at the surface of the flame. If a large piece of paper is held across the widest part of the flame, the paper directly above the center of the flame will not at first 
be burned. The part of the paper which is first burned forms a ring corresponding to the position of the outer part of the flame. The same tests may be carried out with the flame of illuminating gas in a Bunsen burner.

57. Products of the flame. When the gas formed from the wax of the candle has been burned, it has not passed out of existence. It has changed so that we may not at first be able to recognize it, but it still exists. The changes that have taken place in it are not merely changes in temperature, expansion, and the like, such as we have been discussing in former chapters, for if this were true the gas which passes away from the flame would condense into a liquid, and the liquid would harden into the kind of wax with which we started. It may readily be observed that this does not take place. The molecules which leave the flame and mingle with the air are different from the molecules of the wax as they come to the flame. Let us see, then, what sort of substance we can find coming from the flame, and learn how the changes occur which give us other substances in place of the wax with which we started.

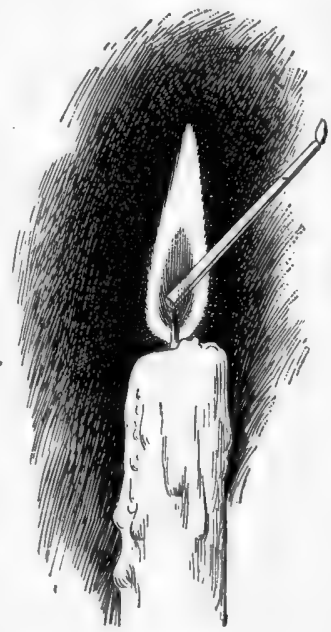

FIG. 34. Inflammable gas secured from the flame

By the use of a tube the unburned gas from the center of the flame may be conducted outside and there burned

58. Water produced by a flame. If a cold object, as a piece of iron or a test tube full of water, is held in the flame, soot may collect on it. We shall not give attention to the soot for the present. Another thing that we shall find in the flame is not ordinarily expected. Drops of water collect upon the cold object, but if the object is allowed to get hot, the water evaporates again. The water came from the flame. It must have been formed in the flame, for we did not supply water to it. 


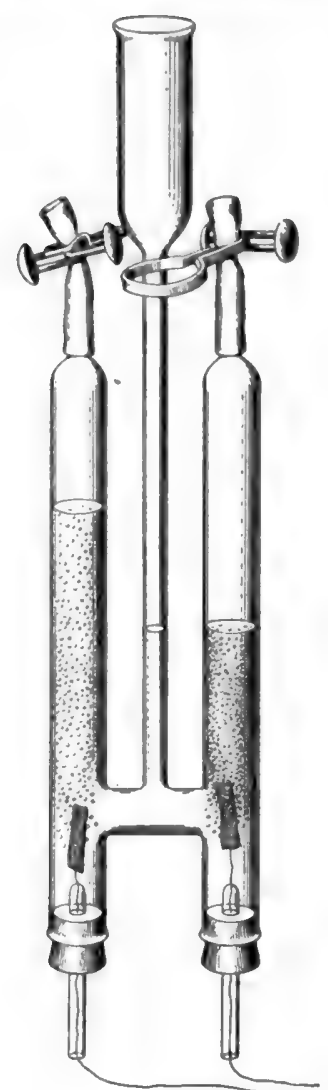

F1G. 35. Decomposition of water

By use of an electric current passed through the water in the tubes the water is decomposed into the hydrogen and oxygen of which it is composed. The upper clear region in the right-hand tube contains hydrogen, and the upper part of the lefthand tube contains oxygen. The volume of hydrogen is twice that of the oxygen.
If we had done so, it would doubtless have been extinguished. Furthermore, if a gas flame is used instead of a candle flame, and every precaution is taken to make sure there is no water vapor either in the gas or in the air, the same result follows. Since this water was produced from substances other than water, it is important for us to know what changes and what substances have produced it. The best way to find what substances compose water is to find what results when water is decomposed. It is not easy to determine what the component parts are, and we shall have to use experiments directly related to that problem. These experiments require the use of an electric current, and in the use of that current many interesting problems arise, but we shall give our attention at this time only to those which help us to understand the composition of water.

59. The composition of water. When we put the ends of two platinum wires in water and pass a current of electricity through the water between the wires, it is noticed that bubbles of gas arise from both wires. By suitable apparatus it is possible to collect these bubbles until there is enough gas to allow us to examine it (fig. 35). It will be noticed that the volume of gas that may be collected from one wire is about double that collected from the 
other. Both gases are colorless and look like air. One of them, that of the greater volume, takes fire and burns with a pale blue flame; the other does not take fire, but a splinter burns much more brilliantly in it than in the air. The one which takes fire is called hydrogen; the one which makes other things burn more brilliantly is oxygen. They can be caused to unite, and when they do so they form water. We may conclude that water is made up of two substances, hydrogen and oxygen, and that the electric current causes them to separate.

It appears strange that water, a liquid, should be composed of two gases, but such is the case. Are the two gases merely mixed? If so, we should expect to find that the results of the mixture would be a gas, and if we mix hydrogen and oxygen, as we did air and illuminating gas, we have a mixture of gases, nothing more. Water is something different from a mixture. In fact, if we mix hydrogen and oxygen and bring a flame to them, the mixture will explode. After the explosion we cannot find either of the gases, but instead we have water or water vapor. Making a mixture is quite a different thing from forming a new substance. If we mix hydrogen and oxygen, we have in the mixture two kinds of molecules - the molecules of hydrogen and the molecules of oxygen. When water is formed, we have molecules of only one kind - the molecules of water. The two kinds of substances must combine to form the water molecules.

60. The molecule of water. The theory as held by scientific men about this matter is that the molecule of water is not a simple thing - that it is composed of two kinds of particles. These particles are called atoms. The atomic theory states that each molecule is commonly made up of two or more atoms, and that these atoms may be of the same kind or of different kinds.

Each molecule of hydrogen is believed to be made up of two atoms of hydrogen; each molecule of oxygen, of two atoms of oxygen. Each molecule of water is believed to 
contain both hydrogen and oxygen atoms. When we decomposed water by the electric current, we secured twice as much hydrogen as oxygen. That would suggest that in the molecule there are probably twice as many atoms of hydrogen as of oxygen. Further study by chemists has shown that in a molecule of water there are two hydrogen atoms and one oxygen atom, making three atoms in all.

Chemists have a very convenient shorthand way of representing these facts by a symbol. They let a certain letter stand for a certain kind of atom. Thus, $H$ stands for a hydrogen atom and $\mathrm{O}$ for an atom of oxygen. If there is more than one atom, a small figure is written below and to the right of the letter to tell how many atoms are meant. Written in this way the symbol for a molecule of water is $\mathrm{H}_{2} \mathrm{O}$. We shall find it convenient to use this symbol.

61. Explanation of some chemical terms. When a substance is made up of molecules having two or more kinds of atoms in them, as in water, it is clear that it is possible to separate such a substance into two or more different substances, as we did with water. Such a substance is called a compound sub. stance. Water is a compound. A substance whose molecules have in them only one kind of atom, as oxygen, cannot be separated into simpler substances. It is called a simple substance (element). Hydrogen, oxygen, iron, silver, lead, copper, and gold are examples of simple substances.

Another chemical term that you will need to remember is chemical decomposition. When a compound is separated into its elements or into simpler compounds, the process is called chemical decomposition. Have you seen an example of chemical decomposition? It is sometimes said in that case that the compound has "broken down."

Any change in a substance in which the molecule is changed by atoms being taken away from it, added to it, or exchanged for others is called a chemical change. So long as the molecules remain the same, there is no chemical change. 
The following table contains the names of the more important simple substances, their symbols, and a few words descriptive of their appearance and condition at ordinary temperatures. Those marked with a star are metals. Look over the table and note what familiar substances are simple. 'There are in all eighty-four known simple substances.

\begin{tabular}{|c|c|c|}
\hline NaME & SYMBOL & DESCRIPTION \\
\hline *Aluminium & Al & A white or silvery solid, very light in weight. \\
\hline Antimony & $\mathrm{Sb}$ & A bluish-white solid. \\
\hline Arsenic & As & A gray solid ; it and its compounds are poisonous. \\
\hline *Barium & $\mathrm{Ba}$ & A solid. \\
\hline Bismuth & $\mathrm{Bi}$ & A solid. \\
\hline Boron & B & A solid. \\
\hline Bromine & $\mathrm{Br}$ & A dark-red liquid, much heavier than water, \\
\hline *Calcium & $\mathrm{Ca}$ & A solid. \\
\hline Carbon & C & $\begin{array}{l}\text { Commonly a black solid, but when crystallized it } \\
\text { may be transparent; diamonds are crystallized } \\
\text { carbon. }\end{array}$ \\
\hline Chlorine & $\mathrm{Cl}$ & A pale greenish gas with a suffocating odor. \\
\hline *Chromium & $\mathrm{Cr}$ & A solid. \\
\hline *Cobalt & Co & A solid. \\
\hline *Copper & $\mathrm{Cu}$ & A red solid. \\
\hline Fluorine & Fl & A very pale yellow gas. \\
\hline *Gold & $\mathrm{Au}$ & A heavy yellow solid. \\
\hline Hydrogen & $\mathrm{H}$ & A transparent, colorless, odorless gas. \\
\hline Iodine & I & $\begin{array}{l}\text { A shining, purplish-black solid, readily changed } \\
\text { by heat into a violet gas. }\end{array}$ \\
\hline *Iron & $\mathrm{Fe}$ & A silver-gray solid, readily tarnished. \\
\hline *Lead & $\mathrm{Pb}$ & A soft, heavy, silvery solid. \\
\hline *Magnesium & $\mathbf{M g}$ & A silvery solid. \\
\hline Manganese & $\mathrm{Mn}$ & A solid. \\
\hline *Mercury & $\mathrm{Hg}$ & A silvery-white liquid, very heavy. \\
\hline *Nickel & $\mathrm{Ni}$ & A solid; white, hard, not readily tarnished. \\
\hline Nitrogen & $\mathbf{N}$ & A colorless, odorless gas. \\
\hline Oxygen & 0 & A colorless, odorless gas. \\
\hline Phosphorus & $\mathbf{P}$ & A waxy solid, spontaneously combustible in air. \\
\hline *Platinum & Pt & A silvery solid, very heavy. \\
\hline *Potassium & $\mathbf{K}$ & A solid, but easily cut with a knife. \\
\hline Silicon & $\mathrm{Si}$ & A solid. \\
\hline *Silver & Ag & A white solid. \\
\hline *Sodium & $\mathrm{Na}$ & A solid, but soft enough to be easily cut. \\
\hline Sulphur & $\mathrm{S}$ & $\begin{array}{l}\text { A yellow solid, forming many strong-smelling } \\
\text { compounds. }\end{array}$ \\
\hline *Tin & Sn & A white, moderately hard solid. \\
\hline *Zine & $\mathrm{Zn}$ & A bluish-white solid. \\
\hline
\end{tabular}


62. Formation of water in the flame. By this rather long route we have come back to the question with which we started. How was the water formed in the flame? After what we have learned we should expect to find that the water had been formed in the flame by some sort of chemical change. This is the case. Hydrogen and oxygen unite to form water. In fact, the flame is merely a place where chemical changes are occurring. The formation of water is one of the most important of the changes going on in the flame.

The wax is a compound containing hydrogen; the air is a mixture containing oxygen and several other gases. When the wax is melted and then turned into a gas by the heat of the flame, this gas mixes with the air, and the atoms of hydrogen leave the other atoms and unite with the atoms of oxygen which are in the air. The compound thus formed is water. When hydrogen and oxygen unite, the union produces great heat, and at the resulting high temperature the water remains in a state of water vapor. It is only when this water vapor is cooled, as by contact with a cold object, that it changes into the liquid form and becomes visible as drops of water.

The flame of the candle consists principally of gases heated to a high degree by the changes which are taking place in the flame. The gases in the candle flame with which we are already somewhat familiar are the vaporized wax, water vapor, and the gases of the air. A flame is always composed essentially of buiming gases, but these gases may not always be of the sort that we have found in the candle flame.

The chemical change which we have been discussing and which takes place in the candle flame may be briefly stated thus: Hydrogen unites with oxygen to form water.

63. Other products from the flame. We shall not study the water of the flame any further. There are other substances formed by the burning of the candle.

It was said that the candle wax is a compound, and that the hydrogen which unites with the oxygen is taken away from 
the wax. The wax is a compound containing a great deal of hydrogen and carbon. When the hydrogen is taken away from this compound, - when the compound is decomposed, - the carbon atoms are left. The small particles of carbon float upward in the flame and are heated red-hot or white-hot. The part of the flame in which the white-hot carbon is present is the part from which the light comes.

The substance which we call carbon is so familiar to us as electric-light carbons, charcoal, lampblack, soot, etc. that it is not necessary to describe it. If a cold object is held in the flame of a candle a moment, carbon (soot) is deposited upon it.

Some of the carbon may be seen to pass upward from the tip of the flame as smoke, but if the candle is well trimmed, there should be little or no smoke. Carbon as well as hydrogen is able to unite with oxygen, and though there is much carbon in the flame, very little of it passes away from the flame in the form of soot. It unites with the oxygen of the air to form a compound made up of carbon and oxygen. We need to make a further study of this compound.

64. Carbon dioxide formed by the flame. If a candle or other flame is allowed to burn for a time in a bottle of air, the bottle ought then to contain anything that is formed by the flame. If limewater is poured into the bottle and shaken slightly, the limewater will become milky. If we do the same with a bottle of air in which the flame has not burned, the limewater remains clear. This shows that there is something in the bottle that was not there before the flame was put into it. Chemists tell us that the substance which caused the limewater to become milky is a gas composed of carbon and oxygen. Is it an element or a compound? Taking this suggestion, we may burn some charcoal (carbon) in a jar filled with pure oxygen. In that case anything that is formed can contain only carbon and oxygen, since there is nothing else in the jar. If we test the results of this burning, as before, the limewater turns white, showing us the evidence of the same 
substance. We shall therefore take the word of the chemist, that this substance which is produced by the burning candle is

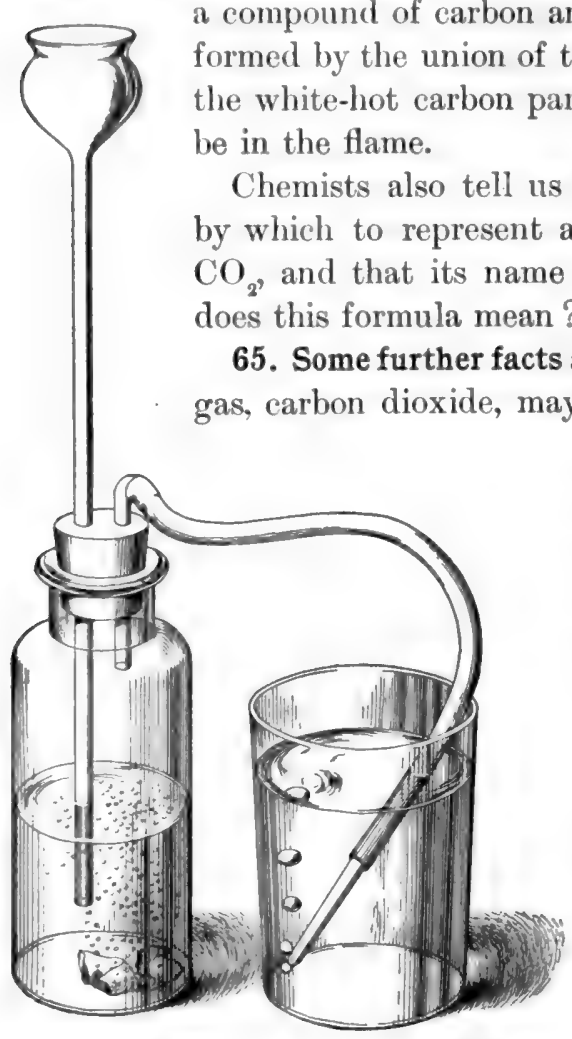

FIG. 36. A carbon-dioxide generator

The bottle contains pieces of marble and hydrochloric acid. The action of the acid on the marble decomposes it, releasing carbon dioxide, which escapes through the bent tube. Additional acid may be added through the funnel besides by burning. Most convenient, perhaps, is the method of producing it by putting hydrochloric acid on marble (fig. 36). However produced, it is always the same. If we collect it in a bottle, it is found that the gas is perfectly clear and colorless. It will not burn, but instead it extinguishes fire. It may seem strange that things will not burn in carbon dioxide when the gas is composed partly of oxygen, but it must be remembered that the oxygen atoms are joined
they are not free to unite to the carbon atoms, and therefore they are not free to unite with something else. Since the oxygen atoms will not leave the carbon atoms of the carbon dioxide, there is no free 
oxygen to maintain the burning of a flame, and therefore the flame is extinguished.

Carbon dioxide is about one and one-half times as heavy as air, and therefore can be collected in an open bottle. With care it may be poured from one bottle to another.

It is familiar to us as the gas that bubbles up in our soda water and in other effervescent drinks, and as the important substance in chemical fire extinguishers. Sometimes it occurs in wells, cisterns, sewers, and in mines, where it is called choke damp. One may drown in it as truly as in water, since it fills the lungs but does not supply any free oxygen for respiration. There is a very small amount always present in the air; and this will be discussed later.

66. The gases of the air. We have already found that the air consists of several gases. These are merely mixed; they do not form a compound. The most striking one of those that we have been studying is oxygen. It constitutes about one fifth of the volume of the air. Of carbon dioxide there are only about 3 parts in 10,000 .

There is yet another gas present in large quantities in the air. It is called nitrogen. We shall have more to say about it in connection with the food of plants and animals.

Several other gases have lately been discovered. Also, dust particles are always present, and some of these are of great importance. They will be discussed in Chapter VIII.

Below is a table showing the gases commonly found in the air, and the average amount of each, given in percentage. The exact percentage cannot be given, because the amounts vary slightly from time to time.

Сомposition of Air

(Approximately)

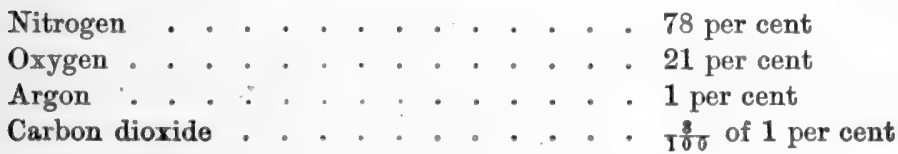


67. More about oxygen. The gas oxygen is the most abundant simple substance upon the earth. In an uncombined state it makes up about one fifth of the air, as noted above. It is found in combination with almost every known simple substance, forming eight ninths (by weight) of water and about one half of the rocks of the earth's crust. It is estimated that about 50 per cent of the earth is oxygen.

68. Nitrogen and argon. While oxygen is a very active substance chemically, readily entering into combination with a great variety of other substances, quite the opposite is true of nitrogen and argon. These gases serve to dilute the oxygen of the air, but they remain unchanged under most circumstances. Certain compounds of nitrogen are of great importance, however; the living substance of plants and animals contains nitrogen compounds, and these compounds are essential constituents of the food of all living things.

69. Summary. The air is composed of molecules of several kinds of gases. These molecules are all moving about and tend to get away as far as possible from each other. This is what explains the expansion of gases.

Each molecule is ordinarily composed of two or more atoms. The molecules of simple substances contain atoms of the same kind. In a compound, such as carbon dioxide, a molecule contains atoms of more than one kind.

When a candle is burning in the air, atoms of oxygen from the air unite with atoms of hydrogen from the candle wax to form water, and with the atoms of carbon to form carbon dioxide. 


\section{CHAPTER VII}

\section{RELATION OF AIR TO FOOD MANUFACTURE}

70. Sources of our food. A large part of our food consists of plants or parts of plants (such as fruits and vegetables) that are eaten in almost or quite the natural condition. Such substances as flour and sugar are manufactured from plants. Of course, in all these cases there can be no doubt that our food comes directly from plants. Another important class of food materials includes meats and other animal products. The animals feed upon plants, and here again there are only one or two stages before we come back to plants as the source of our food. The more we think of this the more fully we shall be convinced that almost all of the things that we eat come directly or indirectly from plants. The next question is, How do plants produce these food materials?

71. Source of plant food. It is commonly believed that plants secure their food from the soil, but this is not wholly correct. If it were true, a plant growing in a small pot would consume the soil, but we all know that a plant may grow for a long time and become larger and heavier than the soil in the pot was at first, and yet the soil will not appear to have decreased. The plant takes water from the soil, and very careful observation would show that an extremely small part of the soil itself is used. The remainder of the material in the plant is not supplied from this source.

Another thing that leads to the same conclusion is that some of the most important substances in plants are not found in the soil or are very scarce there. An example of this is the case of the black substance called carbon. Wood contains a great deal of carbon, though we do not usually recognize it as such, because 
there are other substances combined with it. If the wood is heated sufficiently to burn or drive off other substances, that which remains will be a black mass called charcoal. Although the soil and the water contain at times a small amount of car-

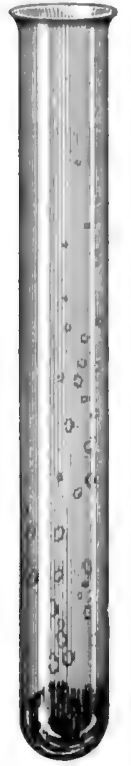

FIG. 37. Decomposition of starch

When starch is decomposed by heat, a black deposit of carbon remains in the bottom of the tube, and water condenses on the inside of the tube bon, it has been shown that this is not the source of the plant's carbon supply. There is only one other source for the carbon, and that is the air, for the air does contain some carbon in the form of carbon dioxide. It is from this that the carbon of plants is secured.

72. Food of plants. The food materials of plants are not very different from those of animals. For instance, starch and sugar are very common in our own food; they are also an important part of the food of our common plants. The difference between the food habits of common plants and those of animals is not so much in the sort of things that they require as in the way in which they secure these things. The animal secures the starch, sugar, and other compounds from a plant or from some other source, where they may be found in such a condition that it can use them directly. The plant, on the other hand, is able to make these compounds from their elements.

Such compounds as starch and sugar are composed of three simple substances, - carbon, hydrogen, and oxygen. We ean easily prove that this is the composition of starch by heating some in a test tube (fig. 37). The heat decomposes the starch, and we have carbon and water. Water, we already know, is composed of hydrogen and oxygen, and therefore we have here the three substances.

73. The place where food is made. If a green leaf is exam. ined early in the morning, little or no starch will be found in 
it. After several hours' exposure to sunshine, however, starch will be abundant in the leaf, and the quantity will increase with longer exposure to the sun's rays. The starch was made in the leaf from carbon dioxide and water. This manufacture may go on in any green part of the plant under the influence of sunshine. Since the leaves are the principal green parts of plants, it is in the leaves that most of the starch-making is carried on. Starch and other starch-like substances, as the sugars, may be used as food by the leaf or may be transferred to other parts of the plant and then used or stored.

74. Some problems. We shall now want to know how the carbon dioxide gets into the leaf, how the water gets there, what chemical changes take place, and what the light does in this process. As an aid to the solution of these problems we shall have to learn certain things about the structure of the leaf. We shall therefore study next this organ of the plant, which seems to be the food factory of the world.

75. Structure of the leaves. The most conspicuous part of the ordinary leaf is broad, thin, and green, so that it is common to call anything which is thin and flat leaf-like, and many persons consider this part the whole leaf (fig. 38). This is not the whole leaf, however, but is the blade. Besides the blade there is usually a stalk, called the petiole, and sometimes also, at the base of the petiole, two objects more or less like little blades, which are called stipules. Stipules, petiole, and blade make up the leaf. These are the parts of a complete leaf, but the stipules are often very small or altogether missing, and the petiole is sometimes absent.

The stipules are not important parts of the leaf and will not be studied here. The petiole is rather strong and woody and serves to hold the leaf blade in the proper position.

The blade of a leaf contains many veins, which serve as a framework to support it, as well as for other purposes. The arrangement of the veins differs in various kinds of leaves. In many leaves there is a main vein extending from the petiole 
toward the tip of the blade; smaller veins branch out from this and extend obliquely toward the edge. These smaller veins branch again and again, until the smallest of them are invisible to the naked eye and form a very fine and close network. This is the pinnate (feather-like) type of veining. Other

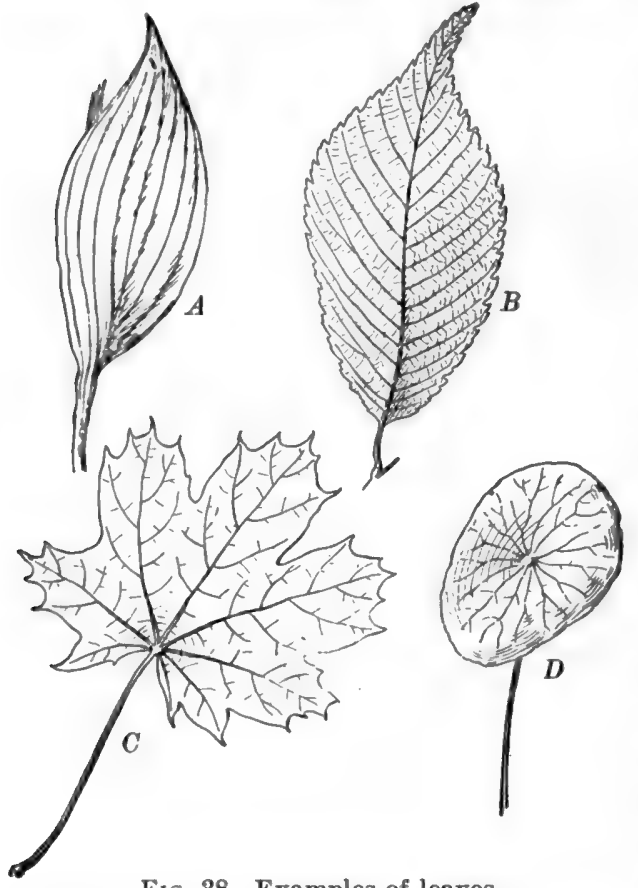

Fig. 38. Examples of leaves

$A$, parallel-veined leaf of the lady's-slipper orchid; $B$, pinnately veined leaf of the elm; $C$, palmately veined leaf of the maple; $D$, palmately veined leaf of the water shield leaves, like those of the geranium or nasturtium, have no single central vein, but instead several large veins extend outward like a fan from the end of the petiole. These leaves have the palmate (hand-like) type of veining. There are other leaves, like that of the common plantain, in which the principal veins all start from the petiole and run nearly parallel toward the tip of the blade. There is no conspicuous network. The grasses also illustrate this kind of veining. These leaves are said to be parallel-veined.

The spaces between the veins in the meshes of the network are filled with a soft, green material called the mesophyll. This material is very easily injured by contact with anything and quickly dries if exposed to air. It is protected by a thin skin, 
or epidermis, which covers it and the veins together. This epidermis is ordinarily as thin as fine tissue paper and almost as transparent. It can be quite easily peeled from some leaves, while on others it is too delicate to be removed. The epidermis is found on petioles and young stems, as well as on the blades.

Although it is so thin, the epidermis is able to protect the mesophyll. If it is removed, the lightest touch seems to crush the mesophyll, and within a few minutes it will begin to shrivel or turn black from loss of water. It is easily understood that if the epidermis were not present, the mesophyll would soon be destroyed by the whipping of the wind, as weil as completely dried. The epidermis is therefore an important protective structure.

76. Structure of the epidermis. How is air able to enter the leaf if the epidermis is a complete covering for the blade? It is very plain as you peel it off that the epidermis covers the entire blade, and it is equally certain that air gets into the leaf in some way. Just how it gets in is to be explained by examining the structure of the epidermis, and this must be done with the microscope, for the unaided eye gives us little information on this point.

If a bit of the epidermis from a lily or a blue-flag leaf is examined with a high-power microscope, it will be found that it looks something like a brick pavement. It is made up of many small oblong bodies closely joined together. These bodies are like bricks only in shape and in the way they are joined. They are called cells, and not only the epidermis but also all the other parts of the plant are made up of cells. The cells differ very much from the bricks with which we compared them. They are transparent and, so far as you can see in the piece of epidermis, they are hollow. You will learn as you examine cells more closely that they contain the living material of the plant, though this is often so transparent that it is difficult to see, as in this case. What you ordinarily see 
in the piece of epidermis is really nothing but the wall which incloses the living part of the cell.

The cells of the epidermis are not all alike; a few of them are crescent-shaped or bean-shaped instead of rectangular. These cells are always in pairs, with their concave surfaces next to each other. These curved surfaces do not come together tightly, as the surfaces of all the other cells do, and this leaves a little space between them which makes an opening through the epidermis. This explains how the water gets out. There are many such openings in the epidermis. Of course, each opening is very small, but the great number makes up for the small size. These openings are called stomata, and the two bean-shaped cells with each stoma are called the guard cells. The guard cells make the opening larger or smaller by changing their shape, but it is not entirely clear what service is actually done to the plant by this change.

The number of stomata is much greater than at first appears. If you look in the microscope, they seem to be far apart, but one must remember that the view in the instrument is very much magnified. Perhaps half a dozen stomata are seen, apparently much scattered over a wide surface, but in reality the surface of the epidermis seen under a high-power microscope is not larger than the period at the end of a sentence. It is common for leaves to have more thản 60,000 stomata to the square inch, and some leaves have as many as 700,000 per square inch. Most of these are found on the lower surface. It has been estimated that one large sunflower leaf contains $13,000,000$ stomata. This great number allows the carbon dioxide to enter freely.

The cells of the epidermis are not always so regular in shape as in the lily. In very many plants they are extremely irregular, though always fitting together very closely. The stomata, too, vary in shape and appearance.

77. Structure of the leaf interior. The mesophyll of the leaf (fig. 39), like all other parts of a plant, is made up of 
cells. Each of these cells consists of a thin, transparent wall, a semi-liquid, clear mass of living substance (protoplasm) filling the space within the wall, and a number of green granules called chloroplasts. There are several other important things in the cell, but we need not concern ourselves about them at present. The cells in the part of the leaf near the lower epidermis are arranged very irregularly, with large spaces between them. This part of the mesophyll is called the spongy tissue, and its many spaces give the air which enters through the lower epidermis an opportunity to reach all the cells of this tissue. Since there are few stomata or none at all in the upper epidermis, little air enters through it.

The mesophyll of the upper surface is made up of cells of fairly regular shape. They are long, narrow, and cylindrical. They stand side by side, with the end of each cell toward the epidermis,

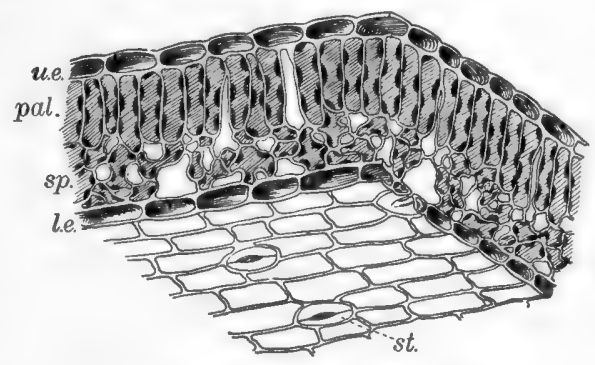

Fig. 39. Diagram of a leaf section

The view shows a part of a leaf, greatly magnified. The lower surface and the cut edge are represented: u.e., upper epidermis; pal., palisade tissue; $s p$. , spongy tissue; l.e., lower epidermis; $s t$., stoma

and are fitted together quite closely. They may be arranged in one or more rows, the surface row being immediately under the upper epidermis. There are narrow spaces between them, so that the air which has entered the spaces in the spongy tissue is able to penetrate into this more compact layer. It is called the palisade layer.

The green coloring matter, or chlorophyll, is distributed in a very peculiar way. It does not color the cells green throughout, as one might suppose. In each cell there are found some small, rounded grains that are bright green in color, and the remainder of the cell is quite colorless. These grains are 
called chloroplasts. They are colored by a very important green pigment called chlorophyll, somewhat as a piece of cloth may be colored by a dye. The chlorophyll may be removed from the chloroplasts, leaving the leaf white. These chloroplasts are much more numerous in the cells of the palisade than in those of the spongy tissue, so that the upper side of a leaf is usually much darker green than the lower side. It is upon these chloroplasts that the light acts in the manufacture of sugar and starch.

78. Entrance of materials into the leaf. Water, which has been absorbed from the soil by the roots, passes up the stem and reaches the various parts of the leaf through the leaf veins. Those cells which are not in contact with the veins receive water through other cells. The water supply therefore reaches every cell of the leaf.

Carbon dioxide, as well as other components of the air, passes through the stomata by diffusion. The spaces between the cells of the mesophyll allow the gas to spread throughout the leaf. In this way carbon dioxide and water, the raw materials of food manufacture, are brought together in the cells of the mesophyll.

79. Manufacture of carbohydrates. It is in the cells of the mesophyll that a change occurs in the two compounds, water and carbon dioxide. The change is a complicated one, but we may get some conception of its main features if we say that the leaf causes the earbon of the carbon dioxide to separate from the oxygen and unite with the water. Since water is itself made up of hydrogen and oxygen, the molecules of the new compound will contain atoms of carbon, hydrogen, and oxygen. These substances unite only in certain definite proportions. Very frequently the proportion in the compound formed in the leaf is that of six atoms of carbon to twelve atoms of hydrogen and six of oxygen. This is sometimes represented by the symbol $\mathrm{C}_{6} \mathrm{H}_{12} \mathrm{O}_{6}$, and it is called grape sugar. Sometimes it is starch $\left(\mathrm{C}_{6} \mathrm{H}_{10} \mathrm{O}_{6}\right)$ that is formed, and 
sometimes other substances may result. In any event the formation of starch and sugar is preceded by the formation of simpler substances which we do not need to discuss in this connection. All of these compounds of carbon, hydrogen, and oxygen which resemble sugar and starch are called carbohydrates. There are many different kinds of carbohydrates, and the compound formed by the leaf from carbon dioxide and water is always a carbohydrate of some kind. That such a compound as starch does, in fact, contain carbon and water may be proved as suggested above (sect. 72).

80. The waste material. Not only is there a carbohydrate formed, but there is also some oxygen left over. This oxygen has been separated from the carbon and is therefore in exactly the same condition as if it had never been united with it. It is gaseous oxygen exactly like that in the air, and it may pass out through the stomata into the air, where it mingles with the other gases. It may be called the waste material of the process of manufacture which we have just been studying. Bubbles of oxygen may often be seen rising from plants which are growing under water. It is escaping from land plants in a similar way, though it is not visible in the air.

81. The source of energy. A factory needs energy, and our carbohydrate factory in the leaf must have energy to operate it. Most factories that we are familiar with are operated by energy derived from a waterfall, or from burning coal under the boilers of a steam engine, or by electric power, but the leaf derives its energy from a source that is different from all of these and at first appears rather surprising - the sunlight. Light is as much a source of power or form of energy as is electricity, heat, or falling water, but men have not yet learned so well how to use it. We may cause light to do work on a photographic plate, we know that it will change the colors of the chemicals we use to dye our fabrics, and we may cause it to do other kinds of work for us, but we have not learned how to make it run our factories. The leaf is able to use this 
energy of light in manufacture of carbohydrates. If there is no strong light shining upon the plant, it is not able to carry on this work, and the plant factory stops. For that reasun all green plants must live where there is light, and they cannot make starch or sugar at night. Artificial light will answer if

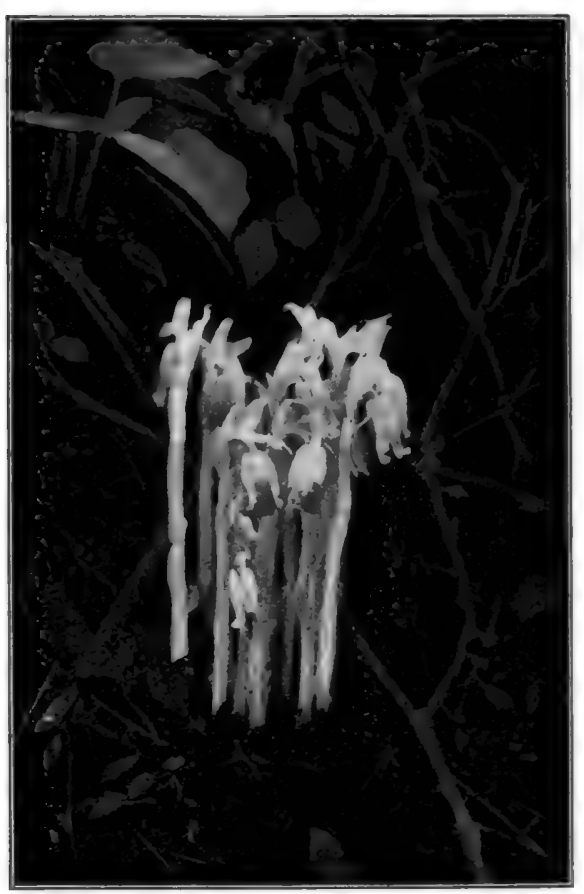

Frg. 40. Indian pipe, a dependent plant

The plant is wholly without chlorophyll. It secures its food from organic substances in the soil it is strong enough, but usually it is too weak to have any appreciable effect.

82. Importance of chlorophyll. It follows from what has been said in the preceding sections that the carbohydrate manufacture can go on only in the presence of light and chlorophyll. This fact causes us to regard chlorophyll as a very important substance. All plants which have chlorophyll are able to manufacture their own food, while plants which do not (figs. 40 and 41) have it are obliged to depend upon securing the food already made. We may call those plants which have chlorophyll independent plants, and those which do not have it dependent plants.

83. Photosynthesis. The process in which the chloroplasts of green plants, with the aid of light, manufacture carbohydrates out of water and carbon dioxide, is called photosynthesis. This is the name for the process we have been studying. 
84. Sugar and starch in the leaf. Sugar is commonly formed in the leaf in the process of photosynthesis, and it is being continually carried away for use in other parts of the plant. On a bright, sunny day it is made much more rapidly than it can be carried away or used, and if there were not some way to dispose of it, the sugar would accumulate in the leaf until the sap became so filled with it that the work of the leaf could not go on. The leaf has the power of changing the excess sugar into starch. This removes the excess carbohydrate from the sap, since starch is not readily dissolved in water. It is possible that when the leaf is working rapidly, instead of forming sugar and changing it into

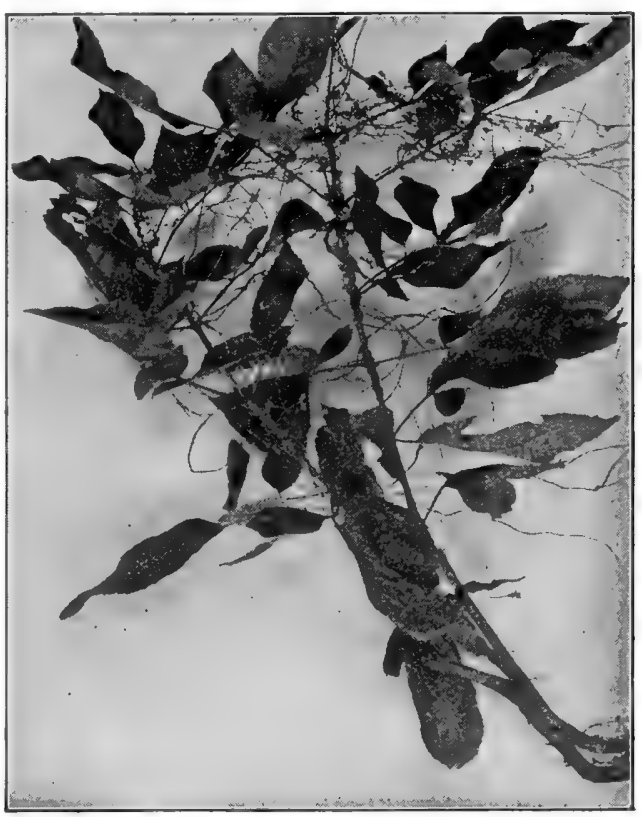

Fig. 41. Dodder, a dependent plant

The tangled, leafless vine is the dodder. It secures its food from the other plant, which is known as its host, while the dodder is a parasite starch, the leaf may form starch directly from the simpler compounds. At any rate, by evening, if the day has been a bright one, a great deal of starch is stored in the leaf. At night, when no sugar is being made, the starch in the leaf is slowly changed into sugar and carried away, and by morning little starch remains in the leaf. The process of changing sugar into starch or starch into sugar does not require light. 
85. Comparison with a factory. It may be interesting to sum up the process of photosynthesis by comparing it with a factory. This comparison may be made as follows:

The factory . . . . . . Green part of the plant

Machinery . . . . . . Chloroplasts

Energy . . . . . . . Light

Raw material . . . . . Water and carbon dioxide

Finished product . . . . . Carbohydrates

Waste product ...... Oxygen

86. Importance of photosynthesis. The food supply of all living things depends upon the work of green plants. Carbohydrates make up a very large part of our own food and of the food of many animals. Other food also is made, either directly or indirectly, from carbohydrates. Even the meat which composes part of our diet is derived from carbohydrates, for the animals from which it comes feed mainly on plants. The green plants and the work which they do are therefore of the very greatest importance. 


\section{CHAPTER VIII}

\section{DUSTS, MOLDS, AND BACTERIA OF THE AIR}

87. Dust in the air. There is another part of the atmosphere of which we have said nothing. It is the dust. It is a part of the atmosphere that we might very well get along without, it often seems, but it is always present. Unlike other parts of the atmosphere, dust is a solid, not a gas. It consists of very small, solid particles, which are borne along by the air. The larger particles settle very rapidly, but the finer ones fall through the air so slowly that they remain floating for a long time. If a wind is blowing, they may be carried great distances.

The abundance of dust in the air becomes obvious when we see a beam of sunlight crossing a darkened room. All the bright points dancing in the light are bits of dust, but most of the particles are too small to be seen in this way. The housewife has an equally good demonstration when she finds a covering of dust on the furniture which was carefully cleaned but a few hours before.

88. Dust is everywhere. Dust is a very troublesome thing. It accumulates on articles in our homes to such an extent that much time is spent by the housekeeper in sweeping and dusting. When we go out of doors, it gets into our mouths and nostrils, irritates our eyes, and clings to our clothing. Indoors we cannot escape it, for, even though we close the house, it filters through the smallest cracks. It is upon the food we eat, particularly if we purchase articles from street stands or in stores where the food is displayed uncovered. In our cities the air is often so filled with solid particles, whether called dust or smoke, that it is impossible to see very far. Even in the clear air over the desert or the ocean, dust is not wholly absent. 
It is certainly worth while to find out something about this ever-present dust. We ought at least to know whether it is harmful or helpful.

89. The nature of dust. What is this dust which we eat along with the apples or other fruit that is purchased from a street stand at some dusty corner? Undoubtedly a large part of it comes from the dust of the street, ground up by the hoofs of horses and the wheels of vehicles. A glance into the street will enable us to see some of the things which are being crushed to powder, and which will later make part of the common dust as it is picked up by the wind and whirled about.

Another part comes from greater distances, though it may have had a similar origin. Some particles are bits of unburned carbon (smoke or soot), and in cities this may make up a large part of the whole amount of dust. Bits of wool and cotton from clothing of all sorts of people, fragments of hairs from the coats of animals, dead cells from the skins of people and animals - all these things and many more enter into the composition of the dust.

If this were all, it might not seem so bad. True, some of these things offend our sensibilities, and some of them may irritate the delicate membranes of the nose and lungs, or a larger particle in the eye may occasion more serious trouble, but if this and the household inconvenience were all, we might be inclined to think dust merely an annoyance.

90. Living dust. We shall get some more information about these particles in the air if we will perform certain experiments. Cut a slice from a fresh loaf of bread, using a clean knife. If this slice is exposed to the air for a while and then covered up in such a way that it cannot get dry, within a few days it will be covered with a growth of fine, white, thread-like bodies and will exhibit the appearance of the growth to which we apply the name mold. Mold is a living plant.

Within a few days we shall see that the mold is bearing small black heads which yield a fine, dust-like black powder. 
These dust-like particles are called spores. The spores are easily blown about by the wind, and any one of them, alighting upon a piece of bread or in any other favorable place, is able to grow into a new mold plant. Can you imagine how the mold got started on the piece of bread?

Again, if a weak solution of sugar in water is exposed to the dust of the air and allowed to stand for several days, it ferments; that is, bubbles of gas rise through the liquid. This gas is found to be carbon dioxide. The sugar can no longer be found in the solution, but in its place there is a small amount of alcohol, and a peculiar odor is present. A scum collects at the surface of the liquid and probably at the bottom also (fig. 42). The microscope shows that this scum is made up of minute living plants. These are the yeast plants.

If a sugar solution is boiled in order to kill any yeast that may be in it, and is then inclosed so that no yeast can enter, fermentation will not occur ; but if the solution remains exposed to the air after boiling, fermentation will follow. This may be taken to prove that the yeast gets into the solution from the air and that it is the cause of fermentation.

Another experiment may be per-

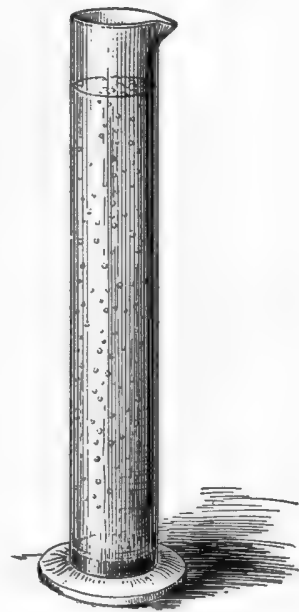

FIG. 42. Fermentation by yeasts

In the sugar solution within the jar, yeast plants were placed. Bubbles of gas formed by fermentation rise through the solution, and large numbers of yeast plants settle as sediment at the bottom formed. Take several shallow dishes and into each pour a thin layer of beef broth or similar substance. The broth or other nutrient substance may be stiffened with gelatin or agar. This must have been heated to destroy any living things that may have been in it. One of these dishes should be uncovered 
to the dust of the air and allowed to remain so for perhaps fifteen minutes, and then covered again; the other dish should not be uncovered at any time. After several days it will be found that the gelatin in the dish (fig. 43) which was exposed to the air has upon it a number of small, round spots, which are usually colored white but are sometimes pink, orange, or yellow. These will enlarge from day to day. Study with the

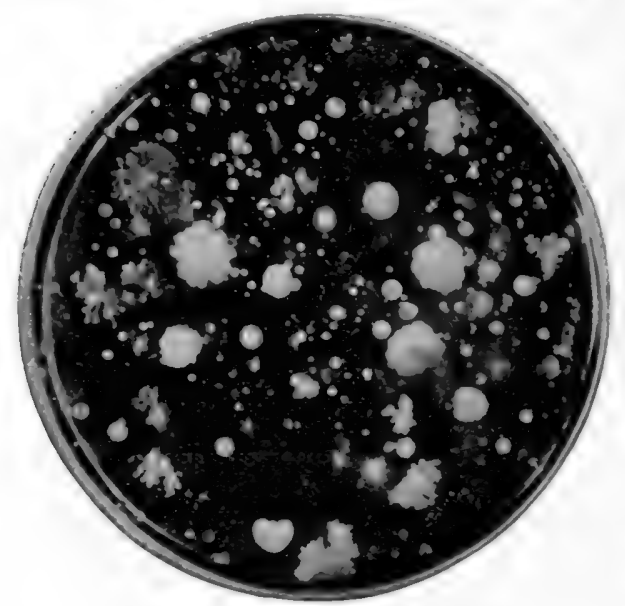

Frg. 43. Colonies of bacteria

Each of the circular or irregular patches represents one colony of bacteria. The bacteria grew in a thin layer of nutrient agar. The dish is $9 \mathrm{~cm}$. in diameter and contains 350 colonies of bacteria. The colonies have arisen from the multiplication of bacteria which fell upon the agar during fifteen minutes' exposure out of doors microscope shows that some of these spots consist of millions of very minute objects which can scarcely be seen even with the aid of the microscope. These minute objects are living plant cells of the simplest structure and are called bacteria. Each of the bacterial colonies has resulted from the multiplication of one or a few bacteria which fell upon the gelatin at that point while it was exposed to the air.

Therefore we learn from these experiments (1) that a part of the dust of the air consists of things that are able to grow and multiply if they happen to alight upon favorable substances; (2) that there are at least three kinds of living things represented in the air-bacteria, yeasts, and mold spores; (3) that each of these is able to grow vigorously if only it falls on the right kind of substance; (4) that all of 
these are so numerous that they are likely to fall upon every favorable place, and of course upon unfavorable places as well.

91. Dependent plants. In a preceding study we saw that green plants make their food from carbon dioxide and water. There are some plants that are not green; that is, they have no chlorophyll. Such are the mushrooms and molds. They are therefore unable to make their food and are obliged to secure it from other plants or animals. Since these plants depend upon other living things for their food, they are called dependent plants. Some of them secure food from living plant or animal bodies and are called parasites. Others live upon
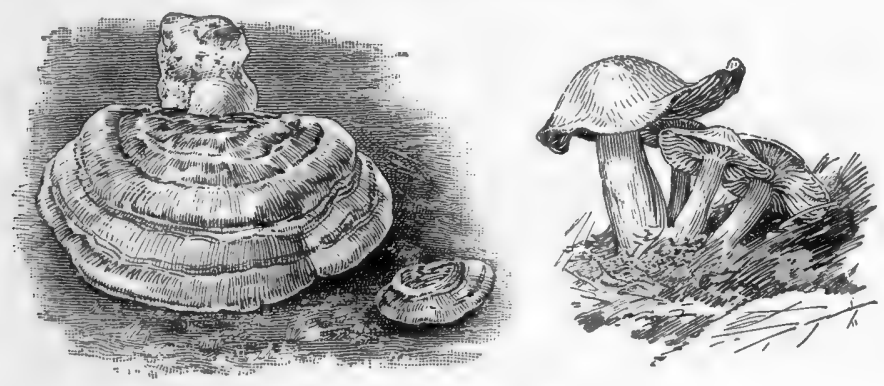

FIG.44. Saprophytes

These plants secure their nourishment from decayed wood and similar substances

the material secured from dead bodies of plants and animals, or materials formed by plants and animals. These are called saprophytes. The common mushrooms live and grow in soil in which pieces of dead leaves, decaying wood, and bark are mingled, and it is from this material that they secure their food. They are therefore saprophytes (fig. 44).

A great many kinds of parasites (fig. 45) and saprophytes exist, and some of them, particularly the parasites, cause great damage to crops, but we shall not study many of them at this time. Some of the bacteria which are under discussion in this chapter are parasites while others are saprophytes. Either plants or animals may be hosts for parasitic bacteria. 


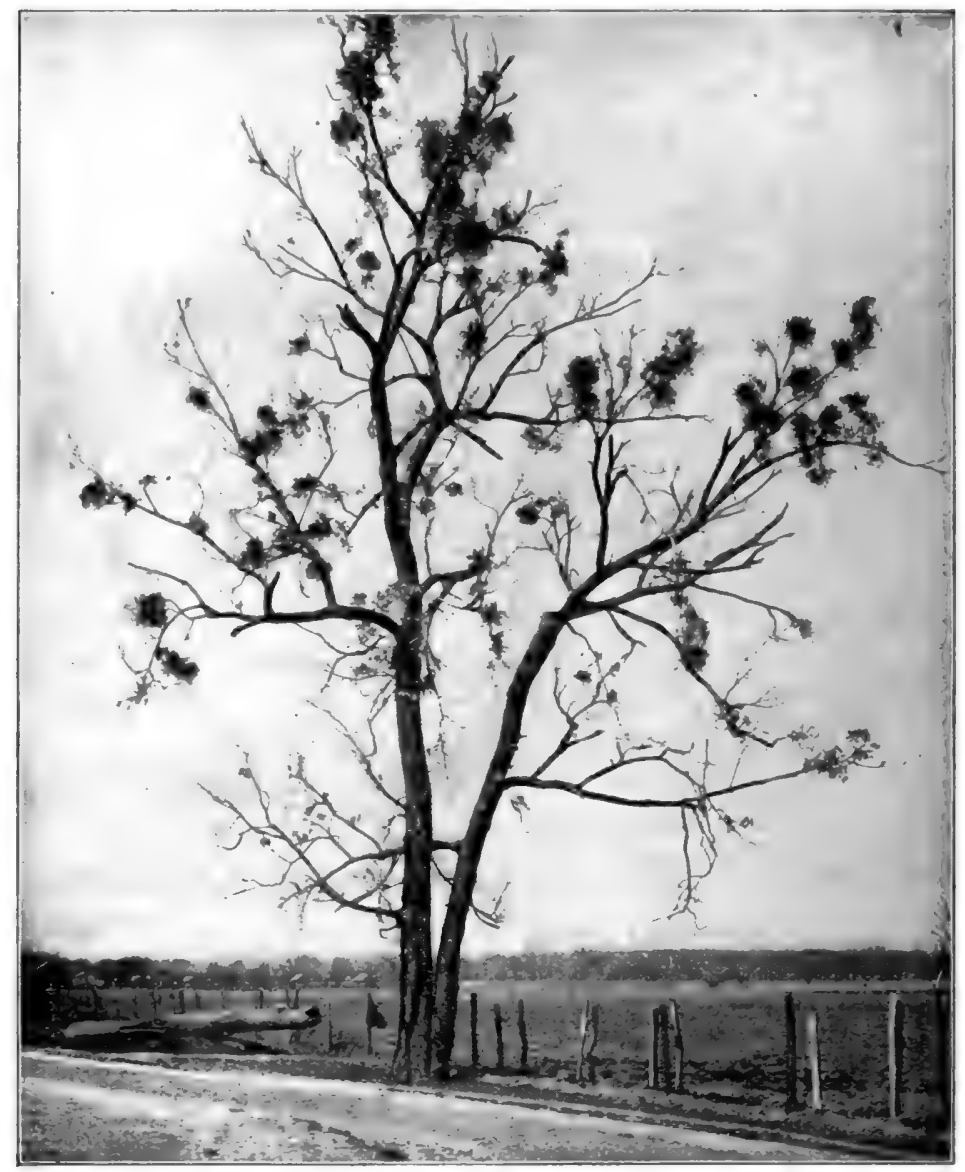

Fı,.45. A parasitic plant

Mistletoe on an elm tree. The chusters seen on the branches are the parasites. There were no leaves on the tree, as the picture was taken in winter. 
92. Bacteria. The bacteria are dependent plants. They are the smallest of living things, often measuring not over $5 \frac{1^{\prime}}{000}$ inch in diameter. Some kinds are considerably larger than this, while others are müch smaller (fig. 46). Only the very highest powers of the microseope will give information about their internal structures, and there is good reason to believe that there are bacteria so very minute that they are quite invisible even with the best microscope.

They multiply by simple division. After one has grown to adult size, it may divide into two, each of which may continue
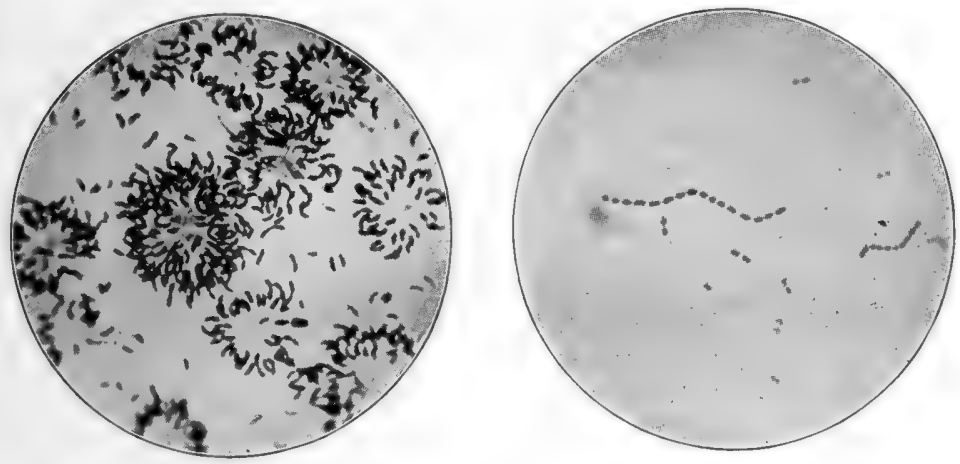

FIG. 46. Photomicrographs of bacteria

These photographs were taken through a high-power microscope. The small, dark bodies are the bacteria, very highly magnified. Photographs by Dr. N. M. Harris

to grow and divide. The division may be repeated as often as once in every twenty minutes, though usually not so frequently. Like other dependent plants they feed upon and destroy organic materials, and on account of the rapidity with which they multiply they are usually found in very large numbers.

93. Bacteriology. The study of bacteria is of great impor-tance, and the methods that must be used in studying them are different from those used in studying larger plants. This study is known as bacteriology. One who wishes to know 
much about bacteria must give his attention to this branch of science alone. On account of the danger to man from disease-producing bacteria, the science of bacteriology has been taught largely in connection with the study of medicine, but its importance in other respects is coming to be more commonly recognized.

94. Relation of bacteria to decay. Since it is chiefly bacteria which cause the change in organic substances known as decay, one way to prevent the decay of anything is to prevent the growth of these organisms in it. This may be done either by keeping them out of the substance or by adding to it something that is fatal to them and so making their growth impossible.

The latter method is sometimes used to preserve milk, formaldehyde being added in small quantities for this purpose. Formaldehyde is quite effective in preserving the milk, but it is very objectionable in a food material. Other chemicals are used in canned goods for the same purpose, but in general it may be said that any chemical which will destroy bacteria is not likely to be a suitable article of food. This objection does not apply, however, to the preservation of things by means of salt, sugar, or vinegar.

In every way the most successful method of preventing harm by bacteria is to kill those present and prevent the entrance of others. This is practiced in the canning of fruits and other food products. Since bacteria are sure to be in the fruit at the outset, it is first boiled in order to kill them. It is then sealed up air tight while still hot, in order to exclude all dependent plants, and if both operations have been successful (that is, if there are no living things in the can and no opportunity exists for them to get in), the fruit will keep indefinitely.

The process by means of which all life of every kind is destroyed by heat, chemicals, or other means is known as sterilization. The decay of substances may also be hindered through drying or refrigeration. 
95. Bacteria and disease. Bacteria that are able to grow parasitically in the bodies of men, animals, and plants frequently produce more or less serious diseases. In many cases the bacteria are easily transferred from one person to another, when the diseases are said to be infectious. Other bacteria of this class are distributed through the agency of air or of water.

Examples of bacterial diseases are boils and carbuncles, blood poisoning, lockjaw, pneumonia, diphtheria, typhoid, influenza, tubereulosis, leprosy, cholera, and the plague.

96. Useful bacteria. Bacteria are of direct use in many manufacturing processes, as in vinegar-making, for the fermentation that produces the sour substance in vinegar is the result of bacterial action. Others of these organisms cause the change in cream known as "ripening," and the flavor of butter is due, in part at least, to the kind of bacteria that ripen the cream. In cheese-making the work of bacteria is indispensable, and a large part of the difference in flavor of the different varieties is due to the different kinds of bacteria which have assisted in the ripening, though some kinds of cheese are ripened by certain molds.

97. Bacteria in cultivation. On account of the value of certain kinds of bacteria they are sometimes cultivated, in order to have them always on hand. For instance, it has been found that if milk is sterilized and then inoculated with certain kinds of bacteria, the cheese made from this milk will always have the desired flavor, whereas if this is not done, the flavor will depend upon the bacteria that may chance"to get into it from the air, and the results may not be at all desirable. It is quite probable that in the future we shall domesticate many kinds of bacteria for which we find use. 


\section{CHAPTER IX}

\section{DISTRIBUTION OF BACTERIA AND OTHER DISEASE GERMS}

98. Distribution of bacteria. There are many ways in which bacteria may be distributed, but one of the most common of these is by means of the air. It often happens that substances upon which bacteria are growing become dry and powdered, as in the street dust of which we have spoken. The bacteria are then blown about with the remainder of the dust, to settle wherever they may. The air is never free from them, though they are more plentiful at some times than at others. Also, there are some places where they are not abundant, as in the air over deserts and over the ocean. Water is also a prominent agency in the distribution of bacteria, and this will be discussed in connection with our consideration of water supply.

Certain kinds of disease-producing bacteria are most commonly communicated more or less directly from person to person (fig. 47). Insects are agents of great importance in many cases. The common house fly is an especially bad offender in this respect.

99. Bacteria upon carelessly handled bread. A special student of bacteriology recently made a careful study of loaves of bread, to ascertain how many bacteria there are upon the surfaces of the loaves. This student secured bread from various parts of the city and from people who handled and sold it in many ways. Unwrapped bread had more bacteria upon it than wrapped bread. From 31 loaves collected from dirty shops the average number of bacteria upon each loaf was 64,970 . Of the unwrapped samples 39 per cent had an average of 14,000 bacteria upon each loaf, 39 per cent had an average of 4000 bacteria upon each loaf, and the remaining 
22 per cent had an average of 2500 bacteria upon each loaf. Of the specimens of wrapped bread, 45 per cent averaged 848 bacteria to the loaf, and 55 per cent averaged 371. Obviously, if the fresh loaves are wrapped in clean paper, bread will be a much less important carrier of bacteria.

Few of the bacteria upon the samples of bread were found to be disease-producing, but unclean bread is not especially attractive, even if its load of bacteria does contain but few that produce disease.

A careful study of other common food substances which are handled by many persons, or not carefully handled, might produce equally striking - evidence regarding the distribution of bacteria.

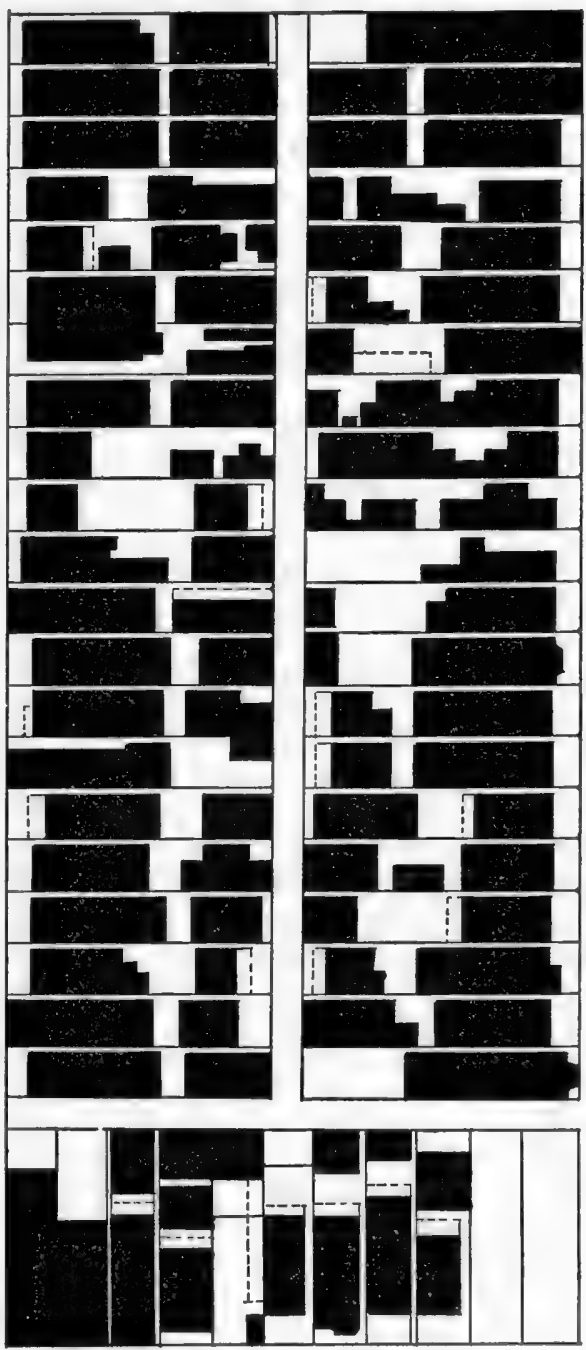

FIG.47. A crowded city block

The dark areas represent buildings. These buildings house 1600 persons, and in such crowded quarters it is difficult to prevent the spread of disease. After Report of the Department of Health of Chicago 
100. Transmission of typhoid bacteria. Within the body of a person who has typhoid the number of bacteria may become enormous and they may produce such injury as to cause death. But no matter how many typhoid bacteria there may be that affect this person, no other person would catch typhoid from him unless some of the bacteria were transmitted to the second person. Obviously it is of great importance that these diseaseproducing bacteria shall not be transmitted from one person to another. The way to prevent transmission of disease bacteria is to make sure that all bacteria from a person who has typhoid or other disease are promptly killed. This is most difficult, for it is not easy to sterilize everything that might carry bacteria. Furthermore, some people who have recovered from typhoid continue to have living typhoid bacteria in their bodies for several years, thus making possible continuous distribution of disease germs.

101. Importance of pure milk and water. Milk and water have often been the means of carrying typhoid bacteria. Many cases show conclusively that when a dairyman or some member of his family has typhoid, many of the people whose milk supply comes partly or wholly from this dairy may take the disease. Lack of care has made possible the introduction of typhoid germs into the milk, and it is distributed to unsuspecting patrons.

If the water and milk are not polluted with typhoid, or if, when polluted, they are sterilized, they do not carry the disease. Milk may be pasteurized (that is, heated for twenty minutes to between $140^{\circ}$ and $150^{\circ} \mathrm{F}$.), and this kills the typhoid germs. The number of bacteria in a cubic centimeter of milk or water may be very large. There may also be wide variations in the number of these bacteria, due to different ways in which milk and water are handled or to the length of time they have been allowed to stand in places favorable to the growth of the bacteria (fig. 48). Thus, in the city of St. Paul, Minnesota, in a special investigation it was found 
that samples of "wagon milk" contained 409,477 bacteria per cubic centimeter, while "dipped store milk" contained 8,206,000 bacteria per cubic centimeter. In Newark, New Jersey, it was found that "bottled wagon milk" contained 416,000 bacteria per cubic centimeter, while " dipped wagon

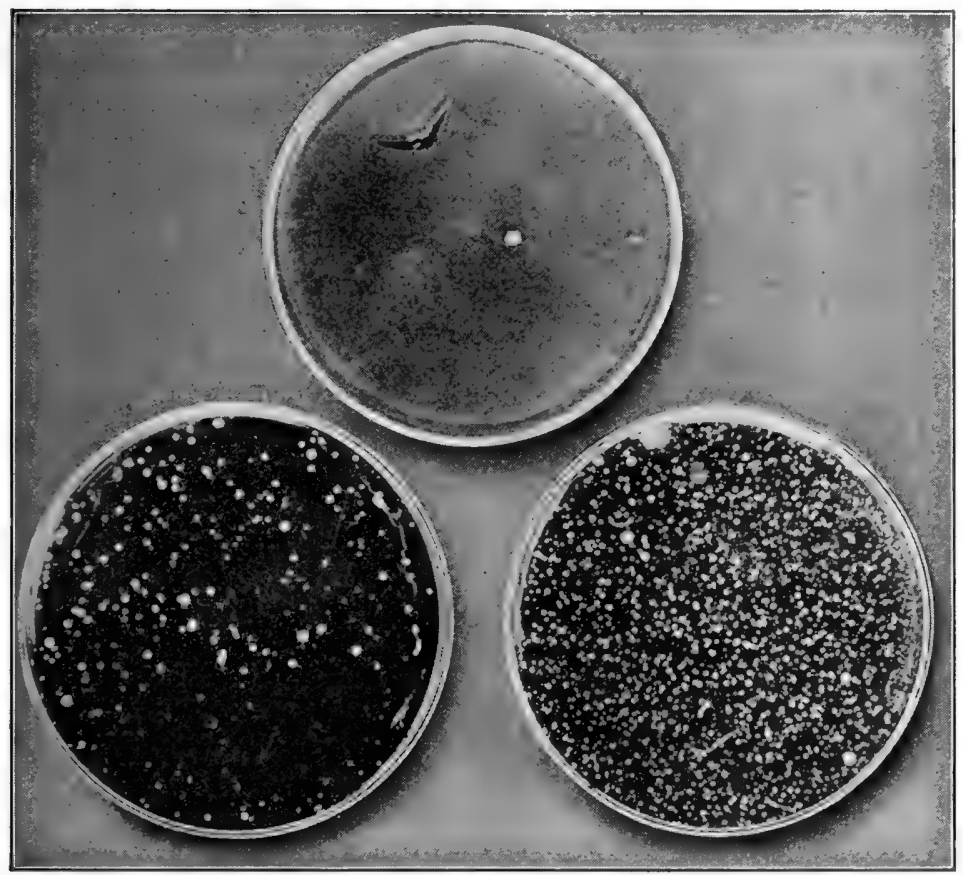

Fig. 48. Bacteria in milk

Each colony was produced by a single bacterium. The upper plate was inoculated with sterilized milk, the left-hand plate with certified milk, and the righthand plate with ordinary milk. After J. C. Olsen, "Pure Foods"

milk" contained $3,623,333$ bacteria per cubic centimeter; that milk delivered to a store contained at the time of its - delivery 280,000 bacteria per cubic centimeter, while eight hours after its delivery the number had increased to $1,488,000$ bacteria per cubic centimeter. 
102. Results of improved hygienic conditions. There are many unquestioned instances of lowering the human death rate through improvement of hygienic conditions (fig. 49). In the city of Chicago prior to 1908 less than 2 per cent of the milk was pasteurized, and the average death rate from typhoid per 100,000 population was 24.8 . In the years 1909,1910 ,

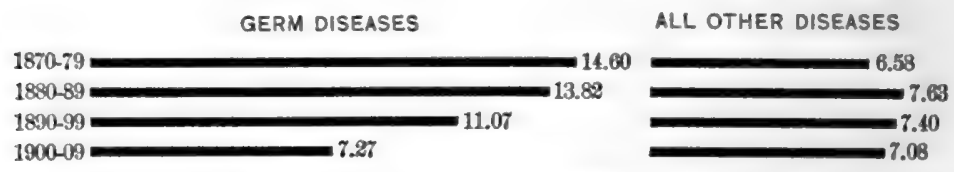

FrG. 49. A comparison of death rates

The diagram shows tha number of deaths, per 1000 population, from germ diseases and from all other diseases, in one of the largest American cities. As knowledge and care have increased, the number of deaths from preventable diseases has decreased

and 1911 between 50 per cent and 75 per cent of the milk was pasteurized, and the average death rate per year from typhoid per 100,000 population was 12.4 .

In the city of Boston a better milk and water supply was introduced during the closing decade of the last century and the first decade of this century. In 1910 it was claimed that about one half of the milk used in Boston was pasteurized. In the light of these facts the following table, showing the Boston annual death rate from typhoid, is instructive:

\section{Reduction of Typhoid in Boston 1}

\begin{tabular}{|c|c|c|c|c|c|c|c|c|c|c|c|c|c|c|}
\hline Year & & & & & & & & & & & & & $\begin{array}{r}\mathrm{T} \\
\text { per } 1\end{array}$ & $\begin{array}{l}\text { yphoid deaths } \\
100,000 \text { population }\end{array}$ \\
\hline 1891-1895 & . & . & - & . & - & : & $\cdot$ & - & $\bullet$ & - & - & - & . & - $\quad 31.1$ \\
\hline $1896-1900$ & . & . & - & . & . & . & - & . & . & - & . & • & . & . 30.6 \\
\hline 1901-1905 & . & . & . & . & . & . & . & . & . & . & . & . & . & . $\quad 22.4$ \\
\hline $1906-1910$ & . & . & . & . & . & . & . & . & . & . & . & . & . & . 16.0 \\
\hline 1911 . . & . & - & . & - & . & . & . & . & . & . & • & . & - & 9.0 \\
\hline
\end{tabular}

The average for 1909,1910 , and 1911 was 11.5 per 100,000 population.

1 Jordan, General Bacteriology. W. B. Saunders Company, 1911. 
The opening of the sanitary drainage canal in 1900, furnishing Chicago a better means of sewage disposal and a cleaner water supply, was an important factor in the reduction of deaths from typhoid in Chicago. How much of the reduction of the typhoid death rate is due to better milk and how much to sewage disposal, better water, and other factors cannot be definitely stated, but the facts of reduction as shown in the following table are significant:

Chicago Typhoid Death Rate after the Opening of the Drainage Canal

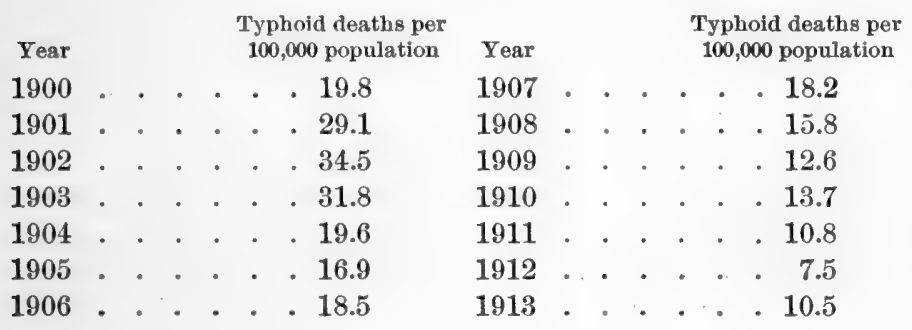

103. Typhoid carried by flies. Disease bacteria may be transmitted by many other agencies. For example, typhoid bacteria may live in waste organic matter and may then be carried by flies and deposited upon solid food or in milk or water, and later gain entrance to the human body. The flies are not causes of disease, they are merely the agents of transmission. If no typhoid bacteria had been allowed to get to the organic matter upon which the flies fed, the flies could not have carried them. Since many people are so careless as to allow distribution of disease bacteria to places from which flies may carry them, it is important to study the habits of the fly, with the hope of preventing further distribution of bacteria (fig. 50).

104. The life history of house flies. An individual house fly lays about 120 eggs. They are usually laid in horse manure, but may be placed in any animal or plant refuse. The eggs 
hatch in from six to eight hours, forming larvæ. The larvæ do not look like flies (fig. 51). They are small, white, worm-

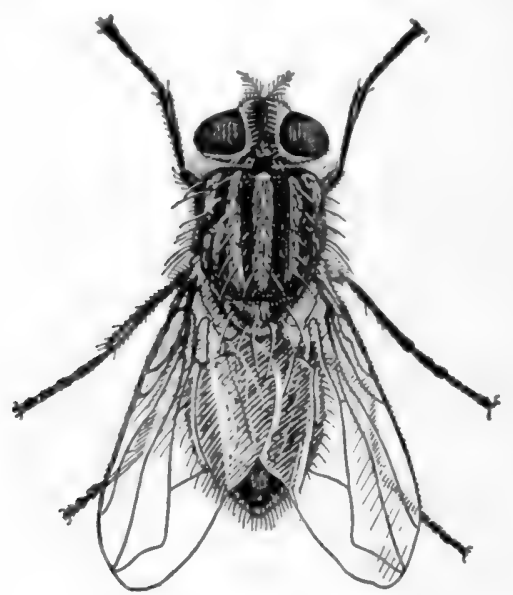

Fr. 50. The house fly

'The rough and hairy body of the fly is well adapted to carrying bacteria. After Howard like creatures, but of course they are really insects and not worms. They are called maggots. For about five days they feed upon the refuse in which the eggs were laid, after which they become quiet and change into pupæ. After five or six days the pupæ transform into adult flies. In a few days these flies lay eggs, and another generation is begun. In ten days 120 flies may develop from one pair of house flies. Suppose that half the flies of the second generation are females and that they lay eggs within two days. At that rate, how many flies might be produced from a single pair during four summer months?
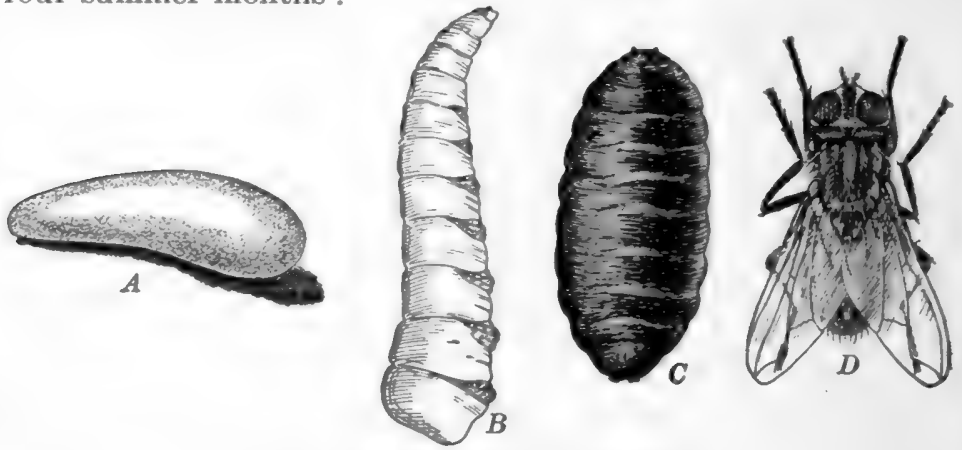

FIG.51. Life history of the house fly $A$, egg; $B$, larva; $C$, pupa; $D$, mature fly 
105. How flies carry bacteria. The mouth and feet of the house fly are covered with small, roughish hairs which, when magnified under a lens, show clearly that many bacteria may lodge there as the fly walks upon the refuse which usually forms its food. Some of the bacteria are swallowed by the fly and may later be excreted and deposited at its next lighting place - perhaps upon some one's food. The transmission of bacteria by the feet of flies is shown in the accompanying illustration (fig. 52).

\section{Disposal} of house flies. House flies may be disposed of if a little attention is given to the matter. If the refuse in which they lay their eggs, and in which the larvæ

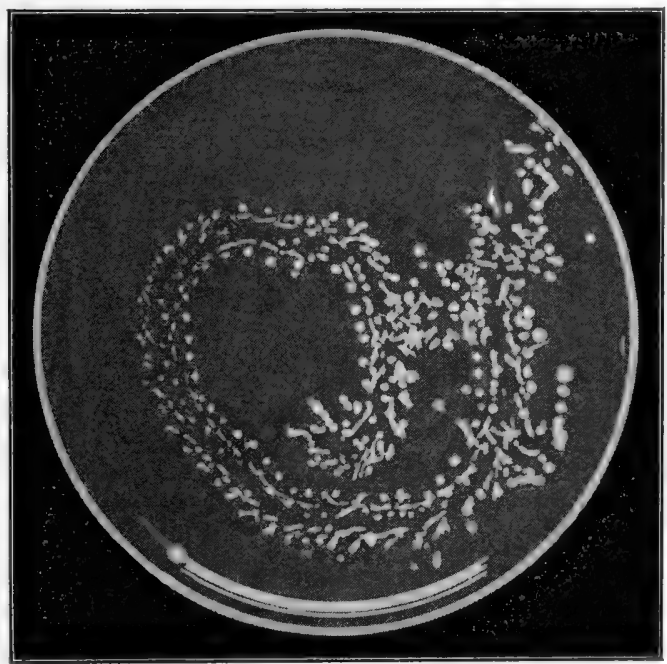

By permission of Review of Reviews

FiG. 52. Bacteria carried by a fly

A plate of agar culture medium over which a fly was allowed to walk. Colonies of bacteria have developed where the fly touched the culture medium live, is removed, no new crops of flies can be produced. Traps may be so arranged as to catch adult flies, after which they may easily be killed. Obviously coöperation is needed to eliminate flies, for so long as any person in a community supplies the materials for growth of flies, just so long will that community have flies. It is also to be noted that people who will leave refuse exposed so that flies breed in it are likely to be the kind of people who would allow disease bacteria to get into the refuse, 
thus making possible their further distribution by flies. If no disease germs were allowed to get into the refuse, the increased number of flies would be annoying but not necessarily of any importance relative to disease.

107. Cleanliness and disease. Individual and civic cleanliness are important. Our standards of taste and decency should demand that sewage, garbage, and all kinds of refuse be removed at proper times and in proper ways. But infinitely more important is care which will insure that disease germs may not be allowed to pass to other people. When, in 1898, the United States took possession of Havana, Cuba, the harbor, naturally one of the finest in the world, was filled with refuse from Havana. In the eity open sewers carried bacterialaden sewage, and flies, mosquitoes, dogs, and rats had ready access to this filth. During the year 1898 one human being in each twelve died - the terrible price that ignorance and carelessness exacts. Our army had vanquished the Spanish, but a far more difficult conquest remained. It is easy to locate and fight a political enemy, but very hard to fight ignorance, especially when it is backed by unfounded prejudice. Consequently the Cuban resident of Havana who had been set free from Spain had to be set free from himself. Martial law prevailed until the harbor was cleaned, a new and pure water supply was found, a more sanitary system of sewage disposal installed, and, last but greatest, those who were in charge of sick people were compelled to sterilize all material containing disease bacteria, so that the agents of transmission did not carry disease germs. Soon average health returned to Havana - a conquest of more import than her release from Spain. Is it better to vanquish a nation in war or to discover and apply principles through which people may live better and accomplish more?

108. Practical questions. What can you do in your home neighborhood to improve the healthfulness of it? What are the laws relative to quarantine in case of infectious diseases? 
Do you think these laws are just? Do you know of cases where the laws have been broken? Was it justifiable to break quarantine? Is it in any sense indecent or unclean for one to have typhoid?

109. Mosquitoes and malaria. There is a strong popular antipathy to mosquitoes. In themselves they are merely an annoyance, but because of disease germs that may sometimes live in the bodies of certain kinds of mosquitoes, and which may be transferred to the bodies of men, they may become a positive danger. In order that we may understand the relation between mosquitoes and malaria, and know how to prevent malaria, we must discuss both the disease and the mosquito.

110. Malaria caused by an animal organism. When a person has malaria, his red blood corpuscles are more or less infected with an extremely small one-celled animal. One of these malarial organisms lives within a red blood corpuscle for a brief period (three days in case of one kind of malaria), and by the end of that time has undergone repeated divisions, resulting in the formation of several of the organisms. The wall of the blood corpuscle breaks, and all the newly formed malarial parasites are set free in the liquid of the blood. It is usually just after many such parasites are set free in the blood that the paroxysm known as the malarial chill ensues. The germs may enter other red blood corpuscles, and in due time another crop of their kind will have been produced and another chill ensues. We must discuss the life history of the mosquito before continuing the discussion of malaria.

111. The life history of the mosquito. Mosquito eggs are laid in little groups on the surface of the water (fig. 53, A). When the eggs hatch, the individual emerging from each egg is a little squirming, insect-like creature, technically called a larva but popularly known as a "wriggler" (fig. 53, $C$ ). The eggs may hatch in less than a day after they are laid. The larvæ live about seven days in warm weather, but longer if the temperature is cool or if the food for the larvæ is scarce. 
Finally each larva changes into another form, the pupa (fig. 53, $F$ ), which lives in the water three days or more. The pupa changes into the adult mosquito. The mosquito

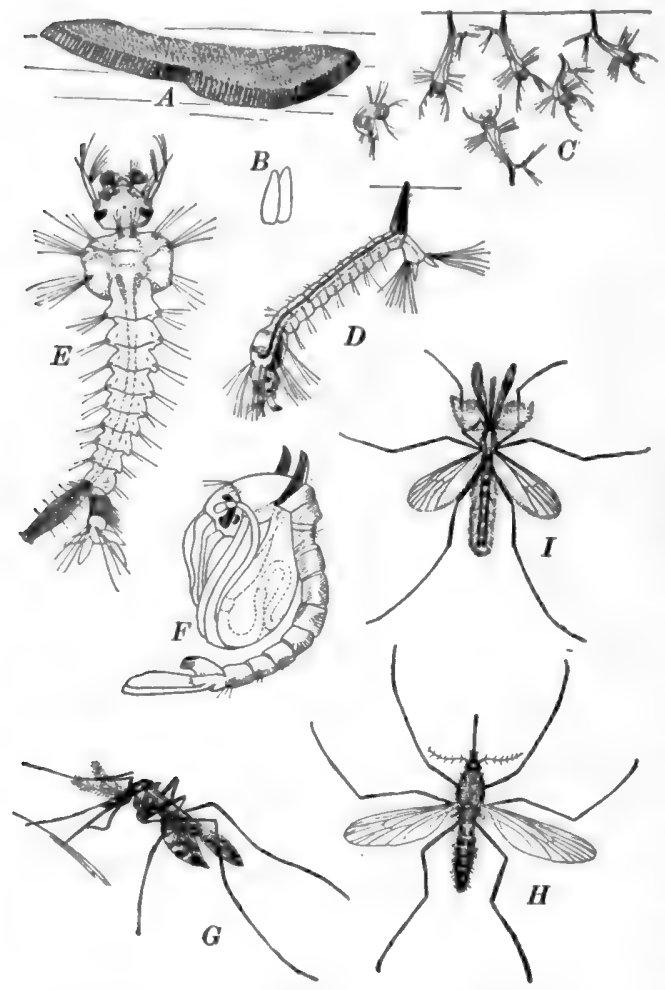

F1G. 53. Life history of the mosquito

The common mosquito (Culex). $A$, egg raft; $B$, eggs; $C$, young "wrigglers," or larvæ; $D$ and $E$, views of larvæ; $F$, pupa; $G$ and $H$, females; $I$, male. $A, B, C$, $G, H$, and $I$, somewhat enlarged; $D, E$, and $F$ very much enlarged. After Howard lives in the arr, but it lays eggs on the surface of the water. When the eggs are produced, another life cycle is begun.

In its larval stage the mosquito feeds upon very small living things in the water. It frequently comes to the surface and protrudes through the surface small tubes by means of which a fresh supply of air is gained. The adult female mosquito may secure its food by biting through the skin and sucking the blood from man or other higher animals.

112. How mosquitoes carry malaria. When a mosquito of a certain kind, Anopheles (fig. 54), feeds upon human blood, it injects a small amount of salivary fluid into the wound that 
it has made. If the person has malaria, the mosquito secures blood which may carry malarial germs; and if these germs are present, they multiply rapidly within the mosquito, really living in quite a different way as compared with their life in the human blood. Some of the germs get into the mosquito's salivary glands. When the infected mosquito bites another human being, some of the malarial germs may be injected into

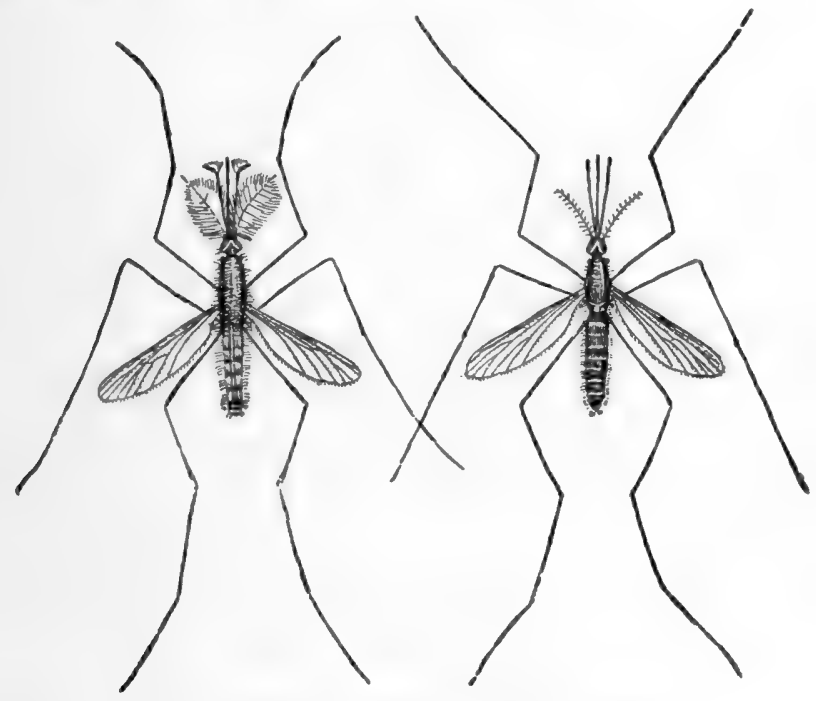

FiG. 54. The malarial mosquito (Anopheles)

Male at left; female at right. After Howard

the wound with the salivary fluid. These germs may grow and increase in number, and sooner or later produce the disease in a person who had not previously had it.

113. How to destroy mosquitoes. Since malaria and some other diseases are carried only by mosquitoes, it is evident that if we can remove the mosquitoes, we shall be free from danger of infection. These insects pass through the early part of their life in ponds, lakes, and quiet water. If this water is drained away, mosquitoes cannot reproduce. Where such 
drainage is possible, it is a good method of guarding against the diseases carried by mosquitoes. Another method of destroying these insects is to pour kerosene over the water. The oil spreads over the surface of the water and kills the eggs. The larvæ and pupæ cannot secure air through the surface film of oil, and so die. The adults cannot get to the surface of the water to lay more eggs. The mosquitoes are killed if they get into the kerosene in their attempt to lay eggs on the

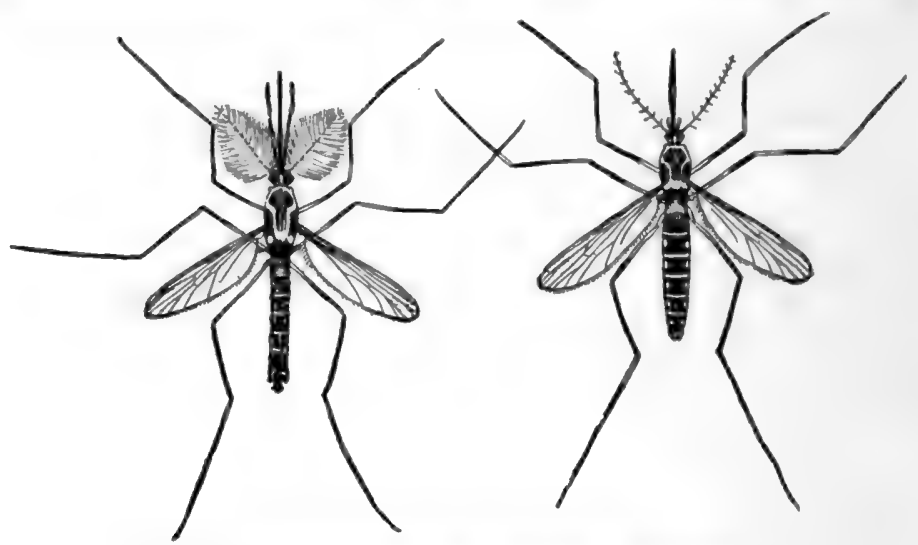

Fig. 55. The yellow-fever mosquito (Stegomyia)

Male at left; female at right. After Howard

surface of the water. Still another method of getting rid of mosquitoes is to subject them to their natural enemies. Fish eat the larvæ, and therefore if the ponds are stocked with fish, the mosquitoes will be less abundant. A very small body of water, as that in an old tin can or in a partially filled horse track, may be ample for the development of a crop of mosquitoes, and it is necessary to give attention to such places in order to avoid danger.

114. Different kinds of mosquitoes. There are several different kinds of mosquitoes. Only one of these, the genus Anopheles, carries the malarial germ. Our most common 
mosquito, Culex, does not, so far as we know, carry any disease germ. Yellow fever is produced by another animal germ that is carried by the mosquito known as Stegomyia (fig. 55).

115. Disease germs distributed by other insects. House flies and mosquitoes are not the only insects that transmit diseases. It is known that the germs of bubonic plague are transmitted from person to person by a kind of flea that commonly lives upon rats. The rats are subject to the plague, and when they die from it the infected fleas leave their bodies and find new hosts. If they take up their abode on the body of a human being, their bites will probably infect the person with the plague bacteria. Very obviously the disease is much less likely to attack the careful and cleanly person, living in a well-kept dwelling, than it is to attack his less cleanly, vermininfested neighbor. The only complete protection from the disease in countries in which it is prevalent is to be secured by the total destruction of the rat population. The facts mentioned above explain how it is that in such a country as India the natives may die of the plague in great numbers, while their European neighbors, with cleaner surroundings, usually escape. During the Middle Ages, when all dwellings, from the hovel of the peasant to the palace of the king, were unsanitary and infested with vermin, epidemics of the plague and other diseases frequently swept Europe, but in modern times nothing of the sort is likely to occur in enlightened nations.

Various other insects, as bedbugs, roaches, and certain flies, have been accused of carrying different diseases. The very deadly spotted fever is carried by a tick, and another tick carries the Texas fever of cattle. 



\section{PART II. WATER AND ITS UTSES}

\section{CHAPTER $\mathrm{X}$}

\section{ICE, WATER, AND STEAM}

116. The three states of matter. In previous work we have seen that the same substance may occur in either solid, liquid, or gaseous form. This is noticed more frequently in the case of water than with any other common substance, but it will be worth while, in the following study of water, to remember that many of the things which are true of it are true of other substances also. We need to be clear about the names which are used for the different states of water. The liquid form is most commonly found, and to this form the name "water" is especially applied. It must be remembered that when liquid water evaporates (thus passing into the form of gas) or when it freezes (becoming a solid) it does not cease to be water. For instance, we may speak of the water that is contained in the air although it is a gas, and if we calculate the amount of water in the ocean, we include also the ice. The word "water," therefore, may refer either to the liquid state or to the substance, without regard to whether it is solid, liquid, or gas. "Ice" is the name of the solid form, and "steam" is the name of the gas. Sometimes the latter is called water vapor.

117. When water freezes. What happens when water freezes? Perhaps most of us have observed nothing more than that when water gets cold it changes into a solid, and perhaps we have also been compelled to notice that when it becomes a solid it frequently breaks the containing vessel. But that is not the whole story. 
In the first place, the temperature at which water freezes is perfectly definite, and under ordinary circumstances it is always the same. You may perhaps remember that in making the centigrade thermometer the freezing point of water is taken as the starting point in making the scale, and that point is called zero. What is the freezing point on the Fahrenheit thermometer?

There are some very peculiar facts about the behavior of water in connection with its freezing. If a quantity of water in liquid form is cooled slowly, it will be found that as it cools it contracts. Perhaps that is as we should have expected, since most substances contract when cooling. As the water approaches the freezing point, however, it begins to expand, and very quickly expands more than the whole amount that it has contracted in cooling. After it has become solid, if it is cooled still more it continues to contract, but it never contracts to so small a volume as it had when it was a liquid. You should determine for yourselves the temperature at which water begins to expand and at which it freezes.

The temperature while freezing behaves almost as peculiarly as the volume. If the thermometer is observed during the experiment, it will be found that the temperature falls regularly until the water begins to freeze; it then remains stationary until all of the water is frozen, after which it begins to fall again. If a substance (salt, for instance) is dissolved in the water, the freezing point is much lower - just how much lower depends on the amount of salt that is dissolved.

118. Changing water to steam. When water is heated, as over a lamp or a stove, it finally gets hot enough so that some of the water nearest the flame (that is, at the bottom) is changed to steam. The steam rises in bubbles through the remaining water, and the bubbles burst at the surface. The disturbance which results is called boiling (fig. 56).

The temperature at which boiling begins is called the boiling point. On the centigrade scale the point is $100^{\circ}$. What 
is it on the Fahrenheit scale? After a mass of water has reached the boiling point, its temperature does not rise as long as any of the water remains in the liquid form. In your experiment you will find the boiling point somewhere near $100^{\circ} \mathrm{C}$., but it is not probable that it will be exactly that.

The most common cause for variation in the boiling point above or below $100^{\circ} \mathrm{C}$. is difference in air pressure. If the air pressure is 30 inches on the barometer, the boiling point of pure water will be $100^{\circ} \mathrm{C}$.; if the pressure is greater, the boiling point will be higher; and if the pressure is lower, water will boil before it is as hot as $100^{\circ} \mathrm{C}$. To most of us this makes little difference, but to people who live on the mountains it is sometimes a serious matter. Since the air pressure grows less as one goes higher up, of course the air pressure in elevated places is less than that near the sea level. Likewise the boiling point is lower. On the top of Mont Blanc the boiling point of water is only $84^{\circ} \mathrm{C}$. ; at the city of Quito, Ecuador, it is $90^{\circ} \mathrm{C}$.; and at many places in our own country, particularly in the West, the same condition exists (fig. 57). When you boil eggs or potatoes it is not the boiling that cooks them, it is the heat. If you cannot get water hotter than $90^{\circ} \mathrm{C}$.,

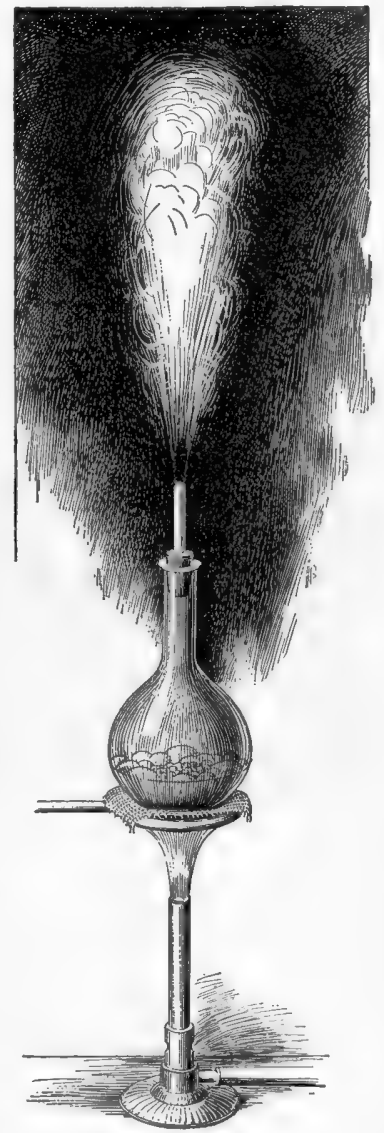

Fig. 56. How water boils

Note the bubbles rising through the water and the steam issuing from the tube. The steam is transparent when it is in the flask, and also when it issues from the end of the tube 
for instance, it will take very much longer to cook food materials; and if the temperature is too low, it may be quite impossible to cook certain foods. 'This, of course, applies only to those foods that are cooked by boiling.

On the other hand, increased pressure raises the boiling point very decidedly. In the steam boiler, where steam is not allowed to escape until it has reached a high pressure, the pressure of the steam has the same effect upon the boiling point

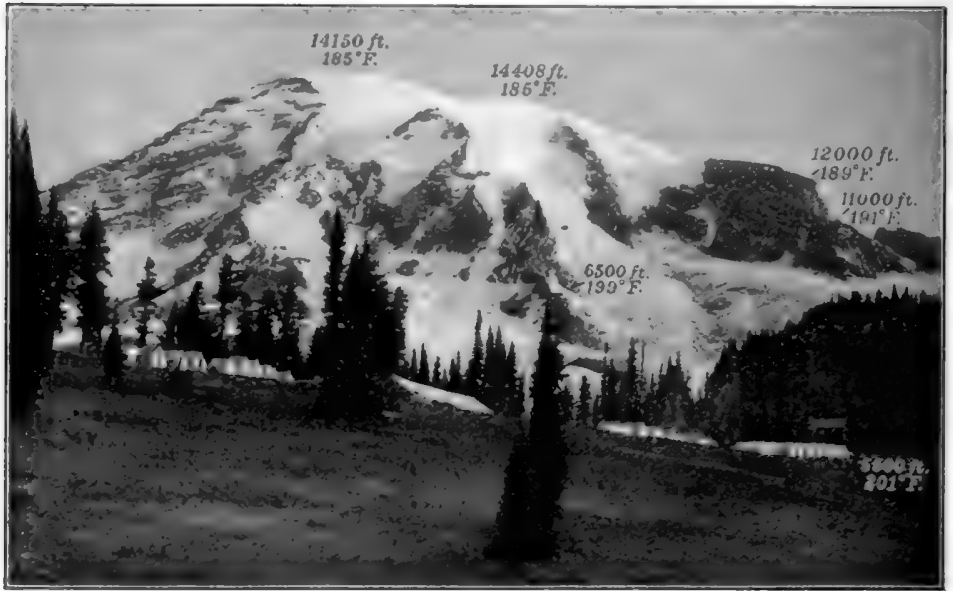

FIG.57. Boiling point upon a mountain

Mount Rainier, Washington. The figures show boiling points (Fahrenheit scale) at different elevations when the air pressure is 30 inches at sea level

as does the increased pressure of the atmosphere. The boiling point under additional pressure of 30 pounds to the square inch is $120.6^{\circ} \mathrm{C}$., at 100 pounds it is $155^{\circ} \mathrm{C}$., and at 300 pounds it is $130^{\circ} \mathrm{C}$.

The boiling point is also raised by the presence of any solid substance (salt, for instance) which is dissolved in water.

119. Other facts about steam. When water changes into steam, it increases enormously in volume if it is free to expand. Steam at atmospheric pressure may occupy about 1600 times 
as much space as the liquid water from which it was formed. Since steam occupies so much more space than water, it is of course correspondingly lighter. It is in fact lighter than air. If water is boiled in a closed vessel (as in a steam boiler), the steam cannot expand, but as the temperature increases, the pressure also increases, and finally the steam finds some way of escape, either by breaking the boiler or through some means provided for its escape, as through a safety valve. This power of expansion is utilized by means of the steam engine.

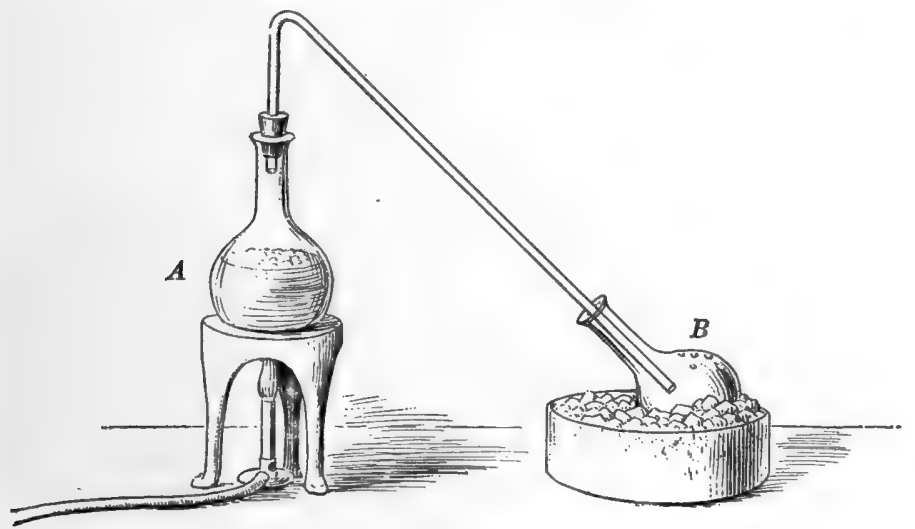

FIG. 58. Distillation

The solution to be distilled is placed in $A$; the steam which passes through the tube is condensed in $B$, which may be cooled with ice or snow

Steam is a transparent, colorless gas. When steam escapes into the air, there is always a white cloud. This cloud is not steam. The steam quickly cools to a temperature near that of the air, and this is so much below the boiling point that the steam returns to the liquid form. The white cloud is made up of many little drops of liquid water.

As the steam is emerging from the spout of a teakettle in which water is boiling, it may be observed that the steam is transparent as it passes from the end of the spout. In this transparent area the steam has not yet condensed (fig. 56). 
120. Distillation. Formerly it was customary for ships to carry with them enough fresh water to last throughout the voyage, but the larger steamships now prepare their daily supply from the salt ocean water by distillation. When water containing salt or other solid impurity is boiled and thus evaporated, the solid does not evaporate. Since the steam does not contain the impurity, it condenses into pure water. The process is called distillation. This is the most certain method of securing absolutely pure water (fig. 58).

Large distilling plants are employed to produce commercial supplies of pure water for drinking purposes, for ice manufacture, and for other uses. Also, in private establishments smaller plants are sometimes maintained.

121. Boiling and melting points. Every substance has its boiling and melting point, but these may be at temperatures very different from those of water. The melting point may also be called the freezing point. The approximate melting and boiling points of a few substances are given below:

\begin{tabular}{|c|c|c|c|c|c|c|c|c|c|c|c|}
\hline & & & & & & & & & & $\begin{array}{l}\text { MELTING PoiNT } \\
\text { IN DEGREE C. }\end{array}$ & $\begin{array}{l}\text { BoIliNg PoINT } \\
\text { IN DEgREes C. }\end{array}$ \\
\hline Air.. & . . & . & . & . & . & . & . & . & . . & - & -185 \\
\hline Alcohol . & . . & . & . & . & - & . & . & . & . . & -130.5 & 78. \\
\hline Ammonia & . & . & . & . & . & . & . & . & . . & - & -33. \\
\hline Benzene . & . . & . & . & . & . & . & . & . & . . & 7. & 80.4 \\
\hline Carbon dio & loxid & de & . & . & . & . & . & . & . . & - & -80 \\
\hline Cast iron. & · $\cdot$ & . & . & . & - & · & . & . & . . & 1200 . & - \\
\hline Copper . & •. & . & . & . & . & - & . & . & . . & 1100. & - \\
\hline Ether. & . . & . & . & . & . & . & . & . & . . & - & 35.5 \\
\hline Hydrogen & . & . & . & - & . & - & - & . & .. & - & -252 \\
\hline Lead . & - $\cdot$ & - & . & - & . & . & . & . & . . & 330. & 1000. \\
\hline Paraffin . & • . & . & . & . & - & . & . & . & . . & 55. & 400. \\
\hline Platinum . & •. & . & . & . & $\therefore$ & . & . & . & . . & 1775. & - \\
\hline Sulphur . & . . & . & . & . & . & . & . & . & . . & 114. & 445.5 \\
\hline Water. & . . & . & . & . & . & . & . & . & . . & 0. & 100. \\
\hline
\end{tabular}

Excepting for differences in temperature, most substances behave very much like water in changing from solid to liquid 
and from liquid to gaseous condition. There is one important exception, however. Few expand at the time of freezing, as water does, and these expand much less.

Substances such as glass and wax do not have a definite melting point. They gradually soften, becoming first like a very thick liquid, and finally flow freely.

122. Evaporation. Even when the temperature of water is not high enough to cause it to boil, the water changes into vapor, but not rapidly. This is shown by the drying of wet objects when exposed to the air.

Water will slowly change into vapor (evaporate) at any temperature. Even if water is frozen, evaporation continues. This is shown when wet clothing is hung out of doors on a cold day. It immediately freezes, and remains frozen until it has become dry by evaporation of the frozen water.

123. Laws of evaporation. The rate of evaporation depends upon several factors. For instance, it is commonly known that things dry more rapidly when the air is warm than when it is cold, and that drying is assisted by wind. There are three conditions that strongly affect the rate at which water evaporates, and the facts may be stated thus: Rapid evaporation is favored by high temperature, dry air, and winds.

124. Cooling effects. If one stands on the beach in wet clothing after bathing in a lake or in the ocean, he soon becomes chilled, even though it is a warm day. He is chilled more when the wind is blowing than when the air is quiet. When the clothing has become dry, the air seems warm again. One is cooled as long as water is evaporating from the surface of his body or from his clothing. Whenever water or any other liquids evaporate, the temperature is lowered, and the more rapidly evaporation occurs the more the temperature is lowered.

Under ordinary conditions water does not boil unless con. siderable quantities of heat are supplied to it. If heat is sup. plied more rapidly, it results in more rapid formation of steam, but there is no change in temperature of either the water or the 
steam. At the end of half an hour's vigorous boiling, a kettle of water will have the same temperature as at the beginning of

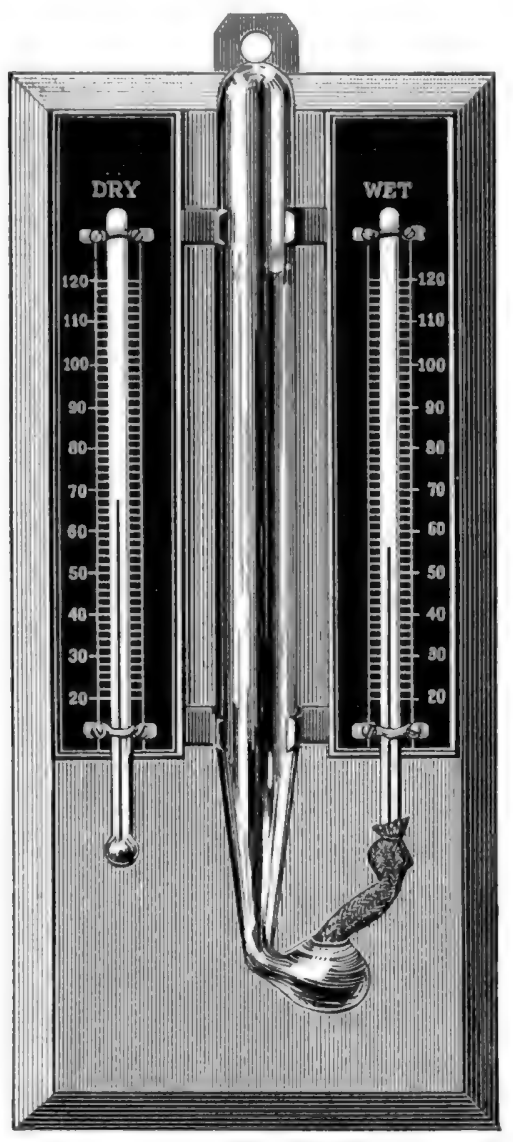

Fig. 59. Wet-bulb and dry-bulb thermometers

The bulls of one of the thermometers is covered with a cloth, which is kept moist by the water in the glass reservoir with which it is connected. Evaporation cools the wet-bulb thermometer, which registers the lower temperature the period, but the amount of water in the kettle will have decreased. The effect of the heat, therefore, has been to evaporate the water, but it has had no effect upon the temperature. The flame or stove has lost the heat which has passed into the water, but the water is not hotter because of it.

The total amount of heat that disappears when a gram weight of water changes into steam is the same whether the steam forms rapidly, as in boiling, or slowly, as in evaporating from wet clothing. In the latter case there is usually no source of intense heat, such as the flame, and the heat which disappears during evaporation is taken from the water itself and from the surrounding objects (fig. 59). Since heat disappears from the water and its surroundings, they are cooler. In the case of the bather on the beach, the heat which was used in evaporating the water from 
the wet bathing suit was drawn from the water remaining in the suit and from the body of the bather, thus giving him the sensation of cold. As soon as all the water had evaporated from the suit, this withdrawal of heat ceased, and the usual air temperatures were felt.

Substances which evaporate more rapidly than water may cause greater lowering of temperature. Ether and alcohol evaporate so much more rapidly than water that they feel very cold when poured over the hand. Ether may produce so low a temperature that water will be frozen by its use. Surgeons sometimes use ether to partly freeze the surface of a portion of the body upon which a surgical operation is to be performed, since the frozen tissues are so numb that the pain is lessened.

In many hot, dry countries use is made of the cooling effect of evaporation to secure a supply of cool water for drinking purposes. In such countries the water from wells is usually warm and needs cooling. Often ice cannot be had, and other methods of cooling must be resorted to. The water is put into porous earthenware jars or into canvas bags, and these are placed where the dry winds can blow over them. The water soaks through the canvas or the porous jar and evaporates so rapidly in the dry, hot air that the contents of the vessel are made pleasantly cool. Travelers in such regions have learned to cover their canteens with layers of woolen cloth, and to wet this at every possible opportunity. So long as the cloth cover is wet, the water in the canteen will be kept cool enough to be palatable.

125. Ice machines and cold storage. Cooling by evaporation is applied in a practical way in plants for the artificial production of ice and in cold-storage plants. In the operation of these plants advantage is taken of the fact that the boiling point of ammonia at atmospheric pressure $\left(-28^{\circ} \mathrm{F}\right.$. or $-33^{\circ} \mathrm{C}_{0}$ ) is so little below atmospheric temperature that the boiling point can be raised above the usual temperature 
of the air by increase of pressure (see sect. 118). Thus, while the boiling point is $-28^{\circ} \mathrm{F}$. at atmospheric pressure, its boiling point is raised to $80^{\circ} \mathrm{F}$. by a pressure of 155 pounds to the square inch.

Figure 60 represents the essential features of an ice-manufacturing plant. The condensing pump forces the gaseous ammonia into the pipes to the right with a pressure of at least 155 pounds to the square inch, and the gas is cooled to the necessary degree by the water which flows over the cooling pipes. The gas therefore condenses into a liquid. This liquid ammonia is allowed to escape through

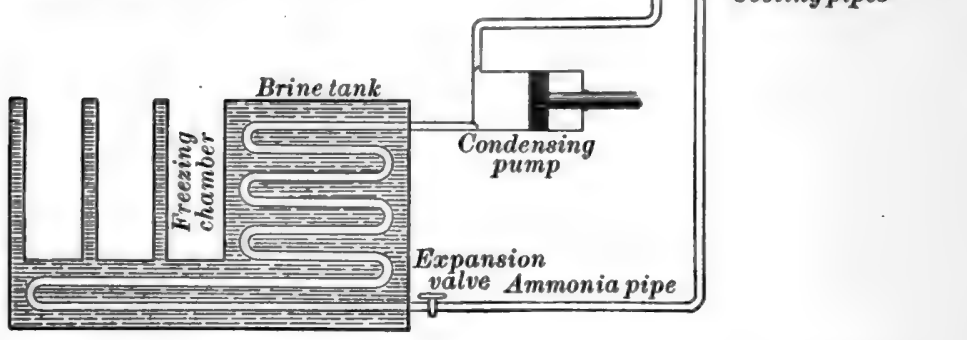

Fig. 60. An artificial-ice machine

Note names of parts and the use of these parts as described in section 125

the valve into the pipes at the left only as rapidly as the excess is removed by the pump, and the pressure in these pipes therefore never rises much above 30 pounds to the square inch. The liquid which has escaped into this place of lower pressure immediately begins to change into a gas, and in so doing it absorbs heat from its surroundings. The pipes into which the liquid ammonia expands are usually surrounded with brine, and this is cooled by the evaporating ammonia several degrees below the freezing point of water. The brine, in turn, cools the water which has been placed in the freezing chambers. The gaseous ammonia passes on to the pump and is used again. 
In cold-storage plants the machinery is similar to that used in making ice, but it is used to cool rooms instead of to cool vessels of water. It is possible to secure in a room a temperature below the freezing point of water, and to keep this temperature constant throughout the year. Of course, any degree of cold above the freezing point can be had, and thus it is possible to store each kind of food in the particular temperature that is best suited to it. Cold storage has made possible a supply of fresh foods at seasons when they could not otherwise be obtained.

126. Perspiration. The bodies of men and of some animals are cooled by evaporation. In the skin there are multitudes of small pores through which water is given off from the body. Usually there is so little water given off that it evaporates as rapidly as it appears, and we do not notice either the water or the cooling effect of the evaporation. When the weather is unusually warm or when we are making great exertion, the perspiration is poured out so rapidly that the surface of the body becomes moist, and if one stands in a draft, the cooling effect is very evident. The cooling is important also when one is not in a draft, though it is not noticed so much. If the perspiration were to stop suddenly, we should quickly feel a rise in the temperature of the body. Indeed, that is what happens in a fever.

The temperature of the body does not usually vary more than a fraction of a degree. When we feel hot we are really not much warmer than at other times, as would be proved by a thermometer. The temperature remains constant because the amount of water thrown out for evaporation is regulated by the perspiratory glands. But in case of fever the perspiratory glands cease to work, the skin becomes dry and hot, and the temperature of the whole body rises. If the temperature becomes very high (say four or five degrees Fahrenheit above normal), it indicates a serious condition, and death may result. 
What is the normal temperature of a healthy person? Try your own temperature by placing the bulb of a thermometer under your tongue.

127. Amount of water evaporated by the air. When we consider that the oceans, lakes, and rivers make up the larger part of the surface of the earth, and that water is evaporating from this surface all the time, it is plain that a very large amount of water evaporates. How much it is, no one knows

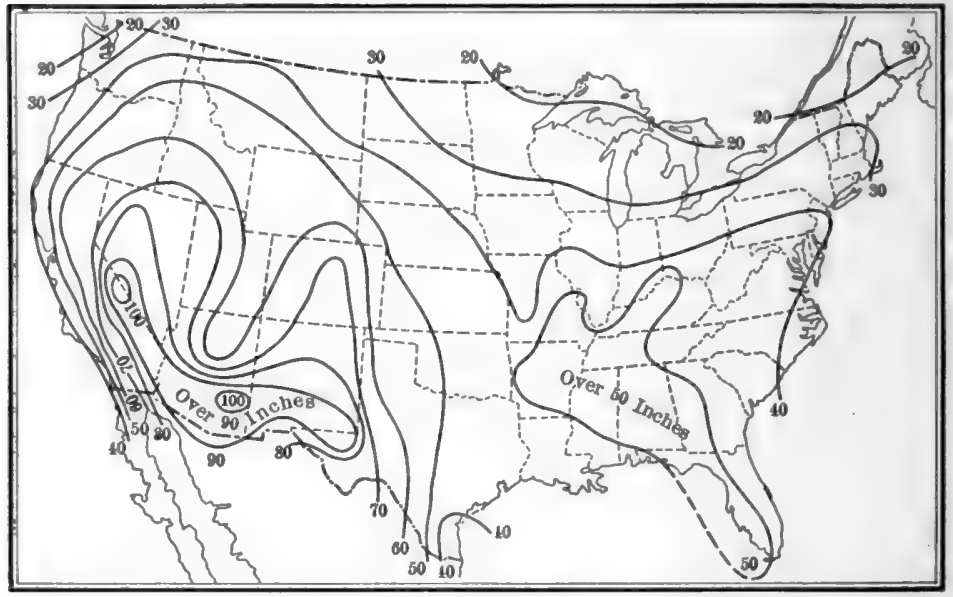

FIG. 61. Rate of evaporation in the United States

The map shows the estimated rate of evaporation in inches per annum. Note the great differences between different parts of the country. After Cox

exactly, but we get some idea when we remember that all of the water that falls as rain or snow has evaporated somewhere - most of it from the ocean, but some of it from the land.

A study has been made of the rate of evaporation in the United States (fig. 61), and it is believed that about 30 inches of water evaporates each year from the surface of Lake Michigan, and about 70 inches from the Great Salt Lake; in some of the desert regions of the Southwest perhaps as much as 100 inches would evaporate annually if there were any body 
of water there. A great deal of water evaporates from the surface of the land also, but of course not so much as from a free water surface.

128. Evaporation from plants : transpiration. The evaporation of water from land is greatly accelerated by plants. Trees, grasses, weeds, cultivated crops - in fact, all common land plants - absorb water from the soil, and most of this water may afterwards evaporate from the leaves.

Usually we are not aware that water is evaporating from the leaves of plants, since it passes off as a gas and is therefore not visible. There are ways in which it can be made visible. A demonstration of this may be made by inclosing several leaves in a bottle or tumbler (fig. 62) in such a way that there is little chance for water to enter or leave the bottle excepting through the leaves. The water given off from the leaves soon saturates the space in the bottle, and

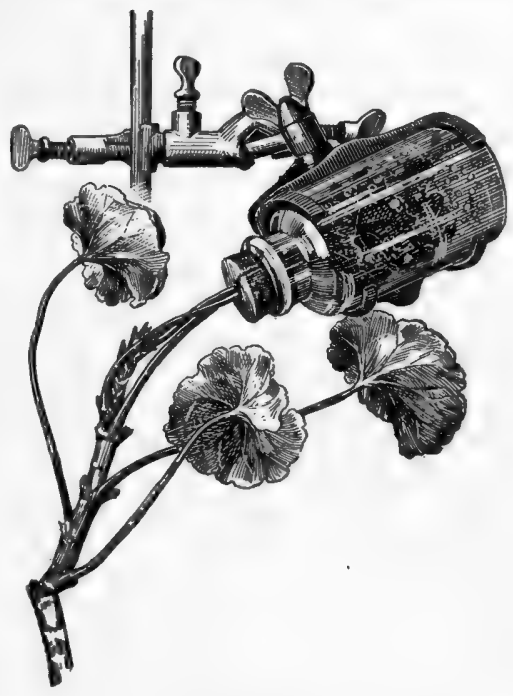

Fig. 62. Transpiration by leaves

Some of the water which evaporates from the leaves condenses upon the inside of the bottle

the excess is deposited on the inside of the bottle. Anyone can easily perform the experiment for himself. If the leaves are removed from the plant, they should be placed with their lower ends in water.

A more satisfactory way to show the loss of water is to weigh a potted plant from time to time, having first wrapped the pot in sheet rubber (why?). If the area of the leaves is ascertained, it is possible to know just how much water 
has been evaporated per square inch in a day. It has been found that a good-sized sunflower plant may evaporate as much as a quart of water daily. A large tree will evaporate from 700 to 900 pounds of water on a favorable day, and the grass on a vacant eity lot may give off a ton of water in a day.

129. Refrigerators. As water in freezing does not change temperature until all of it is frozen, so when ice melts, it does not get warmer than $0^{\circ} \mathrm{C}$. until all the ice is melted. The heat necessary to melt it is taken from surrounding objects, and so they are cooled as long as the ice is melting. It is on this principle that refrigerators work. In order to economize as much as possible in the use of ice, the walls of the refrigorator are packed with substances through which heat does not easily pass. If the refrigerator is not well built in this particular, so much heat comes into it from the outside that the ice does not lower the temperature in the box very much, and a great deal of ice is consumed. If a twenty-five-pound piece of ice is placed in an ordinary wooden box, and the same amount in a refrigerator, and records are kept showing the length of time required for both pieces of ice to melt, an interesting demonstration will be provided regarding the efficiency of the refrigerator. It will also prove interesting to perform a similar experiment to determine the relative efficiency of different kinds of refrigerators.

130. Freezing mixtures. Some substances absorb moisture very readily. Common salt is one of these. It absorbs it so readily that when the humidity of the air is rather high, it absorbs water even from the air and becomes wet, as all of us have had occasion to notice when using a salt shaker in damp weather. Salt not only absorbs gaseous water from the air, but it can also absorb water from a piece of ice, thereby changing the ice to the liquid form. This is the explanation of the use of salt to melt ice on sidewalks and in other places.

When ice is melted, heat is required to carry on the process. When salt melts ice, the source of heat is the ice and the 
surrounding air or other objects. If salt and ice are well mixed, the ice will be melted rapidly by the salt, but the temperature of the mixture will not remain at $0^{\circ} \mathrm{C}$. It will fall to $-17^{\circ} \mathrm{C}$. or even slightly lower. The heat needed is taken from the mixture itself, and the presence of the salt prevents the water from freezing at the lower temperature, as it otherwise would do. Such a freezing mixture of salt and ice is often used to produce a temperature slightly below $0^{\circ} \mathrm{C}$, as in freezing ice cream.

There are a number of substances other than salt which will produce the same result, and some of them will produce even a lower temperature, but they are not commonly used, because they cost much more than salt. 


\section{CHAPTER XI}

\section{WATER PRESSURE}

131. Importance of water. We are so accustomed to the use of an abundance of water that we do not stop to think how great its importance really is unless we are deprived of it by accident or by residence in an arid country. It is, in fact, one of the absolutely indispensable substances. If deprived of it, we soon die of thirst. We bathe in it and use it to wash our clothes and to cleanse our homes and our utensils. It floats our ships, turns our water wheels, supplies steam for our engines, moistens the ground for our crops, and takes a part in almost every manufacturing industry.

Many interesting questions arise in connection with the use of water: Why does an iron ship float? Does it take a stronger dam to hold back a lake of large area than a small one? If pipes lead down into a house from a tank on the roof, will the pressure be greater directly beneath the tank than it is at a faucet on the same floor but off to one side? Will the pressure depend on the size of the tank? How strong do the pipes need to be in order to withstand the pressure? How does a pump lift water? How does a siphon transfer water from one dish to another?

132. The siphon. The siphon may be used to transfer water or other liquid from one vessel to another over an intervening elevation. This can be done only in case the outlet of the siphon is at a lower level than the surface of the liquid which is being transferred. For instance, in the illustration (fig. 63) the tube, which serves as a siphon, is represented as transferring water from the beaker at $A$ to the one at $D$, and this latter is at a lower level. In starting a siphon to work it is 
necessary to fill the tube with the liquid. The liquid will flow through the tube if there is a greater force acting in one direction than in the other. In the experiment shown in the illustration the upward pressure in the short arm of the tube is due to the pressure of the air. In the tube at $b$ this pressure is equal to the atmospheric pressure minus the downward pressure due to the weight of the column of liquid $a b$. The upward pressure in the tube at $b^{\prime}$ is the atmospheric pressure minus the downward pressure due to the column $b^{\prime} d$. The force tending to drive the liquid from $A$ to $D$ will therefore be greater than that tending to drive it in the opposite direction. It will be greater by an amount equal to the difference in weight of the two columns of liquid, corresponding to the height $a^{\prime} d$. Evidently the siphon will cease to operate if $d$ is at the level of $a a^{\prime}$ or if the distance $a b$ is greater than the distance the liquid will be raised by the atmos-

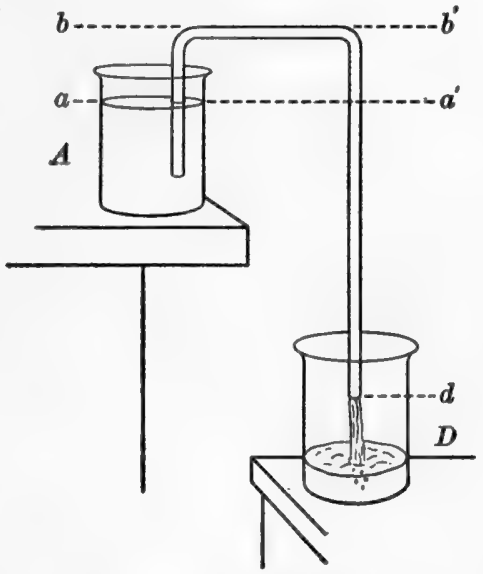

FIG. 63. The siphon

Water flows from $A$ into $D$ when $d$ is below the line $a a^{\prime}$, if the tube is first filled with water. The water is lifted to the level $b b^{\prime}$ by atmospheric pressure pheric pressure. This is about 33 feet in the case of water and about 30 inches in the case of mercury.

133. The lift pump. Everyone has seen examples of the common pump which stands on the platform built over a well. When the handle is operated, a stream of water is said to be "lifted" from the well. The structure of a pump is best learned from an examination of the pump itself or, if that is not possible, from a diagram (fig. 64). The essential part of the pump is the cylinder, which is hollow, usually two or three 
inches in diameter, and possibly eight or ten inches in length. At the bottom it is connected with the pipe, sometimes called the suction pipe, which extends down into the water in the well, and at the top with a pipe leading to the spout, or the spout may be connected directly with the cylinder. At
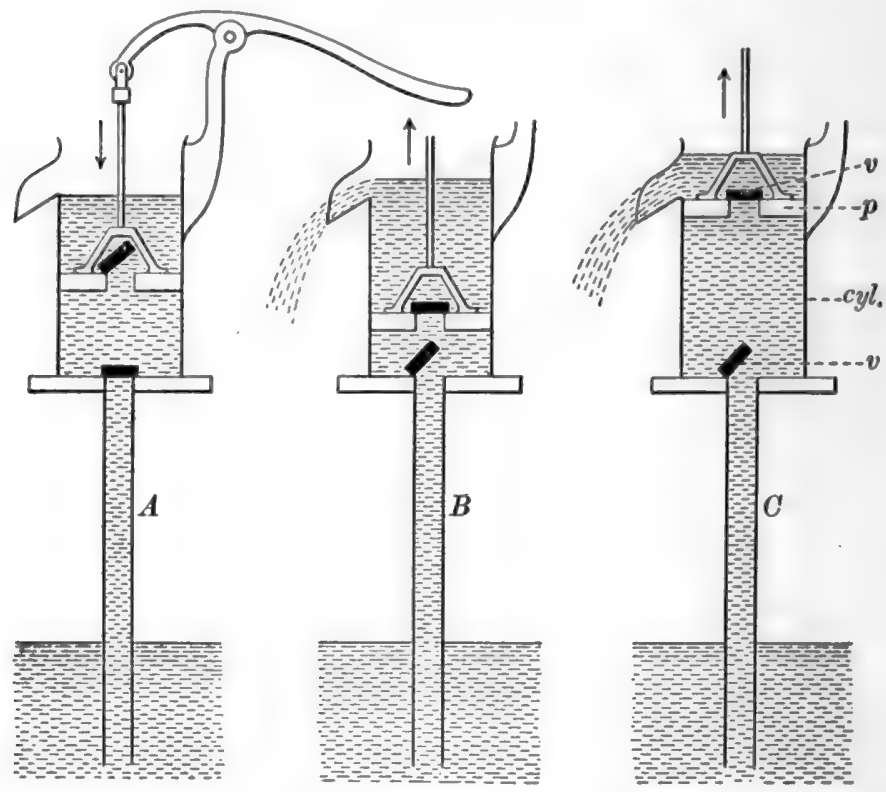

FIG. 64. The lift pump

Three stages of the stroke of the pump are shown: $A$, down stroke; $B$, up stroke; $C$, completion of the stroke. By noting the position in each case of $v$ (the valve), $p$ (the piston, or plunger), and cyl. (the cylinder), the action of the pump may be understood

the bottom of the cylinder, over the opening leading to the pipe, there is a valve which is so constructed as to allow the water to pass upward but not downward. In the cylinder there is a tightly fitting piston. This may slide up and down, and in it there is another valve which allows the passage of the water upward through the piston. Other parts, such as 
the handle, for example, may be added for convenience or ease of operation, but the parts mentioned above are the really essential parts of the pump.

As to the operation of the pump, we may suppose that at the start the cylinder and pipe to the well are filled with water, and the piston is at the top of the cylinder. If the piston is pushed downward, the valve in it will permit the water in the cylinder to pass through the piston into the space above it as it descends. When the piston reaches the bottom of the cylinder, the water in the cylinder will be above the piston. As the piston ascends it is perfectly clear that the water in the cylinder, which is now above the piston, will be lifted by the piston and may flow out of the spout. When the piston ascends, lifting with it the water that is in the cylinder, it does not leave the lower part of the cylinder empty. The water in the well flows up the pipe into the cylinder and fills it to the bottom of the piston. Since the piston is above this water, it cannot be said that the piston lifts the water, for the piston does not in any way have a hold on the water that is below it, yet the water rises.

134. Why the water rises in the pump. The rise of the water in the suction pipe of the pump is due to atmospheric pressure. The atmosphere is pressing downward upon the surface of the water in the well with a force of approximately 15 pounds to the square inch, and this pressure is transmitted to the water within the pipe as an upward force. If the pipe were open at the top, the atmosphere would exert a pressure of 15 pounds per square inch upon the surface of the water within the pipe also, and the two forces would exactly counterbalance each other. In that case the water in the pipe would be at rest at the level of the water in the well. Since the pipe is tightly closed by the piston which supports the pressure of the atmosphere, there is no downward pressure exerted upon the water below the piston, but there is an upward force of 15 pounds to the square inch transmitted to it by the 
water in the well. The atmospheric pressure will force the water up the pipe and against the piston, opposed only by the pressure due to the depth and weight of the water. If the suction pipe is too long, the water may not reach the cylinder. The water will stand at such a height that the downward pressure in the pipe, due to the weight of the water, will be equal to the atmospheric pressure outside. Since, as noted above, the height to which the atmospheric pressure will raise a column of water is about 33 feet, the suction pipe should not exceed this length.

135. The problems of water pressure. In the discussion of the pump and the siphon, as in all discussions dealing with water, it is necessary to refer to water pressures. For this reason a somewhat more exact knowledge of pressure in liquids is needed to understand such problems as those suggested.

Let us set ourselves the problem of discovering the pressure upon the bottom of a rectangular aquarium tank, the bottom of which is 6 inches wide and 24 inches long, and which is filled with water to a depth of $\mathbf{1}$ foot (fig. 65). The bottom will be pressed upon by the weight of the water in the tank, and the total pressure on the bottom will be equal to the weight of the water. If the bottom is 6 by 24 inches, its area is 144 square inches, or 1 square foot, and the total amount of water in the tank is 1 cubic foot. The pressure on the bottom is therefore the weight of 1 cubic foot of water, and this is 62.5 pounds. The pressure on each one of the 144 square inches of the bottom is equal to $\frac{62.5}{144}$, or 0.434 , pound. We may say that the bottom of the box is under a pressure of 0.434 pound per square inch.

We may think of our cubic foot of water as being divided into vertical columns 1 inch square, in which case we should have 144 such columns, one above each square inch of the bottom. Each square inch of the bottom may be thought of as supporting the weight of one of these columns, each of which 
contains 12 cubic inches (fig. $65, a$ ). A cubic inch of water will weigh $\frac{62.5}{1728}$, which equals 0.0362 , pound, and the entire column of 12 cubic inches will weigh $12 \times 0.0362$ pound, which is exactly 0.434 pound, as in the former calculation. If the depth were not 12 inches, but only 6 , the pressure would of course be only one half as great $(6 \times 0.0362)$, and if it were only 1 inch deep, it would be 0.0362 ; that is, $1 \times 0.0362$ pound per square inch.

From these examples we discover that the pressure is proportional to the depth, and that the pressure on any area is equal to the weight of the column of water whose base is the area in question and whose height is equal to the depth of the water. Pressure equals area $\times$ depth $\times$ weight of unit volume of water.

136. Pressure on horizontal surfaces in general. The pressure on any horizontal surface under the water may be obtained in the same way as above. For instance, if we submerge in the water of our tank a cube measuring 1 inch on the edge, and cause it to rest on the bottom, its top will be 11 inches

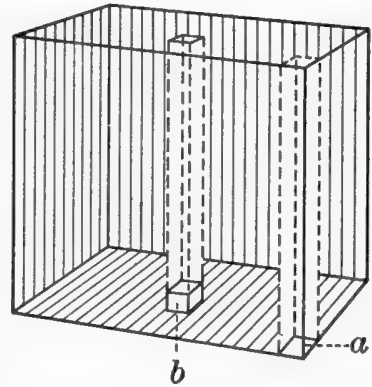

Fig. 65. Pressure upon the bottom

The pressure upon any part of the bottom, as $a$ or $b$, is equal to the weight of the water above it beneath the surface of the water (fig. $65, b$ ). The pressure upon it will be that of the weight of a column of water 1 inch square and 11 inches high. (How much will it be?) The same principles will apply to any horizontal surface anywhere under water.

137. Pressure on the sides of a tank. Since we can easily find the pressure downward at any depth, it will be convenient to compare the pressure against the side with the pressure downward. If we submerge any form of pressure gauge in 
the water to a certain depth and turn it so that it faces in various directions, we find that so long as it remains at the same depth, it registers the same pressure, no matter in which direction it faces. We thus come to the conclusion that in a liquid at rest, and at a given depth, the pressure is the same in all directions.

If we apply this to the case of determining the pressure on a square inch of the side of the tank, we may use the same method that we should use for a square inch in a horizontal position, but with this difference: the top and the bottom of our square inch on the side are not at the same distance from the surface, and we must therefore take the average depth. The pressure against 1 square inch of the wall of the tank, with the upper edge of the square inch 10 inches below the surface of the water, would be $1 \times 10.5 \times 0.0362$ pound. Solve this and explain just why each number is used.

138. Upward pressure in a liquid. Our statement that pressure is equal in all directions should indicate that there are upward pressures in a liquid. This may be made plain if we place a card across the end of a lamp chimney and force the chimney downward into the water. The card is held by the water against the end of the chimney with considerable force. In fact, if we attempt to force it away by pouring in water as weight, before the card will be forced away we shall have to pour in water until it stands at the same level inside the chimney as outside. Can you show that this corresponds with the facts we have learned in preceding sections?

139. Relation to size of a tank. It is common for people to suppose that the pressure in a system of water pipes will be affected by the size of the tank that supplies water to the pipes. Let us imagine that our aquarium tank has a hole in the bottom, to which is attached a pipe having an opening 1 square inch in area (fig. 66). If that opening were closed by a stopper and the water were 1 foot deep, the pressure upon the stopper would be 0.434 pound. If the stopper were 
removed and the pipe filled with water, the pressure upon the water in the pipe, tending to force it out, would be also 0.434 pound; that is, the pressure would be equal to the weight of water directly above the hole. The width or length of the tank has nothing to do with this. The pressure depends on the area and the depth of the water but not upon any other feature of the tank.

140. Effect of the shape of a tank. Since, as we have found, the pressure on any area may be found by the use of only three factors, - the area, the depth of the liquid, and the weight of unit volume of the liquid, - the shape of the vessel can have nothing to do with the pressure. This can be easily shown by experiments with a variety of apparatus, and these experiments should be performed in the laboratory.

141. Pressure in other liquids. If any other liquid than water (petroleum, for example) is to be stored or handled, the problems of pressure are precisely the same as in the case of water, excepting that the weight of the liquid will be dif-

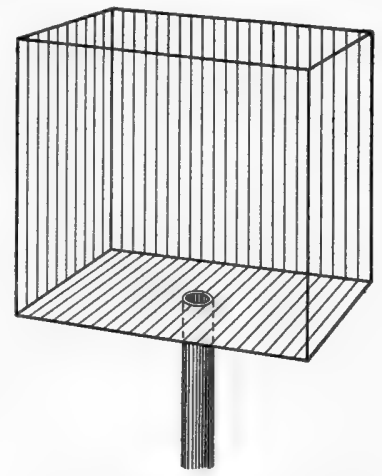

Fig. 66. Pressure in a pipe

The dimensions of the tank, excepting its depth, do not affect the pressure in the pipe ferent, and therefore in solving problems concerning it we must ascertain its weight per cubic foot or cubic inch and use this quantity as our weight per unit volume.

142. Calculation of fluid pressure. It will be sufficient if we remember that to calculate any liquid pressure we must take area $\times$ depth $\times$ weight of unit volume.

If the English units are employed, the unit of weight may be either ounce, pound, or ton, but the same unit must be used throughout any given calculation. In the metric system the solution of problems is much more easily accomplished. 
This system of weights and measures is so constructed that a cubic centimeter of water weighs $1 \mathrm{gram}$. The pressure upon any surface is therefore 1 gram per square centimeter for each centimeter of depth. There are no fractions, such as are encountered in calculating pressures by the English system, and the operation may often be performed mentally.

It will be well to remember the following data or to be sure to know where to find them:

1 cubic foot of water weighs 62.5 pounds.

1 cubic inch of water weighs 0.0362 pound.

1 cubic centimeter of water weighs 1 gram.

143. Transmission of pressure in liquids. In a squirt gun the pressure which is applied to the liquid by the aid of a piston or a rubber bulb is transmitted to the liquid in the nozzle and projects this liquid to some distance; or the pressure applied to the stopper of a bottle completely filled with water may result in breaking the sides of the bottle. In a city water system the pressure exerted by the pumps at the pumping plant is transmitted throughout the system and may be discovered in the pressure of the water at any faucet. Many common appliances, such as water motors, lawn sprinklers, and fire engines, depend, in their operation, upon the transmission of pressure by water.

The transmission of pressure by liquids is sometimes utilized to secure the application of great force at a given place by means of the hydraulic press. This machine consists essentially of two communicating cylinders, each containing a closely fitting piston, one of the cylinders being of larger diameter than the other (fig. 67). If the diameters of the cylinders are such that the area of the end of one piston is ten times that of the other, it will be found that if a pressure of 1 pound is applied to the water in the smaller cylinder by means of the piston, the pressure exerted by the water against the larger piston will be sufficient to support a weight of 
10 pounds; that is, the force exerted by the second piston will be greater than the force applied to the smaller piston by as many times as the area of the larger piston is greater than the area of the smaller one. This rule holds for cylinders and pistons of any size. Hydraulic presses are commonly used in processes in which great force must be exerted, as in baling cotton.

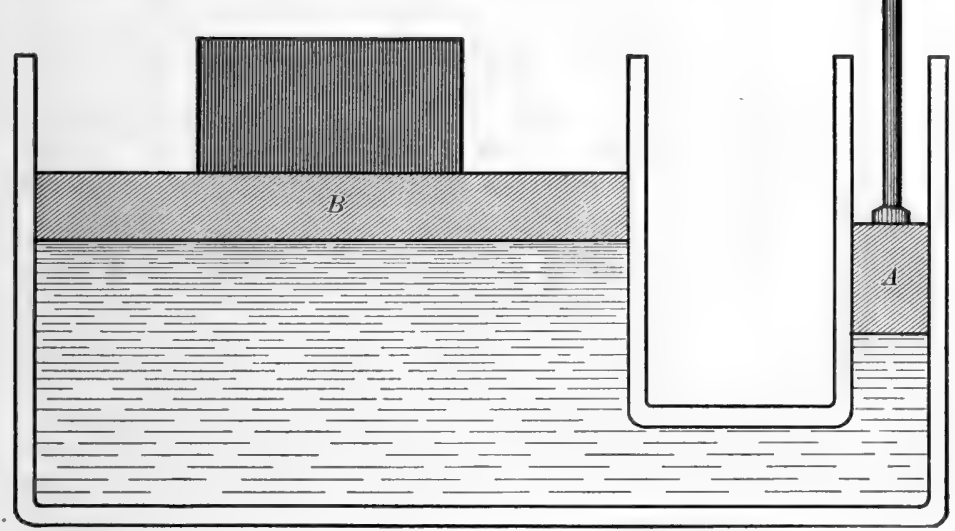

Fig. 67. The hydraulic press

The diameter of $B$ is 8 times that of $A$, and its area is therefore 64 times as great. A pressure of 1 gram exerted by $A$ upon the water surface beneath it would be transmitted undiminished to each of the 64 equal areas at $B$, and might lift a weight of 64 grams at $B$

144. The principle of the hydraulic press. In order to understand the principle of the hydraulic press or of other appliances in which the transmission of pressure by water is important, we must attempt to discover the laws of transmission of pressure in liquids. Here again we may draw an illustration from an aquarium such as we have used to illustrate other subjects in this chapter. Let us suppose that the aquarium is filled with water and covered on top, and that a pipe leads up through the cover (fig. 68). If, now, we pour into the pipe enough water to fill it to a depth of $1 \mathrm{inch}$, the total depth 
of water will be not 12 inches but 13 inches. The pressure on a single square inch of the bottom will be $13 \times 0.0362$ pound. Since each square inch of the bottom is equally distant from the free surface of the water, the pressure on each square inch will be the same; that is, each square inch of surface will have the pressure upon it increased by the weight of 1 cubic inch of water. Likewise, the pressure upon each square inch of the sides or top is increased by the same

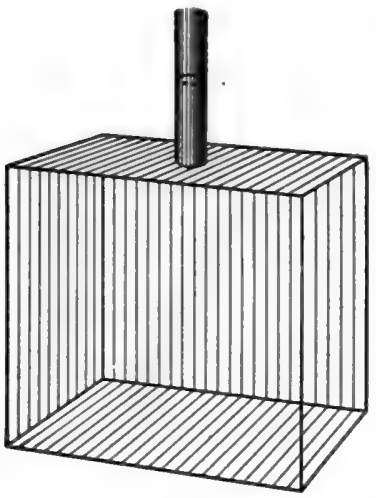

Fig. 68. Pressure in a closed vessel of water

If the pipe is partly filled with water, the additional pressure due to its weight is transmitted to all the walls of the waterfilled vessel amount. We have put 1 cubic inch of water into the pipe, and its weight presses upon the square inch of the original surface at the lower end of the pipe, with the result that every square inch of the whole interior of the tank receives that much additional pressure. (Calculate the total pressure upon the interior of the tank due to the added inch of water.)

When pressure is exerted upon the water in one cylinder of the hydraulic press, this pressure is transmitted undiminished to every equal area of the interior of the apparatus, and therefore to every equal area of the bottom of the large piston. If the end of the small piston has an area of 1 inch, a pressure of a pound exerted here will produce a pressure of a pound on each square inch of the end of the larger piston. The total force exerted by the larger piston will be the sum of the pressures on all these areas. It should therefore be as many times greater than the force applied to the smaller one as the area of the larger piston is greater than the area of the smaller one. This is the case, as we have seen from the discussion in section 143. 
In the case of the faucets at the various places in the house, the pressure on each square inch of the interior of the pipes or faucets depends upon the depth of the water in the pipes and tank, and is exerted equally on every square inch of the interior of the pipe and faucet at any particular level. The violence with which the water will spurt from an open faucet depends on its distance below the level of the water in the tank and not at all upon its position directly beneath the tank or at one side.

145. Air pressure. The pressure of the air is due to its weight and follows the same laws as those we have been dealing with in the case of water, but we cannot measure the depth of the air and calculate its pressure as we do with water. We therefore rely upon the barometer, which is, in fact, a pressure gauge, to give us our information about air pressures (see sect. 5).

It will be recalled that the mercurial barometer consists essentially of a glass tube held in a vertical position, with the lower end immersed in a dish of mercury, the upper end closed, and the air wholly removed from the tube. The mercury fills such a tube to a point about 30 inches above the level of the mercury in the dish. The force which sustains the column of mercury at this height is the pressure of the air on the surface of the mercury in the dish. The downward pressure of the air, due to the weight of the air, is transmitted to the mercury in the tube and causes it to rise until the height of the column is such that the downward pressure which it exerts, due to its. weight, is equal to the pressure of the air.

That the pressure of the air is responsible for the height of the column of mercury in a barometer is shown in a general way by the fact that the column rises and falls in correspondence with changes in air pressure. It is shown still more clearly when a barometer is placed in an air-tight chamber and the air is exhansted by an air pump. As the removal of the 
air proceeds, the barometer falls until, if the air pump is a good one, it may show a height of only a few millimeters or less. If the atmosphere is readmitted, the barometer rises to its usual height.

146. Pressure in other fluids. The laws of pressure hold good for any liquid, allowance being made in the calculations for the difference in weight of unit volumes of different liquids. The same laws are true of gases, excepting that it is always necessary to take into consideration the fact that the weight of a given volume of a gas varies with the temperature and the pressure, and that the lower layers of a gas (for example, the lower parts of the earth's atmosphere) are more highly compressed and therefore weigh more to a given volume than the higher layers do.

147. Dams. The building of dams in order to confine water or raise the surface to a higher level is very common (fig. 69). Dams need to be constructed with a great deal of care in order to be able to withstand the pressures to which they are subjected. A great many lives and much property have been lost by reason of the floods which have been released by breaking dams. One of the greatest catastrophes of this kind was the breaking of the dam near Johnstown, Pennsylvania, in 1889. About two thousand lives were lost in the flood which resulted.

The pressure to which a dam will be subjected may be easily ascertained. The process is the same as that used in finding the pressure against one of the walls of the aquarium tank. It depends only upon the depth of the water and the area of the submerged part of the dam. From the principle that the pressure is independent of the size and shape of the containing vessel, it follows that the area of the body of water held back by the dam has nothing to do with the matter. The dikes which protect Holland from the ocean need be no stronger than those which protect the lowlands of the Mississippi River, even though the former are holding back the whole Atlantic Ocean. 


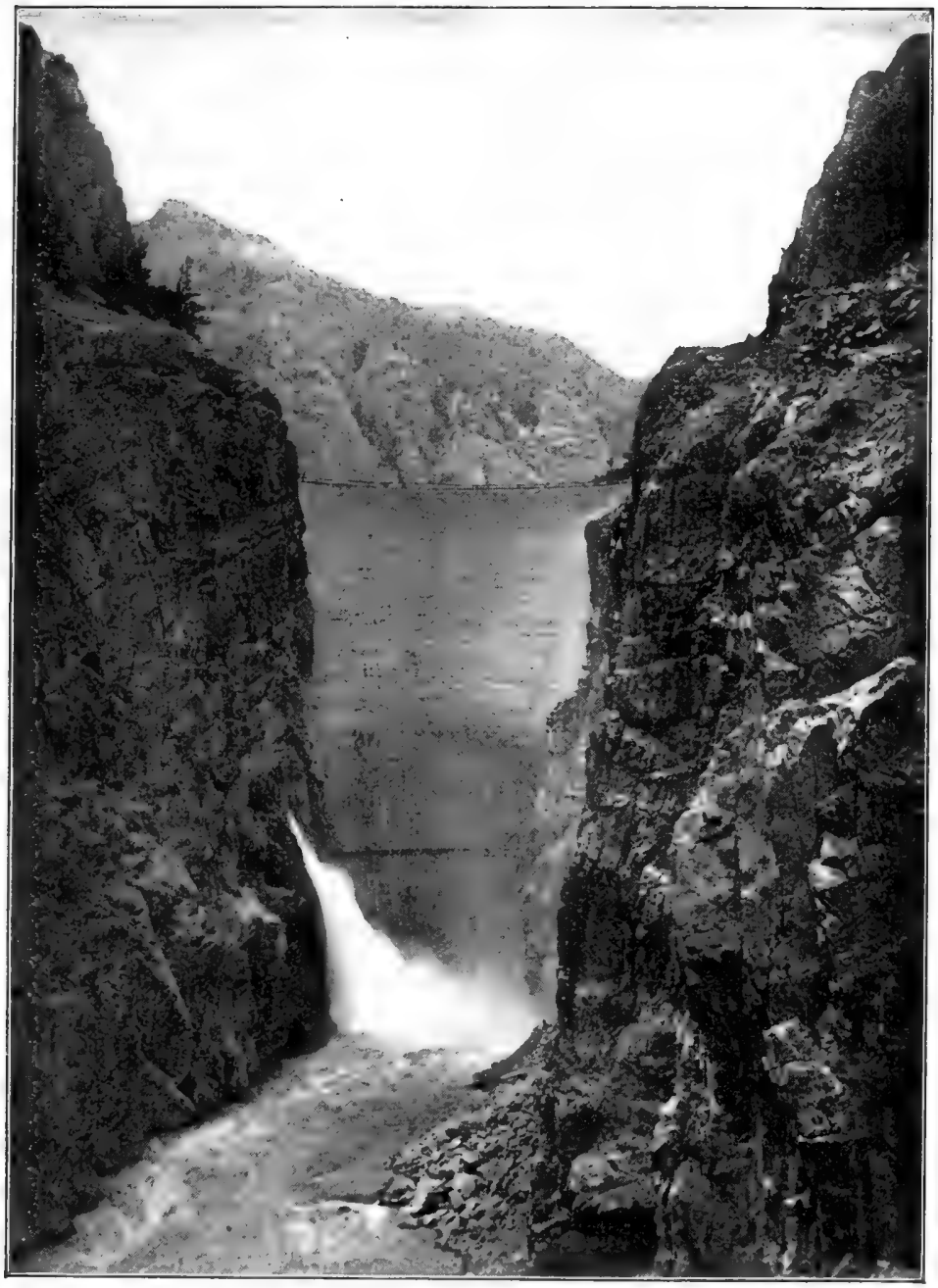

FIG.69. A large dam

This dam was built by the United States Reclamation sarvice to store water for irrigation. It is :3es feet high and is said to be the highest structure of the kind in the world. Photograph by the United states Reclamation service 
148. Buoyancy. We are all familiar with the fact that objects appear to be lighter in the water than out of the water, and that some things float on water. No one has failed to notice this effect when bathing. The floating effect of water may be determined by weighing objects while suspended in the air and again while suspended in water. If we take a cubic centimeter of each of several different kinds of substances that are heavy enough to sink in water, and weigh each in this way,

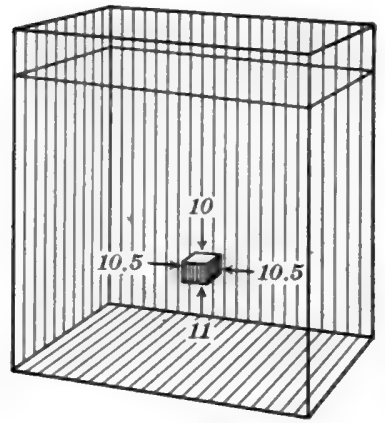

Fig. 70. Buoyancy

If a cube measuring 1 centimeter on each edge is submerged with the top 10 centimeters below the surface of the water, the pressures against the surfaces, in grams, will be as shown in the figure. Note that the pressure against the bottom is greater by 1 gram than that upon the top we shall find that each appears to lose 1 gram of its weight when put into water. No matter what differences there may be in the substances, if the pieces are of the same volume they will be buoyed up by the same force. Also, the objects are buoyed up by a force ( 1 gram) which is precisely equal to the weight of the volume of water they displace when immersed (1 cubic centimeter). It is found that all objects which are immersed in water are buoyed up by a force equal to the weight of water they displace.

In order to assist in explaining why objects are buoyed up by the water, let us imagine a cube measuring 1 centimeter on each edge submerged beneath the water so that the top is 10 centimeters from the surface (fig. 70). The pressure on each of the four sides will be 10.5 grams, since the average depth of the side is 10.5 centimeters. The pressures on the sides exactly counterbalance each other, and the object is not moved either to right or left. The pressure on the top is 10 grams, and upon the bottom it is 11 grams. (Why?) These two do not balance each other. The pressure upward is greater 
by 1 gram than the pressure downward. Plainly, such an object as we have supposed, if its own weight amounted to nothing, would be pushed up to the surface. If it weighed more than a gram, its weight would overcome the upward push and it would descend to the bottom.

149. Floating objects. If an object weighs less than the water it displaces, it will float or, if submerged, will rise to the surface. It will not rest with its top even with the surface of the water, but it will project far enough above the surface so that the submerged part will displace an amount of water the

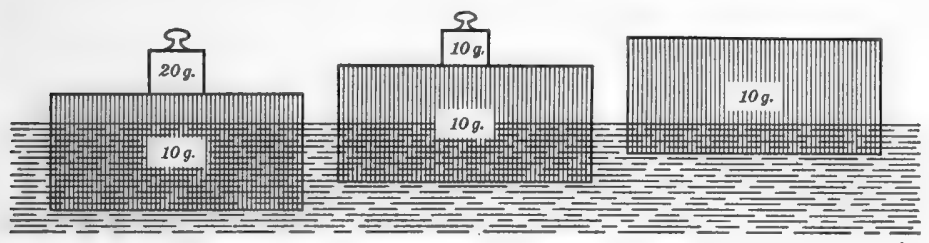

Fig. 71. Floating objects

The object at the right weighs 10 grams and displaces 10 grams of water. When a weight of 10 grams is placed upon it, as in the middle, it displaces twice as much water as at first. When the total weight is 30 grams, as at the left, the displacement is three times as great as at first

weight of which is equal to its own weight (fig. 71). For example, if the 1-centimeter cube weighed 0.5 gram, it would rise until only one half of it was under water, and it would therefore displace 0.5 gram of water. An iron pail will float on the water because, though it is made out of very heavy material, it is so shaped that it displaces a great deal of water. The iron ship floats for the same reason. The weight of the ship and its cargo is less than the weight of the water displaced would be if the vessel were sunk with the gunwales at the water level. The vessel therefore sinks in the water only deep enough to displace an amount of water equivalent to its own weight.

150. Submarines and balloons. A submarine boat is so constructed that no water can enter it, even if it is wholly 
submerged, excepting at the will of the occupants. It is able to float at the surface like any other ship, and that is its usual position. If the occupants wish the boat to dive, water is admitted into special compartments in the interior until the weight of the boat equals or slightly exceeds the weight of the water it displaces. When they wish to rise to the surface again, some of the water is forced out. If the weight of the boat is kept very close to the weight of the water which it displaces, it is possible to steer it to right or left, up or down.

A balloon operates on a similar principle. The bag is filled with a gas that is lighter than the air at the surface of the earth. The air buoys up an object with a force equal to the weight of the air displaced, and, as the balloon is lighter than an equal volume of air, it ascends. It will not rise to the top of the air, for the air is less dense at greater altitudes. The balloon rises until it reaches a layer in the air of such density that the displaced air equals the weight of the balloon and gas, and it remains at that elevation unless something disturbs it. Ballast may be thrown out to reach greater height, and it is possible to descend by allowing the gas to escape.

The balloons commonly used do not have any means of propulsion and cannot be guided. In late years dirigible balloons have been constructed and used to some extent. They are provided with means of propelling them, and may be guided in any direction, like the submarine. Neither the submarine nor the dirigible balloon has passed beyond the experimental stage.

151. Densities. In the preceding paragraphs attention has been called to the fact that an object in the water is buoyed up by a force equal to the weight of the water it displaces. Use may be made of this fact in several ways. We are enabled to determine the volume of irregular objects by this means, for it is evident that if an object loses 5 grams of weight when immersed in water, it must displace 5 grams of water. But water weighs 1 gram per cubic centimeter, and it therefore 
takes 5 cubic centimeters of water to weigh 5 grams. The object must have a volume of 5 cubic centimeters in order to displace 5 cubic centimeters of water.

The facts regarding buoyancy are useful also in enabling us to find the densities of different substances. By density is meant the weight of a unit volume of a substance - one cubic inch or one cubic centimeter. We might secure the weight of one cubic centimeter of iron by cutting a cube of that size and weighing it, but this would be a difficult process. Instead, we can take any irregular piece of iron, weigh it in the air and again in water, and from the weights calculate its density. The loss of weight in water is equal to the number of grams of water displaced, and is therefore equal to the volume. The weight in air divided by the volume equals the weight per cubic centimeter or the density per cubic centimeter. The density in ounces per cubic inch can also be secured, but the process is less convenient for use, and the density in grams per cubic centimeter is practically always used.

In the case of liquids the density is usually ascertained by weighing a measured quantity of the liquid.

Below are a few common substances with their densities

\section{Table of Densities for Reference}

(Grams per cubic centimeter)

\begin{tabular}{|c|c|c|c|c|c|}
\hline Alcohol & 0.8 & Glass . & 3.4 & Pine wood. & 0.6 \\
\hline Aluminium & 2.7 & Gold & . 19.4 & Platinum . & 21.7 \\
\hline Brass & 8.4 & Ice. & 0.9 & Sea water & 1.03 \\
\hline Coal & 1. & Iron & 7.2 & Silver & .10 .5 \\
\hline er & 8.8 & Lead & 11.4 & Cii & 7.3 \\
\hline Cork. & 0.2 & Mereury & 13.6 & Water & 1.0 \\
\hline Ebony & 1.2 & Oak wood & 0.8 & Zinc . . & 7.1 \\
\hline
\end{tabular}




\section{CHAPTER XII}

\section{CLIMATIC INFLUENCES OF BODIES OF WATER}

152. Importance of lakes and oceans. When we think of the earth upon which we live, most of us are likely to think of the broad continents of solid land upon which we have our homes. But however important the land may be to us, it is the smaller part of the earth, for about three fourths of the surface of the globe is covered with water. These great bodies of water, the oceans and lakes, are of much interest. The oceans and interior waterways are highways of travel and commerce, and they greatly affect the climate; the lakes and rivers are sources of supply for the water needed by cities, and too often the rivers are the channels by which wastes are carried away. A great body of water, such as the ocean or a large lake, can scarcely fail to have an important influence upon the lives of the people who live in the surrounding country. This influence may extend far from the lake or ocean and may affect many people.

153. The Great Lakes. The oceans are the greatest and most important bodies of water on the earth, but they are so vast that our study may better begin with a smaller body, such as one of the Great Lakes. These are among the most important lakes of the world and are partly surrounded by populous communities. After we have secured some definite information regarding the influence of one lake upon the surrounding communities, we should be able to apply this information to the explanation of the effect which other great bodies of water have had in directing the course of history, and the influence which they now have upon the lives and industries of men in various parts of the world. 
154. The lakes and summer temperatures. Many of the cities and villages upon the shores of the Great Lakes or upon the seashore have become known as agreeable places for summer residence. It is claimed for them that during periods of warm weather the temperature at these places is usually lower than at inland points in the surrounding country (fig. 72). There can be no doubt that this is sometimes the

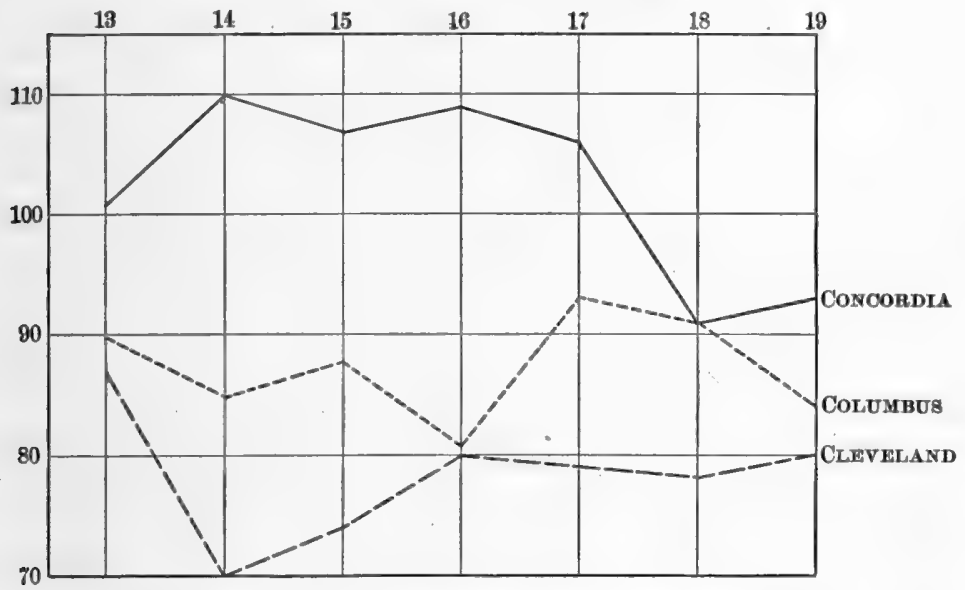

Fig. 72. Temperatures during a hot wave

The diagram shows the relative temperatures of Concordia (Kansas), Columbus (Ohio), and Cleveland (Ohio) on the thirteenth, fourteenth, fifteenth, sixteenth, seventeenth, eighteenth, and nineteenth of July, 1913. Cleveland is on the shore of Lake Erie

case, as it was on July 17, 1913, when the United States Weather Bureau reported the highest temperatures for the day at Milwaukee, Chicago, Detroit, and Cleveland to be from $74^{\circ}$ to $78^{\circ} \mathrm{F}$., while at the same time the adjacent parts of the Mississippi Valley were suffering from a hot wave and nine stations reported temperatures of $100^{\circ} \mathrm{F}$. or higher. There were other days, however, on which the temperature of the cities named was as high as that of the neighboring places. Isolated instances such as those given do not prove anything. 
In order to secure a clear idea of the conditions it is necessary to know the mean temperatures at the places compared.

The accompanying table gives the mean monthly temperatures, as ascertained by the United States Weather Bureau, for three cities which are located on the shores of Lake Michigan and in the adjacent country. These averages have been made up from a study of temperature observations extending over many years. Examination of the data will show that the mean monthly temperatures are definitely lower during the summer months at the lake cities than at inland points in approximately the same latitude. It appears, therefore, that there is foundation for the belief that the shores of the lakes offer more pleasant summer temperatures than may be found at other places. The same conclusions would be reached if other lake cities were compared with places remote from the lakes.

\section{Mean Monthly Temperatures}

\begin{tabular}{|c|c|c|c|c|c|c|c|c|c|c|c|c|c|}
\hline & Jan. & Feb. & Mar. & Apr. & May & June & July & Aug. & Sept. & Oet. & Nov. & Dec. & Annual \\
\hline Mac & 16.9 & 18.7 & 30.4 & 45.6 & 57.6 & 67.3 & 72.0 & 69.8 & 62.3 & 50.0 & 35.1 & 22.8 & 45.8 \\
\hline Milwaukee. & 20.5 & 22.3 & 31.4 & 43.3 & 53.6 & 63.6 & 70.0 & 68.9 & 62.0 & 50.2 & 35.8 & 25.4 & 45.6 \\
\hline Grand Haven & 24.6 & 23.8 & 31.5 & 43.8 & 54.4 & 64.1 & 68.8 & 67.3 & 61.2 & 50.1 & 37.9 & 29.2 & 46.4 \\
\hline
\end{tabular}

155. The lake breeze. Those who live near the shores of any of the Great Lakes are accustomed to attribute much of their freedom from great heat to the lake breeze (fig. 73). This breeze frequently blows on hot days and gives relief from heat. Often the morning is quite warm, and the heat increases rapidly, as the sun gets higher in the heavens, until about ten o'clock, when a cool breeze begins to blow from the lake and the temperature becomes pleasant again. The breeze may continue until about four o'clock in the afternoon or later. Of course, the effect of the breeze is most pronounced near the lake, and it does not extend many miles inland. The same phenomena are observed on ocean shores. 
156. Cause of the lake breeze. To account for the lake breeze, the causes for the movement of air need to be recalled (sect. 11). One cause of the movement is difference in temperature. When air is expanded by heating, it becomes lighter; that is, a cubic foot of it weighs less, because the amount of air that occupied a cubic foot of space before it was heated has expanded and occupies more than a cubic foot of space, and since only a part of the original amount will be contained within a cubic foot, this part cannot weigh as much as the whole. If, next to the warm air, there is a quantity of colder and heavier air, this colder air will tend to flow in under the

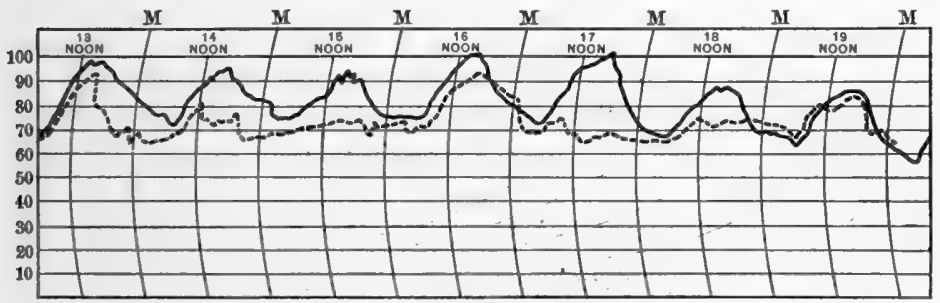

Fig. 73. Daily variations in temperature

Diagrams showing the daily variations in two cities on the thirteenth, fourteenth, fifteenth, sixteenth, seventeenth, eighteenth, and nineteenth of July, 1913. The solid line represents Peoria, and the broken line represents Chicago. Note the effect of Lake Michigan

warm air and lift it up. This is what happens in the vicinity of a stove or radiator where the cool air is continually flowing toward the stove, where it is warmed and in turn displaced by other cool air, thus making a continuous current.

The same thing occurs along a lake shore. In summer the land is much hotter than the waters of the lake, at least while the sun is shining. Like the stove, the land heats the air which is over it until this air becomes so light that the heavier air of the lake begins to flow out over the land, crowding the warm air upward (fig. 74). The air from the lake becomes heated as it flows across the land, and rises as it is displaced by more air from the lake. Thus there is a continuous flow of 
the air across the shore line from lake to land as long as the land is hotter than the water, excepting when local breezes are counteracted by stronger and more general movements of the air. The breeze gets well started about the middle of the forenoon, because it takes until that time to get the land sufficiently heated. During the night the land may be cooler than in the daytime. Sometimes the land is so much cooler than the water that the air flows from the land to the lake, but this land breeze is much less noticeable than the lake breeze.

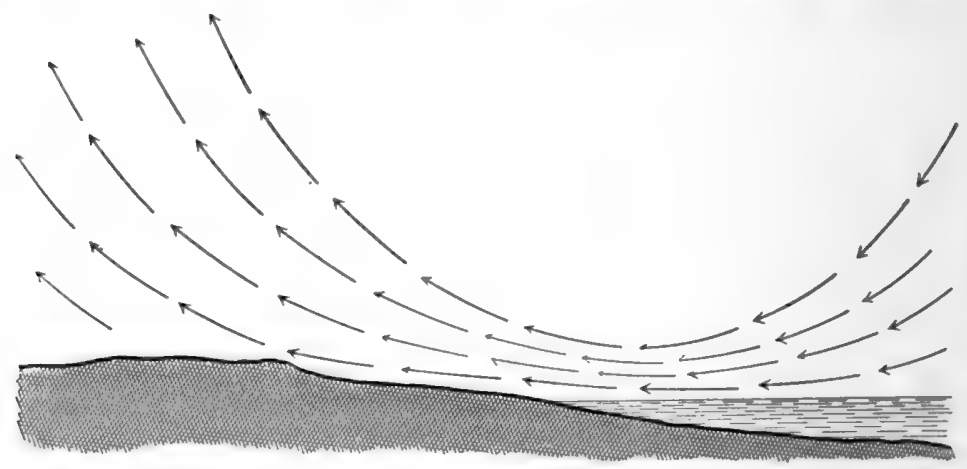

Fig. 74. Air movements from water to land

When the land is warmer than the water, cool and heavy air from the water flows over the land, pushing the lighter, warm air upward. Such movement of the air is known as a lake breeze or sea breeze

The question why land and water equally exposed to the rays of the sun should differ so much in temperature needs further explanation. To understand this matter we shall study some of the effects of heat on water and land. This study should also give information that will enable us to see whether the lake has influences on temperature other than those represented by the lake breeze.

157. Causes of unequal heating of land and water. The more rapid heating of the land is due, first, to the fact that it is not transparent. All the heat of the sun is received on the surface of the land, and the upper few inches are very rapidly 
heated, while the lower parts receive the heat slowly. Indeed, so slowly is the heat transmitted to the deeper layers of the soil, that at a depth of comparatively few feet the temperature does not change, summer or winter. On the other hand, the sun's rays penetrate into the water to a considerable depth (fig. 75), the exact distance depending on the clearness of the water. If the water is clouded by sediment, the rays of the sun do not penetrate very far. A second reason is that, since the sun's rays are reflected from the water more than from the land, much of the heat is reflected also and does not actually enter the water. A third reason lies in the fact that the water moves easily. Waves and currents mix the warm surface waters with the cool

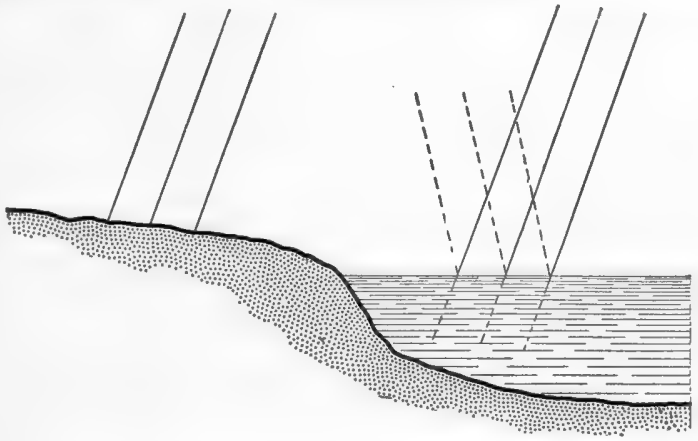

Fig. 75. Action of the sun's rays on land and water

When the sun's rays fall upon the surface of the land, they are mostly absorbed at the surface. The water reflects some of the light and heat, and the remainder may penetrate to considerable depths

deeper layers,

thus scattering the heat widely. For these reasons, although as much heat will be received upon a square foot of water as of land, no part of the water is heated so highly.

The fourth and most important reason is found in the effect of a given amount of heat upon different substances. If we expose equal amounts of two different substances to equal heat for the same time, the two bodies will not usually be equally heated. If a kettle of water and a flatiron are placed on the kitchen range at the same time, the iron will be heated more rapidly than the water. If a pound of iron and a pound of 
water are placed on the stove and exposed equally to the heating surface, it will be found after a short time that the iron is much hotter than the water. The same amount of heat has much less effect on the water than on the iron, so far as raising its temperature is concerned. The amount of heat which will warm a pound of iron $1^{\circ} \mathrm{C}$. will warm a pound of water only 0.11 of $1^{\circ} \mathrm{C}$; that is, it takes 0.11 as much heat to produce a given rise in temperature in iron as is required for the same rise of temperature in the same weight of water. If we had used soil instead of iron, we should have had a result somewhat similar, but there are so many different kinds of soil that differing results would be possible.

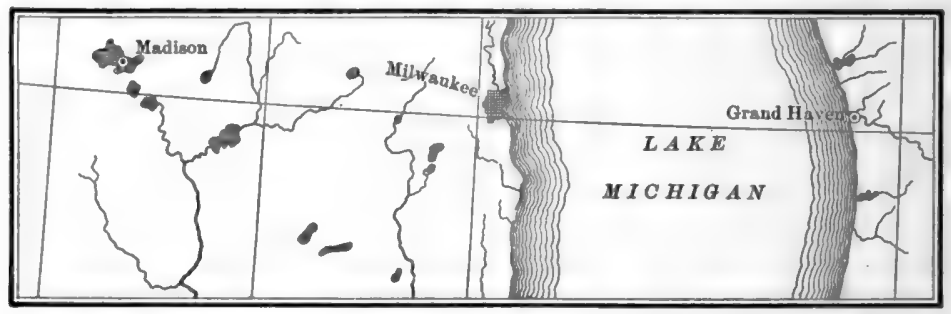

F1G. 76. Cities with different locations in the same latitude

158. Cooling of land and water. The land cools more rapidly than the water, and this is at least partly due to the facts that have been mentioned in connection with the heating. As it is necessary to put more heat into water than into land in order to raise its temperature a given amount, so the water gives off this larger amount of heat when it cools. Furthermore, as water cools it gives off its heat slowly, and since much of the heat is in the deeper parts of the water, it is not readily given off.

We may therefore expect that any body of water will be cooler in summer than the neighboring land, at least during the daytime and while the sun is shining, and that breezes from water to land will be common. During the winter the water may remain much warmer than the land. 
159. Effects of Lake Michigan on temperature. In the preceding discussion of the lake breeze we have noted that the effects of this breeze are restricted to a narrow area near the shore. The effects of the lakes are carried much farther inland, however, by other means. We need to study again the table of mean monthly temperatures in order to see what this effect is. Since the three points are in the same latitude

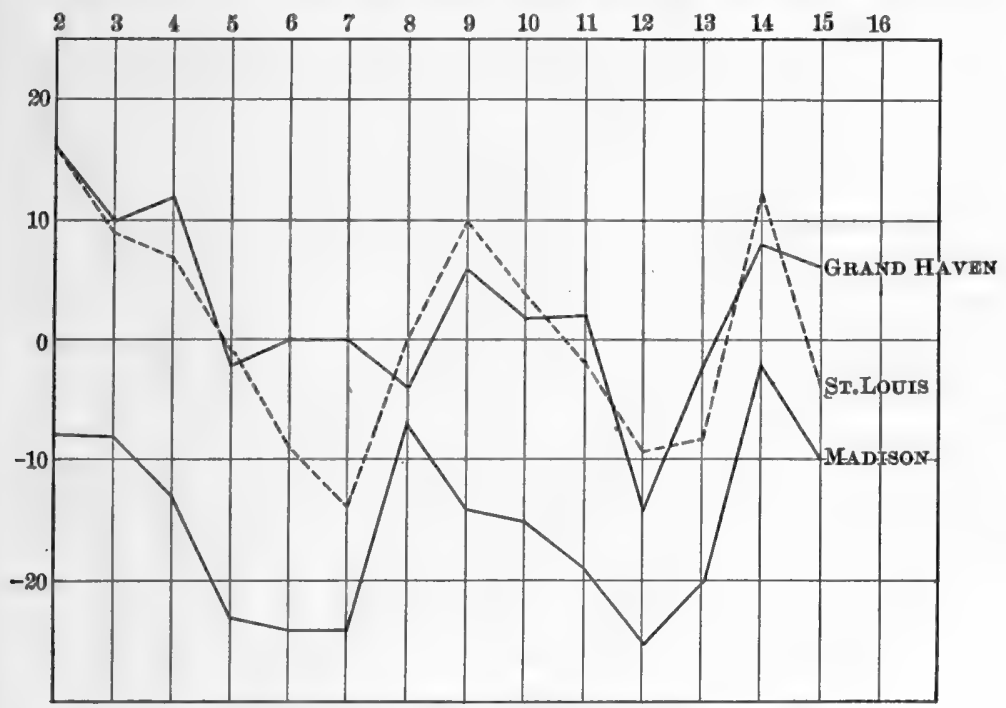

Fig. 77. Temperatures during a cold wave

The diagram represents the variation in temperatures between three cities on the dates January 2 to January 15,1912 . Grand Haven is in the latitude of Madison, but its temperature is like that of St. Louis

(fig. 76) and are so located that one is close to the east shore of the lake, one near the west shore, and one remote from the lake, we shall have proper points for comparison.

If we give our attention to the summer months, we find that the means are a little lower at Grand Haven than at Milwaukee, and highest of the three at Madison. From this it appears that, in the case of these three towns at least, the lake 
may bring about lower summer temperatures in its vicinity, particularly on the eastern shore. We cannot be sure of a general law by studying three eities only, but others have studied the records for other places, and a similar state of affairs is found to exist in all places in this region.

If it is the winter temperatures to which we give our attention, we find that here again the west shore occupies an intermediate position, the east shore is warmer, and the country away from the lake is much colder. The same fact is brought out by the study of the lowest temperatures reached during a period of cold weather in the winter. In one of the tables there is given the record of the lowest point reached by the thermometer on each of several days during a severe cold wave in the first part of January, 1913. The illustration (fig. 77) represents similar conditions in 1912 . It will be noticed that the cold is less severe on the east shore than on the west, and less severe on either shore than at places far distant from the lake but in the same latitude.

Minimum Daily Temperature during a Cold Wave in 1913

\begin{tabular}{|c|c|c|c|c|c|c|c|c|}
\hline DATE & CHICAGo & DUBUQUE & $\begin{array}{l}\text { Grand } \\
\text { HAvEN }\end{array}$ & $\begin{array}{l}\text { GRAND } \\
\text { RAPIDS }\end{array}$ & MAdison & $\begin{array}{c}\text { MIL- } \\
\text { WAUKEe }\end{array}$ & $\begin{array}{c}\text { ST. } \\
\text { LoUIs }\end{array}$ & $\begin{array}{c}\text { Sioux } \\
\text { City }\end{array}$ \\
\hline Jan. 2 & 5 & -5 & 9 & 9 & -8 & -4 & 16 & -13 \\
\hline 3 & 5 & -6 & 9 & 9 & -8 & -4 & 9 & -9 \\
\hline 4 & -6 & -9 & 2 & 2 & -13 & -11 & 7 & -13 \\
\hline 5 & -10 & -19 & -1 & -2 & -23 & -18 & -1 & -20 \\
\hline 6 & -11 & -19 & 0 & -1 & -24 & -18 & -9 & -20 \\
\hline 7 & -16 & -22 & -3 & -5 & -24 & -18 & -14 & -26 \\
\hline 8 & -3 & -3 & -2 & -2 & -7 & -5 & 0 & -7 \\
\hline 9 & -4 & -10 & 8 & 2 & -14 & -10 & 10 & -5 \\
\hline 10 & -6 & -15 & 2 & $\mathbf{0}$ & -15 & -13 & 4 & -7 \\
\hline 11 & -3 & -19 & -3 & 1 & -19 & -14 & -2 & -26 \\
\hline 12 & -3 & -26 & -14 & -9 & -25 & -14 & -9 & -35 \\
\hline 13 & -1 & -18 & -2 & -1 & -20 & -9 & -8 & -8 \\
\hline 14 & 4 & -2 & 10 & 9 & -2 & 0 & 12 & -9 \\
\hline 15 & -2 & -10 & 5 & 3 & -10 & -5 & -4 & -17 \\
\hline 16 & -2 & -12 & 5 & 2 & -11 & -5 & 0 & 1 \\
\hline
\end{tabular}


160. Reason for difference between east and west shores. A reason for the difference between the east and west shores is not difficult to find. It will be recalled that in connection with the study of the wind movements of the earth we found that the United States is in a belt of prevailing westerly winds. We have winds from all points of the compass, but our winds much more frequently blow from a point west of a north-and-south line than from a point east of such a line. They are usually southwest, west, or northwest. It follows from this that on most days of the year the air over the country to the east of the lake has come across the lake. On the west side the influence of the lake is very slight excepting on a few days when the wind is from some easterly direction or when the west wind is so light that a lake breeze develops. The effect of the lake is particularly important in case of a cold wave, for our coldest winds are from the northwest. This is well illustrated by the cold wave for which temperatures are given.

161. Some general conclusions. We are safe in concluding, from the facts which we have learned, that Lake Michigan has a great influence on the temperature of the surrounding country. The influence of the lake tends to reduce the extremes of temperature. Places near the lake have on the average cooler summers and warmer winters than they would otherwise have. This effect is great enough to be of some importance on the west shore of the lake but of much greater importance on the east shore.

We are justified in expecting that similar conditions will be found in the vicinity of any large body of water in a temperate latitude. In tropical countries, where there is no cold season, conditions are somewhat different, but the same principles apply. The conditions around Lake Michigan correspond exactly with the well-known fact that the western coast of each continent is warmer than the eastern coast in the same latitude. 
162. Some effects of lake climate. The coolness of the summer months attracts thousands of people from the hotter parts of the country to the eastern shore of Lake Michigan and to similar locations on the shores of other lakes and the ocean. Thousands of summer residences have been built and whole summer cities have grown up along shores so barren that otherwise scarcely anyone would live there. During the winter these settlements are often almost wholly deserted.

Back from the shore, and for many miles inland, the climate is so modified by the lake that it is possible in the lower peninsula of Michigan to grow fruits which eannot be grown with success away from the lake, excepting some hundreds of miles farther south. For instance, peaches are grown largely on the east side of Lake Michigan, but they do not succeed at all on the west side; indeed, it is necessary to go as far south as southern Illinois and middle Missouri to find an equally favorable elimate.

The advantages of the climate on the east side of the lake are not only such as might appear from the warmer average in the winter; it is equally important that the influence of the lake hinders the occurrence of early frosts in autumn and delays the return of warm weather in spring. The peach trees are thus prevented from starting growth during an occasional warm spell in spring and are often preserved from the dangers of late frosts in spring.

There are other, regions besides the lower peninsula of Michigan which are similarly favored by the influence of the lakes. Conspicuous among these may be mentioned the fruitgrowing country lying east and southeast of Lake Erie, and the great Canadian peninsula extending down between lakes Huron, Erie, and Ontario. In the same way, the mildness of the climate of the Pacific coast even as far north as Alaska is due to the influence of the ocean, assisted by certain ocean currents. 


\section{CHAPTER XIII}

\section{COMMERCIAL RELATIONS: THE GREAT LAKES ${ }^{1}$}

163. Commercial importance of the Great Lakes. Most residents of Chicago and many visitors in the city have stood by an open drawbridge and watched a lake steamer pass slowly up or down the river. On such an occasion they may have wondered where the vessel came from and what it was carrying, and may have appreciated something of the importance of the lake traffic. While the oceans are the greatest highways of water-borne commerce, the amount of such commerce on inland waters, as the Great Lakes, is large. Indeed, the importance of the ports of. these lakes causes them to rank with the greatest of the ocean ports as points of shipment. The traffic through Sault Sainte Marie Canal, connecting lakes Superior and Huron, is about four times as great as that through Suez Canal, even though the Sault Canal is closed by ice about five months of the year. A yet greater amount of traffic passes through the Detroit River, and this stream is one of the busiest waterways in the world.

164. Advantages of water transportation. It may at first appear strange that much of the commerce of such a city as Chicago, the greatest railroad center in the country, should be carried by water, but there are certain advantages of water transportation which must be mentioned. In the first place, it is often cheaper. It costs a great deal to build railways, but the lake is already here. There is less expense for repairs than

1 In this chapter and the following one conditions about the Great Lakes are frequently cited as illustrations. Those of other regions where the records have been kept for a considerable period will serve equally well, and such records should be secured as means of demonstrating the local importance of the facts under discussion. 
there is on a railway; on the other hand, it does cost a great deal to provide and maintain harbors and docks. On the whole, however, the expense per ton for moving freight by water is usually less than by land.

Water transportation is usually slower than transportation by rail. In the shipment of such commodities as coal or lumber, the demand for which it is possible to estimate many months in advance, it is necessary to start the freight on its way a little earlier, so as to allow plenty of time. It is not always true, however, that the railways are more rapid. Sometimes the railways are so crowded that the freight is not sent on promptly or cars are allowed to stand on sidetracks for days. A ship, on the other hand, usually proceeds quite promptly . from one port to another. It may move more slowly, but since it does not stop so long or so often, it may arrive before the car does. Heavy and bulky articles, such as coal, iron ore, stone, lumber, and grain, are commonly transported by the lake route where this is possible. One of the most important phases of the use of the lakes to-day is the transportation of iron from the mines near the west end of Lake Superior and near Green Bay to the iron and steel plants on the shores of lakes Michigan and Erie. The great furnaces of South Chicago, Indiana Harbor, and Gary at the south end of Lake Michigan are supplied by lines of steamers which run directly from the ore docks on Lake Superior and on Green Bay to the private wharves of the steel plants. These boats are built for this service and carry no other freight. Other lines of boats run through lakes Huron, St. Clair, and Erie to Cleveland and other ports on Lake Erie, where the iron ore is either smelted or shipped to inland points, such as Pittsburgh. Other important articles of commerce on the Great Lakes are coal, grain, and lumber.

There can be no doubt that the commerce which is earried on upon the lakes is of great importance to the lake ports. Many of their industries depend largely upon the materials 
which are brought by water, and many citizens are there because of the opportunities afforded them by the industries which depend wholly or in part upon this commerce. It is true that these cities might be able to exist without the lakes, as other cities do, but they doubtless would be different in many respects, and it is quite possible that they might not have been established or that they might be at different places and engaged in different activities.

165. Origin of lake cities: Chicago as a type. The first white settlers and travelers in the region of the Great Lakes were the French. They came into the country by way of the St. Lawrence River and early discovered the Great Lakes. As they

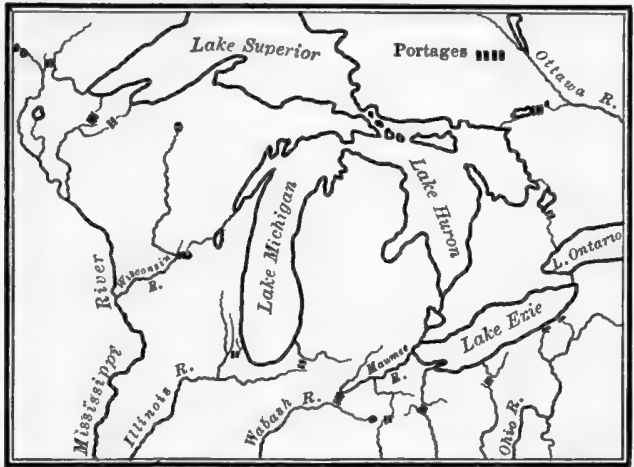

Fig. 78. Early routes of travel

The map shows the headwaters of rivers and the lakes which were important in determining the courses taken by early hunters and settlers

pushed their explorations farther west they adopted the Indian canoe as their chief means of travel, and the most important roads for them, as for the Indians, were the rivers and lakes (fig. 78). When they had discovered the Mississippi River and formed settlements and military posts upon it, their route from Canada to the Mississippi was through the lakes to the shore of Lake Michigan, then up some stream emptying into the lake, and across the country to another river down which they might float to the Mississippi. There were several such routes in use. One of them crossed the present site of Chicago. When traveling by this route, the voyageur paddled his canoe to a point near the south end of the lake, where he 
entered the Chicago River and ascended this stream and its south branch to a point near the western limits of the present city. A short carry, or portage, brought him to the Des Plaines River. Indeed, in times of flood it was often possible to travel the entire distance by canoe. When once in the Des Plaines River, he might easily pass with the current down to the Illinois River, to the Mississippi, and even to the Gulf of Mexico. The easy portage at Chicago and the importance of the French posts on the Illinois River made this a favorite route. When sailing ships began to be used on the lakes, it was natural that the traveler should wish to go as far as possible on the ship and as short a distance as possible on the canoe. Ships brought travelers and goods to the south end of the lake, and the mouth of the river afforded a safe harbor for the vessels and a landing place for the goods. The French lost possession of the country, but the routes of travel and commerce did not change.

When travel and commerce had increased, people began to settle at the point where the ships came to unload. A fort was built to protect the settlement and to defend the route of travel. This was known as Fort Dearborn, and its location was in the center of the present city of Chicago.

166. Extension and improvement of waterways. As population increased, the need for good transportation facilities increased also. Steamboats abounded on the larger rivers, and sailing vessels on the Great Lakes, but there was no route by which freight vessels could pass between the lakes and the greater river systems. To meet these needs a number of canals were dug. Erie Canal is the most widely known, but there are others in Pennsylvania, Maryland, New Jersey, Ohio, Illinois, and other states.

One of the canals connects Lake Michigan with the rivers of the Mississippi system. It was completed in 1848. The conditions which made it easy for the French and Indians to get their canoes from Lake Michigan to the Illinois River by way of the Chicago and Des Plaines rivers also made it 
easy to dig a canal, now called the Illinois and Michigan Canal, along the same line, for the divide between the two rivers is at one place not more than $\mathbf{1 5}$ feet higher than the lake. The canal begins only a few miles from the old French and Indian portage and extends along the valley of the Des Plaines and Illinois rivers to La Salle, Illinois, where it enters the Illinois River. Thus the route used by the Indians for many centuries became the route of modern commerce, and the small town at the mouth of the river, where the ships met the canal boats, grew and flourished.

167. The railroads. Soon railroads were built, and then the canal became less important, but two of the railroads were built along the same old route of the early Indian travel. In the valley of the Des Plaines River leading southwest there are the river and the old canal, two railroads, a wagon road, a trolley line, and the sanitary canal.

The railroads could not afford to miss the city at the end of the lake, for here was the only harbor in this vicinity where freight might be transferred between train and ship. Furthermore, the lake extends so far south that railways built westward from the larger cities of the east toward the rich prairies of the west found their shortest route close to the end of the lake, and were built into the city. Thus the settlement that was on the main line of pioneer travel came to be on the main line of railway travel and the principal meeting place of commerce by land with that by water.

Elsewhere upon the shores of lakes, rivers, and ocean the towns which were originally centers of commerce by water have become railway centers also. The importance of river commerce has decreased greatly since railways have become more numerous. In many cases the railways have followed the routes which were earlier used by water-borne commerce. Thus the New York Central Railway parallels the Hudson River, Erie Canal, and Lake Erie, and two railways follow the route of the Illinois and Michigan Canal. 
168. Harbors. A good harbor is a necessity for any city which carries on commerce by water. There must be some place where vessels may lie in quiet water while unloading or taking on cargo. This purpose was served from the first by the Chicago River. The river was a shallow stream, and as lake vessels increased in size it was necessary to deepen the river and to make other improvements. Since the harbor is open to all vessels, it is the business of the government to make these improvements. The main stream and many miles on both its branches have been dredged until they have now a depth of at least 20 feet throughout, and the lake steamers can land alongside at any point. The river has not proved sufficient for the commerce of the city, and therefore a harbor with more room has been constructed by building great breakwaters at some distance from the shore in front of the city. These breakwaters check the force of the waves and produce a fairly quiet area behind them in which vessels can lie in security. Such artificial harbors must be constructed at many ports.

169. Lights, buoys, and life-saving stations. Lighthouses are placed at the harbor entrances and at other places, to guide the master of a vessel safely into the harbor or to warn him of danger. Certain important lighthouses are equipped with foghorns, which are sounded at intervals of a number of seconds during rainy or foggy weather, when the lighthouse may not be visible. Obstructions, shallow places, and other dangers are commonly marked by buoys of different shapes and colors.

Life-saving stations are maintained at many places. Each station is in charge of a crew of trained and experienced men and is equipped with boats and other special apparatus for the saving of life in case of wreck or other accident. It is better, however, to prevent wrecks than to save life after a wreck, and one of the measures taken for this purpose consists in maintaining storm-signal stations, which are frequently 
connected with the life-saving station. Storm warnings are usually displayed upon a tower, where they are visible from vessels about to leave the harbor. Flags are used in the day and lights at night.

170. Other ports. Our study has been mainly a study of the port of Chicago. As the largest city on the lakes and the port closest to the heart of the country, it has particular interest. A similar study might very well be made of any other lake port or ocean port, and quite similar facts would be found to account for its existence and growth. 


\section{CHAPTER XIV}

\section{WATER SUPPLY AND SEWAGE DISPOSAL ${ }^{1}$}

171. Sources of water supply. One of the most important problems confronting the people of cities is the matter of proper water supply. It is an important problem because the health of the people is to a great extent dependent upon it. There must be enough water to serve the purpose of cleanliness and for drinking and other uses, and its quality must be such that it may be used without danger. One of the most serious afflictions that.can befall a city is scarcity of water in the hot summer weather.

To find a suitable supply for a city is not easy. In the country or small villages dependence is placed upon wells or occasionally upon springs. In a city this source is not practicable. It would be extremely difficult to secure from wells a supply sufficient for a large city, and furthermore the soil in cities becomes so filled with various waste materials that the waters from surface wells would hardly be suitable for use. The only other available sources of supply in most cases are lakes or rivers. A great many American towns pump their water from rivers. We shall see later some of the objections to this source of supply.

The waters of large lakes are among the purest we have, provided only that impurities are not introduced into them from the shore.

172. Importance of pure water. The importance of pure water lies very largely in its relation to disease. We have learned that many sorts of bacteria are commonly found in water, and that no water is entirely free from them unless it

1 See footnote at beginning of Chapter XIII. 
has been sterilized. If these bacteria are of the kinds that produce disease, serious results may follow when the water is used for drinking and for other domestic purposes.

The most important disease bacterium found in water is the typhoid bacillus. For that reason the death rate from typhoid fever is often taken as a sort of index to the condition of the water supply. There is given here a graphic representation of

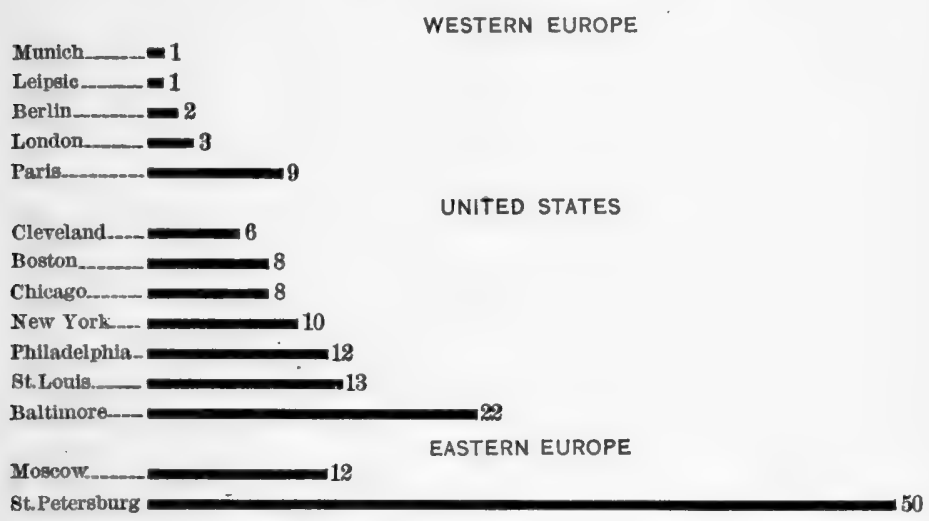

Fig. 79. Death rate from typhoid

The figures show the number of deaths per hundred thousand population, based upon data for 1912. The dark line indicates the proportionate number of deaths in each city

the typhoid death rates in a number of cities (fig. 79). You will be able to draw your own conclusions as to the safety of the different sources of supply.

At one time Chicago had a typhoid death rate of 173 per 100,000 population, and at that time this was the highest death rate from typhoid in the civilized world. The rate was only 13.7 per 100,000 in 1910 and 7.5 in 1912. The manner in which such changes are brought about will be an important subject of discussion in this chapter.

173. Kinds of impurities. There are many kinds of impurities found in water. Some of these are highly objectionable, 
while others are of very little consequence. For our own purpose it will be useful to put them all into three classes: dissolved substances, sediments, and bacteria.

One of the commonest substances is lime, which is really dissolved limestone. This is the substance which is deposited in a teakettle if hard water is boiled in it. The presence of lime in water is an annoyance in many ways, but the substance is not known to have any serious effect upon health. The same may be said of other substances which are commonly present in solution in water.

Sediments, or solid particles, of various sorts are present in all natural waters. We usually speak of them as mud, clay, sand, etc. If the water is allowed to stand for some time, the sediment tends to settle to the bottom. The sediments present in lake waters are such as have been brought in by rivers or stirred up by waves along the shore. Very naturally there is little sediment in water a few miles from land, while in rivers these sediments remain in suspension for a longer time. Such sediments as we have been describing make the water less inviting, but they are not in themselves dangerous.

The third kind of material present in water - bacteria is in reality a sort of sediment, but the bacteria are of such great importance that it seems best to discuss them separately. Indeed, the principal importance of other sediments lies in the fact that bacteria are likely to be associated with them. For instance, the mud along the shore usually has a great deal of refuse mixed with it, for the shore is likely to be made a general dumping ground. Thus there are great numbers of bacteria living in the mud. If waves stir up this mud and it mingles with the water, the bacteria are likely to be distributed as widely as the mud is. Therefore water which is muddy is often dangerous and always open to suspicion.

174. Sources of bacteria in lakes and rivers. Natural waters are never wholly free from bacteria. Every rain washes them into the streams, and they are further increased by the common 
habit of disposing of rubbish by dumping it into streams. The most important source of bacteria in many of our streams is the sewage of the cities on their banks. The bacteria from this source are particularly objectionable, because the sewage includes human wastes and therefore commonly contains the germs of such infectious diseases as are present in the community. As the water of the river flows onward many of the bacteria settle to the bottom along with other sediments or are killed by exposure to air and sunlight, but the water is not likely to be wholly purified by the time it reaches the next city or town. Excepting near the source, very few rivers are suitable for domestic use in their natural condition.

The larger lakes are fed by many rivers and therefore receive large numbers of bacteria from this source. The contamination is increased by refuse dumped alongshore and by the sewage of adjoining cities. It should be noted that all the principal sources of contamination of lake waters are located near shore. The waters of the center of the lakes are polluted only as bacteria and other sediments are carried out into the lake by currents in the water. The movements of lake water are so slow that bacteria and other sediments usually settle to the bottom before they have traveled many miles from land.

- For this reason the water in the central part of large lakes is usually of excellent quality. As cities increase in size, however, the zone of pollution alongshore extends farther into the lake.

175. Methods of securing pure water. The cities on the Great Lakes have ordinarily taken their water supplies from the lakes, and they have sought to secure pure water by constructing tunnels in the lake bottoms which make it possible to secure water from points at a distance of from one to six miles from shore. Even this distance is not great enough to guarantee pure water in all cases, and filtering or other means of purification is desirable. 


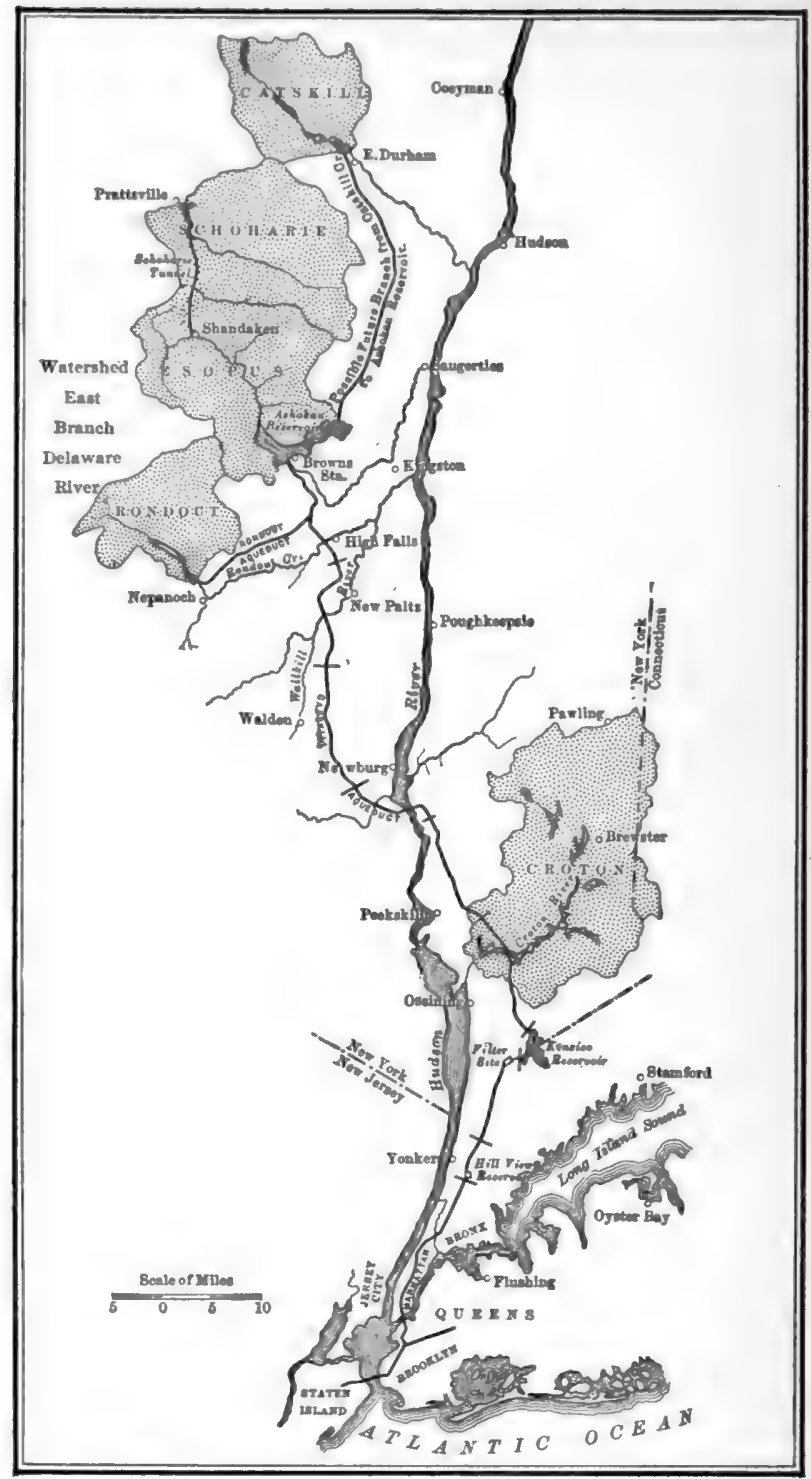

FrG. 80. The water supply of New York City

Through a large aqueduct the water is taken from the Catskill Mountains to the city 168 
Some cities are so situated that it is possible for them to secure water from mountain streams which flow from valleys that are almost or quite uninhabited. The water of such streams is usually of excellent quality and, if protected from contamination by the inhabitants, will carry almost no diseaseproducing bacteria. Since the lands in the mountain regions are commonly of comparatively little value for agricultural purposes, it has been possible for certain American cities to acquire control of the entire drainage areas of the streams which supply them with water (fig. 80). With proper care these regions may be preserved from contamination and the purity of the water insured. The United States Forest Service is

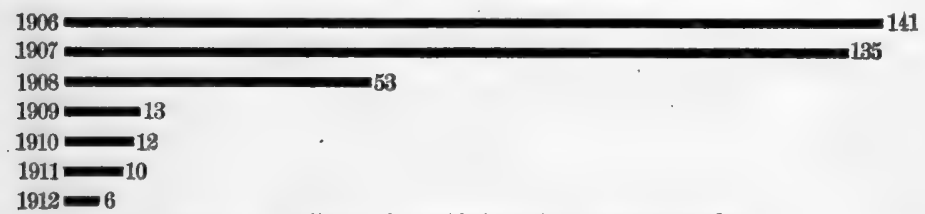

FIG. 81. Effect of purifying the water supply

Diagram showing the typhoid death rate per hundred thousand population in Pittsburgh, Pa., during a term of years. A filtration plant was installed in 1908

coöperating with certain cities in preserving from contamination those parts of the reserves which drain into the streams from which these cities derive their water supply.

For many cities the only available source of water supply is a river or lake which has become contaminated. In some cases this water is pumped into the mains without any attempt to remove or destroy the contamination. In these cases the health of the people suffers and the death rate is abnormally high (fig. 81). The citizen of such a city can protect himself from the danger of polluted water only by sterilizing the supply that he uses for drinking and domestic purposes.

All cities that are properly organized and governed guard the health of their citizens by proper attention to the quality of their water supply. If this must be taken from a contaminated source, it can be purified by any one of several 
methods. Many modern cities have installed filtering plants in which the bacteria are removed from the water by passing it through beds of sand. Other cities kill the bacteria by the action of certain chemicals which, when added to the water in very small proportions, are fatal to the bacteria but are not harmful to people.

Storage reservoirs in the form of natural or artificial lakes are common accessories of water systems. Usually the principal purpose of a reservoir is to accumulate a supply of water when it is plentiful, in order that there may be no scarcity during a dry season or in case of unusual demands of any kind. At the same time the quiet waters of the reservoir offer a favorable place for the finer sediments, including bacteria, to settle to the bottom. The water is thus purified while it is being held in storage, and in some water systems this is the most important means of purification used.

176. The problem of sewage disposal. Enough has been said in the preceding chapter to indicate that the disposal of city wastes is an important matter. Much of the waste is in solid. form (garbage, ashes, etc.) and the proper disposal of this is important and difficult. We shall here concern ourselves only with that which is washed away in running water - the sewage. That there will be a great volume of this is evident, for most of the water that is pumped into the eity eventually finds its way into the sewers. In addition most of the water from rains is turned into the sewers by the catch basins in the gutters.

177. Sewers. The simplest way to get rid of waste water and sewage is to allow it to run off over the surface of the ground in gutters. Obviously there are objections to this practice, but it is common in oriental cities, and several American cities have such systems. Indeed, open sewers may be found in neglected parts of many of our cities. An open sewer is always a source of danger and should be a matter of concern to every citizen. 
The modern and sanitary way to construct sewers is to place them underground. There is usually a sewer in every street, and every house should be connected with the sewer. These smaller sewers unite into larger ones, which finally discharge the sewage into a lake, river, or ocean.

178. A problem in sewage disposal. Every city has its own peculiar problems relative to water supply and sewage disposal. In Chicago the problem was to find a place to empty the sewage so that it could not flow into the lake. This was very difficult to do, because the streams flow into the lake. The problem was solved by reversing the current of the river, and by means of a canal the water was made to flow into a branch of the Illinois River. Although Chicago is in the basin of the St. Lawrence River, at the present time its sewage flows into the Gulf of Mexico. The way this was accomplished and the peculiar geography which made it possible form an interesting story.

179. The sanitary canal. The route which afforded an easy passage for the Indians, the French, and the builders of the Illinois and Michigan Canal and of wagon roads and railroads has proved equally suitable for the route of the canal built to carry away the sewage of Chicago.

The building of this canal was possible because, as stated in the preceding chapter, no part of the old portage was more than 15 feet above the level of the water of the lake. The current now flows from the lake into the mouth of the river and up the South Branch, where it enters a new canal, known as the sanitary or drainage canal. This canal is made wide and deep to serve as a ship canal as well as for drainage. In this way part of the water of Lake Michigan, the normal outlet of which is through the St. Lawrence system, now flows into the Gulf of Mexico and carries with it the sewage of Chicago. It is known that in prehistoric times Lake Michigan stood at a higher level, and its waters emptied into the Mississippi system along the route now followed by the drainage canal. Therefore the canal restores an ancient outlet. 
The construction of the sanitary canal cost more than $\$ 56,000,000$. Did it pay? Let us look at some of the facts. The City Health Department reports that during the ten years before the opening of the canal in 1900, the average annual death rate from typhoid was 66.8 per 100,000 , but in the ten years following, the rate was only 22.3. It is calculated that this represents a saving of 8814 lives. Each life has a money value, dependent upon earning capacity. The Health Department has calculated that the actual money value of these lives to the community was nearly $\$ 53,000,000$. In other words, the canal almost paid for itself in the first ten years. It will always pay any city to secure pure water at any necessary cost.

180. Sewage treatment and disposal. The common method of disposing of sewage and other wastes by discharging them into streams, lakes, or ocean is obviously highly objectionable, and the nuisance tends to increase with the growth of population. At many places it has become necessary to treat the sewage in a manner that will remove its objectionable qualities before allowing it to enter the watercourses. This is usually accomplished by bacterial action and filtration, or by using the sewage to irrigate land. Chemical treatment may be used, also, to destroy bacteria.

181. Rural water supplies. The water supply of farms and villages has not usually received as much attention as that of cities. Most of the inhabitants of a city secure their water from the same source, - the public waterworks, - and any fault in the system affects the whole city, thereby attracting attention. In rural districts, on the contrary, each home has its own independent source of water, commonly a well, and contamination of any one well does not usually affect so many people. It is quite possible, however, that many wells may be in a polluted condition at the same time, and the average character of the water in a rural community may be very bad. Indeed, at the present time typhoid and other water-borne 
has of course percolated a long distance through soil and rock and is very nearly free from bacteria (fig. 82), but such wells must be carefully guarded against the entrance of surface water. The lining of the well should be water-tight, and the surface waters should be carefully drained away from the vicinity of the well. A deep well which is protected so that surface water cannot enter is one of the most reliable sources of pure water. What has been said above regarding wells applies also to springs.

182. Disposal of wastes in rural districts. In many rural districts the disposal of wastes is not given the attention that its importance demands. Too often manure heaps are allowed to become breeding places for flies, human wastes accumulate in cesspools where they are accessible to flies as well as sources of contamination to wells, and the barns and outbuildings are in a condition that is a continual menace to health. It is obviously impracticable to construct sewage-disposal works which will serve an entire rural district as a city is served by its sewer system. It is, however, entirely practicable for each country residence to have its own individual plant for this purpose, and for each family to keep its own surroundings in a sanitary condition. Better sanitary conditions must be secured in the country before it can become as desirable a place of residence as it should be. 


\section{PART III. WORK AND ENERGY}

\section{CHAPTER XV \\ WORK BY RUNNING WATER}

183. The power of running water. Those who bathe in the surf of the ocean or of large lakes soon come to have an appreciation of the power of moving water. The power of the waves is even more impressively shown by the damaged piers, ruined breakwaters, and wrecked vessels which sometimes strew the coasts after severe storms.

The power of flowing water may be felt as one wades a small creek; its possible magnitude is exhibited only too often by the results of floods and freshets. Even small streams may, in flood times, destroy bridges and roads, tear down stone walls, carry away buildings, and wash the fertile soil from great areas of land.

184. Work done by Niagara Falls. One of the most impressive examples of the power of running water is to be found in the falls and gorge of the Niagara River. This river flows from Lake Erie to Lake Ontario. Several miles from Lake Erie the water falls about 160 feet into the head of a narrow gorge, through which it races swiftly toward Lake Ontario (fig. 83). The falling water has worn a deep pool and has also undermined the foot of the cliff over which the water falls. From time to time masses of rock at the edge of the cliff are loosened by undermining and fall into the whirling pool below. In this way the face of the cliff is slowly eaten away and recedes upstream. • The falls are moving upstream toward Lake Erie at the rate of about 5 feet per year, lengthening the gorge by that amount. 
It is believed that the whole gorge, seven miles in length, was formed by the recession of the falls. When the river first began to flow between the lakes, it fell over a cliff that runs parallel to the shore of Lake Ontario, the falls being located near the present town of Lewiston, New York. During the many centuries that it has been flowing, the falling water has been wearing away the head of the gorge and thus lengthening it.

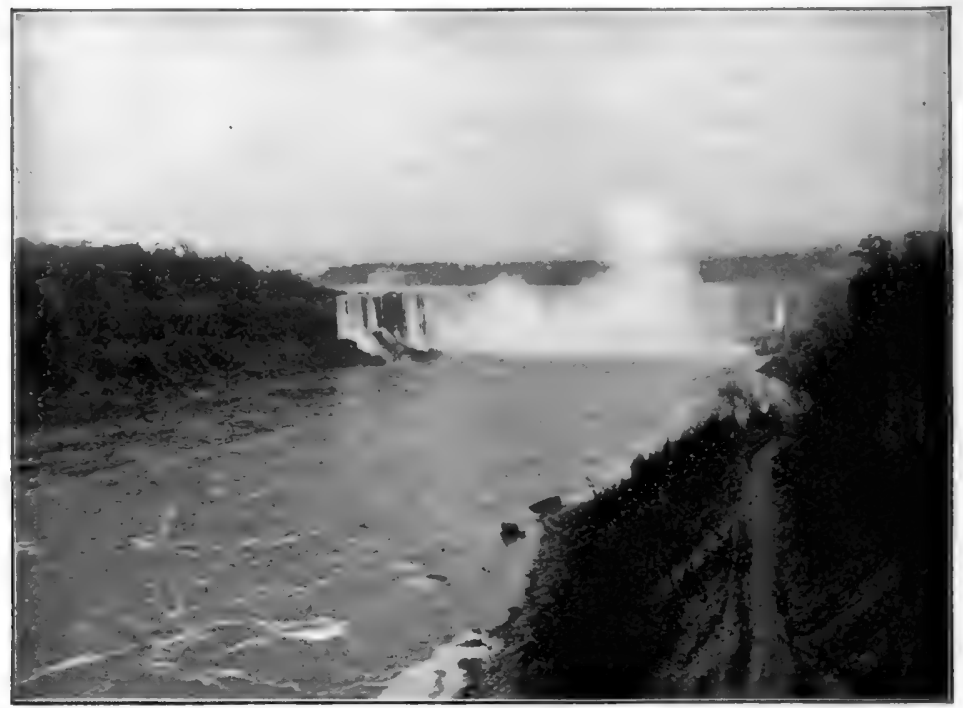

FIG. 83. Niagara Falls

At Niagara the river falls into the head of a narrow, steep-walled gorge. The gorge has been made by the river

The rock which formerly occupied the present position of the gorge has not only been broken loose, but most of it has been worn into sand and gravel, which has been carried to the lower stretches of the river or into Lake Ontario. Many hundred tons of rock have thus been loosened and transported a long distance by the water of this river. There are many other rivers which have transported much more material than the Niagara River has. 
185. Utilization of running water. The power of doing work which running water possesses has long been recognized. Centuries ago men devised water wheels, by means of which streams of water were caused to turn the millstones which ground grain into flour. In the United States small water-power flour mills and saw-mills were formerly found in almost every neighborhood. Many of these are no longer used, since it has been found more satisfactory to carry on the work in a smaller number of larger and well-equipped mills. The larger mills often owe their location and success to the abundance of water power, as in the case of the flour mills of Minneapolis, which have been built alongside the neighboring falls of the Mississippi River.

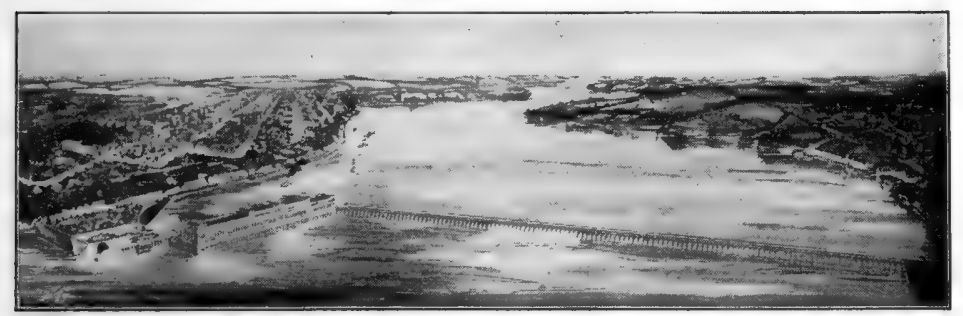

FIG. 84. An important water power

The dam in the Mississippi River at Keokuk, Iowa. It will supply 300,000 horse power

In later years water power has been more largely used for a great variety of industrial purposes. The water wheels are usually caused to operate dynamos, and the electric current thus generated is transmitted to trolley lines, factories, and industrial plants of various sorts, where it is made to do work through the agency of electric motors. These plants may be several hundred miles from the location of the water power. A dam which has been built across the Mississippi River at Keokuk, Iowa, is expected to produce electric energy equivalent to more than 300,000 horse power (fig. 84 ). This is said to be about three times the total amount of power now used for manufacturing purposes in the whole state of Iowa. The 
electric current is transmitted as far as St. Louis, Missouri, and possibly it may be found advantageous to transmit it

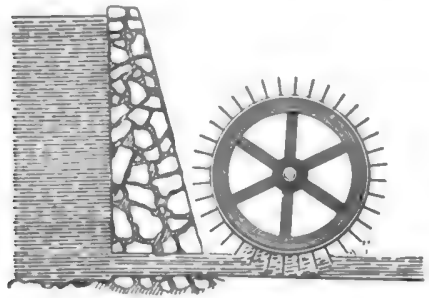

Fig. 85. An undershot water wheel

The wheel is turned by the pressure of the water against the paddles even greater distances.

186. Undershot water wheels. A simple type of water wheel is one which consists essentially of a wheel with a number of paddles projecting from its circumference. The wheel is so mounted that paddles dip into a swiftly flowing stream which flows beneath it, and the push of the water revolves the wheel (fig. 85). Somewhat similar wheels are often made and used as toys and offer excellent opportunities for individual ingenuity in constructing a waterdriven machine.

187. Overshot water wheels. The rim of the overshot wheel is provided with boxes, called buckets, which are placed in positions indicated in the illustration (fig. 86). Water is carried out over the wheel in a pipe or a flume and allowed to run upon the upper part of the wheel. The upward-facing buckets of one half of the wheel are filled, and the weight of the water turns the wheel. Each descending bucket gradually turns over as it descends, and spills out the water, returning empty up the other

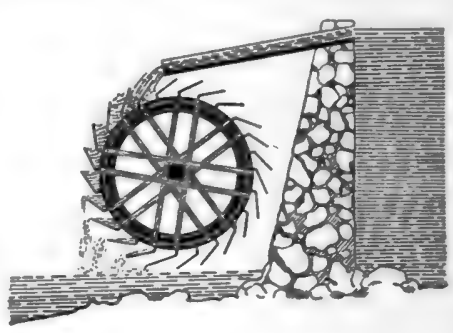

FIG. 86. An overshot water wheel The wheel is turned by the weight of the water in the buckets side. The wheel is called an overshot wheel because the water passes over it and then into the current.

188. Turbines. A third kind of water wheel is the turbine. In this type many streams of water under pressure are directed 
from pipes against curved paddles, or blades, on the wheel. The angle of the streams and the curvature of the blades are carefully adjusted to secure the greatest possible power.

Turbine wheels can be built to suit a wide range of conditions with respect to pressure and volume of water. When properly constructed and adjusted they will give more power under given conditions than either of the other types of wheels. For these reasons they are now more commonly employed than either of the other types.

Most large modern water-power plants, as those at Niagara Falls and Keokuk, are equipped with turbine motors. These are used to operate dynamos, and the electric current generated is transmitted to the points where power is needed. 


\section{CHAPTER XVI}

\section{WORK}

189. About work in general. A great deal of the work of running water is of no immediate benefit to man. The great waterfalls of the earth may thunder away for many future centuries without producing any noticeable change in the desirableness of the surrounding region as a place of human residence. To be sure, the gorge of Niagara may in time be extended so far upstream that it will reach and partly drain Lake Erie, but that event is far in the future, and in the meantime its work in loosening and transporting material does not greatly affect any of us. As a sublime spectacle it may be of very great value, but as a worker it is unimportant, because its work is not of a useful sort.

Of late years men have taken part of the water from the river above the falls and caused it to flow through turbine water wheels on its way to the lower level in the gorge. This part of the water, therefore, turns the wheels and the dynamos connected with them instead of wearing away the rock of the falls. Thus the falls have been harnessed and compelled to do useful work (fig. 87). The beauty and impressiveness of Niagara Falls are so great that the falls are probably worth more to us in their natural state than the power we could derive from them would be worth, but there are many other places where water power can be secured without destroying great scenic beauty, as at Keokuk. It is necessary for us to take advantage of water power and of other sources of energy, for there are many kinds of work to be done in the world in order that all of us may live. Buildings are to be constructed, trains to be moved across the country, steamships to be driven 
across the ocean. Land must be plowed, crops planted, ditches dug, the floors scrubbed, the lawns mowed. Work must be done every day in every inhabited part of the world, and the work is very important to each one of us. If the land were not plowed and planted and the crops harvested, there would be little for us to eat. If the trains and ships did not carry food for our great cities, many of us would starve to death, as has

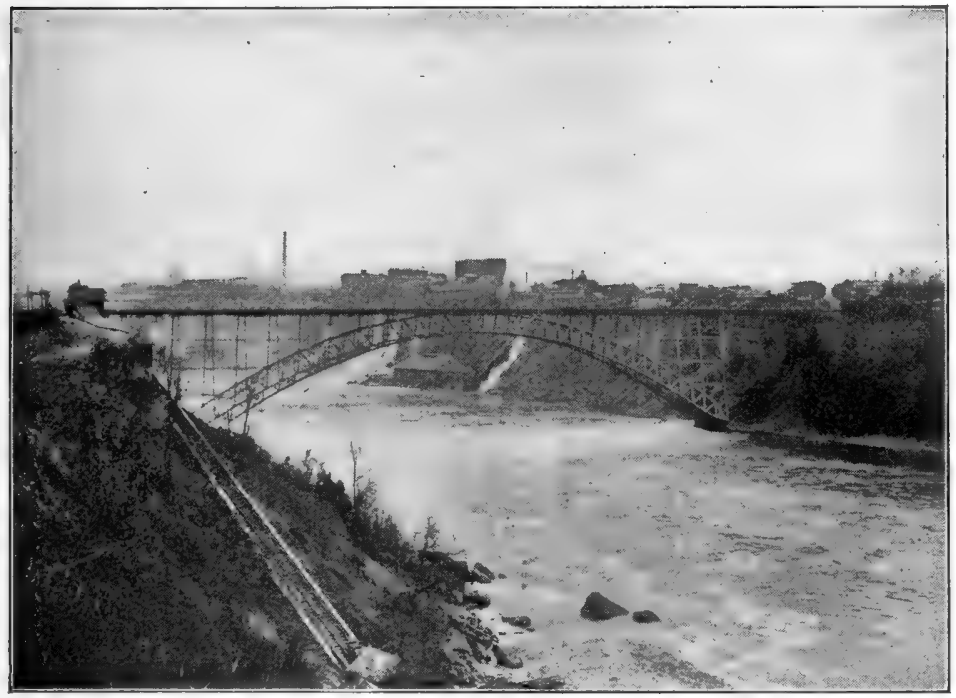

Fra. 87. The Niagara gorge

Back of the bridge, in the center of the picture, may be seen some of the power plants using water from the river. Much of the energy is wasted

happened in countries like India, where transportation facilities are not equal to the task of properly distributing the food that is produced in the country.

It is not possible for us to accomplish all these tasks by our unaided strength, and we therefore use various machines to assist us or to utilize the forces of nature. One of the great differences between savage and civilized men lies in the ability 
of the latter to help themselves in getting this work done. In this chapter we shall study about work and the means of accomplishing it.

190. Different methods of working. When our ancestors were living in a state of savagery, as they did many centuries ago, their ways of working were doubtless as primitive as the methods in use at the present time among some savage tribes. The first men doubtless did everything with their unaided hands, but soon they learned that a heavy object could be pried up with a stick more easily than it could be lifted by the hands, that a sling would throw a stone harder than the unaided hand, that a $\log$ could be rolled up an incline if it was too heavy to be lifted, and that an arrangement of rope and pulleys would make it possible to hoist very heavy weights by the use of small force. Gradually the more intelligent part of mankind has developed the lise of simple machines and combinations of them, until now there is scarcely any work done without the use of some sort of mechanical contrivance. The simple machines, which are the basis of the devices which we employ to assist us in working, are the lever, the pulley, the inclined plane, the wheel and axle, the screw, and the wedge.

The knowledge of the use of machines is of great value to civilized man. If we had been compelled to depend on bare hands and our own physical strength alone for accomplishing all sorts of work, our present civilization could not have developed. We should be in very much the state of the tribes in those parts of Africa, Asia, and Australia where the soil is dug with a stick and goods are transported on the backs of men. The use of various contrivances which assist in the accomplishment of work, and the knowledge of their possibilities, are among the marks which distinguish civilized people from savages.

191. A problem in work. If a savage wishes to remove his dugout canoe from the water, he knows no way to do so but 
to lift or drag it out. If it is too heavy for this, he may call in his neighbors and thus secure enough men to do the work. If there are no neighbors, it cannot be done.

The more intelligent races have learned ways of helping themselves which enable them to overcome obstacles of this sort. Let us suppose that a boy owns a boat weighing 2000 pounds and that he wishes to pull it out of the water. It is not necessary for him to call in his fellows if he understands

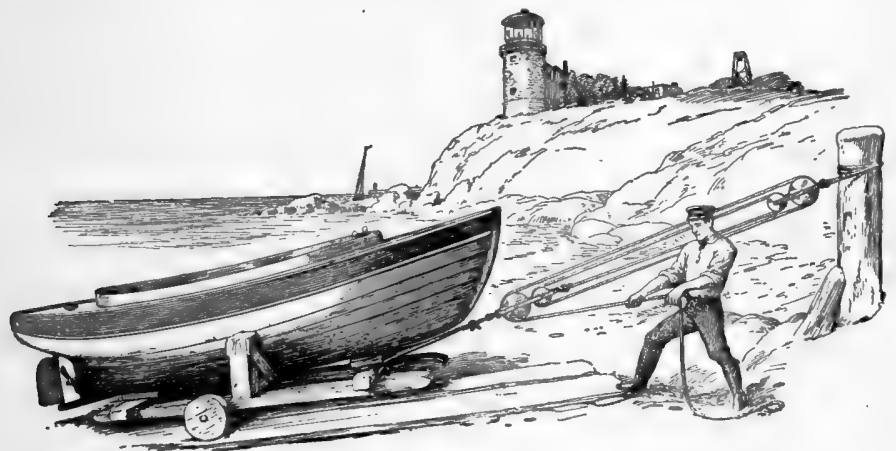

Fig. 88. The use of pulleys

By the use of pulleys, rope, and wheels one man may move a much greater weight than he could by pulling directly upon the object

the use of simple machines. There are several sets of appliances which might serve his purpose, but let us suppose that he has at hand some boards, rollers, rope, and two pulley blocks, each of which contains two pulleys.

The most convenient arrangement the boy could make would be to lay boards on the beach, with the rollers ready to support the boat, attach one pulley block to the boat and the other to a tree or post, and thread the rope through the pulleys as represented in figure 88 . The boat could then be moved along the boards by pulling on the rope.

192. Decreasing friction by the use of rollers. Everyone knows that if he were to attempt to slide the boat along the 
board, he would find a great deal of resistance. Even if the boards were horizontal, instead of sloping up the beach, we should find that it would take a great deal of force to move the boat. We also know that this resistance, which would be found if any attempt were made to slide the boat over the board, is found whenever one surface is moved in contact with another surface, and that this resistance is called friction. If the surfaces are very smooth, as in the case of a skate which slides on ice, the friction is very small, but it is not wholly wanting. Friction is due mainly to the fact that surfaces are never perfectly smooth and the little irregularities tend to catch on each other and thereby resist the force which is moving the objects. The friction on the board would be so great that there could be little hope of moving the boat. When one object rolls over another, there is also some friction, but rolling friction is very much less than sliding friction. The boy would therefore place rollers under the boat in order to reduce the friction as much as possible. He could not get rid of friction entirely.

We may speak about perfect machines (machines without friction) and calculate just what results might be obtained from such machines, but we must always remember that no frictionless machine can be constructed.

193. Some facts about pulleys. Questions must certainly arise regarding the advantage of using rope and pulleys either in moving a boat or for other purposes. Anyone who has observed the use of pulleys, as when a building is being moved through the street or when a piano is being moved to an upper floor of a house, has probably noted that the load is moved more easily by their use. It is also noted that the load is not moved rapidly. Ability to move a greater load is an advantage, but the slow motion is often a disadvantage. It is important for practical use of pulleys that one should know precisely the relation between the force exerted and the load moved, as well as understand the accompanying rate of 
motion. It is only by the performance of experiments with pulleys that these questions can be satisfactorily answered.

We might arrange a set of small pulleys and cord similar to the arrangement for moving the boat, but employ them for lifting a weight. It will be noted that in this arrangement, as shown in the figure, the hanging, or movable, pulley is supported by 6 strands of cord (fig. 89). If one experiments with this apparatus, it is immediately discovered, first, that the force exerted by the apparatus in lifting the weight is much greater than the force applied to the free end of the cord, and second, that the weight moves a much shorter distance than does the hand which is pulling at the end of the cord.

If the distances are measured, it will be found that the hand travels 6 times as far as the weight in the case of the pulley system so arranged that 6 strands of cord are supporting the weight. A measurement of the force applied at the end of the cord will show that it is a little more than one sixth of the amount which must be applied to the weight in order to lift it. There is, of course, some friction in the apparatus, and if care is taken to reduce this as much as possible, it will be found that the force applied is very little greater than one sixth of the weight lifted. We may conclude that

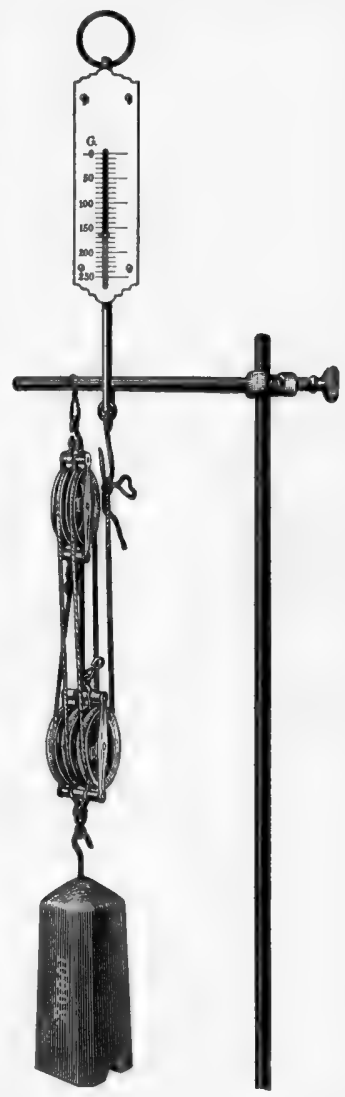

Fig. 89. Pulleys and cords The pull on the cord is measured by the spring balance. The weight of the load is divided between strands of cord by which it is suspended. Disregarding friction, the pull on the spring balance will be one sixth as great as the pull exerted by the load 
if friction could be wholly eliminated, we should find that the ratio of the force applied to the weight lifted is 1 to 6 .

We find, therefore, that in the particular pulley system which we have been studying, the applied force must move six times as far as the weight, but that if friction is neglected, it need be only one sixth as great as the resistance of the weight. With different combinations of pulleys the ratio might not be represented by the number 6 , but it would always be equal to the number of strands supporting the weight.

194. Mechanical advantage of pulleys. The advantage in the use of pulleys lies in the fact that by their means a small force may be made to overcome a great resistance. This advantage is measured by the number of times which the force exerted against the resistance is greater than the force applied. In the case considered in the preceding section, the mechanical advantage was 6 . The mechanical advantage of a pulley system may be determined very readily, for it is always equal to the number of strands of rope which are supporting the weight or other resistance.

195. Work and pulley systems. If the boy uses rope and pulleys to pull the boat out of the water, he does not escape the necessity of doing work in order to move the boat, for he must pull on the rope. Likewise, the pulley system does work upon the boat in moving it up the beach. We may call the work done by the boy in pulling on the rope the work in, and the work accomplished in overcoming the resistance of the boat and the friction on rope and pulleys will be called the work out.

The part of the work which is performed in moving the boat is the useful work, while that wasted in overcoming friction in the pulley system will be known as the wasted work.

We now arrive at a second problem in our study of pulleys. We have learned that the force which the boy applies is less than that which is exerted upon the boat; but is the same true of the work that he puts in and the work that he gets out? 
Before we can solve this problem, we must agree upon a definition of work and upon some means of measuring it.

196. Work defined. It is always necessary to be sure that we mean the same thing by the words we use; therefore we define work. We say that work is done when force is used to move an object any distance; as when a box is lifted from the pavement into a wagon, or when a weight is pulled across the floor. Pushing the lawn mower, sweeping, pumping water, shoveling coal, are all forms of work, and in each case force is used to make something move against resistance.

We must guard ourselves against the error of thinking that work is done when there is no motion; as, for instance, when the boy pulls on the end of the rope, but not forcibly enough to move the boat, or when a person stands still and holds a heavy object in his hand. In these cases it would be absurd to speak of work being done, for in fact nothing is being accomplished, and at the end of a period of time everything is just as it was at the beginning. In these cases there is effort but no accomplishment, and therefore no work is done.

197. Measurement of work. If a force of 1 pound is exerted in moving an object through a distance of 1 foot, it is plain that a certain small amount of work has been done. This amount is called 1 foot-pound, and this is the unit of measurement. If the distance is increased 2,3 , or 4 times, the amount of work accomplished is increased proportionally. Likewise, the increase in resistance and therefore in force exerted is accompanied by a proportional increase in work. Thus, if 1 foot-pound of work is done in lifting a pound weight 1 foot, it should be clear that 3 foot-pounds would be accomplished if the distance were 3 feet; and if in the latter case the weight were 2 pounds, the work done would be 2 times 3 footpounds. That is, we calculate the work by multiplying the force by the distance.

198. Calculation of work in pulley systems. We may now calculate work in and work out in the case of the pulley 
system used in moving the boat, in which case 5 and not 6 strands of cord are used. If we suppose that a pull of 500 pounds was necessary to move the boat, and that it was moved 50 feet, the work accomplished was 25,000 foot-pounds, since useful work, or work accomplished, equals resistance overcome (500 pounds) times distance through which resistance was overeome ( 50 feet).

We know that the applied force acted through a distance 5 times as great as the distance the resistance was moved, and its distance was therefore 5 times 50 feet, or 250 feet. We know also that the force which it was necessary to apply in order to overcome this resistance was one fifth as great as the resistance (neglecting friction). It was therefore 100 pounds. Calculating the work done by the applied force through the distance of 250 feet, we find it to be 25,000 foot-pounds. This is exactly the same as the work out, as found above. We conclude, therefore, that if there were no friction in the machine, we should get out of the machine just what we put into it.

It has been pointed out in a preceding section that there can be no frictionless machine. We must therefore include friction in our calculations. It is clear that the resistance due to friction would be added to the resistance offered by the boat. The pull on the end of the rope would need to be greater than 100 pounds in order to overcome both types of resistance. The work in would be correspondingly greater. If it were necessary to pull with sufficient additional force to make the total applied force amount to 125 pounds, the total amount of work done upon the machine would be 125 times 250 foot-pounds, or 31,250 foot-pounds. These relations may be tabulated as follows:

FOOT-POUNDS

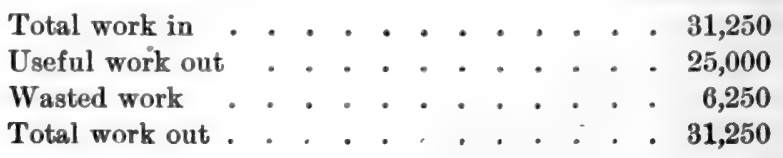


The total work out is in this case and in all cases the same as the total work in. Useful work out is less than total work in.

199. Efficiency. The proportion of wasted work will not always be the same as in the problem above. If the machine is very carefully constructed, the friction may be so reduced that there is very little waste. Such a machine is said to be very efficient, since it does its work with but little waste.

The efficiency of a machine is measured by the fraction of the total work done upon it which appears in the useful work accomplished by it.

$$
\text { Efficiency }=\frac{\text { useful work out }}{\text { total work in }} \text {. }
$$

In the particular case which we have been considering, the efficiency is calculated as follows:

$$
\begin{aligned}
& \text { Efficiency }=\frac{25,000}{31,250} \\
& \text { Efficiency }=\frac{4}{5}, \text { or } 80 \text { per cent. . }
\end{aligned}
$$

200. Summary. The principles which have been developed in connection with the study of the pulley apply to all machines.

Work is equal to force times distance. There is no work without movement.

Force applied times distance equals work in.

Resistance times distance traveled equals useful work out.

Useful work out is always less than work in.

Total work out equals total work in.

Machines do not increase work; they only transmit it. 


\section{CHAPTER XVII}

\section{MECHANICAL ENERGY AND HEAT}

201. Capacity for doing work. In all the experiments with the system of pulleys which you may have performed in connection with the preceding chapter, you yourself applied the

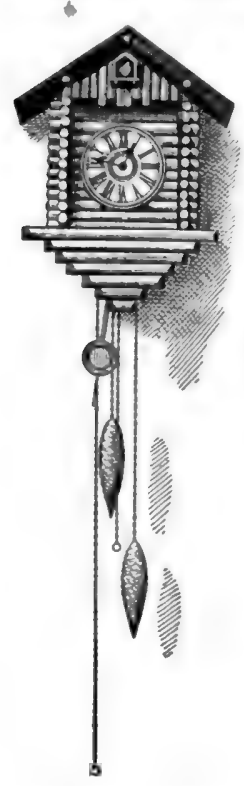

Fig.90. A clock run by weights force, since you pulled at the end of the cord. You might have obtained the same results in another way. You might have attached a weight of some sort to the end of the cord, and if this were of the proper size, it would, when released, descend and cause the load carried by the movable pulley to rise. It requires work to raise the load, and it therefore follows that the weight upon the end of the cord is able to do work. Also the pull upon the cord might have been sipplied by an electric motor or by a steam engine. In either case the weight, the motor, or the engine demonstrates that it has the ability to de work. This ability, or capacity, to perform work is called energy. 202. Examples of bodies possessing energy. The energy possessed by a weight in a condition similar to that in our last example is utilized in clocks which are run by weights (fig. 90). In this case, when the clock is wound, the cord is wrapped on a small windlass and the weight is lifted to the top of the clock. In this position it possesses energy enough to turn the wheels of the clock for some time. When the weight has reached the bottom of its 
descent, the clock must be wound again. Most modern clocks are driven by coiled springs, and in this case it is the tightly coiled spring that possesses energy. A sled coasting downhill possesses energy, as may be observed if it strikes any other object on the way; a cannon ball possesses energy, which is expended upon objects in its path; a moving hammer possesses energy, which may be utilized in driving a nail.

203. Kinds of energy. The weight in the clock possesses energy because of its position. When it is wound up and is suspended upon the cord, it is able to descend, and in doing so it will do work in turning the wheels of the clock. When the cord is unwound, it is not in a position to do further work. The energy which it possessed was dependent upon its position. The same is true of the bent spring, which possesses energy by virtue of the position of the parts of the spring in relation to each other. This energy of position is called potential energy.

On the other hand, the cannon ball does not owe its energy to position at all, but to the fact that it is moving rapidly. It is the moving cannon ball and not the stationary one that is effective for purposes of destruction. The hammer and the sled also owe their energy to motion. Energy of motion is called kinetic energy.

204. Measurement of energy. Since energy is simply the capacity to do work, it can be measured in the same units as those which are used to measure work. Energy is measured in foot-pounds.

A 5-pound weight at a height of 2 feet possesses 5 times 2 foot-pounds of energy, since in order to place it there a force of 5 pounds had to be applied through a distance of 2 feet. Thus the energy which a body possesses is in general equal to the work which has been done upon it.

205. Work against friction produces heat. It is a common experience that when work is done against friction, heat is produced. Anyone who has attempted to break a wire by 
bending it back and forth has had occasion to know that it becomes very hot at the place of bending, and the harder and longer one works, the hotter the wire becomes. The same thing results from hammering a nail, and a saw becomes much heated when in use, particularly if there is much friction. If a wheel is allowed to run for some time without oil on the axle, the latter becomes very much heated. A match is lighted by the heat which is produced by friction when it is rubbed on a smooth surface. In all of these cases work is done, and a part of its result appears only in the form of heat.

206. Energy transformed into heat. Careful studies have shown that in cases like the above the amount of heat developed is in proportion to the amount of energy lost in overcoming friction; that is, it is proportional to the amount of wasted work. In lifting a weight by means of pulleys a part of the energy which is exerted at the end of the rope goes to the direct raising of the weight and makes its appearance in the form of potential energy in the weight which has been lifted. But not all of the energy which was applied to the machine can be found in the weight. You may have noticed in the calculation of work done upon a pulley system that the work out is less than the work in. The difference between the work put in and the work taken out measures the work which was necessary to overcome friction and which has resulted in the formation of heat. Careful studies have shown that the amount of energy lost and the amount of heat produced are proportional to each other.

207. Work done by heat. Most of us have noted that a steam engine, such as a railroad locomotive, must be supplied with water and coal. There are some kinds of engines which are so equipped that the escaping steam is condensed and returned to the boiler, and in this case water need not be supplied excepting to replace leakage. Thus the water is a permanent part of the machine and not a source of energy. The coal is quite useless unless it is burned under the boiler and supplies 
heat to the water in the boiler. The coal is therefore only a means of supplying heat, and heat from any other source would be just as effective; that is, if only heat is supplied to the boiler in sufficient quantity, we shall be able to get work out of the engine. Work may produce heat, as when we hammer a nail, and heat may produce work, as in the case of the steam engine.

We have shown that heat has the ability to do work; but ability to do work is the definition of energy; therefore heat is a form of energy, and work may be transformed into heat as well as into other forms of energy.

208. The steam engine. The machine which is commonly called a steam engine really consists of two principal parts - the steam engine proper and the boiler. The engine and boiler may be very closely connected, as in the railway locomotive, or they may be located at a considerable distance from each other, as in some manufacturing establishments or on board ship, where they are usually in different rooms. In the boiler, water is changed into steam by means of the heat supplied by the fire in the furnace. This steam is conveyed through a pipe to the parts of the engine, where the energy is changed from heat into the mechanical energy of moving parts.

The more important facts regarding the structure and operation of a simple engine may be understood by referring to the accompanying diagram (fig. 91). The essentials of a steam engine are a cylinder $C$, containing a tightly fitting piston $p$, together with some means to control the admission of steam into the cylinder. The piston is free to move from end to end of the cylinder, and as it moves, the connected piston rod $r$ moves with it. With the parts in the position indicated in the diagram, if steam from the boiler is admitted through the pipe $s t$ into the steam chest $S$, it will pass through the channel ch into the cylinder. Here it will exert pressure upon the piston and drive it to the other end of the cylinder. Steam which may have remained in the opposite end of the 
cylinder from the previous stroke escapes from in front of the moving piston through the channel $c h^{\prime}$ under the slide valve to the exhaust pipe $e$, which leads into the open air or into a condenser. A working engine is so arranged that when the piston reaches the position indicated by the dotted lines, the slide valve $s$ is moved into the position indicated by the dotted lines. This, it should be noticed, hinders the steam from passing into the right-hand end of the cylinder, while at the same time it admits it to the opposite end. The pressure of the steam on the other side of the piston drives it back toward

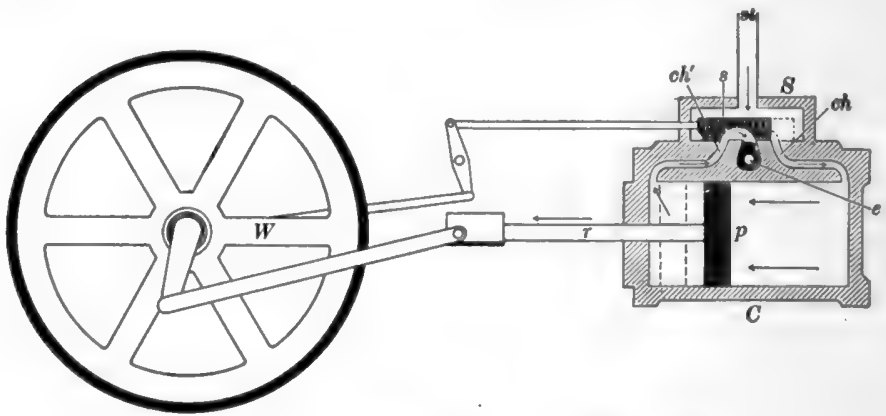

FIG. 91. The working parts of a steam engine

$W$, flywheel; $C$, cylinder; $S$, steam chest; $s t$, steam pipe from the boiler; $c h, c h$, passages for steam between steam chest and eylinder; $s$, slide valve; $p$, piston; $r$, piston rod; $e$, exhaust pipe

the end of the cylinder from which it started. When the piston again reaches the end of the cylinder, the slide valve returns to the original position, and this action is repeated for each stroke of the piston.

The moving piston may be connected to machinery which is to be operated. The work which is done by the piston upon the machinery is derived from the steam as it expands in the cylinder. The steam which leaves the exhaust outlet, having parted with some of its energy to the piston, is no longer as hot as it was when it entered the cylinder. 
209. Transformations of energy. There are other forms of energy besides heat and mechanical energy, but we shall not discuss these at any great length. Both electricity and light are forms of energy, and potential or kinetic energy may be transformed into heat, light, or electric energy. The steam engine, together with some of the machinery that it may drive, furnishes a good illustration of the many possible transformations of energy. Let us suppose that our engine is driving a dynamo, and that the electric current which the dynamo generates is employed in operating a number of lights. In that case we may start with energy in the form of heat contained in the steam. In the engine cylinder a portion of the energy is imparted to the moving piston, and this energy no longer appears in the form of heat. This energy in the moving piston is transmitted to the dyramo, and there it is transformed into a current of electricity. We therefore speak of an electric current as a form of energy. The current is passed through a lamp in which it gives off its energy in the form of light and heat. This energy passes off into the surrounding space and is usually lost to us.

210. Loss of energy. The amount of heat and light energy that is secured from the lights which may be operated by the dynamo is not at all equal to the amount of heat energy that was produced by the coal burned in the furnace. It may be no more than 5 per cent of the total produced by the coal. Plainly there has been a very great loss somewhere in the route that the energy has traveled in passing from the furnace to the light. This is not difficult to find. A great deal of heat goes up the chimney, some radiates from the boiler and engine into the air, and some passes off in the exhaust steam. In these and other ways the steam engine wastes possibly 85 per cent or more of the energy produced by the coal. Of the energy actually utilized by the engine some is lost by friction in the engine and dynamo, showing itself in the form of heated bearings, and some is lost through the heating of 
the wires by the currents of electricity. Notice that in all these cases of lost energy the energy is not destroyed. It changes into some form in which it is not useful to us (usually into the form of heat which may warm the surrounding air), but it has not gone out of existence.

There is no way known by which we can destroy energy.

There is no way known by which we can create energy.

211. The source of energy. Since there is no way in which we can create energy, where does the energy come from which we are all the time using and allowing to escape from us?

Perhaps this question may be best answered by taking

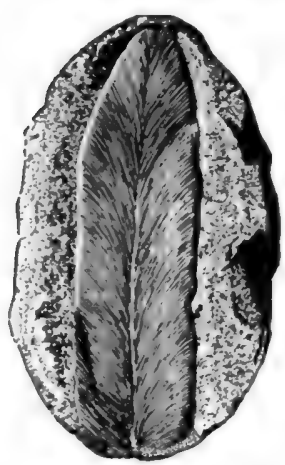
some energy-using machine as an example and tracing back the energy as far as we can toward its source.

We will take a trolley car for ex. ample. It is operated by electricity.

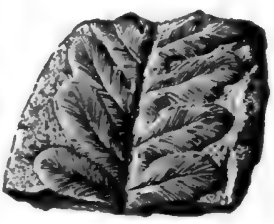

Fig. 92. The remains of ancient plants

These fossils are found in rocks associated with the coal beds

The current is generated by the dynamo, which is run by a steam engine. The engine secures its energy from coal. Plainly the coal contains energy, and we must find out where this energy came from.

Those who have made it their business to examine into the origin of coal tell us that it is formed of the remains of plants of former ages. The plants grew and their dead bodies accumulated in great abundance in some places, somewhat as plant materials are accumulating now in our peat swamps. These swamps were buried by sediments which later became rocks. The plant material was buried far enough to be affected by the heat in the interior of the earth, and it was under great pressure from the rocks lying over it. All these things caused it to condense into a solid, stone-like mass which does 
not at first look much as though it were made up of dead plants (fig. 92). The story of the origin of coal is a very interesting one, but we cannot take it up now.

Of course, if there is energy in the coal, it must have been in the plants from which the coal was made. That seems all the more probable, since we know that we can burn wood to make steam about as well as we can burn coal. Indeed, wood is still sometimes used as fuel under boilers. Where, then, did the plants get the energy? Where do they get it now? Do you remember that when we were studying about how plants make their food, we found that they could do so only when they had light? We called light the power that ran the factory. That may have seemed rather fanciful at the time, but it is literally true. By means of the energy that comes to it in the form of light, the plant is able to separate the carbon from the oxygen of the carbon dioxide and to build up those complex compounds from which its body is constructed. When we burn the wood, oxygen again unites with the other elements to form carbon dioxide, water, and other compounds, and, most important to us, the energy that was put into the compound is released in the form of heat.

The sun, then, is the source of the energy which we find stored up in wood and in coal. If we were to take any other example and trace back the energy, we should in all cases arrive at the sun as the last term in our series. The sun is the great source of the world's energy. The sun is the engine that runs the trolley car.

212. Amount of energy from the sun. Some careful studies have been made to find out how much energy the earth receives from the sun. It is believed that the amount is equivalent to more than $200,000,000$ horse power for each inhabitant of the earth. It is this continual supply of energy from the sun that maintains the temperature of the earth's surface, evaporates water, causes convectional air currents, and provides the energy for photosynthesis. Since the earth is continually 
giving off heat to the surrounding space, it is continually losing energy. The part of the sun's energy which is stored up in plants and animals, or used in evaporating water, supplies most of the energy which is used by man in accomplishing his work. This is probably not more than the one thousandth part of the whole. It has been estimated that enough energy falls upon the deck of a steamship in tropical regions to propel it at a rate of several miles per hour if there were some way in which all of this energy could be made useful. There have been many attempts to construct "solar engines" which should use this supply of energy directly, but so far none of them has been very successful.

Of course, only a small part of the energy given off by the sun comes to the earth, -1 part in 2,000,000,000, - and therefore the sun must be giving off energy very rapidly. Perhaps its supply of energy is growing less, but it is so big that the loss has not been great enough to be noticed during the short time that men have been making careful observations. It seems certain, however, that the sun must finally lose so much energy that it will not be able to continue to give off as much heat and light as it does now.

213. Energy and work in living things. Many of the instances of work which have been given in the preceding chapters are examples of work accomplished by living beings. If you climb a flight of steps, push a lawn mower, or saw a board, you are doing work; you are expending energy. Even when you are sitting still or when you are sleeping, there is some expenditure of energy, for the heart continues to beat, you continue to breathe, and heat is radiated from your body. The lower animals expend energy in similar ways. Plants too use energy, for they open and close their flowers, move their leaves, lift large quantities of water from the soil to the leaves, and engage in many other activities. Everything is expending energy as long as it lives. Energy is supplied to living things through food somewhat as energy is supplied to a steam engine 
through the agency of the coal which is put into the furnace. Since the origin of foods can be traced back to the manufacture of carbohydrates through the aid of the sun's energy (Chapter VII), it is not difficult to see that the sun is the ultimate source of energy for all the activities of living things. This matter will be taken up again in connection with our study of the nutrition of plants and animals. 



\section{PART IV. THE EARTH'S CRUST}

\section{CHAPTER XVIII}

\section{NATURAL FORCES UPON THE SURFACE OF THE EARTH}

214. The surface of the earth. In previous studies both land and water have been discussed in connection with other topics. It is a matter of general knowledge that approximately two thirds of the earth's surface is water and the rest is land; or, to state it differently, about two thirds of the solid surface of the earth is covered by water. The water has different depths in different places. The floors of oceans and lakes, like the uncovered land surfaces, are undulating in nature. Sometimes whole mountain ranges and the intervening valleys are covered by the same body of water.

Conspicuous irregularities in the land surfaces are easily noted in mountain regions, and even in the most level plains some irregularities in the surface appear. Such unevenness may be abrupt or gentle in slope, and its nature often gives the distinctive character to a region.

In places the surface is readily seen to consist of solid rock (fig. 93), and solid rock may be found anywhere if the surface material is penetrated. For example, the area upon which the city of Chicago is located varies from places where solid rock lies bare upon the surface to places where the sand and clay must be penetrated more than 100 feet before solid rock is found. It is thought that ages ago, when the earth's surface was newly exposed, the surfaces were all solid rock. A study of how the present conditions have developed presents most interesting questions. In some parts we find good soil and abundant natural vegetation; in others, rich garden soil 
which makes our commercial gardens possible; in others, un. drained swamp lands; and in still others, sand and bare rock. How have these regions come to be as they are?

215. The surface and water. If the eartl's surface were perfectly level, water which falls upon it would not flow off in any definite direction. With the unevenness that exists, water runs from higher to lower levels, except where absorbed and held by the surface materials. Thus, in the development of the earth's surface, water has accumulated, making pools

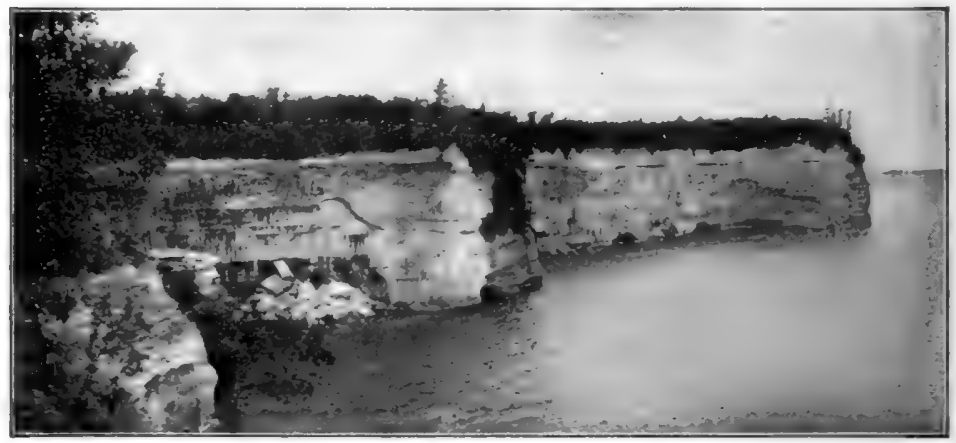

Fig. 93. The solid rock

Solid rock may always be found at a relatively short distance from the surface. Here the layer of soil is particularly thin. (Presque Isle, Michigan)

in some places, lakes in others, and oceans in others. Where water runs over the surface of the earth it follows the depressions until it finally comes to a place of so low a level that it 'no longer flows. When the difference in level is great enough between two places which are near one another, water runs rapidly from one to the other. If the difference is abrupt, a waterfall is formed. Falling water wears away the hardest rock if the falling continues long enough. Not only does the water itself wear the rock upon which it falls, but many large and small pieces of rock are carried by it, and these add greatly to its cutting power. The wearing power of water will be discussed more fully later. 
216. Work by freezing water. When water falls upon rock surfaces, some of it may enter crevices in the rock. When water freezes, it expands, and its expansive force is very great. Alternate freezing and thawing may break the rock into smaller and smaller pieces. An interesting experiment upon the effect of freezing water may be made by filling a

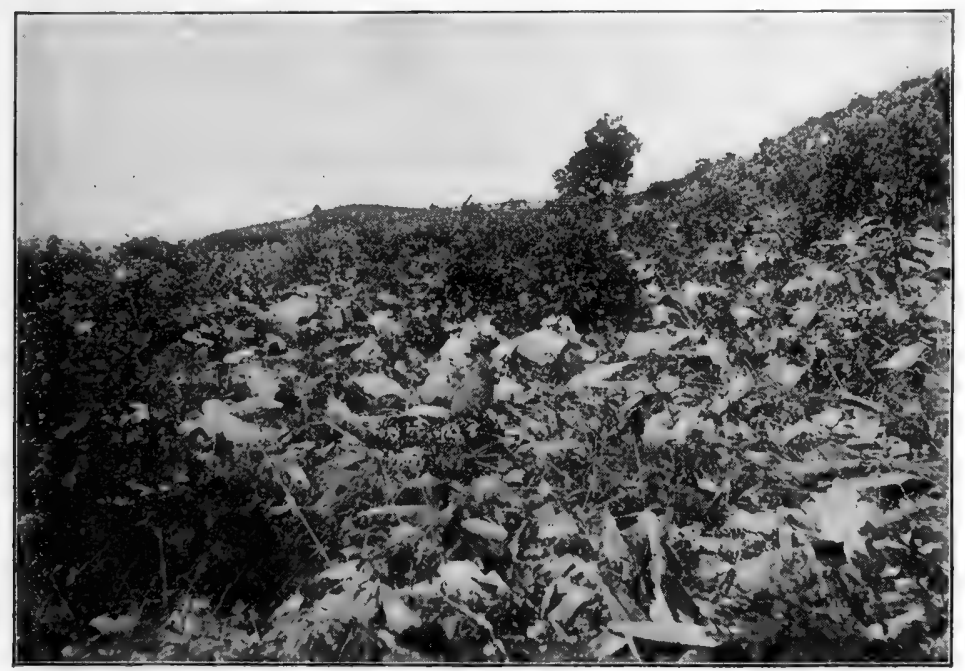

FIG. 94. The results of frost action

A mountain field strewn with rock which has been broken, principally by frost. (Alleghany Mountains in Pennsylvania)

strong metal cylinder with water, plugging the ends of the cylinder tightly, then placing the cylinder where the water will freeze and carefully noting the results.

Along rocky cliffs where water runs into crevices and freezes, one may often observe its effects in breaking up the rock (fig. 94). Tons of rock may be pushed aside a short distance by the expansive force exerted through the freezing of a small amount of water. When we think of all the small crevices in rock into which water may run and afterwards 
freeze, we may imagine the enormous amount of work that is done in breaking up rock. These broken pieces help to make the soil.

217. Other changes due to water. Rock often contains substances, as lime, salt, or sulphur, which may be taken up in solution in water. If water has filtered for a long time through rock which contains soluble substances, the rock is made porous by the removal of these substances. Great caves, as the Mammoth Cave, Kentucky, have been made in this way. If the water is heated (as sometimes occurs within the earth's crust) or if it contains acids, its dissolving effects are much greater.

Streams and waves of water are also important factors in disorganizing rock. In streams, stones are rolled, turned, and ground over one another and constantly worn thereby. In swift-flowing mountain streams very large rocks are torn from their positions and rolled over and over, and often carried down to levels where the current is not so swift. From the large rocks smaller pieces are broken and then are.carried down the stream to places where the current is much less swift than where the larger rocks are left. From the mouth of a stream to its mountain source, soil and rock particles furnish an index of the carrying power of the stream, and this carrying power indicates the wearing power of the stream. Many of the finer rock particles may be carried by the stream until it reaches the large body of water into which the stream empties - sometimes the ocean. When streams overflow their channels, there is an abundant deposit of fine soil particles that were carried by the water.

Along the shores of lakes and in the riffles of streams there may constantly be seen the process of wearing rocks into smaller and smaller particles. Also, this same action of the water sorts the materials into the different sizes, and one may find these sizes assorted in definite regions as he passes from the shore into deep water. 
Many beds of rock have been disorganized and much soil made through the different kinds of water-action upon rocks.

218. Glaciers and the earth's crust. In former times glaciers were important agencies in changing the earth's crust, and in some places their work is still going on (fig. 95). The glaciers

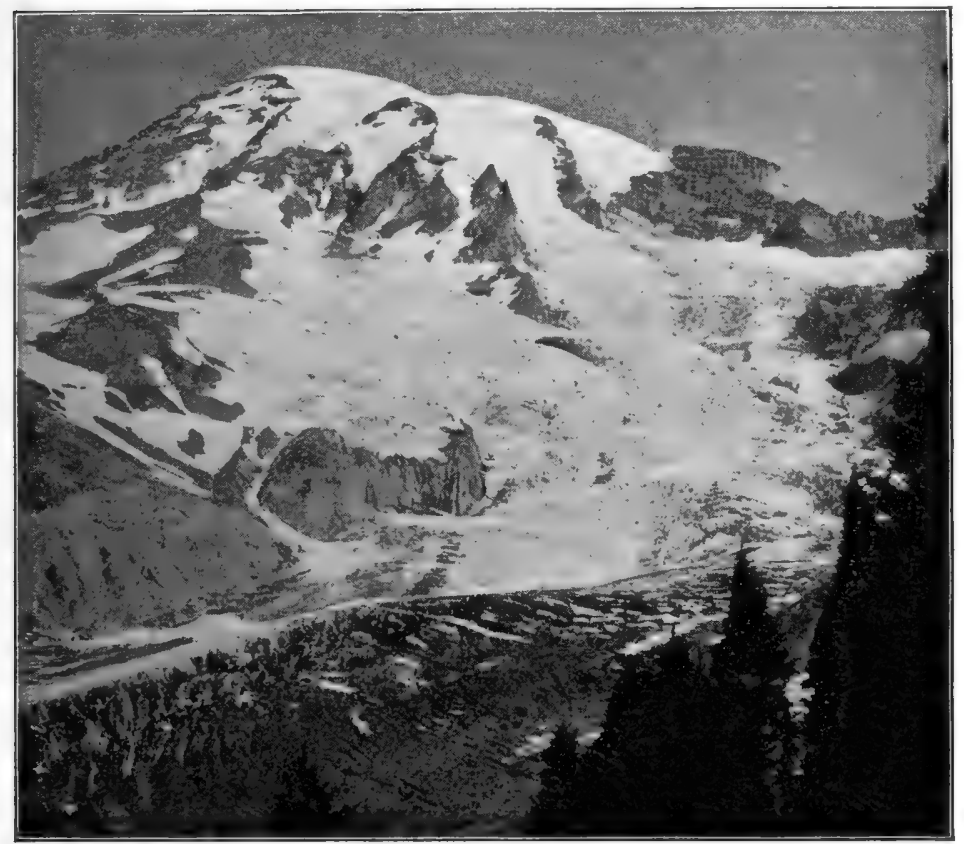

Frg. 95. A valley glacier

A glacier on the slopes of Mount Rainier. At the lower end the ice is covered by the broken stone which it is carrying. Photograph by Dr. G. E. Nichols

have been formed by tremendous accumulations of ice, which fell as snow and then by pressure of its own weight became ice. Ice, like water, flows toward places of lower level, though it flows very slowly. As it moves it may grind or tear away the rocks in its path and carry the fragments along with it. Often these rocks are ground over one another, and marks or 
scars are left as evidence of their contact and the force which acted upon them. When the temperature becomes warmer or when the glaciel reaches a place of warmer temperature, the ice may melt, thus leaving the rock and sand that were carried (fig. 96). The melting ice forms streams which, as they flow from the slacier, carry away some of the solid material.

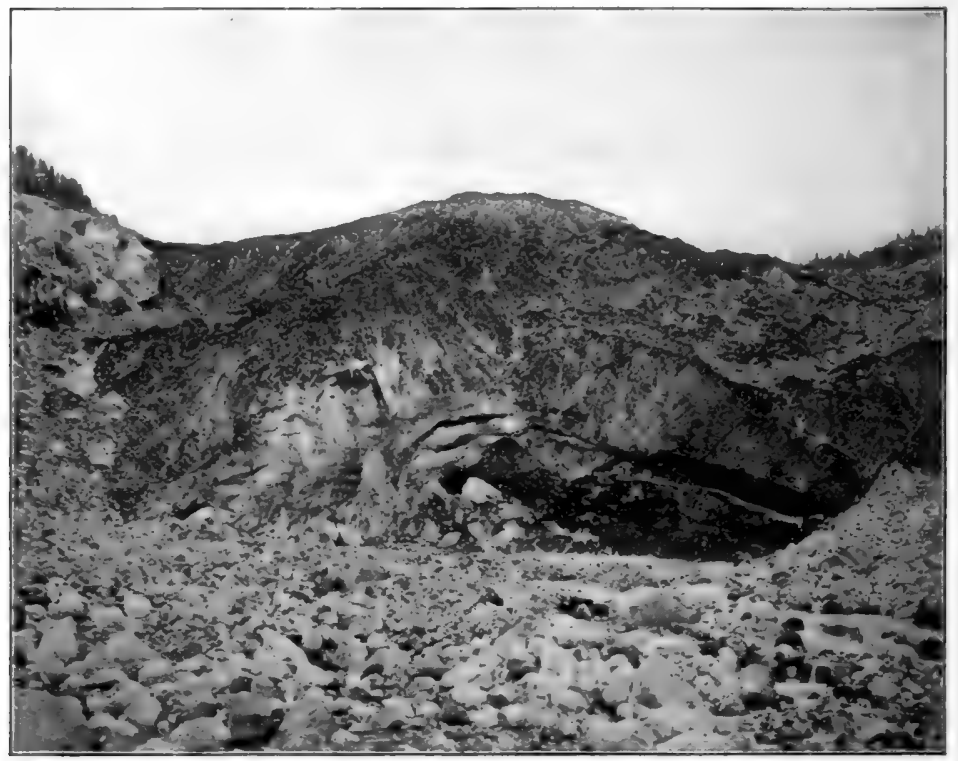

FIG. 96. The end of a glacier

The ice is covered with stones and gravel. In the foreground is an accumulation of the material which has been brought down by the glacier. Photograph by Dr. G. E. Nichols

Much of North America (fig. 97) was once covered by glaciers, and we still have many evidences of the tremendous effect they have had upon the surface and upon the soil formation. Much of the richest soil of the central United States was brought to its present position by glaciers. A study of the maps of Illinois, Iowa, etc. will show that the so-called corn belt is of glacial origin. 
219. Effect of plants and animals. When the roots of plants grow into crevices of rock, they often exert sufficient force to split it (fig. 98). Many lowly plants, as lichens and mosses,

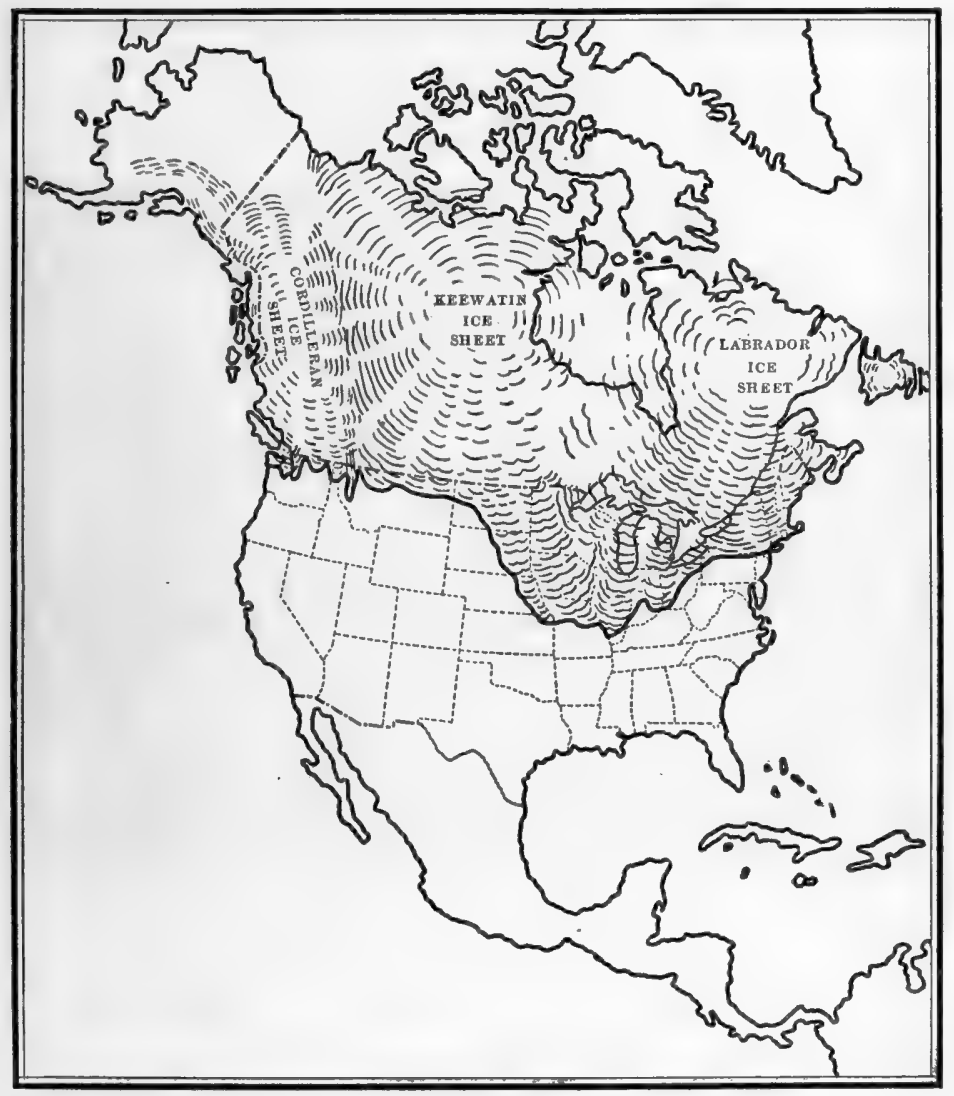

Fig. 97. The continental glacier

The map shows the extent of the continental glacier in North America. After United States Geological Survey

grow upon the surfaces of rock, and the organic products (acids) formed by them assist in disintegrating the rock. Animal and plant bodies contribute much to soil formation. 
220. The soil and its significance. It is customary to speak of the soil as including the top layer of earth material. The term is sometimes nsed to apply to whatever earth materials there are upon the solicl rock. In agriculture and gardening the term applies to the more nutrient layer in which plants grow.

The soil is the natural growing place of most plants and many animals. 'The roots of plants are usually embedded in

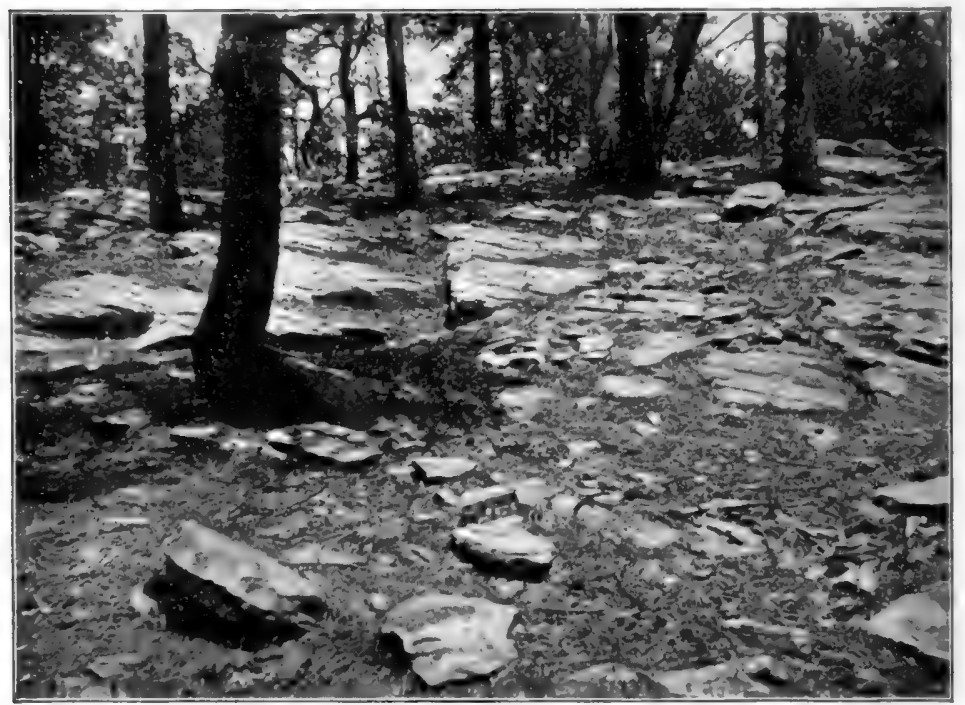

Fig. 98. Action of plants upon rocks

The roots of plants enter crevices and break the rock. Here there is not enough soil to cover the rock, and the pine trees are rooted in the sandstone. (Mogollon Mountains, Arizona)

the soil. In the case of many plants the stem is also underground, as is true of the dandelion, plantain, parsnip, and radish. Plant roots spread more or less in the soil, sometimes many feet from the rest of the plant, and may also descend to considerable depths. From the soil these roots secure various substances. The soil serves not only as a source of supply of food materials, but also gives anchorage to the plants whose 
roots are embedded in it. Many animals also live in the soil, and all of them are dependent directly or indirectly upon the plants that grow within or upon the soil. Animals burrow in the soil, as the earthworm, the gopher, the fox, and the hedgehog, and thereby secure food in the form of plant roots or decaying organic matter, or secure homes that furnish them a measure of protection from enemies or from extremes of temperature.

All must have noted the fact that the soils of different regions may vary widely, as well as the plants and animals that live upon or within the soil. What are the differences of these various soils, and what are the common elements in them? 


\section{CHAPTER XIX}

\section{PHYSICAL STRUCTURE OF THE SOIL}

221. Kinds of soil. If we examine a handful of the soil from near a lake shore, we may find it chiefly composed of sand. Sometimes this sand is coarse or gritty and sometimes almost as fine and smooth as flour. Near the water's edge quite coarse sand may usually be found. Back from the lake, where plants are growing abundantly, the sand is discolored and contains the results of decay of plant and animal bodies. Where decayed organic matter is abundant, the soil is called loam. In some streams of water along the riffles small stones are found in large numbers, and more or less sand is mixed with them. This material is gravel, and a soil in which such material predominates is gravelly soil. Often by digging only a little way down we find a soil which is composed of very fine and compact material — so compact that when moist it may be pressed into balls which will hold together when thrown with great force. This is clay. "Silt" is the name applied to the fine, rich soil that is deposited by currents of water. It is commonly deposited on broad bottom lands at times of high water. In low, swampy ground, plants may grow in great quantity and fall down year after year. Their bodies partially or completely decay and become pressed into a porous soil known as peat. It must be obvious that these different kinds of soils may be found mixed together in various ways; indeed, it is seldom that any one of them is found unmixed with one or more of the others. Thus we have sandy, clayey, or gravelly loam, or a peaty soil in which a little clay, sand, and gravel are mixed. There are many names for the various combinations and grades of soils. 
222. The structure of the soil. If pure coarse sand is examined under Inagnification, it is readily seen to consist of many small rock particles. Some are flattish, others are cuboid or oblong, some have sharp corners, and some are well rounded. The surfaces of these small particles of rock are glistening and glass-like. In fact, glass is made by melting pure sand so that the silica of which sand is composed flows together in a solid mass (for articles on glass-making see the encyclopedias). An examination of sand of different degrees of coarseness readily shows that the difference is due to variation in the size of the rock particles of which the sand consists. In sand that is fine enough to be blown by the winds the particles are usually so small as to look like dust, but upon magnification their rock-like nature appears.

Clay consists chiefly of extremely small particles which fit together so as to make a compact soil - so compact that, when quite dry, pieces of this soil are sometimes said to be "as hard as rock." A high power of magnification is required in order to distinguish the smallest rock particles in clay soils. Mixed with the finest clay particles we sometimes find sand, peat, or gravel, the result being sandy, peaty, or gravelly clay.

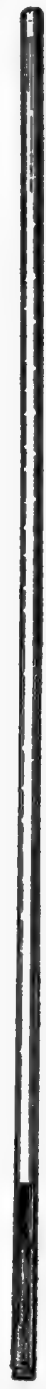

FIG. 99. Soil particles

Particles assorted by settling long in water. Gravel at bottom; fine sand and silt at top 
We may therefore have many gradations in soil : from finest clay to coarse clay, from finest sand to coarse sand, and on to coarse gravel and even to rocky soil (fig. 99); from sandy or clayey soil with but a slight amount of decayed organic matter to peat in which there is little or no clay or sand. In nature these soils are found in all possible mixtures. A careful study of the table giving the structural analysis of different types of soils will enable you to learn a good deal about how soils may be mixed, and also about the size and percentages of the different component parts.

223. Size of soil particles. Careful measurements have been made of the actual size of the particles of different kinds of soils; also of the percentage of air space in these different kinds of soils. The following table presents these data for a few types:

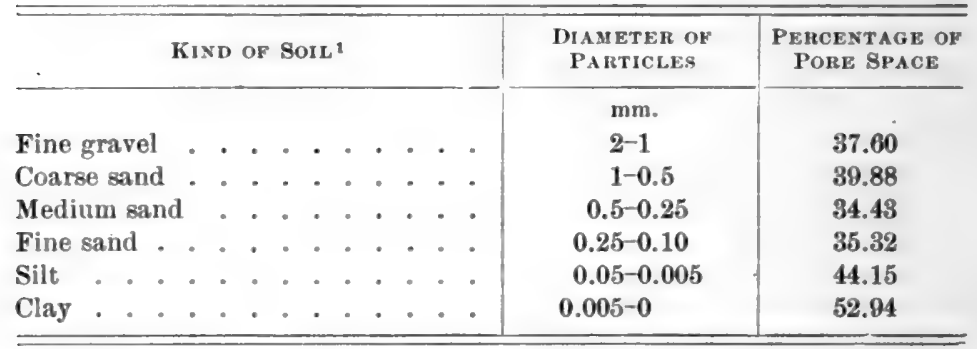

224. Plants and animals as soil formers. In sand upon which plants have grown for a year or more, magnification will usually show, in addition to the sand, some of the remains of plant roots, stems, or leaves, although these may have decayed to an extent that makes it difficult to recognize their origin.

When peat is examined under magnification, little or no sand is seen, but this soil consists of the more or less divided particles resulting from dead plant and animal bodies. Peat

1 King, F. H., Physics of Agriculture. 
is so nearly pure plant material that when dry it makes a fuel of importance in some parts of the world, and it is cut from the earth in brick form, dried, and sold in the markets. Sometimes peaty soils get afire and may burn slowly for weeks or even months.

While rock particles are the basis of most soils, these particles alone would furnish little support for animal and plant life. As already shown, dead plant bodies may accumulate so as to produce almost pure plant material in the form of peat. In deep woods we have another illustration of the deposition of plant material in large quantities. Leaves, twigs, and stems of plants fall and decay, thus forming a layer rich in humus, in which luxuriant growths of plants are found. All soils, to be fertile, must have some humus in them, and one of the great problems of modern agriculture is to supply by natural or artificial means the organic matter that may decay and produce the needed humus in the soil.

The influence of earthworms in soil formation is often very large. They eat their way through the soil, thus making burrows. In their bodies digestive fluids are added to the soil that has been eaten, and when voided from their bodies, the soil is changed so that its fertility is increased. Also, the burrows of the earthworm provide added opportunity for air to enter the soil - a matter of much importance. A garden with many earthworms in it is likely to be a rich garden.

225. Raw materials for plant food. There are numerous elements that plants need in order to grow well. The most important of these are carbon, oxygen, hydrogen, nitrogen, iron, phosphorus, and potassium. The carbon is obtained from the air in combination with oxygen in the form of carbon dioxide, which is found in ordinary air in the proportion of approximately 3 parts of carbon dioxide to 10,000 parts of air. All the other elements are secured from the soil, where they appear in various combinations. Obviously a soil is fertile that has an abundance of the needed substances and that 
does not hold other injurious substances, as plant poisons, which do sometimes exist in the soil. Very little is known about plant poisons in the soil, but recent investigations show that some plants excrete substances which may be injurious to them, and possibly to other plants. Much attention is now being given to problems of soil fertility.

Water is one of the most important substances of the soil. Plants use water directly as a raw material for food manufacture, and they also use other materials which are secured from the soil only when they are dissolved in water. If water were absent from the soil, plants would starve; and if there is too much water, some plants will drown from lack of air. 


\section{CHAPTER XX}

\section{SOIL WATER, DRAINAGE, AND IRRIGATION}

226. Amount of water in the soil. It is commonly observed that coarse, gravelly soils do not hold water for a long time and that fine soils do. If a series of glass tubes are filled with soils of different degrees of coarseness, and the same amount of water is poured into each, it will be noted that less flows out from the finer soil. Why is this? Water may be held in the soil in either of two ways: it may adhere closely to the surfaces of the soil particles, in which case it is known as water of adhesion, or it may be free between soil particles (fig. 100), when it is known as free water. Most of the free water may flow away if there is adequate outlet for it, but adhesion water is not easily removed.

Obviously the more surface exposed, the more water may be held by adhesion. In the finer soils much more surface is exposed than in coarse soils. This may be illustrated readily by measuring the exposed surface of a cube, then cutting

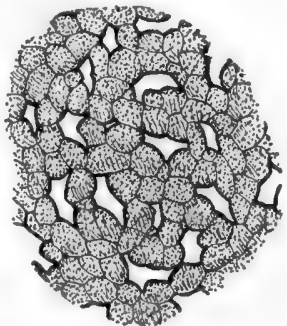

Fig. 100. Distribution of soil moisture

Diagram to represent soil particles, each covered by a film of water. In wet weather or immediately after a rain all the spaces might be filled with water the cube into many small cubes and measuring their surfaces and comparing the last measurement with the first. A special student of soils, F. H. King, says: "Suppose we take a marble exactly one inch in diameter. It will just slip inside a cube one inch on each side, and will hold on its surface a film of water 3.1416 square inches in area." If, however, we reduce the diameter of the sphere "to one thousandth of an inch, it will require $1,000,000,000$ of them to completely fill the cubic 
inch, and their aggregate surface area would be 3141.59 square inches." In the coarse silt the surface area of the particles reaches an astonishing figure, since in 1 cubic foot of such soil the particles would have a surface area of $\mathbf{3 7 , 7 0 0}$ square feet. So large a surface area makes possible a large water content in such a soil. In some kinds of clay 100 pounds of the wet soil may contain 40 pounds of water, or 40 per cent of the whole weight. Since 1 cubic foot of clay ordinarily weighs about 80 pounds, 40 per cent of it, or 32 pounds, might be water. These facts make clear the tremendous differences in the water-holding power of soils.

227. Soil water and soil temperature. Anyone who has walked back and forth along the lake or ocean shore while in bathing has noticed differences in the temperature of the soil, and any well-trained gardener who desires to grow early spring vegetables selects what he calls a "warm soil." What do these things signify? Soil which is very wet changes temperature much more slowly than dry soil (sect. 157). The water of the soil, being at lower temperature than the air above the soil on a sunny spring day, makes the soil feel cold. If in the hot summer weather the soil may be cultivated in such a manner that the water will be held in it, the soil will not become so hot and will therefore be a better living place for plants.

228. Amount of water used by crops. From the calculations given it is evident that some soils may contain much water, but it is also true that large amounts of water pass off from the soil by evaporation and that plants take large quantities of water from the soil. Growing plants are constantly carrying water through their roots, stems, and leaves, using some of it in food manufacture but allowing most of it to pass off into the air. The following data show the average quantity of water used by three common farm crops:

Corn : 50 bushels per acre require 1,500,000 pounds of water.

Potatoes : 200 bushels per acre require $1,268,000$ pounds of water.

Oats : 29 bushels per acre require $1,192,000$ pounds of water. 
Professor King says that during the growing season, in producing a ton of clover hay, which after drying is $85 \%$ dry matter, 375 tons of water are carried into the air either through the plant or by evaporation directly from the soil. There may often be a yield of more than 2 tons of clover hay to the acre, but assuming it to be 2 tons, the amount of water taken from the soil to make the crop is equal to more than 6 inches of rainfall. It is estimated that a rainfall of almost 10 inches is used in producing a crop of corn of 50 bushels per acre. What amount of rainfall is there in your locality during the growing season?

229. Soil water as affected by tillage. The ways in which farm and garden soils are cultivated has much to do with their water-holding capacity. When water evaporates from the surface of compact soils, the water from below, if there is any, immediately comes to the surface. Water passes readily through relatively solid soils.

If an extremely fine-drawn glass tube is placed with one end in a dish of water, the water will rise some distance in the tube. This is known as capillarity. The fine spaces between the walls of the soil particles act as capillary tubes, and the soil water passes upward if the soil is compact so that spaces are continuous.

The action of the soil may be illustrated by use of a piece of compressed sugar. Touch one end of the lump to a liquid and the liquid soon goes through the entire lump. In the same way in dry weather compact soils lose their deep soil water through evaporation. Another experiment with two lumps of sugar will suggest a method of cultivating soils so as to hold moisture. Allow a second lump to lie loosely upon the first, which just touches the liquid, and the liquid will pass into the second very slowly if at all. The so-called capillary connections within the lumps of sugar are not continuous between the two; there are no continuous lines along which the water passes. In the same way constant surface cultivation of the 
soil keeps the capillary spaces broken, and water does not pass upward through the soil rapidly. If the soil is deeply plowed at the beginning of the season and thoroughly cultivated on the surface throughout the season, there is (1) a reservoir for catching water and (2) a device for preventing its rapid evaporation.

230. Natural drainage of the soil water. Water may be drained from soil by surface drainage or by underground drainage, and either may take place naturally or artificially. When rains or snows leave more water on the soil than the soil will absorb, it flows away toward regions of lower levels. When very heavy rains fall in a short time or when snow that lies upon frozen or rocky soil thaws rapidly, the run-off may be very great. When rain falls slowly, the soil will take up quantities so large that, if it had fallen in a brief time, floods would have been produced. Surface drainage naturally results in making streams of water, which flow together, finally forming a large stream which may by means of its tributaries drain many hundreds of thousands of square miles. A river system is a natural system of soil drainage.

Under the surface the water also flows toward a lower level, and these subterranean currents may sometimes open to the surface as springs or natural wells, or open directly into the watercourses and thereafter augment the surface streams. The level at which water stands (fig. 101) beneath the surface (the water table, as it is called) varies in its depth below the surface in different regions. The deep clay and rock layers of the earth are often undulating, and the water table conforms to these undulations. For example, in digging a well for domestic supply of water one farmer reached the water table and secured an abundant supply at a depth of 16 feet. Another farmer less than half a mile away had to dig down 48 feet before he secured water. Underground water may exist in layers of rock or clay. Artesian wells are usually made by boring into deep layers of water, but they are 
bored in such a location as to strike the water in the lower parts of the layer, so that the pressure from the higher portions of the same layer will cause the water to rise to the surface. Sometimes this pressure is sufficient to cause the water to rise many feet into the air.

231. Artificial drainage of soil water. Much of the surplus water of the soil will naturally drain downward to the water table, but agricultural plants grow better when by artificial drainage as much water is removed as will readily flow into underground drains. The advantages are probably at least fourfold: surplus water is removed, the soil is better aërated, the soil becomes warm earlier in the season, and injurious

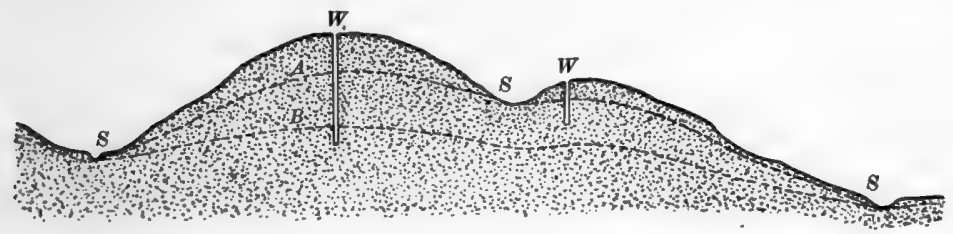

Fig. 101. The water table

Diagram to represent the water table in a series of hills and valleys. Line $A$ repk resents the position of the water table in wet weather; line $B$, in dry weather; $S$, springs; $W$, wells

soil substances excreted from plant roots may be removed as surplus water passes downward. If you will plant two jars of seedlings, one in a well-drained glass jar and the other in a jar without drainage, and give them the same amount of water, you will see some of the advantages of soil drainage.

232. Irrigation. In many parts of the country the annual rainfall is too small or is confined to so short a period of the year that there is not sufficient water in the soil to enable plants to grow. There are many hundred thousand acres of soil the composition of which is favorable to the growth of plants, but which are deficient in water. Various devices are used for irrigating some of these lands, with varying degrees 
of success. There are in the United States (fig. 102) over $10,000,000$ acres of artificially watered lands, and projects under construction will add much to that figure. There are

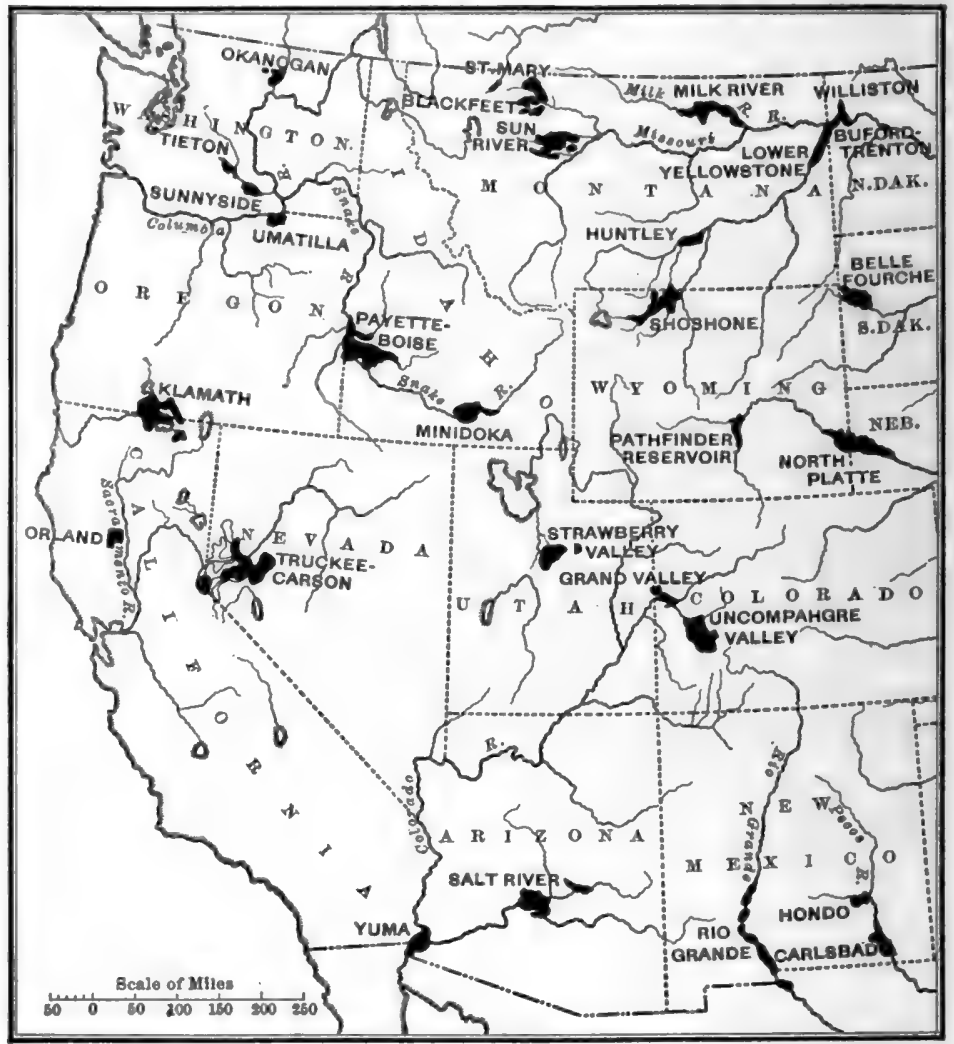

F1G. 102. Irrigation in the United States

The map shows the location of the more important government irrigation projects. There are in addition many other areas irrigated by government, private, and state enterprise. From map by United States Reclamation Service

several methods of irrigation, but that along the banks of the Rio Grande River may serve as a type. In the lower stretches of this river the annual rainfall is quite low, but a large 
volume of water comes from the mountainous country hundreds of miles away in Mexico and the United States. In the lower Rio Grande valley there is much rich alluvial soil, needing only water to make it fertile. Hundreds of miles of ditches have been constructed to direct the water from the river to the land. A main canal, looking like a river, carries water

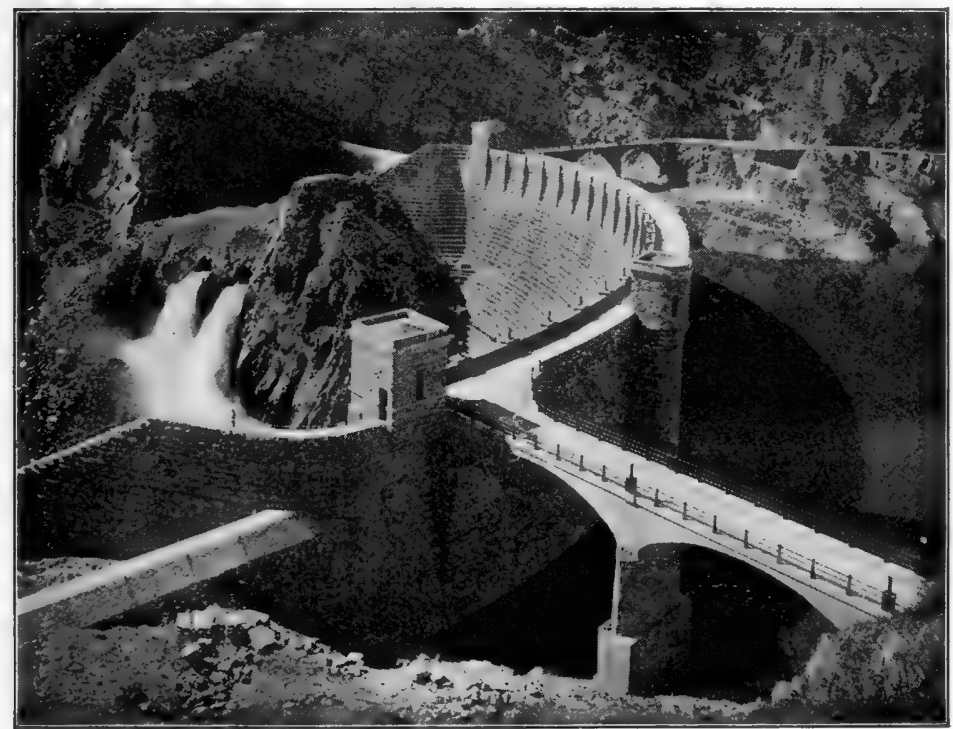

Fig. 103. An irrigation dam

The Roosevelt dam on Salt River in Arizona is 280 feet high and 1080 feet long. The water which it holds back forms an artificial lake with an area of 25.5 square miles. The impounded waters will be used to irrigate 190,000 acres of land. Photograph by United States Reclamation Service

in one case for more than 100 miles. From this main canal smaller ones branch off, and finally the smallest ditches run to the individual farms. Floodgates are used in turning water upon the fields when it is needed. In this way, with an abundant supply of water and with constant sunshine, a rapid and luxuriant growth of plants is made possible. 
It must not be forgotten that underground drainage is advantageous for other purposes than the removal of surplus water, though even at times irrigated farms need it for that purpose also. The failure to introduce underground drainage in irrigated districts is now beginning to prove a limiting factor in the production of plants, and doubtless such drainage will soon become usual in irrigated lands.

233. Source of water for irrigation. The larger part of our irrigation projects consist in diverting mountain streams into nearby valleys. Sometimes streams are dammed (fig. 103) either to assist in diverting the water or to store the water for later use. Tunnels have been made through mountains, and elevated aqueducts have been built over valleys to carry these mountain streams. In some regions irrigation by the use of deep wells is practiced. Water is pumped into reservoirs, and from these it is led off through ditches to the fields. In case of rivers which flow through flat valleys, the water is sometimes pumped into irrigation ditches or into elevated reservoirs.

(Read a description of one of the larger irrigation projects and report upon it in class.)

234. Dry farming. In some parts of the United States there is an amount of rainfall which would give the soil sufficient water to produce a crop if evaporation could be prevented. In some such regions the experiment has been tried of keeping the soil under surface cultivation for a long time. First deep plowing is done, furnishing a deep soil for the absorption of rainfall. Then constant surface cultivation retains most of the moisture, and after a time enough moisture may thus be caught and held to make it possible to grow a crop. In some cases where this type of farming is done, the rains are so scanty that a crop can be grown only once in two years. Possibly some water may be drawn upward from the deep soil, but most of it must come from the scanty and infrequent rains. 
It is evident that dry farming requires much labor in order to put the soil in proper condition for the production of a crop. Even with these difficulties fine crops have been grown by dry farming, and when we consider the extreme cheapness of land in the dry-farming regions, the relative amount of labor seems well repaid in results. It must be said that dry farming is still somewhat in the experimental stage, and whether it is to be extended to cover other large areas where there is scanty rainfall cannot be safely predicted. In any event, there are large areas of dry land which receive no rain, or practically none, and these areas must look to some form of irrigation as the means of securing the water needed to make them productive. So far the limitations of irrigation are very great. The quantity and availability of the water supply have thus far limited irrigation to relatively small areas, though the total acreage seems large. Whether the Great American Desert is to be obliterated and become a most fertile region is largely a question of quantity and availability of water. There may be sources of water supply (deep wells or the air) not yet within the range of practicability, but these are for future developments. There is untold wealth in the soil of the arid regions for those who can put a good supply of water upon it.

235. Reclamation of swamp lands. The opposite of arid soils is found in such extensive areas as the undrained or poorly drained everglade swamps of Florida, the Dismal Swamp of Virginia and North Carolina, the swamps about our inland lakes, both large and small, and the overflowed areas along the lower stretches of our great rivers. The United States Geological Survey estimates that in this country there are over $100,000,000$ acres of undrained swamp land, much of which is drainable. Along the Atlantic coast alone there are estimated to be over $3,000,000$ acres of drainable soil. Often this kind of soil is the most productive, when it is properly drained. 
In the United States large drainage systems have been built that are in a way comparable to the irrigation systems. One removes the water, the other adds it. In the Everglades of Florida thousands of acres of fertile soil have been made tillable by the construction of large drainage ditches.

As people are coming to understand better the fundamental importance of the soil in the life of all the nations, they are making constant effort to render greater areas of arid and swamp soils available for the use of men in agriculture, horticulture and gardening, and as homes for men. 


\section{CHAPTER XXI}

\section{EROSION AND SEDIMENTATION}

236. Removal of the soil : erosion. When the formation of soils was being discussed, we spoke of the action of water upon rocks, gravel, and sand. We have but to look at a large

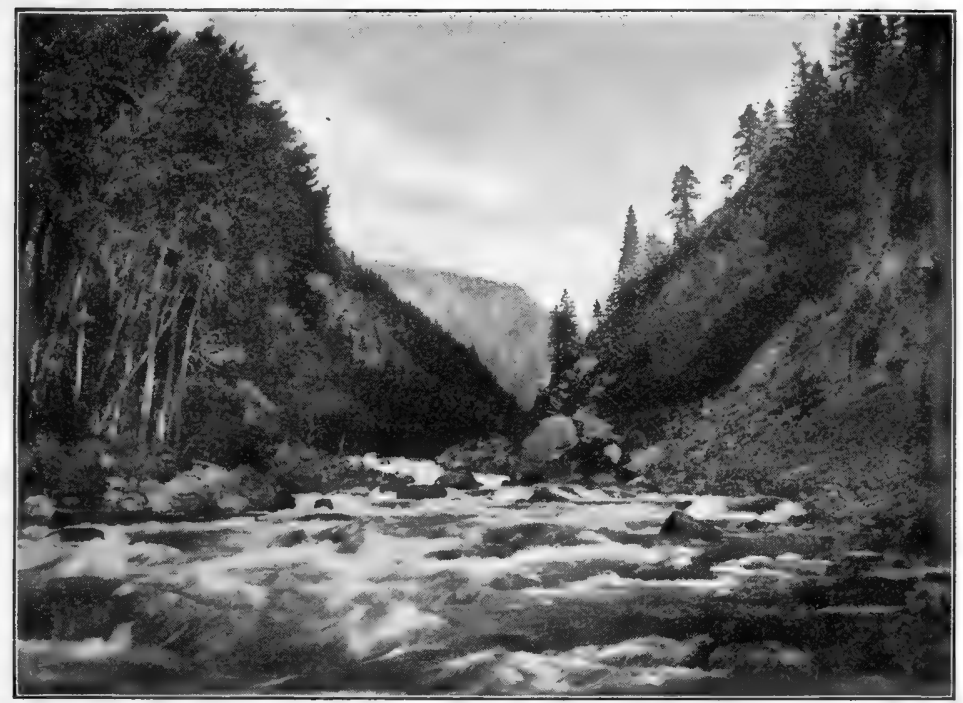

FIG. 104. Erosion by a stream

A swiftly flowing stream wears down its bed rapidly and forms a steep-walled valley. (Tumwater Cañon, Washington.) Photograph by W. B. MacCallum

river (fig. 104) or a gutter stream to get an idea of the power of water to carry soils. A study of a surface stream that is flowing from a field or garden will tell a good many things about erosion. First, the heaviest particles of soil that are moved are carried only by the strongest part of the current. 
This same part of the current may also carry all finer grades of soil material, but the slowest part of the current may be so very slow as to carry only the finest particles. If a dam is made across a very small stream, the heaviest materials are dropped where the current is first slackened, and some very fine material may not be dropped for a long time. If a tumbler

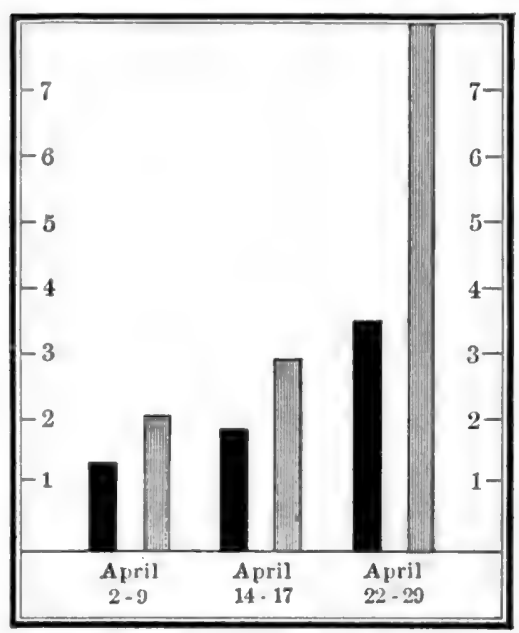

Forested

Fig. 105. Effects of forests upon drainage

Diagram to represent run-off from two similar areas in White Mountains, one of which has been deforested. The vertical bars represent in inches the proportionate run-off. Note that the forested area retains the larger amount of water. From data byUnited States Geological Survey of water which is laden with silt is allowed to stand, an estimate may be made of the time required for all the silt to settle to the bottom of the tumbler. This will show how long the water, if moving, might have carried silt.

If one digs up two squares of soil of similar size, but one bare and the other of turf, and both are then subjected to a stream of water from a hose, it will be seen that the turf withstands the running water much longer than does the bare soil. Erosion takes place less rapidly when soil is covered or when it is held by plant roots. The roots and the plants retard the water flow, as well as hold the soil.

In wooded regions, where there is much undergrowth and humus, the water from rain flows from the surface very slowly. In an open field the same rain will produce quite a stream. The stream upon the field is soon gone, and the surface becomes relatively dry. In the woods no stream appears for 
quite a time, and then it is small and lasts for a much longer time than that in the open field, and when the stream stops flowing, the soil of the woods is still very moist (fig. 105). The trees and undergrowth retard the falling rain. Humus acts as a sponge in holding large quantities of water, so that streams start slowly, and when they do start, the leaves, twigs,

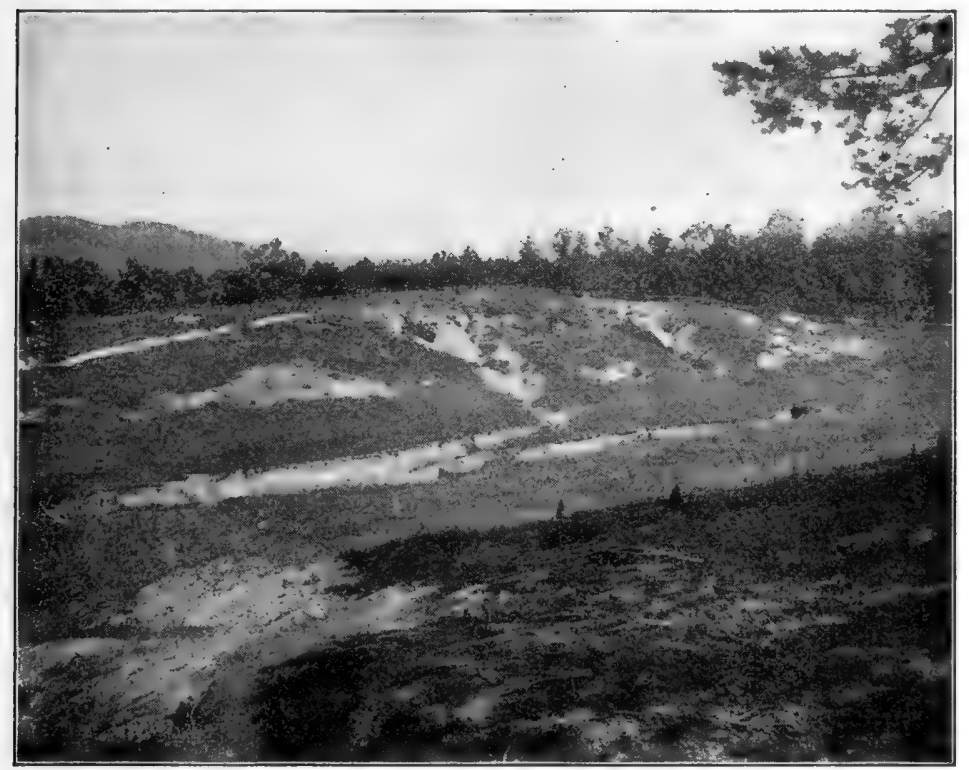

Fig. 106. Early stage in erosion of deforested field

Deep gullies have been washed in the hillside, but they do not extend into the adjacent forested area. Photograph by United States Forest Service

bushes, etc. retard the movement so that the ability of the water to remove soil and to carry it is held in check. The humus retains much of the moisture after the stream has stopped flowing. Furthermore, the covering of trees etc. tends to reduce the loss of water by evaporation. Compare the woods with the open fields and apply the facts to the question of erosion. 
237. Loss from water erosion. The damage done to soils by erosion is very great. 'The soil is carried away, the fields are cut into deep gullies, and often the owner of the soil realizes too late that the best part of his soil has passed entirely beyond his control (figs. 106 and 107). Obviously regions with hilly topography are more subject to erosion than level fields. Such fields will lose less of their soil if they

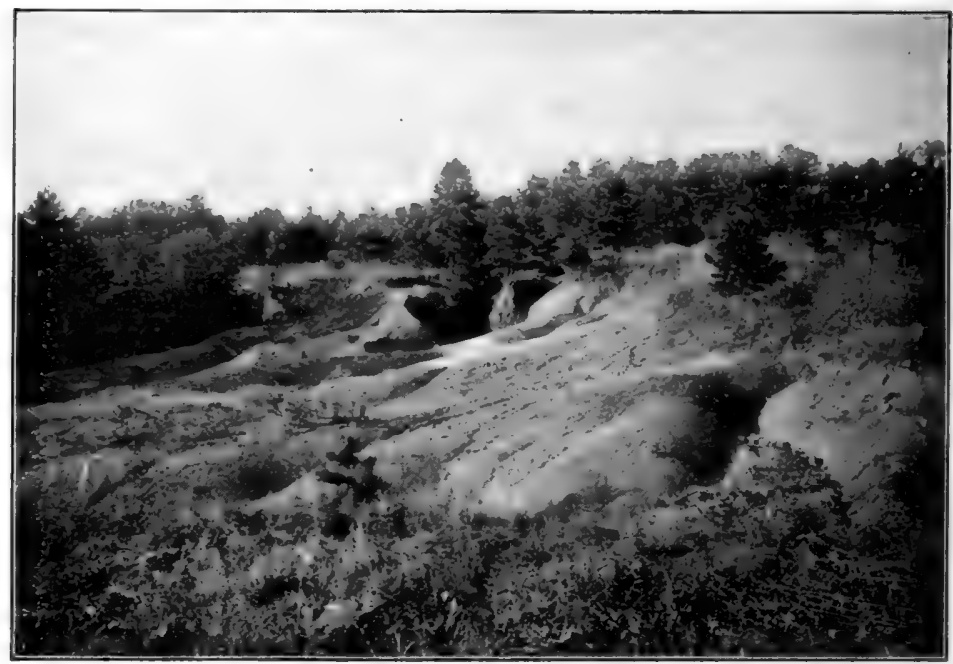

FIG. 107. A late stage in erosion of deforested area

The gullies have broadened until the whole of the original surface has been removed excepting where vegetation has protected it. Photograph by United States Forest Service

are kept planted in grass, as pasture or meadow, or in timber. (Why?) In some places where hilly land must be cultivated it is terraced around the hills in order to prevent erosion or to catch any soil that may erode.

The great importance of erosion of soils is suggested by the fact that the Mississippi River is estimated to carry over $1,000,000$ tons of sediment into the Gulf of Mexico every day, or over 400,000,000 tons per year. Professor Salisbury 
says: "It would take nearly 900 trains of 50 cars each, each car carrying 25 tons, to carry an equal amount of sand and mud to the Gulf. All the rivers of the earth are perhaps carrying to the sea 40 times as much as the Mississippi."

238. Vegetation and erosion. When visiting the banks of a stream which has recently overflowed, we usually find silt or mud deposited upon the plants along the banks. The more

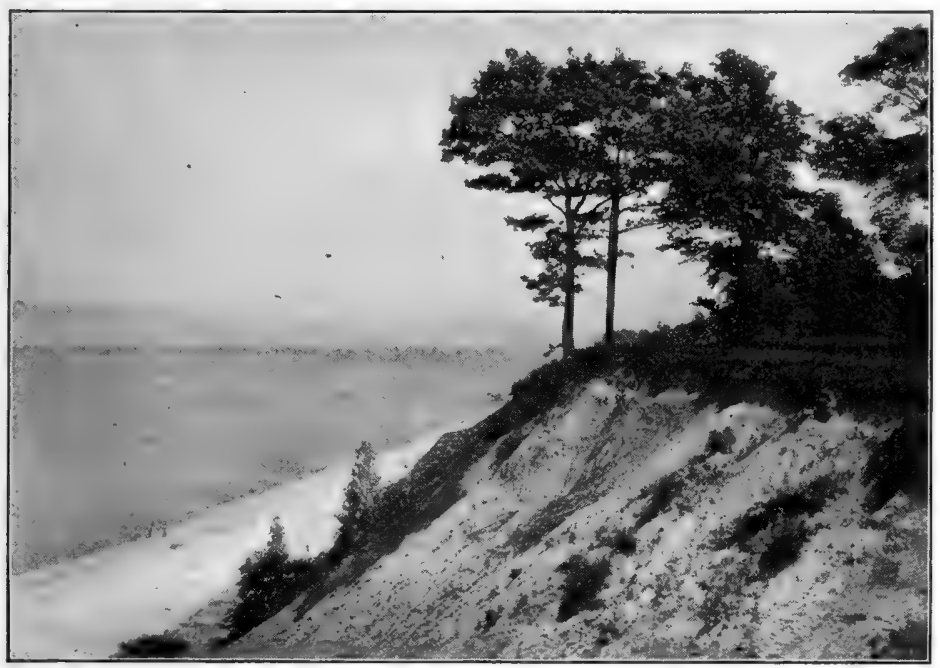

Fig. 108. Erosion by waves

The trees help to hold the soil against erosion by the lake

dense the vegetation, the larger the quantity of silt deposited. In many overflowed regions deep layers of rich soil have been built up through periodic deposits made in this way. Where the water of the stream is flowing rapidly, it can carry its load of silt, but when its rate of flow is reduced, it drops part of its load.

Not only does vegetation exert a strong influence upon the deposit of silt, but it also helps to prevent erosion (fig. 108). The parts of plants above the soil retard the flow of water, 
and the roots within the soil help to prevent the removal of soil. In many places one may see illustrations showing how water has been turned aside and the soil left where plant roots were well established. One of the most effective ways of preventing erosion along hillsides and stream banks is by in. troducing rapidly growing plants which help to hold the soil.

239. Deposit of soil from erosion. It is estimated that at least one third of the sediment carried by streams of water reaches the sea. The other two thirds is deposited in various ways. A study of a stream bank will almost always show the formation of deposits of gravel, sand, and silt. In times of overflow of the channel banks this deposit is large, but we must remember that erosion is also large at such times. When streams overflow, the velocity of the water is usually decreased and much of the load of soil is dropped. In this way large areas along the Mississippi River are annually replenished by the richest soil. Great dangers attend such overflow, however, and effort is made to prevent it by building strong dikes in the attempt to hold the river within the channel.

At the mouth of such great rivers as the Mississippi and the Yangtse the accumulation of sediment has built up great deltas. Much of the tremendous quantity of soil thus carried into the sea goes far from shore and doubtless sooner or later settles to the bottom to contribute its part to filling the ocean basins. Since this sediment has been eroded from the highland areas, it is evident that its removal from one place and deposition in another contributes slowly but surely to the processes of leveling the earth's surface.

In China part of the people near the mouth of the Yangtse River flood their fields at a time when the river is heavily laden with silt in order to replenish their soil. After the silt is deposited, the water is drained away. Untold wealth in soil is constantly being lost to the human race through erosion, and the problem of maintaining the fertility of the soil is annually made more difficult thereby. 
240. Erosion by wind. We have but to recall the dust clouds of windy days to see clearly that the air has a soilcarrying power, and if we will keep a moistened surface, as of a glass or a towel, in the dust-laden air for a few minutes we shall be able to get some notion of the quantity of this dust. Snow soon becomes colored by dust carried by the wind from places where the soil is exposed. The air is never

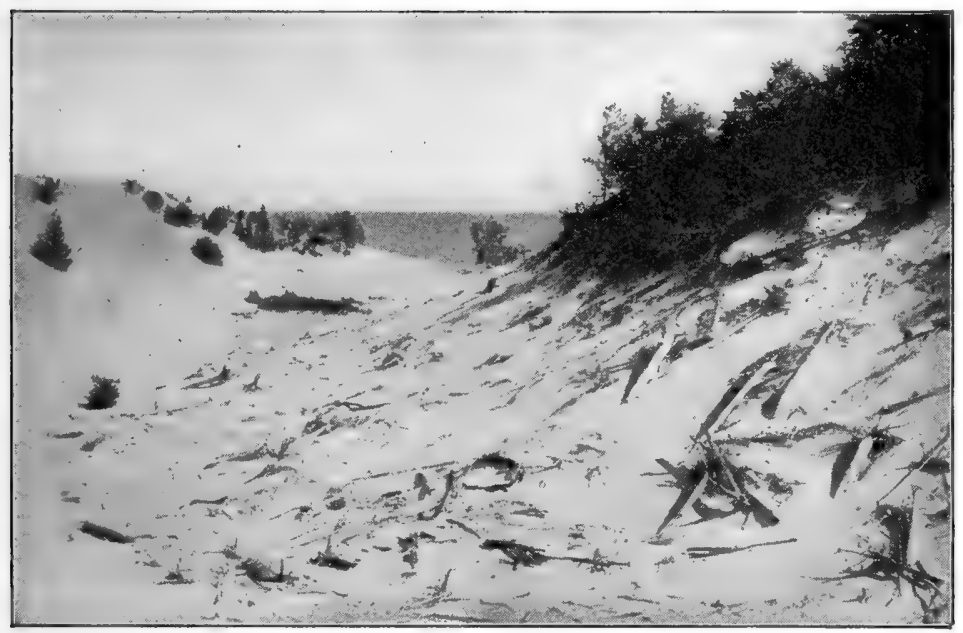

Fig. 109. Erosion by wind

The hill to the right, a sand dune, is being blown away in spite of the protecting cover of vegetation. At the left, sand is burying a group of trees

entirely free from dust. This air-borne dust is deposited everywhere, and in some places it has accumulated in immense banks known as loess.

Sand is carried by air currents, and, as in the case of water, the strongest air currents carry the largest pieces. Along the shores of lakes and oceans the action of wind-blown sand is readily seen (fig. 109). Sometimes it cuts the bark from trees and carves out the softer portions of large rocks. The finest sand may be carried great distances. 
In some regions the winds build dunes, or hills, of sand, those of coarsest sand near the shore and those of finest sand farthest away. Some of these dunes may keep moving inland (fig. 110) as sand from the windward side is carried over and dropped on the leeward side. A dune may thus migrate far inland, and with a change of prevailing winds it might migrate back to the shore or even into the lake or ocean. Sometimes vegetation gains a foothold on a dune, and plants may

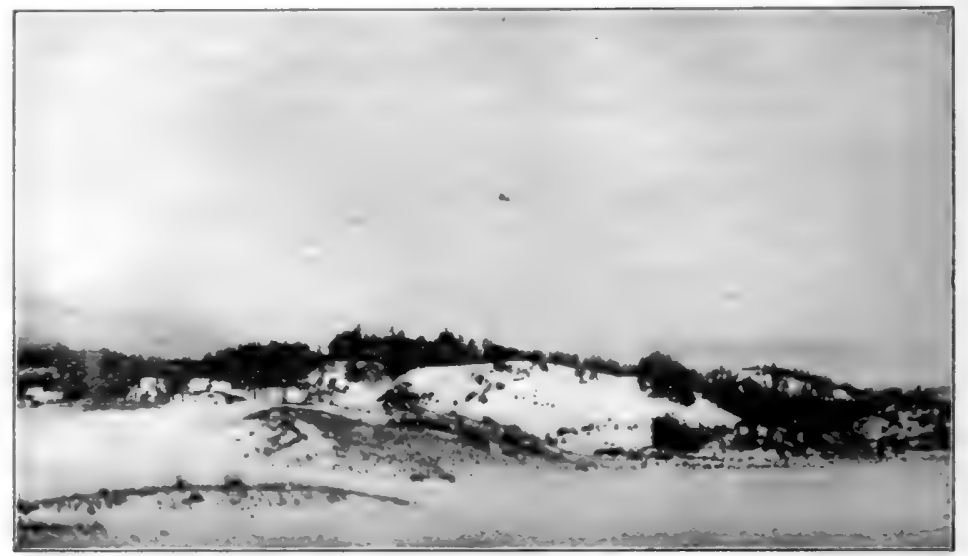

Fig. 110. A group of sand dunes

Trees, grasses, and other vegetation assist in accumulating and retaining the sand upon the dunes

live upon it for ages; then winds may again bring sand to the dune, cover the vegetation beyond the tops of the tallest trees, and later uncover all, and even remove the dune upon which they stood. A visit to dunes will usually enable you to gain some new notion of the wind as a factor in moving soils.

In some of our Western states, as Kansas and Nebraska, there are wide stretches of sandy soil which in some places forms dunes. On some of the cultivated land great annoyance is caused by the soil blowing when it is fresh plowed; at times the soil drifts along fence rows much as snow drifts in winter. 
The American Forestry magazine says: "When the sod is broken, the soil blows so badly that hundreds of 'nesters' who have tried to make a start in this region have moved out only when their fields have blown into the next section or county. On a bright day in spring in the sandhill section of Kansas, with what is known in that country as only a brisk wind, it is possible to locate all the plowed land for from 15 to 20 miles around by the dense clouds of sand that stand out against the blue heavens like pillars of gray smoke." 


\section{CHAPTER XXII}

\section{LIFE IN THE SOIL}

241. Living things in the soil. We have already mentioned some of the living things of the soil, but there are others, chiefly microscopic, which need further discussion. There are many small animals, as the earthworms already discussed, the larvæ of many kinds of insects, many adult insects, and many microscopic animals of the lower forms of life. In addition to the roots of living plants there are many kinds of lower microscopic plants, chief of which are the bacteria. These animals and plants live upon organic and mineral matter in the soil, and through their life processes or by means of their bodies when they die they are constantly contributing to the organic matter available for the growth of higher plants.

242. Interrelationship of living things in the soil. The different things living in the soil may prey upon one another quite as do things that live above the ground. The soil is often filled with a dense population of living things, some living upon mineral matter in the soil, some upon dead organic matter, some upon other living things.

An instructive illustration of the extent to which these interrelations may go is seen in the case of the roots of the corn plant and certain animals that may often be found upon or near these roots. Extremely small insects, known as plant lice, or aphides, bite into the tender roots of the corn and suck out the nourishing juices. These aphides are almost stationary animals and cannot ordinarily make their way from one plant to another without assistance. When well nourished, they excrete small drops of a glistening, sweetish solution sometimes called honeydew. This honeydew is an article of food 
for certain black ants which also live in the corn fields. It has been found that the ants will dig furrows down at the side of the corn plants until they can reach the roots, and will then carry the aphides and place them upon younger and more tender roots. When food for the aphides becomes scanty, they are moved to new plants. The aphides thus secure abundant food, and the ants secure the honeydew as their own food. Both are parasites upon corn, one directly, the other indirectly. Corn and grass are often killed by these animals, and the soil, rendered porous by the burrows, dries more rapidly than it otherwise would. This is but one of many illustrations of the interrelationship of animals and plants in the soil.

243. Bacteria of the soil. In connection with the discussion of bacteria those living in the soil were mentioned, but additional statements need to be made in this connection.

Bacteria are present in most soils in very large numbers. These bacteria are of very many kinds, and they affect the soil in many ways. Some of them live upon dead bodies or parts of bodies of plants and animals, and in so doing they change these things so as to increase the organic content of soils. As instruments of decay in the soil, bacteria and small animal forms are highly important. Different kinds of bacteria carry on different stages in decay. One group of them breaks up ammonia, forming nitrogen compounds that higher plants can use. It will be remembered from an earlier statement that nitrogen is one of the things essential to plant growth.

But there is another group of soil bacteria of peeuliarly striking interest. They are often found growing in great numbers in little nodules (or tubercles, as they are called) on the roots of clover, beans, peas, and other plants that are related to these. It has also been found that these tubercle bacteria are able to use nitrogen from the air of the soil and combine it with oxygen in such a way that higher plants, as corn, wheat, and oats, can then use it. One of the greatest problems in maintaining desirable fertility of soils consists in 
keeping the proper supply of nitrogen compounds. Plants other than these bacteria cannot use the free nitrogen of the air at all, but the tubercle bacteria use it, and in doing so combine it with oxygen, thus making it available to higher plants. Plants such as elover, peas, etc. do not grow so well when bacteria are not present on their roots, and the compounds of nitrogen that are needed for subsequent crops are not deposited in the soil.

244. Soils and man. Directly or indirectly we are all dependent upon the things that grow from the soil. In this sense we are all interested in the origin and structure of soils and in the maintenance of their fertility. In this country our ancestors had a rich, unused soil when agriculture began. It was so rich that they thought it quite inexhaustible. But already, in the parts of the United States that have been longest cultivated, soil has become so unpreductive that in some cases it is worth but little. The waste of one generation can be replaced only by the increased eare and intelligence of succeeding generations. There are now few problems of more consequence to the nation than the study and practice of methods of maintaining and increasing the productivity of the soil. Our national and state governments are annually spending millions of dollars in the study of this problem. 


\section{PART V. LIFE UPON THE EARTH}

\section{CHAPTER XXIII}

\section{THE PLANT COVERING OF THE EARTH}

245. Abundance of plants. In the preceding chapters there has been frequent reference to living things, and some of them, such as bacteria, have been studied. We must now give more attention to living things, for they are a very important part of our environment. Almost everywhere the surface of the land is covered with plants, if they have not been removed by man; and even where this has been done, man has usually introduced other plants to take the place of those he has removed. In countries with abundant rainfall they hide the earth so completely that the landscape is almost wholly green. Even in the desert there are few large areas without sufficient plants to give tone to the landscape (fig. 111). The "bare" rocks of either dry or moist countries are usually partly covered with the plants called lichens, and there are plants on the mountains close to perpetual snow. In the waters of the ocean, plants are found in great abundance. The only land areas of considerable extent which appear to be almost wholly devoid of plants are the interior of Greenland and the region about the South Pole, and these are covered with ice. Even here the surface of the snow may be colored by a small red plant belonging to the algre and commonly known as "red snow."

246. Variety among plant formations. The plant covering of the earth is not everywhere the same. Instead, there is infinite variety, and at first sight there seerns to be little system or order. The plants, however, do not grow altogether at 
random. Fiuch kind of plant needs for its growth certain conditions that may be partly or entirely different from the conditions demanded by other plants. For this reason any place in which the soil, moisture, temperature, and other conditions are favorable to one or a few kinds of plants is likely to be an unfavorable place for certain other plants. Thus, the hilltop which affords just the right conditions for the growth

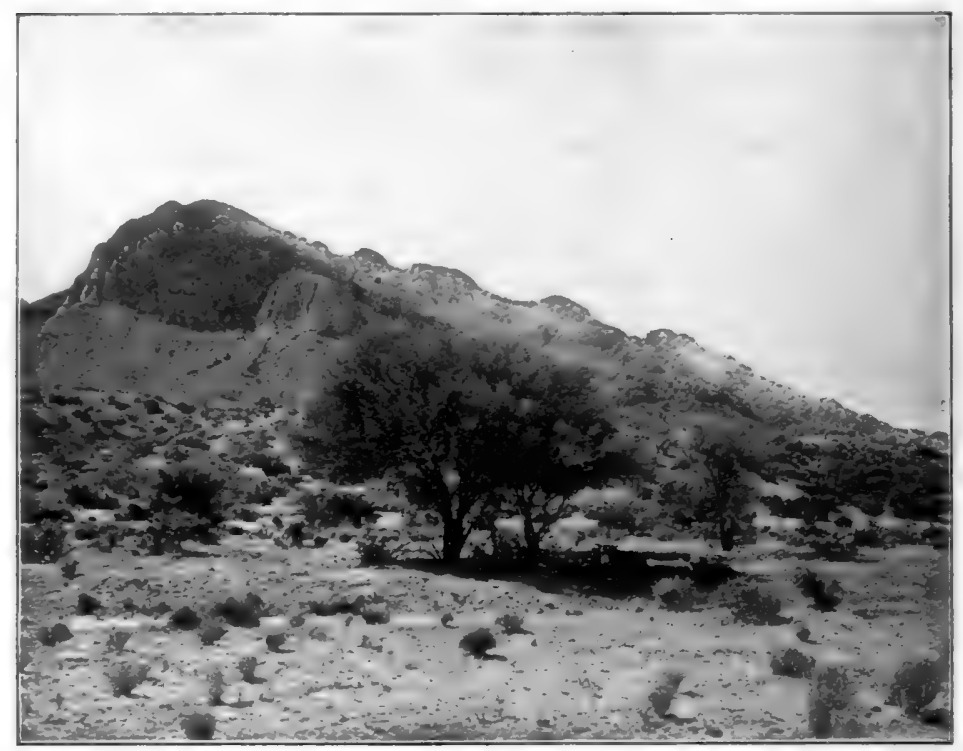

Fig. 111. A desert landscape

The plants are not sufficiently numerous to entrrely cover the soil. (Southern Arizona.) Photograph by Dr. D. T. MacDougal

of oak and hickory trees is not equally favorable to the growth of elm or willow, and these are not usually found there. Plants which can find suitable conditions for their growth at the same place are likely to be found growing together. A group of plants which are commonly associated in this way is known as a plant association (fig. 112). There are many kinds of plant associations, and these constitute an important subject of study. 
Those types of plant associations in which trees are the most conspicuous part are known as forests. There are other types in which the grasses are most important, and they are known as grasslands or meadows.

247. Value of wild plants. The natural plant covering of the earth's surface is of very great value to mankind. Possibly the forests are the most valuable natural plant associations.

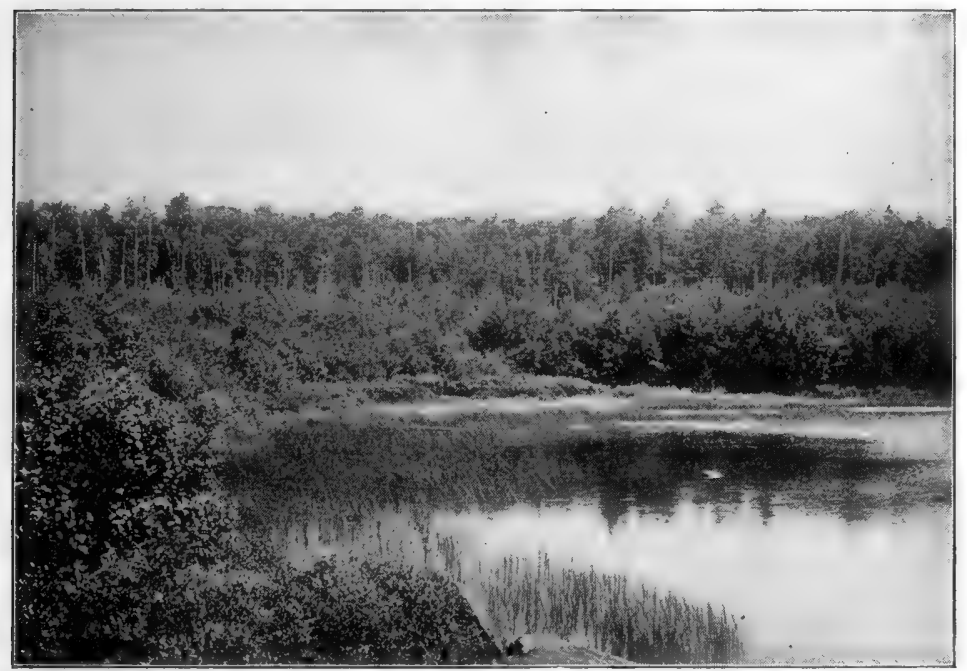

FIG. 112. Plant associations on the margin of a pond

Note the rushes in the water, the low-shrub and tall-shrub associations beyond, and the tree association in the background

They supply us with wood, which we use for numberless purposes. If it were not for our forests we should be deprived of the use of wood for all these purposes, and it is difficult to see how we should meet these needs. It is of greatest importance to our nation that the wood of our forests should be used in such a way as to prevent waste and destruction (figs. 113 and 114). The forest is also of much importance in preventing the erosion of the soil of steep hillsides, as we have 
seen (sect. 238). If the forests are removed in mountainous country, the usual result is that the slopes are soon stripped of soil and neither forests or anything else will grow. It is not probable that rainfall is increased by the presence of trees, but the water that does fall is better conserved in the forest than in the open country, and the streams which flow from the

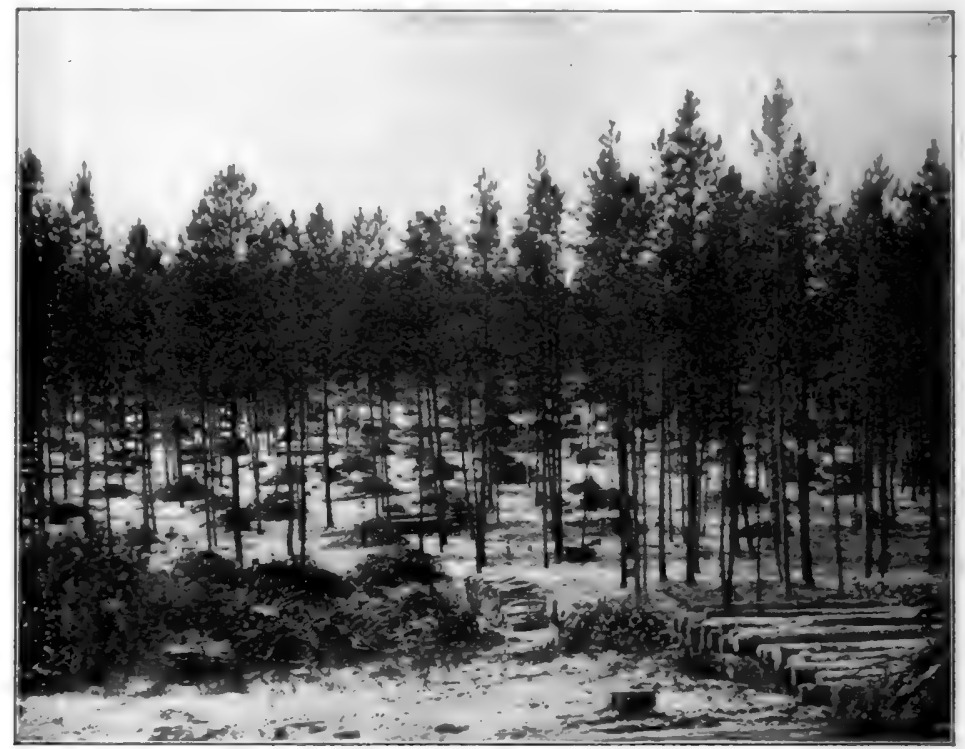

Fig. 113. Careful lumbering

The young trees have been protected while the older trees were cut, and the brush is piled for burning. After a few years another crop may be harvested. Photograph by United States Forest Service

forested mountains are much more constant and uniform than those that flow from a region whose slopes are bare and rocky. For this reason forests are particularly important when they are located upon the sources of streams which supply water for irrigation in the lower valleys.

The grasslands in their natural condition are useful mainly for grazing (fig. 115). In the past a large part of the meat 
supply of this country came from the cattle raised on the great ranches which formerly occupied the Western prairies and plains. A large part of these grasslands is so level and easily tilled that it has been transformed into farms wherever there is sufficient rainfall or a supply of water for irrigation. The land is more valuable for farming than it is for grazing.

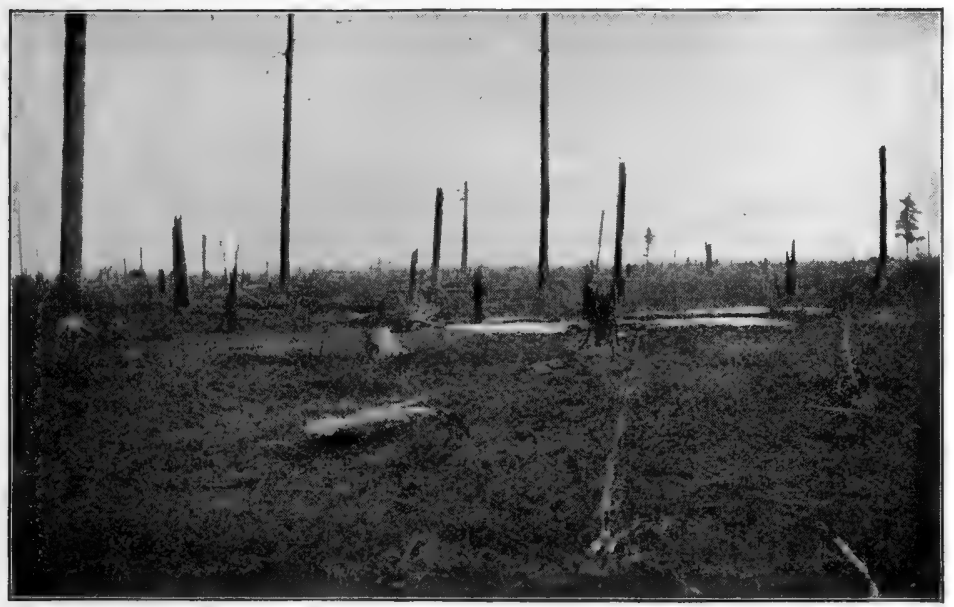

Fig. 114. Wasteful lumbering

The more valuable trees were cut, and the brush was allowed to lie upon the ground. Fire has destroyed not only the refuse but also the remaining trees and the young growth. There will be no second cutting for many years. Photograph by United States Forest Service

Though both the forests and the grasslands are valuable, land that is suitable for agriculture will be of greater value when it is farmed properly than when it grows only trees and wild grasses. The best lands should be cleared of their forests, but there are many thousand square miles of country in the United States which are so hilly or rocky that they cannot be farmed, and these areas ought to be preserved as forests in order that we may have a supply of timber and that rainfall may run off more slowly. There are also great areas of arid 
lands in the West which can scarcely be used for anything but grazing, except when irrigation is practicable.

In order to preserve these benefits for the people, and to protect important natural features, and to supply places of recreation and pleasure, the national government and the states have set aside certain areas as forest reserves, parks, and game preserves.

248. Cultivated plants. Where the natural plants have been removed, it has usually been done in order to substitute for them our cultivated plants, for these supply products which

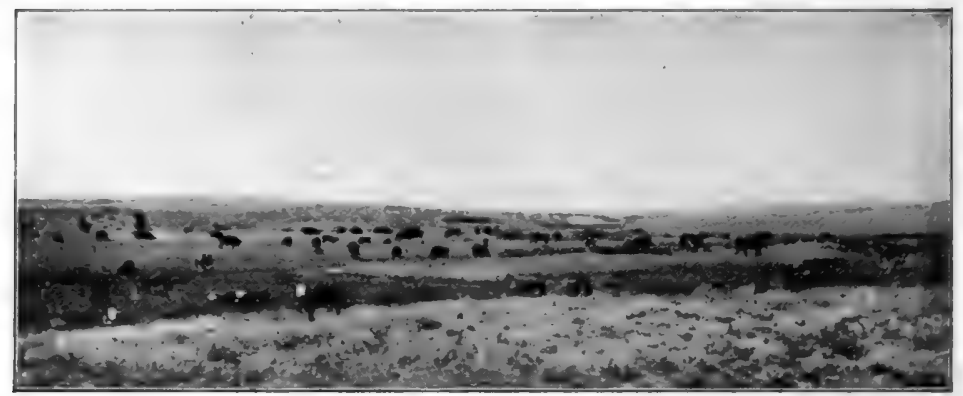

Fig. 115. Grazing country

In some regions stock raising is almost the only industry. The land may be more valuable for this purpose than for any other, especially where it is hilly or stony.

Photograph by United States Department of Agriculture

we need for food, clothing, and other uses. There is no industry in all the world so important as farming. Its products are of more value than the products of any other industry, and all industries depend upon it for their prosperity. Where agriculture thrives it makes a need for transportation facilities; on the other hand, many fertile regions have had their production stimulated through the introduction of railways, since without these railways farm products find only a local market. In similar ways the other industries of the entire country are related to agriculture. See the accompanying table for comparison of agriculture and other industries. 
Statistics of Crops in the United States in 1912

\begin{tabular}{|c|c|c|c|c|c|c|c|c|c|c|}
\hline & & & & & & & & & AMOUNT & VALUE \\
\hline Corn & . . & . . . & . & . . & - & . & . & . & $3,124,746,000 \mathrm{bu}$. & $\$ 1,520,424,000$ \\
\hline Wheat & . . & . . . & . & . . & . & $\bullet$ & 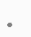 & . & $730,267,000 \mathrm{bu}$. & $555,280,000$ \\
\hline Oats . & . . & . . . & - & . . & • & • & . & . & $1,418,337,000 \mathrm{bu}$. & $452,469,000$ \\
\hline Hzy . & . . & . . . & . & . . & . & & • & • & $72,691,000$ tons & $856,695,000$ \\
\hline Potatoes & & . . . & . & . . & 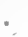 & & - & . & $420,647,000$ bu. & $212,550,000$ \\
\hline Cotton a & and & cottor & nsee & ed. & - & & & . & - & $860,000,000$ \\
\hline Cattle, o & on $\mathbf{f}$ & farms & . & . . & . & & • & . & $56,527,000$ head & $1,872,428,000$ \\
\hline Horses, & on & farms & . & . . & • & & . & . & $20,567,000$ head & $2,278,222,000$ \\
\hline All othe & $\mathrm{er} \mathbf{f a}$ & arm pr & rodu & ucts & & - & & . & & $9,532,000,000$ \\
\hline
\end{tabular}

Statistics of Non-Agricultural Products in 1909

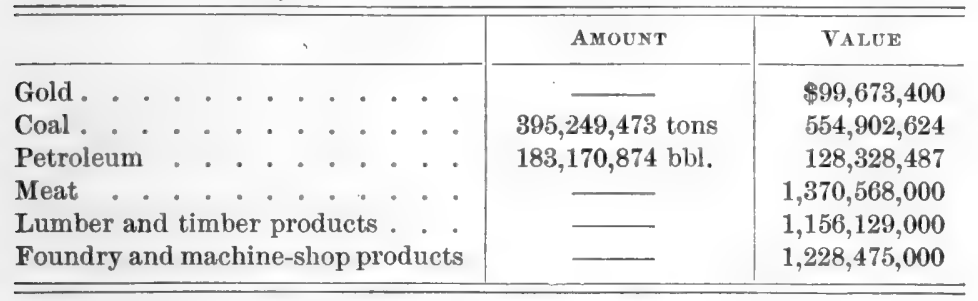




\section{CHAPTER XXIV}

\section{ABSORPTION FROM THE SOIL BY PLANTS}

249. The problem. In the chapters on soils we had frequent occasion to refer to the close relation existing between plants and the water content of soils. If we were to cut off close to the ground the stem of some vigorously growing plant, we should find that the sap would appear from the cut end of the remaining stub. A maple tree or a grapevine will show this escape of sap, or "bleeding," particularly well if a branch is cut off early in the spring. Maple trees are often tapped for the sap, which is evaporated to secure the sugar which it contains, and a single tree may supply from 30 to 50 gallons of the sap. The sap is mainly water. Since the water comes out of plants, there must be some place from which the plants secure it. Our problems are, what is the source and what are the methods by which plants secure water?

250. Loss of water from the soil. It is not at all difficult to prepare an experiment which will show that water is lost by the soil when a plant is growing in it. If a pot with a growing plant is wrapped in a sheet of rubber, so that no water can escape excepting from the plant, it will be found that the soil becomes drier and that weight is lost. A similar pot of soil without a plant in it and completely inclosed in rubber does not lose in weight. We should conclude that the plant must have been taking up water from the soil about as rapidly as it evaporated from the leaves.

251. Osmosis. The first question is, How does the water get into the roots? In order to answer this we shall have to study the peculiar behavior of solutions. This behavior may be shown by the use of a dense sugar solution and pure water. A funnel 
which has been filled with the sugar solution, and over the large end of which a piece of parchment paper has been fastened, is inverted in a dish of water (fig. 116). Since the parchment paper is permeable to water, it might be supposed that the liquid in the funnel and the water outside would come to rest at the same level. This does not occur excepting possibly for a very brief period. The sugar solution increases in volume, and the level of the liquid in the funnel rises until it overflows the top of the tube. If a longer tube were attached, the liquid might rise in it to a height of many feet, unless the pressure due to the height of the column caused the paper to break.

Careful measurements of the water outside the funnel show that it decreases in volume just as much as the sugar solution increases. This means that water has gone through the paper into the sugar solution, although the pressure due to its height in the tube opposed the entrance of the water. (How much pressure per square inch on the inside per foot of height?) A very little of the sugar finds its way out through the paper, as may be determined by tasting the outer. solution. If there had been some sugar in the outer vessel of water, but a smaller proportion than within the funnel, we should still have had the same kind of result, but the more nearly the solutions are alike in amount of dissolved matter, the less will be the difference in pressure.

It will be seen that the essential things about our experiment are two solutions separated by a semi-permeable partition.

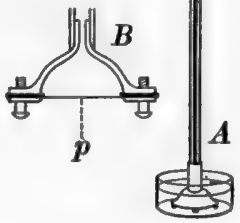

Fig. 116. A simple osmometer

$A$, osmometer, with the liquid in it standing at the height $h$; $B$, sectional view of osmometer, showing permeable partition $p$ It is also clear that the water passes through the partition and dilutes the denser solution, thus increasing its volume. The 
membrane is said to be semi-permeable, because the water will pass through freely but the sugar will not pass so readily. The same results may be secured with other solutions and other membranes. 'This process by which water or other liquids may pass through a semi-permeable membrane between a weaker and a stronger solution, increasing the volume of the latter, is called osmosis. The similarity of the results of this experi-

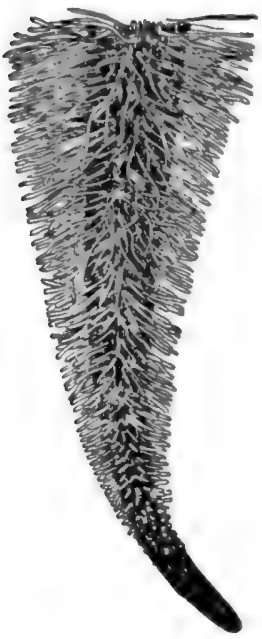

Fig. 117. A root tip

The tip of a clover root covered with root hairs. Very much magnified ment with osmosis to the results of root absorption is striking. Osmosis appears to be an explanation of absorption by the root, but before we accept it as such we must know whether the root is so constructed that it affords opportunity for osmosis to take place.

252. Root structure. When the tip of a root is examined, it is found to be composed of cells, as is any other part of a plant or animal. These cells resemble those seen in the leaf. They are thinwalled, and the walls are permeable to water, so that it is possible for water to pass in through the cell walls. The interior of the cell wall is lined with a layer of living substance (protoplasm) with a space in the center which contains cell sap. Cell sap consists of water and some substances (often including considerable sugar) in solution. This layer of protoplasm is semi-permeable; that is, it permits water to pass but it does not readily permit the sugar and most other substances which are dissolved in the cell sap to pass outward.

Each cell of the root is, in fact, an osmotic apparatus in which the protoplasm acts as a semi-permeable membrane, the cell sap being the more concentrated solution and the soil water the weaker one. If, in our experiment, we had used 
soil water from a well and concentrated plant sap as the two liquids, we should have been imitating the plant. Of course, if the soil water were to be a more concentrated solution than the plant sap, water would be drawn out of the plant and it would die. This is what happens if a strong solution of salt is poured on the grass of the lawn.

The water which is taken in by the cells of the surface is passed from cell to cell farther into the root by osmosis and finally reaches the tubes or pores through which it is carried into the stem and leaves.

253. Root surface. Since water is absorbed only through the surface of roots, it follows that the rate at which watèr will be taken up will be affected by the amount of absorbing surface possessed by the roots. The amount of surface on each rootlet is very small, for only the part within a very few inches of the tip is permeable to water. The older and larger parts of the root are covered by

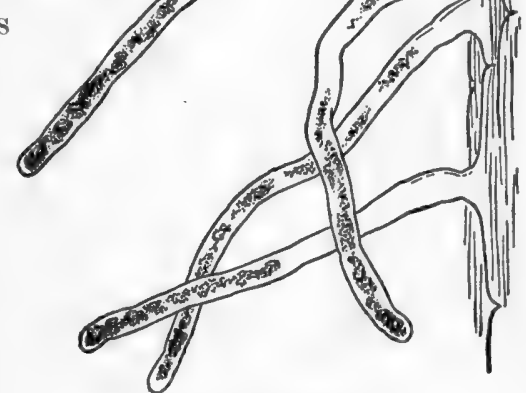

Fig. 118. Root hairs

These hairs add very much to the absorbing surface, and they assist in anchoring the root in the soil. Highly magnified

a bark, or cork-like layer, which is almost waterproof. Extensive branching of the roots and the presence of root hairs increase the surface of root exposure.

The root hairs are hair-like projections (fig. 117) which grow out from the surface of the youngest rootlets to a length of an eighth of an inch in some cases, clothing the end of the root in a "fuzz." They are not found at the tips of the roots, but the zone covered by them begins about a quarter of an inch from the tip and extends back as much as an inch or more. 
Each hair is merely a tube-like extension of a cell upon the surface of the root (fig. 118), and is able to absorb water just as the remainder of the cell does. A root hair usually has many times as much surface as the cell from which it grows, and the surface of the root is increased in this way. A single root hair is very small, but there are thousands of them on even a very short piece of root (1314 to $\frac{1}{100}$ square inch have been found on pea roots), and they increase the surface to many times what it would be without them. Also, they extend into the soil, from which they absorb water and in which they help to anchor the plant firmly.

The number of root tips in a single plant is ordinarily very great. Wc commonly judge the root system by what we see when a plant is pulled out of the ground, but usually much the larger part of the root system is broken off and left in the ground. The roots of a tree ordinarily spread much farther under the ground than its branches do above the ground. Not only do the roots spread widely, but by repeated branching they are divided into innumerable thousands of small rootlets, which penetrate so thoroughly to all parts of the soil that under a tree it is often difficult to find a cubic centimeter of soil that does not contain rootlets. It is these small rootlets that bear the root hairs and absorb the water.

It must not be supposed that root hairs are roots. The hairs never become roots, but, on the contrary, as the root tip grows out farther the old root hairs die and new ones are formed on the newer parts of the rootlet.

254. Water-carrying tissues. We have spoken of the way in which water passes from cell to cell in the tip of the rootlet, and of the way in which this water is transferred from the surface to the interior of the root. In some of the smaller plants, such as the mosses, the water passes through the plant by simple osmosis, but in all the larger plants there is a more intricate system by means of which water is carried. The structure of the water-carrying parts is so similar in roots 
and stems that we shall use a stem for our example. If we cut a stem with leaves from any of our common trees and stand it with the end in red ink for a while, we shall find that the ink has ascended the stem as water would have done, and has left a red stain which marks its path (fig. 119). This red stain is found only in that part of the wood which is near the bark. This means that the water moves up the stem or root in the wood which lies next the bark, called the sapwood.

Closer examination of the wood will show that it contains numerous large pores, and it is through these that the water travels. These pores may be seen easily in oak wood. The cause of the rise of water in the stems of plants is not wholly understood.

255. Solids absorbed only when in solution. If there are substances dissolved in the water, these may pass into the plant cells by osmosis, and in this way the plant takes certain mineral substances from the soil. Only those substances that will dissolve

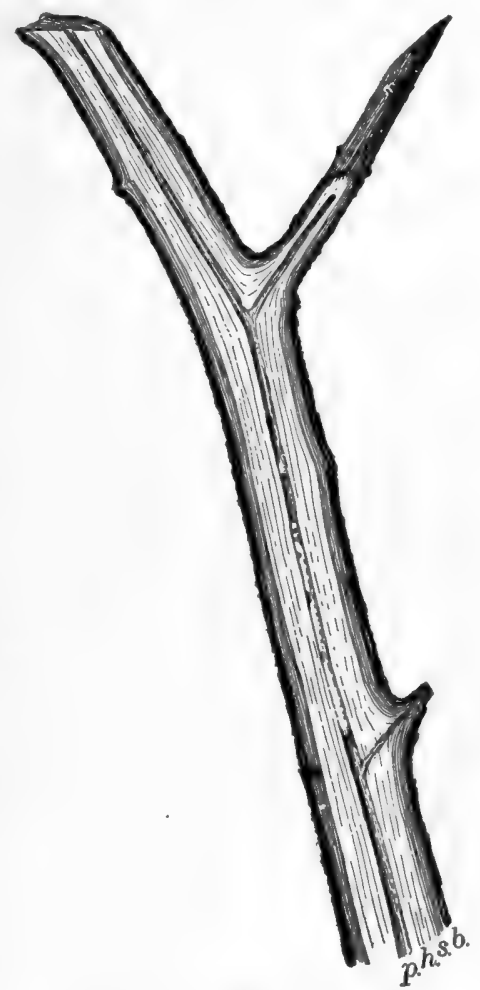

Fig. 119. Ascent of water

Longitudinal section of a stem, showing route of ascent of water: $b$, bark; $s$, sapwood; $h$, heartwood; $p$, pith. Water ascends principally through the sapwood in the soil water can be absorbed. The absorbed mineral material is transferred through the body of the plant in solution in water and may reach any part of the plant. 
256. Root surface and transplanting. It is ordinarily impossible to remove plants from one place in the soil to another without causing serious disturbances to the root system. Many of the root hairs and smaller roots are broken off, as is usually true of parts of the larger roots. This means that in the new location there will at first be less absorbing surface than the plant previously possessed. Usually some of the roots become dry through exposure to the air and are of no use to the plant, thus further reducing the absorbing surface.

In transplanting, the branches and leaves do not necessarily suffer the same sort of reduction as the roots do. Since water continues to evaporate from the leaves (sect. 128), and since the absorbing surface of the roots is reduced, it is necessary to reduce the evaporating surface of the leaves by pruning. In this way the remaining leaf surface should not make too great a tax upon the absorbing power of the roots before new roots and root hairs are developed.

257. Summary. Water is taken from the soil by the roots of plants by means of the process known as osmosis. If there is available water in the soil, it will enter the root as long as the cell sap is a more concentrated solution than the soil water. If it ever happens that this condition is reversed, water may be drawn from the plant. Absorption occurs only at the surface of young root tips and their root hairs. When the root system is seriously disturbed, there is danger of excess of evaporation, which results in death or injury to the plant, unless the evaporating surface is also reduced. 


\section{CHAPTER XXV}

\section{THE WORLD'S FOOD SUPPLY}

258. The demand for food. It is sometimes said that the necessities of life are food, shelter, and clothing; and certainly in our part of the earth all of these are of great importance. Of the three, food is certainly the one that is indispensable, for though men may exist with little shelter, and, in tropical climates at least, with but little clothing, it is not possible for men to exist anywhere very long without food and water. The quantity of food that is consumed by man and by his domestic animals is very great indeed, and a supply of food is at all times a matter of the greatest importance. Lack of food has caused the surrender of cities, defeated armies in the field, changed the policies of nations, and caused the loss of thousands of lives. In former times famines were of common occurrence, because when food failed in certain places there were no means of securing it from the localities where it was more abundant. Modern transportation systems have changed conditions so that now a famine can hardly occur in any country excepting the most backward and undeveloped.

While a general famine is unlikely to occur in modern civilized countries, it is yet possible for people in every country to suffer from lack of food. It often happens that the cost of food is so great that many people cannot afford to buy enough of it. The population of the United States has been increasing more rapidly than the production of food, and this, together with other causes, results in higher prices and actual lack of food on the part of some persons.

259. The source of food. To those of us who live in cities the source of our food seems to be found in the meat market, 
the bakery, and the grocery. For the purposes of this study we must go deeper into the subject. Foods have a long and interesting history before they reach the hands of the local merchant.

In the first place, we already know that our food materials are in general either plant or animal products, and since the foods of animals are either plants or other animals which feed upon plants, it is easy to trace all foods back to a plant origin. For instance, whether we eat the corn ourselves or feed it to the cattle and afterwards eat the meat, it is from the corn plant that the food comes.

Since the cultivated plants are used as food for us or our animals, it may be said that the farmer is in fact engaged in operating a food factory with cultivated plants as his machinery. Our question as to the origin of the world's food now becomes a question as to the kinds of materials which the plants make and how they make them.

There are a few mineral materials, such as salt, to which these statements do not apply, but, with the exception of water, they are not used in great quantities and are not further discussed at this time.

260. Composition of foods. In all our foods there are five classes of compounds: carbohydrates, fats, proteins, mineral salts, and water. The first three are of chief importance.

The carbohydrates we already know from our study of the manufacture of plant foods in green plants. This process, photosynthesis, is the source of all the carbohydrates in our food. The most common carbohydrates are starch and several kinds of sugar.

The fats, like the carbohydrates, contain carbon, hydrogen, and oxygen, but in different proportions. Cottonseed oil and olive oil are familiar examples. There is some oil to be found in almost every plant.

Proteins are the materials of which the living substance is composed. They contain the same three simple subistances as 
the carbohydrates $(\mathrm{C}, \mathrm{H}, \mathrm{O})$, and also nitrogen, with (usually) sulphur, phosphorus, and other substances. They are the most complex chemical compounds and are not well understood.

Common Foodstuffs, with Approximate Percentage Сомposition

\begin{tabular}{|c|c|c|c|c|c|c|c|c|c|c|}
\hline & & & & & & WATER & Proteins & FAT8 & $\begin{array}{c}\text { CARBO- } \\
\text { HYDRATES }\end{array}$ & SALT \\
\hline Beef, lean . & & . & $\therefore$ & . & . . & 72 & 19.3 & 3.6 & - & 5.1 \\
\hline Beef, fat. . & . & . & . & . & . . & 51 & 14.8 & 29.8 & - & 4.4 \\
\hline Mutton, lean & . & & . & . & . . & 72 & 18.3 & 4.9 & - & 4.8 \\
\hline Mutton, fat & . & - & . & . & . . & 53 & 12.4 & 31.1 & - & 3.5 \\
\hline Veal . . & 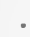 & . & . & . & . . & 63 & 16.5 & 15.3 & - & 4.7 \\
\hline Pork, fat . & 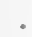 & - & . & . & . . & 39 & 9.8 & 48.9 & - & 2.3 \\
\hline Poultry . . & . & . & - & ?: & . . & 74 & 21.0 & 3.8 & - & 1.2 \\
\hline Whitefish . & & - & . & . & . . & 78 & 18.1 & 2.9 & - & 1.0 \\
\hline Salmon . & • & • & - & . & ${ }^{3}$. & 77 & 16.1 & 5.5 & - & 1.4 \\
\hline Eels, rich in & & t . & . & . & . . & 75 & 9.9 & 13.8 & - & 2.7 \\
\hline Oysters . : & & . & - & - & . . & 75 & 11.7 & 2.4 & - & 2.7 \\
\hline Milk .. & & . & . & . & . & 86 & 4.1 & 3.9 & 5.2 & .8 \\
\hline Buttermilk . & & . & . & - & . . & 88 & 4.1 & .7 & 6.4 & .8 \\
\hline Cream. . & & . & - & . & . . & 66 & 2.7 & 26.7 & 2.8 & 4.9 \\
\hline Cheese, full & & . & . & . & . . & 36 & 28.4 & 31.1 & - & 3.5 \\
\hline Cheese, skim & & . & . & . & . . & 44 & 44.8 & 6.3 & - & 4.9 \\
\hline Eggs, whole & & . & . & . & . . & 73.7 & 14.8 & 10.5 & - & 1.0 \\
\hline Eggs, white & & . & . & . & . . & 78 & 20.4 & - & - & 1.6 \\
\hline Eggs, yolk . & & . & . & . & - . & 52 & 16.0 & 20.7 & - & 1.3 \\
\hline Bread . . & & . & . & . & . . & 37 & 8.1 & 1.6 & 53.1 & 2.3 \\
\hline Flour . . & & . &. & . & . . & 15 & 10.8 & 2.0 & 70.8 & 1.7 \\
\hline Onions . . & & . & . & . & . . & 87.6 & 1.6 & 0.3 & 9.9 & 0.6 \\
\hline Potatoes : . & . & . & . & . & . . & 78.3 & 2.2 & 0.1 & 18.4 & 1.0 \\
\hline Navy beans, & $d r$ & & . & . & . . & 12.6 & 22.5 & 0.8 & 59.6 & 3.5 \\
\hline Green beans & . & - & . & . & . . & 89.2 & 2.3 & 0.3 & 7.4 & 0.8 \\
\hline Apples, edibl & e & por & tion & & . . & 84.6 & 0.4 & 0.5 & 14.2 & 0.3 \\
\hline Strawberries, & $\mathrm{e}$ & dib & le $p$ & por & tion & 90.4 & 1.0 & 0.6 & 7.4 & 0.6 \\
\hline Bananas, edil & ble & $\theta \mathrm{pc}$ & ortic & & & 75.3 & 1.3 & 0.6 & 22.0 & 0.8 \\
\hline Dried figs, ed & & le & port & tior & n. & 18.8 & 4.3 & 0.3 & 74.2 & 2.4 \\
\hline Walnuts. . & - & . & . & . & . . & 2.5 & 16.6 & 63.4 & 16.1 & 1.4 \\
\hline Corn grain . & . & • & . & . & . . & 10.8 & 10.0 & 4.3 & 73.4 & 1.5 \\
\hline Wheat grain & • & • & - & - & . . & 10.6 & 12.2 & 1.7 & 73.7 & 1.8 \\
\hline Rice : . & - & - & - & $\therefore$ & . . & 12.0 & 8.0 & 2.0 & 77.0 & 1.0 \\
\hline Butter. . & . & . & . & . & . . & 11.0 & 1.0 & 85.0 & - & 3.0 \\
\hline
\end{tabular}


Proteins are most familiar to us in the form of the white of egg, cheese, and lean meat.

The mineral salts, such as common table salt, are inorganic chemical compounds. Many of them are of little importance as food materials, and they are never present in large quantities.

261. Protein manufacture. Of the process of making proteins in plants little is known except that the plant appears to add nitrogen and other elements to the carbohydrates which have been made by the process of photosynthesis. These substances have entered the plant in the form of chemical compounds dissolved in soil water. They can be used only in the form of compounds. For instance, the free nitrogen of the air cannot be used by plants. The supply of some of these compounds in the soil at any time is never great, and in case they are exhausted plants cannot flourish.

262. Loss of nitrogen from soil. Where the soil is covered with a growth of wild plants and nature is allowed to take its way unmolested, it is not probable that in the long run there is any decrease in the amount of nitrogen in the soil. The nitrogen is absorbed from the soil by the roots of plants, but it remains in the plants, and when they die and decay, at least the greater part of it is returned to the soil. On cultivated ground the case is quite different. There the whole plant or a part of it is harvested and taken away, and the nitrogen which the removed part contains usually does not return to the soil. We have seen that in a grain of wheat there is $\mathbf{1 2 . 2}$ per cent protein, of which a large part is nitrogen, and it is calculated that in reaping a crop of 20 bushels of wheat from an acre the farmer is removing 25 pounds of nitrogen. At that rate in a few years there would be a deficiency of nitrogen, unless it could be replaced in some way.

We have spoken of the loss of nitrogen only, but it may be that other necessary minerals are exhausted in a similar manner, but this matter is not well understood. 
263. The supply of nitrogen. It is a common practice to return to the soil in the form of manures as much as possible of the straw and other materials which have come from the fields, and in this way much may be clone to maintain the fertility of the soil. There is always a loss, however, in the material that is sold and taken off the farm, and there are certain other unavoidable losses of nitrogen. A very important source of nitrogen is found in the action of certain kinds of bacteria which live in the soil or in the roots of the clover and other plants of the pea family. As stated in section 243, their value lies in the fact that they cause the nitrogen of the air to combine with other elements in such a way as to form the soluble nitrogen compounds which other plants can absorb and use. It is common to restore the nitrogen supply of land by growing clover on it.

If the use of clover and its bacteria does not suffice to restore the land, it is possible to scatter over it certain nitrogencontaining chemicals which may be purchased for this use. The substance used most commonly is Chile saltpeter, which is mined in great quantities in Chile and exported by shiploads.

264. The value of the soil. It is not alone the farmer who is interested in the soil, for the production of foodstuffs for all of us depends upon the productivity of the soil. If it is generally lacking in the substances and conditions necessary for plant growth, there will not be enough food produced to supply the needs of the country, and all will suffer either in the prices paid or because of lack of food.

265. Summary. The food of the world is produced by plants. They make carbohydrates from carbon dioxide anc. water, and fats are made from carbohydrates. Proteins are made by plants and animals by the addition of nitrogen, sulphur, etc. to the elements of the carbohydrates. The former are secured from compounds which are absorbed from the soil. The problem of keeping up a proper supply of these compounds in the soil is a very important one. 


\section{CHAPTER XXVI}

\section{UTILIZATION OF FOOD IN THE PLANT}

266. Need of food in the plant. In the discussion of the manufacture of food there has been no mention of the use made of the food by the plant. People generally give so little thought to the need which a plant has for carbohydrates, fats, and proteins that we frequently speak as if the foods were made for us. This is not the truth. A plant has need for food, as we have, and in addition it has the power of making its food supply from such simple substances as carbon dioxide, water, and other compounds. If a plant is not interfered with, the food which it manufactures is commonly used by it and for its own purposes. For instance, a part of our food is composed of starch from wheat grains, but if the wheat had not been disturbed, the grains would have fallen to the ground, where under favorable conditions they would have started to grow into new wheat plants. These young plants would have used the food that was stored up in the grain. By harvesting, milling, baking, and eating the wheat we have appropriated for our own purposes that which otherwise would have fed a young wheat plant.

There are several purposes for which food is used in the plant. We have already spoken of one in the section on respiration. It will be recalled that when the living substance is destroyed in the process of freeing energy, the loss must be made good by a supply of new material. It is the food that supplies this new material. New material is needed not only to replenish waste but also for the growth of plants. Both the living protoplasm and the cell walls must be built up from food materials. 
267. Where food is used. Since food is necessary in a growing plant as a supply of material from which new leaves, branches, and roots are constructed, it is evident that much of it will be needed in the more rapidly growing parts. Also, since food is necessary to replace the living substance as it is destroyed in respiration, food will be needed in all living parts. This means, of course, that there will be need of food everywhere excepting in a few dead tissues like the dry outer bark.

Although food is needed everywhere, it is not made everywhere. Carbohydrates are made principally in the leaves, but they may be needed in connection with the growth of roots or the development of the fruit or in other parts of the plant. This immediately raises the question of how food may pass from one part of the plant to the other, for very plainly there must be some method of transfer.

268. The method of transfer. Liquids, and solids dissolved in liquids, are able to pass from cell to cell by osmosis, as we learned when studying the absorption of materials by the roots. It is, of course, perfectly easy to see how sugar may be transferred from one cell to another in this way, for the sugar which is in the plant is dissolved in the sap. By osmosis the sugar may travel from cell to cell in the leaf until it comes to the veins, along which it travels to the stem and so throughout the plant. But what about other food materials? Most kinds of food material in a plant are not soluble. For instance, if we soak a potato or a quantity of rice in water, the valuable materials in it do not dissolve in the water, else we should find it of more advantage to drink the water than to eat the rice or potato. The fact is that in most foods comparatively little of the carbohydrates, fats, and proteins dissolve, no matter how long we soak the foods in water. In the examples mentioned the most abundant material is starch, and this is quite insoluble. Since food material is usually found in plants in the form of starch and other insoluble compounds, we must ask ourselves how it is that food can be transferred to the 
various parts of the plants where it is needed. Certainly the solid grains, such as the grains of starch, eannot travel far through the plant unchanged.

269. Digestion of starch. In discussing how insoluble maierials are moved through the plant, we shall take the specific example of starch and remember that the process for other insoluble foods is somewhat similar.

If we examine with a microscope some starch grains from a sprouting seed, where the food material is being carried away to be used in forming new parts, we find that the grains of starch are not smoothly rounded, as they would be at any other time, but rough, with many holes on the surface, as if some of the starch had been dissolved from each grain. Of course, starch does not ordinarily dissolve in water, but it is rather easily changed into sugar (Chapter VII), and the sugar will dissolve. In plants there is a substance (called diastase) which has the peculiar property of causing starch to slowly change into sugar if the diastase is brought in contact with the starch. This substance is in the plant sap. It acts upon the starch at the surface of the grains, and the rough, pitted appearance shows where the starch has been so changed and dissolved.

It is not difficult to secure a solution containing diastase by crushing in water some sprouting seeds, as those of barley. If this solution is mixed with starch in a test tube, it will change starch into sugar as it does in the plant. The use of diastase to digest starch is a commoin trade process. Brewer's malt is simply slightly sprouted barley which has afterwards been killed by heat and drying. The diastase in it digests the starch, forming sugar, which may afterwards be fermented to form the alcohol which is present in beer.

The process, such as we have just been describing, of changing an insoluble substance into a soluble one is called digestion. It is possible to transfer insoluble foods from place to place through the plant only after they have been made soluble by digestion. 
270. Digestion of other substances. Diastase will digest only the carbohydrates, but there are other substances which have a similar action on proteins and fats. All substances which, like diastase, cause chemical changes to take place in other substances while remaining unchanged themselves are called enzymes. There are a great many enzymes in plants, and digestion and many other changes are due to them.

271. Transference in the plant. As pointed out in the preceding paragraph, dissolved food materials may pass from cell to cell throughout the plant. When food reaches the large pores or tubes in the stem, it may pass upward with the general movement of water through the plant, as mentioned in the discussion of absorption and movement of water (sect. 254). Passage in a downward direction occurs through tubes in the inner bark. Immediately within the tissues through which the manufactured food passes downward is the layer of tubes through which water passes upward in the stem. The veins of the leaves are composed of tissues similar to those of living wood and bark, and liquid material moves in these as it does in the wood and bark.

272. Food storage. When the food is in solution and is therefore capable of being transferred from place to place within the plant, it may be disposed of in either of two ways: it may be used immediately for repair and growth or it may be stored.

When food is stored it is usually changed into an insoluble form again. For example, sugar is commonly changed into starch, though there are cases in which sugar itself is stored. Food may be stored in almost any part of a plant, but usually it is stored in large quantities only in much-thickened parts. Examples of thickened storage parts are the potato, carrot, parsnip, radish, onion, beet, sweet potato, various bulbs and tubers, fleshy fruits, and seeds (fig. 120). Very often food is deposited in the roots and other underground parts of the plant. In these cases the food which is made and stored 
during the summer commonly serves for the plant's growth during the earlier part of the following season.

The large amount of food which is brought together within a small space makes these storage organs of plants an
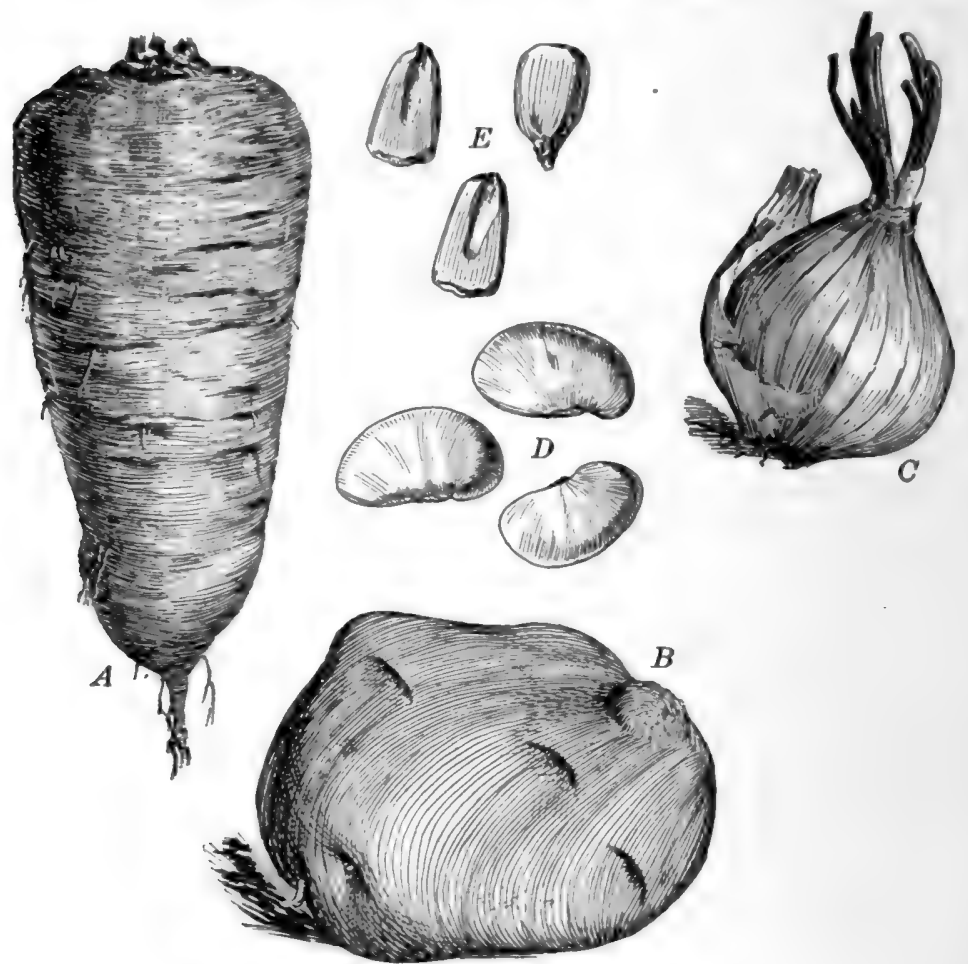

Fig. 120. Plant organs in which food is stored

$A$, root of carrot; $B$, tuber of potato; $C$, bulb of onion; $D$, seeds of bean; $E$, seeds of corn

imporrtant article of food for men and animals. The starch and proteins which are stored in wheat are the valuable things in wheat, and this is the most important single food for the Caucasian race. In the Orient - China, Japan, India - the food storehouse that is of greatest importance is the rice grain, and 
a very large part of the human race is dependent upon it for their principal food. Rye flour is used for bread in some European countries. Beans and peas contain starch and more protein than almost any other common vegetable food. They are therefore particularly valuable as a substitute for meat in hot countries or in places where meat is scarce.

Corn and oats are used for human food, but not to so great an extent as some of the other grains. They are usually fed to animals which may then be used as food. The lean meat of animals is particularly rich in proteins, as the fatty parts are in fats, but flesh is poor in carbohydrates.

The enormous importance of the industries which are producing these supplies - these great quantities of stored plant food - may be understood by reference to the table of the quantities and values of agricultural products in the United States, given in section 248.

273. Use of food by plants. If food which is stored is not used by men or removed in some other way, the plant will finally use it in its processes of growth. It was said above that beans contain much protein material, and this is in an insoluble form. If a bean is planted and starts to grow, the protein grains in the bean will be digested by the aid of an enzyme and dissolved, after which they may be carried to the growing parts, where the protein material will form additional living protein - protoplasm.

This is a wonderful process, for the digested and dissolved proteins are dead materials, but the protoplasm which is formed from them is a living substance. Therefore a dead material has become a living one. Proteins are the only materials in which life may exist, and the only known way by which non-living protein may become living material is for it to unite with some already living substance and thus become a part of it. This process whereby non-living protein material unites with the living protoplasm and thus becomes living material is called assimilation - a process the exact nature of which is not known. 
Precisely the same thing happens in our own bodies when the ligested food is dissolved, carried through the body in the blood, and assimilated by the cells.

Of course protein foods that have never been stored may be assimilated instead of being stored. Carbohydrates may be used for protein-making soon after they are manufactured, or they may be stored and then digested and used as described.

274. Assimilation and respiration. It will be worth while here to contrast assimilation and respiration. Assimilation is a process by which more protoplasm is constantly made from proteins, and it is therefore a constructive process. By respiration the very complex living chemical compound which we call protoplasm is separated into several compounds, which may be as simple as the original proteins or even as simple as carbon dioxide and water. These products of decomposition may be given off as wastes. Respiration is a destructive process by which protoplasm is destroyed and the energy which it yields is made available.

The whole matter may be represented as like the slope of a hill. We begin at the bottom with carbon dioxide, water, nitrates, etc., and by means of photosynthesis, protein manufacture, and assimilation we ascend to the highest point - protoplasm; the descent on the other side is represented by respiration, which reduces the protoplasm to carbon dioxide, water, nitrogen compounds, and other decomposition products. 


\section{CHAPTER XXVII}

\section{NUTRITION OF ANIMALS}

275. Plants and animals. In a previous discussion we have seen that plants which have chlorophyll can manufacture foods. We have seen also that they afterwards use some of these foods in their own nutrition, or that some of the surplus food may be stored in the root, stem, leaf, or fruit. There is a very important relation between the animal kingdom and the food material in plants. Chlorophyll is not found in animals (except possibly in a very few simple animals), and they are dependent upon green plants for the results of chlorophyll work; that is, green plants supply the food materials for all the animal kingdom.

Animals may secure their food directly or indirectly from plants. Some animals may devour the green leaves of plants; others may eat plant food that has been stored in stems and roots: others may eat the rich grains or fruits that have been made by plants; still others may devour animals that have eaten plant food; or two or more series of animals living upon one another may intervene before plants appear as the real source of animal food.

276. Processes of animal nutrition. In but few cases can even the larger animals introduce their food into the interior of their bodies without breaking it up more or less. This process of breaking up the food, known as mastication, usually involves the addition to the food of liquids which, while making chemical changes, also make swallowing easier. Another process, digestion, helps further in reducing the food to a liquid condition. Liquid food may be taken through the walls of the digestive system by the process known as absorption. It may 
then enter the circulatory system and by circulation may pass to the various parts of the body. From the smallest parts of the circulatory system food may pass out into living cells, and

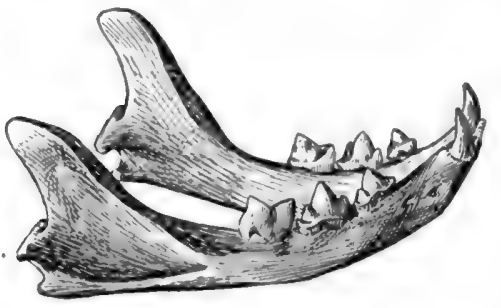

FIG. 121. Lower jaw and teeth of a cat by assimilation it may become a part of the living protoplasm of the body.

277. Mastication : teeth. In all of the higher animals and man the mouth is a special organ of mastication. It is provided with bones, teeth, and muscles so arranged as to make it possible to masticate the food. Some of the teeth are broad-crowned, so that they may serve as crushers; others are sharp and may pierce or tear the food substances (fig. 121). Man has both of these kinds of teeth, but some animals that live upon plant food directly (known as herb eaters, or herbivorous animals) have only the broad-crowned teeth. The teeth of the flesh eaters, or carnivorous animals, are all (or nearly all) cutting or tearing teeth. It is evident that man's teeth enable him to eat a greater variety of food than do tlose of some of the lower animals. It will be found extremely interesting to examine the structure of the teeth to see of what parts they consist and how they are held in place in the bones with which they are connected.

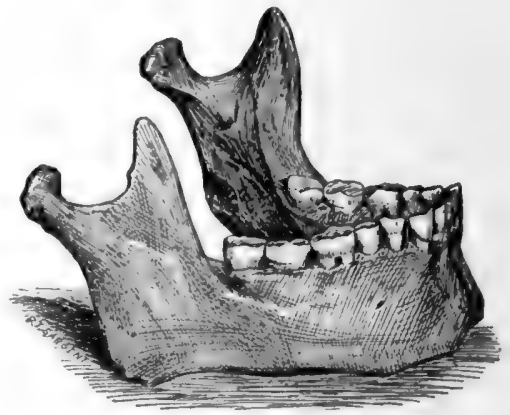

Fig. 122. The human lower jaw and teeth

In form the teeth of man exhibit considerable variation (fig. 122). In the front of the mouth on each jaw there are two pairs of flattened teeth with cutting edges. These are 
the incisors, a name which means "cutters." At the side of the outer pair of incisors is a pair of sharp-pointed teeth, known as the canines, or dog-teeth. Then come two pairs of bicuspids, or teeth each of which has two cusps, or pointed crowns. Back of the bicuspids are the molars, or teeth having four cusps, three pairs of which are present in an adult's mouth. There may also be two additional pairs of molars, known as wisdom teeth, which appear a long time after the other teeth or may not appear at all. Thus a full set of human teeth consists of thirty-two teeth.

278. Structure of the teeth. The teeth, as seen in. the ordinary surface view, appear white and hard. In such a view it is only the hard enamel of the crown that is seen. More thorough examination shows that this crown is joined to one or more heavy roots which extend into the bone of the jaw. This gives the tooth a firm support. When a tooth is cut lengthwise in halves (fig. 123), the following

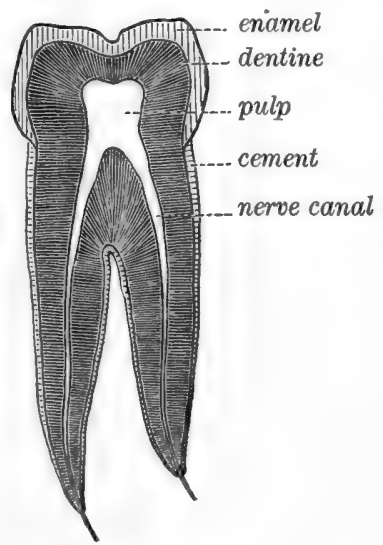

FIG. 123. A vertical section through a molar tooth structures are shown: The enamel is the extremely hard covering of the crown. Beneath the enamel is the dentine, which composes the larger part of the crown and root. The pulp is inclosed by the dentine. The nerves and blood vessels enter through the tip of the root and extend into the pulp. When the enamel is broken or decayed, it is not rebuilt, and the underlying parts may be destroyed in a short time.

279. Mastication : the saliva. One who is hungry and comes into the presence of appetizing food soon experiences an increase in the liquids within the mouth, or, as we say, his "mouth waters" for the food. This liquid is saliva, which is 
produced by special organs, known as salivary glands. There are three groups of these. The largest are the parotid glands, situated one below each ear, each having a duct through which saliva enters the mouth just opposite the second pair of the upper molar teeth. The other glands (submaxillary and sublingual) are the smallest. They lie in the floor of the mouth and discharge saliva through various openings into the lower part of the mouth. It is evident that saliva may be introduced into the mouth at several points, thus moistening the food from different sources.

280. Mastication : use of the saliva. When food is introduced into the mouth the amount of this secretion is increased, and while chewing proceeds, the saliva becomes mixed with the food. Very thorough mixing renders the food almost or quite liquid before it is swallowed. Hasty chewing makes swallowing difficult, and sometimes choking results from attempting to swallow before the food is thoroughly mixed with saliva. Such hasty swallowing often results in passing the food into other parts of the digestive tract without enough liquid in it. The saliva is equally important because of another effect which it produces. A chemical known as ptyalin, an enzyme which composes part of the saliva, affects some of the carbohydrates, as starch and some of the sugars, in such a way as to change them into grape sugar. Starch is not easily absorbed, but the grape sugar made from the starch is readily taken up by the walls of the digestive system. There is another starch-digesting secretion that enters the food after it leaves the stomach. The advantages of thorough chewing and mixing the saliva with the food are apparent. An experiment in eating carbohydrate food for a given length of time, on one day by a very careful chewing and on another by swallowing as soon as possible, will produce some first-hand data upon the advantage of thoroughness in this matter. The food of herbivorous animals, being coarser than that of carnivorous animals, needs to be chewed longer. 
281. Digestion in the stomach and intestines. An acid (weak hydrochloric acid) and an enzyme (pepsin) are produced in the stomach. Since ptyalin cannot act in an acid liquid, digestion of starch is thought to be stopped while the food is in the stomach, but the proteins are acted upon by the pepsin. At the same time, by the constant movements of the stomach its contents are thoroughly mixed. When the food leaves the stomach and enters the small intestine, it is an acid emulsion. At this point, through ducts which open into the intestine, two other important secretions enter. They are the bile and the pancreatic secretion. The bile is produced by the liver, and the pancreatic secretion by the pancreas. The bile is alkaline and counteracts, or neutralizes, the acidity of the food. When the acidity is counteracted, ptyalin that has been carried with the food may again carry on the digestion of starchy substances. One element in the pancreatic secretion may also digest starchy foods. Other parts of the pancreatic secretion, as well as secretions from other small glands in the walls of the stomach and intestines, act upon various parts of the foods.

Since the food has been changed into liquid form, it may pass into the blood by osmosis and be carried through the body. Materials that are not digested, or other waste materials, are carried from the digestive system and eliminated. If waste or undigested materials accumulate in undue quantities, the work of the digestive system and eventually of the whole body is seriously interfered with.

282. Circulation. It is a matter of common knowledge that in the higher animals and man the heart is an organ which, by means of its beats, or contractions, forces the blood through the body. The blood flows away from the heart (fig. 124) through arteries, which divide and redivide into smaller and smaller branches. They terminate in many extremely small tubes, known as capillaries, which are interwoven so as to constitute a fine network. These capillaries are directly in 
contact with the cells of the body. The capillaries unite and form the veins which finally, as large veins, lead back to the heart. So rapid is the movement of blood that it is accurately estimated that a given particle may leave the heart, make its

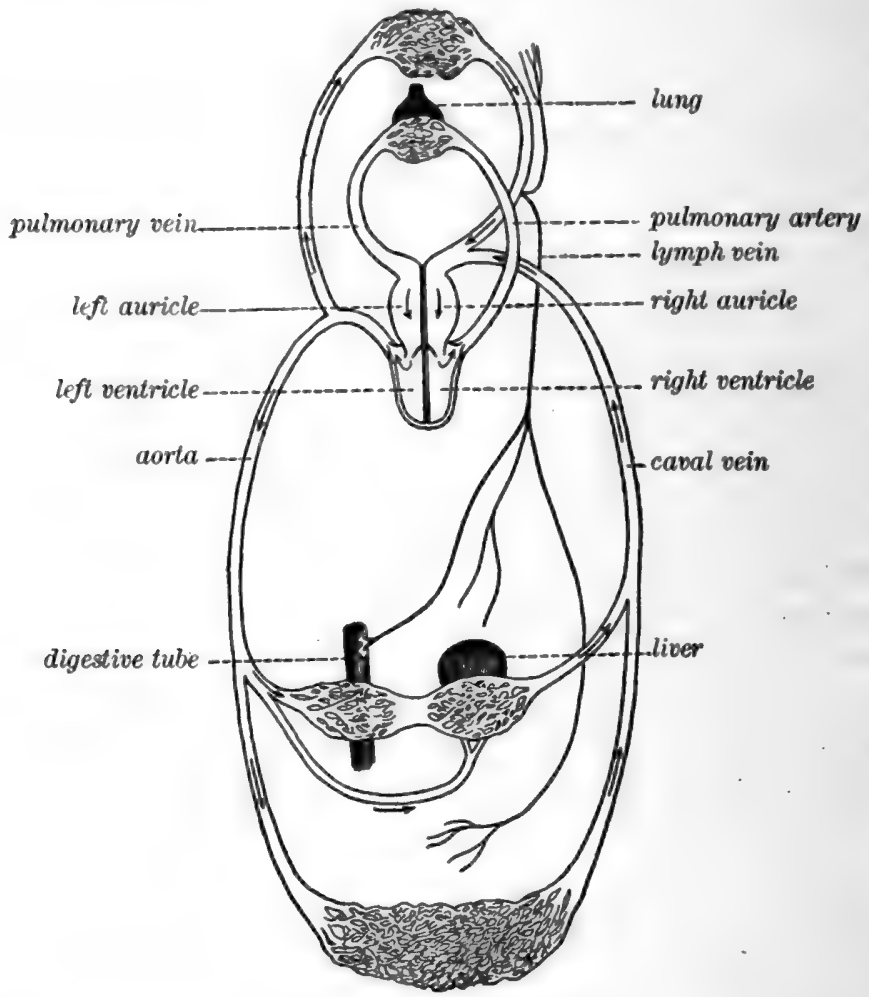

Fig. 124. Circulation of the blood

Diagrammatic representation of the circulation. After Colton

round to one of the more distant parts of the body, and return to the heart within half a minute.

283. The heart as a force pump. The heart consists of four sections, or chambers (two auricles and two ventricles), one auricle and one ventricle on each side of the heart, and they 
are separated by a thin but strong partition. Between the auricle and the ventricle on each side of the heart are valves which at times are closed and prevent the passage of blood. Small valves in the vessels leading to the auricle help to prevent the backward flow of blood. When the blood returns in the larger veins, it enters the right auricle and passes from it into the right ventricle. As the ventricle fills, its valves are closed, so that the blood cannot flow back into the right auricle. There is a large vessel leading from the right ventricle to the lungs. The right ventricle contracts, and when it does so the blood within it is driven through the vessel to the lungs, where it passes through many capillaries. These small vessels gradually merge into the larger ones, until four large vessels lead the blood back to the heart. Upon its return the blood enters the left-auricle and then passes into the left ventricle. It is held momentarily in the left ventricle, and cannot flow backward into the left auricle because of the closure of the valves. The left ventricle is the most muscular of all the four chambers of the heart. Upon its contraction the blood is driven through the large artery which leads away from the left ventricle. From this artery the blood passes to smaller and smaller arteries over the entire body, and finally into the capillaries. From the capillaries the blood passes to the veins, and through them it returns to the right auricle of the heart and again begins its round of circulation.

284. Transportation and assimilation of food. The digested food is absorbed and enters the blood. A new supply of oxygen is taken up as the blood passes through the lungs. This blood, laden with food and oxygen, passes through the heart and is driven through the arteries into the capillaries. From the capillaries the protoplasm takes up needed materials, and the waste products pass into the blood. The process by means of which living protoplasm takes up food material and makes it a part of itself is known as assimilation and was described in the discussion of plant nutrition in section 273 . 
285. Respiration. People often think of respiration as merely involving the process of taking air into the lungs and then expelling it. That process is breathing and constitutes a small and relatively superficial part of respiration. We breathe ordinarily about eighteen times per minute, thus constantly renewing the air within the lungs.

As the blood flows through the thin walls of the tissues of the lungs, some of the oxygen of the air combines with the red coloring matter (hæmoglobin) that is found in the red blood corpuscles. When oxygen is combined with hæmoglobin the corpuscles are bright red. Therefore, when the blood has been in the lungs for a time and its red corpuscles have taken up a load of oxygen, the blood is bright red and returns to the left side of the heart with a distinctly different color from that which it had when it was sent from the right ventricle. While the blood is in the lungs it is also freed from the larger part of its carbon dioxide, so that chemically the blood leaving the lungs is quite different from what it was when it entered them. It contains much less carbon dioxide and much more oxygen.

When the blood is pumped from the left ventricle through the arteries to the tissues of the body, it carries digested food material and a new supply of oxygen. Through the walls of the capillaries the protoplasm of the tissues takes up digested food and oxygen, and at the same time waste products from broken-down protoplasm (carbon dioxide, for example) pass into the blood. Oxygen is used by the protoplasm. When protoplasm breaks down, energy is released, and this energy keeps up the activity and life processes of all living things, both animals and plants. It is this introduction of oxygen into the tissues, and its use therein, that constitutes the most important part of respiration. Respiration includes the exchange of the air in the lungs by breathing, the chemical change of the air in the lungs, and the interchange of oxygen and carbon dioxide in the tissues. 
There are other waste products in the blood which have been taken up from the tissues and which are eliminated through the kidneys.

286. Proper nutrition. From what has been said of the nutrition of man it must be apparent that anything which interferes with any of the processes involved would interfere with ability to work. Energy, as has been seen, is derived from the breaking down of protoplasm, and protoplasm is replenished by food which is digested and brought to the tissues of the body. A poorly nourished body will be deficient in energy. The proper care of the organs of nutrition is very important. This subject is considered in the next chapter. 


\section{CHAPTER XXVIII}

\section{HYGIENIC ASPECTS OF NUTRITION}

287. The purpose of food. Many people do not consider why they take food into their bodies. Doubtless, if asked to give an immediate answer to the question as to why they eat, many would say that it is to satisfy hunger. In a way such an answer would be correct, but it would be superficial. Indeed, if that were the only reason, it would not be worth while to expend all the time and trouble that we do about our eating. One may discipline himself in a few days, as has often been done by men who have fasted, to such an extent that hunger no longer troubles tim seriously. If this were continued, death would ensue, though the person, it is said, might not be conscious of hunger for some time prior to his death.

We eat in order that the body may be nourished, in order that growth may take place, in order that waste protoplasm may be replenished - above all, in order that energy may be brought into the body and used in doing its work, whether it is the beating of the heart or the changes in the brain tissues which make thought possible. Growth and replenishment of protoplasm and the release and use of energy are therefore the real purposes of nutrition.

288. The body a machine. There are many simple machines, as a pair of scissors or a pocketknife, the structure and operation of which are quite easily understood. Few people, however, really understand how a locomotive operates, though most people are interested in learning about it. A smaller number of people know much about the operation of the human body. It is a machine that is far more complex than the locomotive, and a machine which each of us must have a hand in running. 
We have such natural appetites as hunger and thirst, and such pains as headache and stomach ache, which tell us superficially about the needs of the human machine. But sometimes, when these natural guides become intense enough to demand our attention, the machine is already in trouble, and its efficiency is impaired or threatened. If a locomotive engineer did not supply his engine with water until the boiler was nearly empty, it would then be dangerous to add the water. In the human body severe pain is ordinarily an evidence that difficulties have existed for some time. Pain is usually a distress signal. The most efficient use of the body as a machine for using energy is to be had by treating it in such a way that it is neither overfed nor underfed, and that the food is in the best condition for use by the human machine.

289. Prolonged mastication. In the preceding chapter some of the reasons for mastication were stated. Indigestion may be caused by improper mastication, and some students of the human machine believe that nearly all the intestinal troubles are due directly or indirectly to this cause. Large pieces of food are not readily digested in the stomach and intestine. Therefore they should be broken into extremely small pieces while in the mouth.

While the food is being broken into small pieces in the mouth the saliva is mixed with it and makes it partially or wholly liquid, thus facilitating its digestion by other digestive secretions. Furthermore, so much of our food is carbohydrate (starch, sugar, etc.) and is digested by the saliva that the importance of thorough mastication is easily seen. If fruits, bread, pastries, candy, etc. were kept in the mouth and thoroughly mixed with saliva before swallowing, there would be fewer cases of indigestion.

290. Heavy eating. Poor mastication of food is usually associated with overeating. This may result partly from the fact that poorly masticated food does not readily produce a feeling of satisfaction. Since this is true, a rapid eater continues 
to eat until he has swallowed an amount of food much in excess of what he would have desired if he had masticated thoroughly and satisfied his hunger in a proper way. Not only is this extra quantity of food present in the digestive system, but the starchy foods which should have been digested, in part at least, in the mouth add an extra burden to the work of the starch-digesting element of the pancreatic secretion; even here they may not be thoroughly digested and so may not all be used in the nutrition of the body. One is in no danger of being too thorough in the mastication of his food.

291. Variety of food. If one were to eat nothing but carbohydrate food, he would throw the work of digestion upon the saliva and the starch-digesting element of the pancreatic secretion. Similarly, if he were to eat mostly protein food, as meats and eggs, an overburden of work would be thrown upon other elements of the pancreatic secretion. There are more important reasons for a mixed diet, and these reasons lie in the needs of the body. It is generally supposed that the protein foods are the ones that are used in building up tissues, and that fats and carbohydrates are used chiefly as more direct sources of energy. All three kinds of food are needed, and something like a proper balance between them should be maintained. The appetite may serve as a partial guide to the kind of food needed, but it is not fully to be trusted, partly because we are often uncertain concerning the exact kind of food we are hungry for, and partly because our habits of eating often cultivate appetites that may not call for exactly what we need.

It is generally stated that from 100 to 125 grams (about 4 ounces) of protein food per day is needed for a man who is engaged in active work, but it has been proved that people may work well and without discomfort upon less protein. Professor Chittenden of Yale University performed a series of carefully planned tests upon people engaged in various kinds of work - soldiers, teachers, and athletes - and found that they worked well for five months (the period of the 
experiments) on from 40 to 50 grams (from $1 \frac{1}{2}$ to $2 \frac{1}{4}$ ounces) of protein per day. Of course other foods were supplied with the protein foods.

It is safe to say that the following represents an average distribution of foods in making up a proper day's diet: protein, 118 grams; fats, 56 grams; carbohydrates, 500 grams. These amounts may vary greatly, according to personal habits, the kind of work in which one is engaged, and the climate. Men engaged in hard physical work in cold climates demand larger quantities of food than here given, and a larger proportion of fats, while people in tropical regions may work better with smaller amounts of fats and more carbohydrates. In the same way, the quantity of water needed varies in different climates and with different occupations. The proportionate composition of different kinds of food is shown in the tables in section 260 .

292. Contaminated food. Nearly all kinds of food may become the growing place for bacteria or other organisms that will, if allowed to continue to grow, finally bring about the decay of the food. A review of what was said on this point in connection with the discussion of the bacteria and molds (Chapter VIII) will prove helpful. Sometimes these decay-producing organisms are dangerous to human health and sometimes they are not. For example, the blue molds that grow in Roquefort cheese, or the bacteria that ripen other kinds of cheese, are not unwholesome and indeed are the causes of the desired flavors of the different kinds of cheese.

To prevent the decay of foods, preservatives are sometimes used. Small amounts of formalin, benzoate of soda, or other chemicals may be put into the liquid foods, as milk, and will prevent decay; but while from superficial examination such foods may appear to be good, they may at the same time contain enough of the preservative to prove injurious. When milk under exposure to the temperature of ordinary air does not begin to sour within twenty-four hours, it is time to have 
it examined chemically to determine what preservative it may contain. Refrigeration and pasteurization are the safest methods of preserving milk, and these are effective for only a day or two, since they retard but do not prevent the development of bacteria within the milk.

Various kinds of chemicals are used in the preservation of meats. These chemicals are sometimes of a poisonous nature. In most cases, however, preserved meats are injured more by excessive quantities of relatively harmless preservatives. An excessive amount of salt hardens the fiber of the meat and destroys its normal taste. Salt, sugar, etc. are used to cure meat because they take up water so rapidly that bacteria are killed by the extraction of the water from the cells of the bacteria. The older practice of smoking meat gave a coated surface of creosote in which destructive organisms could not live.

293. Food and filth. There is no inherent reason why small particles of earth upon our food should be injurious to our bodies, though they are always unattractive, but dirt of any kind upon our food suggests the possibility of the presence of living organisms that may prove injurious. It is more important, however, to know that our food has been handled only by persons who are free from disease germs than to know that the food is not conspicuously dirty. Apples which are shipped in barrels may have small particles of dirt adhering to them and may not appear so attractive as when highly polished, but if polished by the use of a soiled and bacteria-laden cloth, the apples may thereafter be infinitely more dangerous as food than when first removed from the shipping barrel. Obviously, great care should be exercised to determine whether vegetables and other foods have been handled in cleanly ways. A systematic examination of the vegetable markets, with reports and discussions in class, will prove instructive. Fortunately, thorough cooking will destroy bacteria upon food, and unless it is reasonably sure that there is no contamination, thorough 
cooking should always precede the introduction of food into the body. The body is a machine, and food is the material that builds it up and supplies the energy to run it. Filth and disease bacteria interfere with the normal work and efficiency of the machine.

294. Circulation and nutrition. The rôle of the circulation in carrying digested food to the tissues has already been discussed. It must be clearly understood, therefore, that anything which makes the circulation abnormal will affect nutrition. In most adults the heart beats about seventy-two times per minute. In children and youths the rate is likely to be higher, while in old people it may be lower. By placing a finger upon the inside of the wrist one can usually feel the pulse, which tells accurately how many times per minute the left ventricle is contracting. Count your pulse beats during each of several minutes and determine what the normal average is. By having all members of the class of students report on such calculations the average pulse and the greatest variation of pulses in the class may be determined. After having determined the normal pulse rate, if violent exercise is taken, it will be found that the pulse rate has been increased.

During severe exercise increased release of energy from broken-down protoplasm takes place, and there is increased demand for oxygen and food. This results in increased heart action. In some cases of severe illness during high fever a similar demand is made, with a similar increase of heart action. Prolonged increase above the normal rate means excessive wear upon the parts of the human machine that are affected. A brief period of this unusual stimulation is not necessarily harmful and may often be decidedly helpful.

During digestion excessive exercise retards or stops the digestive processes; hence care should be taken to avoid violent exercise immediately after a heavy meal. Wild animals which feed at irregular intervals, and eat to distention when they do feed, usually become quiet and often sleep for some 
time after feeding. In such cases the chief activities of the body are for a time centered about digestion and the circulatory distribution of food. Animals which feed oftener and eat smaller quantities - man, for example - may safely proceed with some sort of mild exercise after eating.

295. Breathing and nutrition. Experiments similar to those suggested in connection with circulation will enable one to determine that the normal breathing rate is about sixteen times per minute, and also that violent exercise increases the rate. The tissues demand oxygen, which is secured from the blood. The blood's supply of oxygen is replenished in the lungs, where the waste carbon dioxide is disposed of. When an increased amount of blood needing replenishment and purification is hastened through the lungs, there is need of more air in the lungs. It is the demand for oxygen in the tissues which stimulates an increase in the rate of breathing. Any boy or girl who has run until exhausted knows that at such a time the body needs more air than usual. Similarly, in a room in which there is a deficiency of oxygen or an abnormally high per cent of carbon dioxide, the breathing rate may increase unconsciously, owing to the body's call for more or better air. If a mouse or other animal is placed under a bell jar and the air is exhausted, the animal breathes rapidly and with the same violent efforts to get air that are shown by an animal that is exhausted from exercise.

Any exercise which tends to increase the air capacity of the lungs increases one's ability to supply his blood with oxygen and to remove waste products from the blood. Deepbreathing exercises are of great importance in increasing the lung capacity. Vigorous exercise is helpful to many persons, since such exercise often compels them to breathe deeply - a thing which they should practice whether compelled to or not.

It needs no argument to show that pure air is better for the body than impure air. The nasal passages are so constructed as to assist in screening out floating particles, as bacteria and 
dust. "Mouth breathers" are likely to accumulate dust in the passages leading to the lungs, and in large cities with dusty air such persons may accumulate enough dust to prove a menace to the work of the lungs. Collections of dust may become sources of irritation and may be the starting points for the growth of disease germs, such as those of tuberculosis. In wintertime, air that is breathed inward through the nose is warmed before entering the lungs, but if taken in through the mouth, its temperature is changed but little before reaching the lungs and may chill the lung tissue. "Mouth breathers" should consult a physician to determine whether there is any structural reason for their practice. If not, careful attention will enable them to change the habit to normal breathing. 


\section{CHAPTER XXIX}

\section{REPRODUCTION IN PLANTS AND ANIMALS}

296. The meaning of reproduction. Thus far our discussions of plants and animals have dealt with problems in nutrition. In many ways those problems are of the greatest importance. No matter how well nourished a plant or animal may be, its kind will cease to exist on the earth unless there are means by which new and younger individuals can be produced. The process by which younger individuals are produced is known

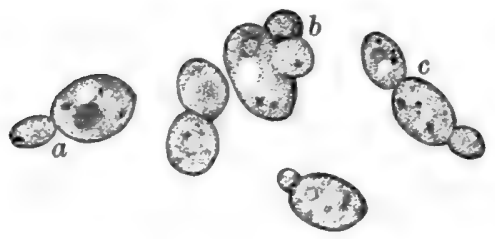

FiG.125. Yeast plants

$a$, a plant from which a bud has begun to grow; $b$ and $c$, plants, each of which has two buds. Greatly enlarged as reproduction (which means "producing again").

In the bodies of plants and animals the cells divide, each cell forming two new cells from one old one. This is reproduction of cells. In most plants and animals increase in number of cells and the enlargement that results is called growth, and not reproduction. Cell division results in reproduction in the case of one-celled animals and plants, as in the bacteria.

297. Reproduction of the yeast plant. The yeast plant consists of a single spherical or oblong cell (fig. 125). It has a simple wall within which are the living substances that constitute the protoplasm. Yeasts get their food material from the solutions in which sugar is dissolved, and in doing so partially decompose the sugar; this partial decomposition results in the production of alcohol. But when nutrition is abundant the yeast plants enlarge and soon begin the 
production of new plants. First there may be noted a small, bud-like outgrowth on one side of the parent plant. This bud enlarges for a time and finally becomes separated. The separated bud is a new yeast plant, and after a brief period of growth it may repeat the budding process by which it came into existence. Indeed, sometimes a large bud, even before it becomes separated from the parent, begins to form a small bud for the production of the third plant in the series.

Budding represents one of the simplest kinds of reproduction. This is known as vegetative reproduction, because reproduction is accomplished by means of the ordinary nutritive, or growing, part of the plant. Many simple animals are reproduced in a similar way.

298. Reproduction of pond scum. Almost everyone has observed the common green "pond seum" floating upon the surface of water or submerged. Some of these are very beautiful plants when seen under the microscope. They are silky threads composed of large cells joined end to end. Sometimes a threadlike plant may become broken into two or more pieces, when each piece may continue to grow as a new individual. This is vegetative reproduction.

Sometimes two of the pond-scum plants.which are near one another perform quite a different kind of reproduction(fig.126). From two cells, one in each plant, there grow two tubular outgrowths. These grow toward one another and unite their tips. They unite in such a way as to form a continuous tubular passage between the cells. When this has been done, all the living substance or protoplasm from one cell passes through the tube into the other cell. The two masses of protoplasm unite, and the mass thus formed becomes very compact and a heavy wall develops closely about it. The old cell walls decay, and the new dense cell goes to the bottom and passes through a resting period which may last through the winter season. At some later time the resting cell grows again, producing a new plant like those that formed it. 
The resting cell is called a spore, which means a special reproductive cell which can form a new plant like those that

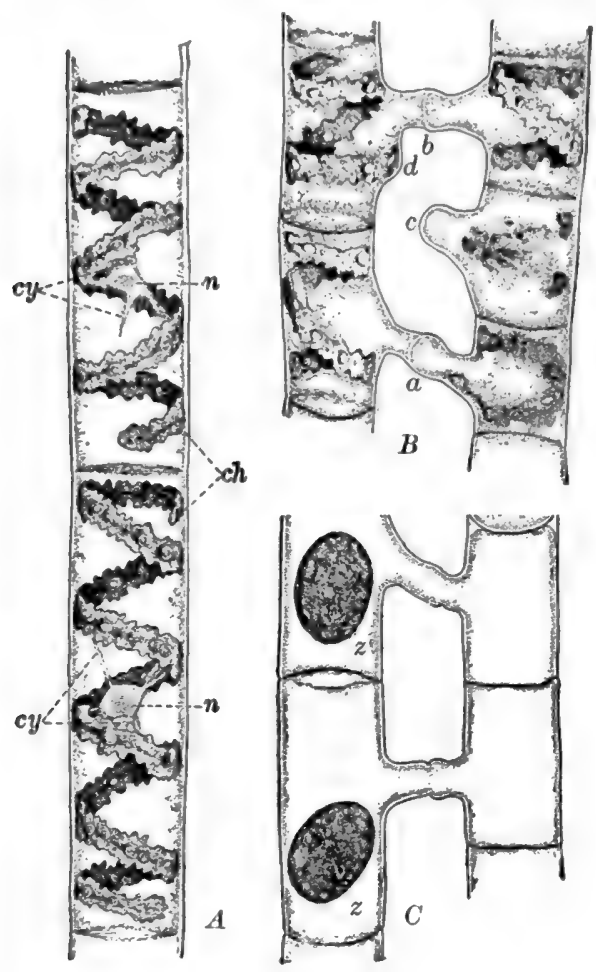

Fig. 126. A pond scum

$A$, two vegetative cells, showing the form of the cell and of the spiral chlorophyll band $(\mathrm{ch})$, also the nuclei of the cells $(n)$, and the granular part of the protoplasm $(c y) ; B$, cells showing the beginning of the union of the tubes ( $a$ and $b$ ), and tubes which have failed to unite $(c$ and $d)$; $C$, completed spores $(z)$ formed the spore. In forming the spore the mass of protoplasm in one cell is fertilized by having the protoplasm from the other cell unite with it. Reproduction that is brought about by having two cells unite to form the reproductive cell is called sexual reproduction. The spore thus formed may be called the sex cell or sex spore. In pond scum many paired cells of two adjacent plants may produce sex spores, and many new plants may thus be provided for.

This one sex cell begins the growth of a new pond-scum plant, and by succes. sive divisions of the cells thus formed a many-celled plant may soon be grown. Whether a plant or animal in its adult form consists of one or of many cells, it consists of one cell at first. This is not true usually of plants or animals formed vegetatively, 
since cuttings, slips, and runners consist of many cells. Sexual reproduction results in the formation of one cell which through growth may become a new plant of many cells. An animal, like a plant, originates from a single cell.

299. The frog's egg. The frog or toad will serve well to illustrate reproduction among animals. The frog is selected for our discussion in the following sections.

Early in the spring, when frogs may first be heard in the ponds, masses of their eggs are easily found. They have the appearance of small black spheres about a sixteenth of an inch in diameter embedded in a transparent jelly (fig. 127). They are usually found in large, numbers, since a single female may lay several thousand eggs. While the eggs appear black as they are seen in the water, it is only the upper surfaces that are dark-colored, the under surfaces being almost white.

Each of these eggs, when laid, consists of a single cell in which is stored a quantity of food material. The egg was formed in the body of the female and expelled into the water when mature. At the same time that the female lays the eggs, the male frog expels from his body into the water a whitish fluid which is shown by the microscope to contain great numbers of very minute cells, known as sperms. The sperms swim about actively in the water and come in contact with the eggs. One of them may enter an egg and unite with it, thus fertilizing it. The fertilized frog's egg resembles the spore of the pond scum in that it is a single cell formed by the union of two cells. Such union of cells - fertilization - occurs in all sexual reproduction.

300. Development of the egg. When the egg of the frog has been fertilized, like the spore of the pond scum it possesses the power of growing into a new organism similar to that which produced it. The first indication of development in the frog's egg is its division into two cells. These again divide, forming four cells, and the process is repeated until the single large egg cell has become a mass of many small 
cells. This mass of cells elongates; mouth, eyes, and tail appear; and the young animal wriggles out of the inclosing jelly. Soon it has the complete form of the familiar tadpole.

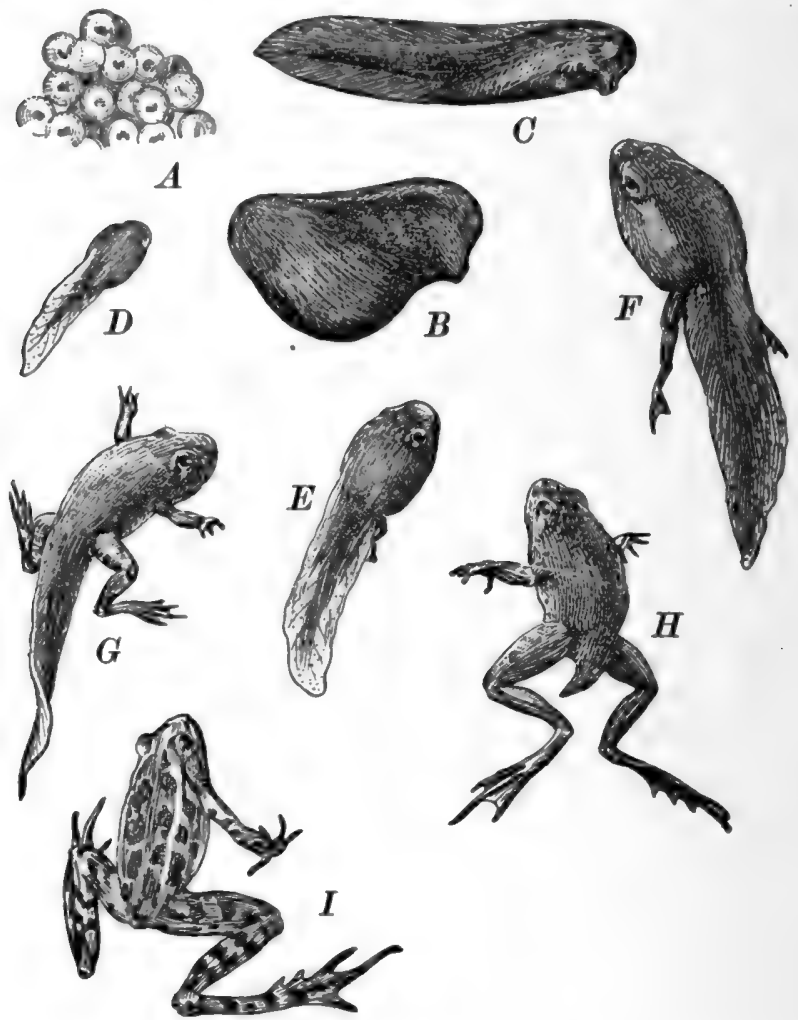

FIG. 127. Development of the frog

$A$, eggs ; $B$ and $C$, early stages of the embryo; $D$, tadpole as commonly seen ; $E$ and $F$, legs appearing ; $G$ and $H$, front legs appearing and tail disappearing ; $I$, mature frog. $B$ and $C$ are enlarged much more than the other parts of the illustration, the others being approximately natural size

301. The tadpole. The tadpoles, or polliwogs, which are commonly seen in the ponds and ditches are the young of frogs, toads, or related animals. The very numerous small, 
jet-black ones are toad tadpoles. All of them resemble fish more closely than they do frogs and toads, so far as appearance and manner of life are concerned. The tadpoles live in the water all the time and breathe by means of gills, as fish do, while the mature animals live upon land much of the time and breathe by means of lungs.

During the hatching period the developing tadpoles have taken no other food than that which was stored in the egg. When they begin to swim about they become voracious feeders, eating minute animals and great quantities of green slime, pond scums, and other minute plants. They grow rapidly, and legs soon appear from the under surface of the body. At the same time the tail decreases in size. The gills disappear also, and lungs are formed. Finally, the tadpole, with a form approaching that of the frog but with some remnants of the tail and gills, creeps out upon the land.

If eggs of the frog or toad are collected carefully and transferred to an aquarium, it is possible to follow the various stages of development at school or at home.

302. Reproduction in birds and mammals. In most of the higher animals the fertilized egg proceeds, immediately after fertilization, to the development of the beginning stages, or embryo, of the adult animal. The exception to the last statement is found in the case of those animals which lay an egg that is incased in a more or less heavy coating, like the eggs of birds and turtles, in which the real egg is a cell similar to the one already described. In these cases there is, in addition to the real egg, a large amount of food material, all of which is incased in the covering. In turtles this covering is a thick, tough, leathery wall; in birds it is thick and fragile, though it varies in its strength in different species of birds. The egg of the bird undergoes a period of incubation ranging from fourteen or even fewer days, in the case of the smaller birds, to four weeks or more, in the case of turkeys, geese, etc. It is possible to discover the stages in the development of the 
embryo by examining eggs in various stages of incubation. It will be seen that at first the small embryo is reddish in color and that radiating lines of blood vessels extend from it into the food material. 'The developing embryo soon differ-

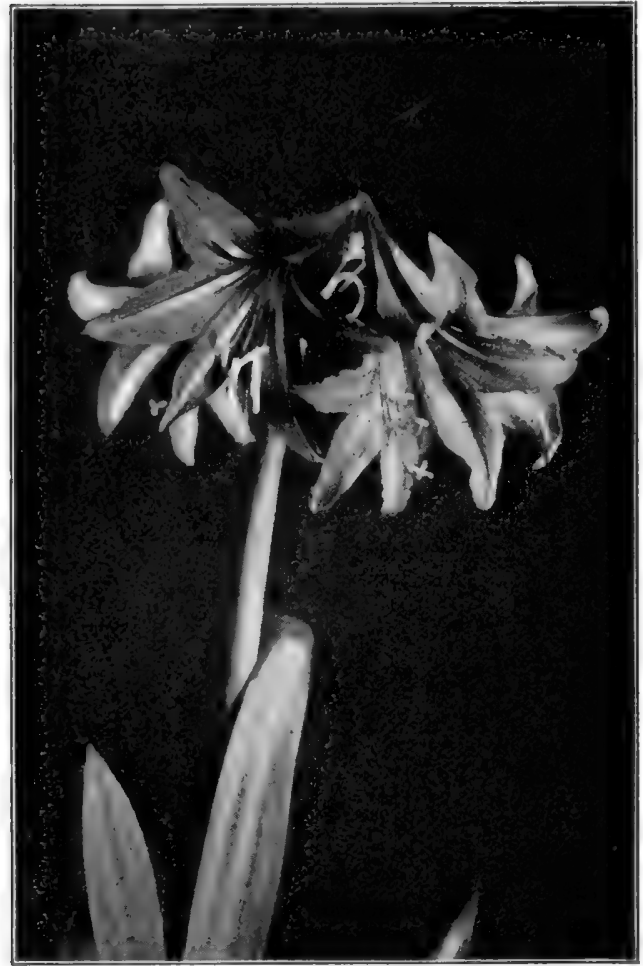

FIG. 128. Flower of amaryllis

The sepals and petals are almost identical in shape and color. There are six stamens and one pistil entiates bone, muscle, nerve, and other tissues. In a short time the organs that are recognized in the adult bird may be found completely differentiated in the embryo that is still retained within the egg wall. It is apparent, therefore, that a development of the embryo within the egg cell has many features in common with the development of the frog, as already noted.

In the higher animals, known as mammals, and in some others, the egg develops into the young animal while still within the body of the mother. In the reproduction of these animals the new individuals are born with their various structures already well formed.

303. Reproduction in seed plants: the flower. Reproduction in seed plants is in some respects quite similar and in others 
quite dissimilar to that of the animals. The flower (fig. 128) is the reproductive organ in seed plants. It consists of four distinctly different kinds of structures; some of these structures may be absent. In a complete flower the lowest floral organs are the sepals (fig. 129), collectively known as the calyx; next above the sepals are the petals, collectively known as the corolla; above the petals are the stamens, and above the stamens, the pistils. In the flowers of some plants the pistils are absent and the flowers are said to be staminate; if the stamens are absent the flowers are pistilate. Sometimes pistilate flowers are borne on somé of the branches of a plant and staminate flowers on other branches.

304. The pistil. Careful observation of the pistil will ordinarily show that there is a swollen basal portion known as the ovary, above which is a more elongated part, the style, and above that the tip portion, known as the stigma. By opening the ovary we may find within it small bodies,

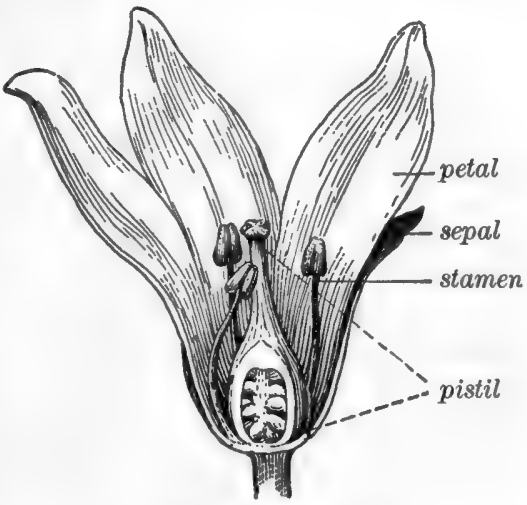

Frg. 129. Diagram of flower, showing the different parts the ovules (fig. 130), which when mature are the seeds. When we take a very thin section of a young ovule and examine it under the microscope, we see that in its center there is an elongated sac, the embryo sac. At one end of the embryo sac the egg cell is formed. Eggs, therefore, may be found in the flowering plant just as truly as in animals, but these eggs remain inclosed within the ovary and are not set free as in the frog.

305. The stamen. The swollen tip of the stamen is the anther. Within the anther there are many small cells, the pollen grains, which, when the anthers break open, are scattered 
in small clouds like yellow dust. When the pollen grains alight on the stigmatic end of the pistil, important changes follow. From the inner wall of the pollen graia there develops a tubular outgrowth which grows down through the stigma and style into the ovule and so reaches the vicinity of the egg. While the pollen tube has been growing down into the. ovule two male cells have developed within it. One of these may unite with the egg cell, thus producing the fertilized egg. Each male cell is capable of fertilizing the egg in the ovule.

306. The embryo plant. After fertilization the egg of the plant - like the egg of the frog - proceeds at once to grow.
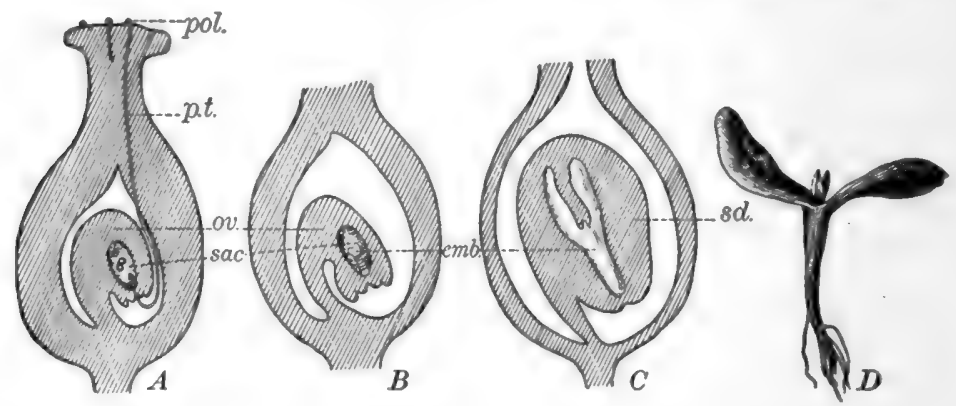

Fig. 130. Diagram to show development of young plant from the egg $A$, entire pistil; $B$ and $C$, development of seed; $D$, seedling plant; pol., pollen grain; $p . t .$, pollen tube; ov., ovule; sac, embryo sac; emb., embryo; sd., mature seed

Through cell division and enlargement one region develops into the root tip, another into the stem tip, and others into one or more leaves. In most cases, when the young plant has developed these different regions, the wall of the ovule becomes hardened and the embryo becomes dormant. This is the mature seed. It may lie dormant for a short or a long period and then grow.

307. The seedling. When seeds of plants are placed in favorable situations, moisture is absorbed by the young plantlet inclosed within the seed coats, and its growth is soon continued. 
The seed coats are burst; the root tip emerges and grows into the earth and develops additional roots. The way in which

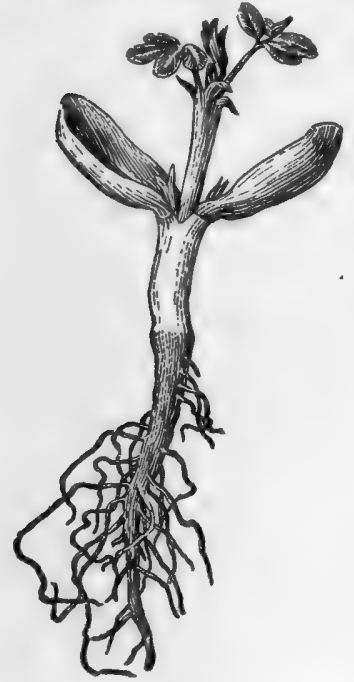

Fig. 131. A peanut seedling the young stem and leaves (fig. 131) emerge from the seed coats is extremely variable. In the seed of the bean there is an elongation of the stem of the young plant. This elongated stem bends in such a way as to pull the leaves out of the seed coats. In other cases, as in the sunflower, the leaves grow upright and push the seed coat into the air, dropping this seed coat only after the leaves have become well separated from one another. When the young plant has become well established in the soil, it may continue its growth and eventually produce flowers and seeds which continue the round of reproduction.

308. Vegetative reproduction. Many plants and animals are able to have individuals arise directly from the old individual without the production of a fertilized egg (fig. 132). It is possible to cut a twig from a willow or cottonwood tree, place it in the ground, and have it grow into a new tree. One may also take cuttings or slips from geraniums, coleuses, and begonias, and plant them so that

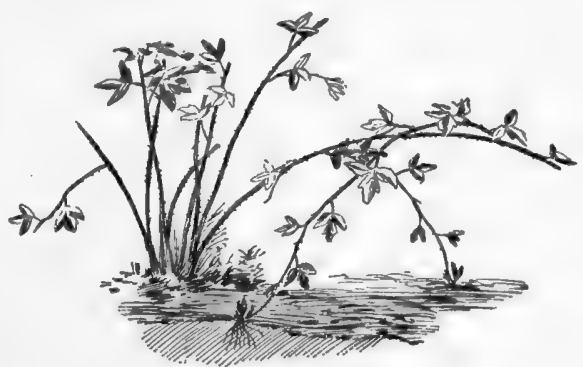

FIG. 132. Vegetative propagation in the raspberry

The ends of the shoots strike root in the earth and grow new plants 
they will grow into new plants. Grapevines are started by means of cuttings. The original Concord grapevine has become the parent of millions of grapevines scattered throughout the civilized world, and this has been brought about entirely by cuttings from the single original grapevine or by cuttings from the descendants of it. This kind of reproduction of individuals is known as vegetative reproduction, because the growing plant is used directly as the means of establishing new individuals.

Different forms of grafting are in a sense types of vegetative reproduction, since they consist in making cuttings from one plant and getting them started to grow upon another plant. It will be found interesting to read agricultural and horticultural books on the subject of grafting, to determine what may be accomplished thereby. 


\section{CHAPTER XXX}

\section{THE STRUGGLE FOR EXISTENCE}

309. Meaning of the term. If we observe a dense forest or a wheat field, we see that there are many kinds of plants that are living under the shade of taller plants. Some of the shaded plants seem to be thriving, and others may show by their condition that they are not doing well. Likewise, along a country roadside or in a vacant lot a great number of plants often start to grow in a relatively small space. By observing such a region at successive periods for some weeks it will usually be seen that fewer and fewer plants persist, and by the time the seeds are ripe the number of plants that have matured is small indeed compared with the number that began growth at the beginning of the season.

Similarly, in a pool of water there may be many hundreds of small fish, tadpoles, and other types of animal life, but only a few mature fish and frogs.

310. Overproduction among plants. We shall get an idea of how the crowded conditions upon the earth are caused if we estimate the number of young that might possibly be produced in a few years from any of our common plants or animals. An ordinary morning-glory plant may bear 3000 seeds in one season; indeed, such a plant often bears considerably more than that number. If each of these seeds should produce a plant that bore 3000 seeds, at the end of the second year there would be $3000 \times 3000$ seeds, or $9,000,000$ seeds. If the second year's crop of seeds should grow in the same way, at the end of the third year there would be $27,000,000,000$ seeds. Similarly, if in the succeeding years all the seeds produced should produce plants like the parent, this one plant with 
which we began, in five years would produce $243,000,000$,$000,000,000$ seeds. If this number of seeds were to grow in the sixth year, and if there is an average of 20 feet of vines to each plant, the total length of the vines of the sixth-year crop would reach over 36 billion times around the earth. Since light travels 186,000 miles per second, how long would it take light to travel the length of this sixth-year crop of morning-glory plants?

Another illustration may show in a better way the possibilities of plant production. A common kind of garden sweet corn may have 4 good ears on a stalk, may have 12 rows of grains on each ear, and may have 20 grains in each row. Therefore one ear may have 240 grains upon it, and one plant may have 960 grains. If each grain produces a new plant the next year, and this process continues for five years, the fifth-year crop will consist of $3,397,346,240,000$ ears. That would be over 37,000 ears for each man, woman, and child in the United States. That would be two ears of sweet corn per day for each man, woman, and child for over fifty years.

Other calculations based upon actual rates of reproduction show equally well what enormous numbers of individuals would soon be produced if these possibilities were allowed to become realities. Jordan says, "An annual plant producing two seeds only would have 1,048,576 descendants in 21 years, if each seed sprouted and matured." It is a matter of common knowledge, however, that the enormous reproduction suggested by these figures does not really occur.

311. Overproduction among animals. Animal reproduction in enormous numbers is also inherently possible. A single female codfish has been known to produce as many as 9,100 ,000 eggs in one year. A female salmon fish four years old may lay 4000 eggs. If half of these 4000 eggs grew into female salmon and produced 4000 eggs each, as did their mother, there would be $8,000,000$ eggs. If we suppose that each of these $8,000,000$ grows into an adult salmon four years 
old and weighing 20 pounds (although four-year old salmon often weigh more than 20 pounds), there would be $160,000,000$ pounds of salmon in this third-generation crop. If these salmon were packed in tins and should net three fourths of their original weight, or $120,000,000$ pounds, and should be sold at ten cents per pound, they would be worth $\$ 12,000,000$; or if the inhabitants of a city of 10,000 people were to use an average of one fourth of a pound per day for each person, this third generation of salmon would supply this eity of 10,000 people for 48,000 days, or for more than 131 years.

Any given species of animal has an inherent rate of reproduction which makes enormous numbers of that species possible if we assume that this inherent rate is to have no limitations. Many an enthusiastic resident of a city has made calculations regarding the number of chickens that may grow in a small number of years from a small initial number of chickens. Some city residents have even moved into the country expecting to grow chickens in numbers comparable to these inherently possible numbers. They have found that important limiting factors prevent the realization of their hopes.

In the first place, it is clear that there is not space enough for more than a small part of the new individuals to develop. Every open space that offers anything like reasonable living conditions for plants and animals is soon occupied by them. If the fifth-year crop of sweet corn, as calculated aboves were planted as corn is ordinarily planted, it would require about 2000 times the land area of Illinois in which to plant it. If one hive of honeybees were to produce for six years as rapidly as inherently possible, and these bees should be housed in hives each of which has 4 square feet as its standing place, the state of Illinois would not supply standing room for the total crop of bees.

Space is too limited for any given kind of plants or animals to increase very rapidly. In a rich river bottom, in a vacant lot, in almost any place where plants and animals may get started to grow, the struggle for space is evident. In the tree 
tops the birds contend for nesting places. The English sparrow has driven many native birds away from their former nesting places. Agriculture has occupied the territory formerly occupied by many kinds of native plants and animals, and has introduced other kinds of plants and animals into the old haunts of native living things.

312. Not food enough for all. The city man who would make a fortune growing chickens finds that his expense for feed is large, often so large that he cannot afford to raise chickens; and if the possible rates of increase are made real for even a short period, it is soon evident that neither space nor food is sufficient. In nature the tragedy of the shortage of the food supply is frequently seen. It would be seen constantly if it were not for the fact that one kind of living thing may serve as food for one or many other kinds. When salmon become quite abundant, other kinds of fish, or other animals, may devour them in large numbers. In our fresh-water streams and lakes the black bass may produce hundreds of eggs and guard them until the young are hatched and are a few days old. After the mother fish has left her young, she as well as other fish may catch and devour any of them that are not so fortunate as to escape when pursued. In this way not so much food is needed for young salmon and young bass, because some of these fish have become food for others. The few of any kind of living things that reach maturity are to be looked upon as the ones that have "run the gauntlet" and have been able to secure enough food to nourish them and enable them to grow, while at the same time avoiding the catastrophe of serving as food for some other hungry animal.

313. Climatic dangers. An unexpected and severe storm in early summer leaves in its path a mass of wreckage, as broken trees, flattened grain, upturned nests of birds, drowned nestlings, and insects killed by wind or water. The small and inconspicuous forms of life that are killed are more numerous than the larger ones. At other times sudden changes 
in temperature prove extremely destructive. When migratory birds are caught in snowstarms, many die. The American golden plover flies southward in the autumn migration over the Atlantic Ocean from Nova Scotia to the Lesser Antilles or even to South America. Often these birds are caught in heavy storms, many doubtless perishing at sea and many being driven ashore in an injured condition. Rainstorins accompanied by hail cause the death of young birds, insects, and some larger animals, and of large, numbers of plants. Excessive heat, drought, and other climatic causes are important factors in the elimination of living things.

314. Destruction by disease. A visit to a corn field or wheat field will usually enable one to discover a parasitic plant known as smut growing upon the corn or wheat. This smut is securing its nourishment from the host plant. After a time it produces its reproductive spores, by means of which new smut parasites may get started on new host plants. But the host plant suffers and may be killed by the smut. Its supply of nourishment may be taken by the smut or the smut may produce poisonous substances that severely affect the host. The smut is merely growing in its own way, but in so doing it may cause the death of other plants.

Bacteria, fungi, and some animals cause the disease and death of other living things. So universal is disease that we scarcely know what is meant by " natural death." In nature, when animals begin to get old and their bodies operate less effectively than when they were younger, such animals are more readily captured by food-seeking animals or are more susceptible to disease. In nature, so called natural death of animals is rarely if ever seen.

315. The balance of life. The grass of the field is eaten by herbivorous animals, and herbivorous animals are eaten by carnivorous animals. It would seem, therefore, if we are to look no farther into the matter, that the number of carnivorous animals is limited by the available grass for grass-eating animals. 
But the balance of life is maintained by complex relations between many kinds of living things. When a grasshopper lays its eggs, the animals that can use grasshopper eggs as food begin to destroy them if they find them. If the eggs hatch, the young grasshoppers begin at once to eat the tender leaves of grass and other vegetation. When there is a large number of grasshoppers, there is danger of destruction of the kinds of vegetation that are used as food, and in any case the vegetation may be hell in check. But birds feed upon grasshoppers, a single bird often eating in one day as many as the entire brood of one mother insect. In California a meadow lark was known to eat 314 grasshoppers in one feeding, and flickers have been known to devour over 5000 ants in one day. Obviously, the insects that survive are the ones which, while getting their own food, escaped the birds and also the diseases and climatic dangers that surrounded them.

The birds that devour the insects are themselves the food for other animals; they too are in danger of disease, cold, heat, and drought, and but few of their kind survive. Every natural region is to be looked upon as a society of living things, each one of which bears certain definite relations to some or many of the others. The squirrels in the woods thrive fairly well, and in undisturbed nature their number remains fairly constant. If they increase too rapidly for a while, their food supply becomes too small or their enemies thus find a larger supply of food and likewise thrive, and in so doing reduce the number of squirrels. If the squirrels are removed from their normal regions, where they play a part in the balance of life, they may fail completely or may find new and unusual conditions well suited to them. How closely living things are related to their surroundings may be shown by supposing a change in living places between a wolf of the Western plains, a squirrel of the Central States forest, and a fish of the Gulf of Mexico. Neither would survive if placed in the region in which the others live. 
Man has disturbed the natural balance of life wherever he has gone. When he cuts a forest, plows a field, drains a swamp, or builds a city, many kinds of life are destroyed either directly or because the necessary conditions of life are removed. Agriculture and horticulture, in fact, are attempts of man to introduce new kinds of life where they did not exist. The destruction of the wheat crop by insects, of cotton by the boll weevil, and of apples by the codling moth are evidences that as yet man has not succeeded in maintaining his artificial balance of life without great loss.

316. Types of disturbance of nature's balance of life. Perhaps one of the best illustrations of what occurs when plants and animals are introduced into new territory is shown in Australia, though the same thing may be seen in a small way in almost every locality. The common rabbit was introduced into Australia, and, finding favorable conditions, it multiplied astonishingly. Under favorable circumstances a pair of rabbits will produce each year six litters, averaging five young in each. Since rabbits feed upon vegetation, when present in large numbers they competed with eattle and sheep to such an extent that the grazing industry was almost destroyed in some sections of Australia.

It requires but a brief calculation to show that our previously acquired facts about rapid multiplication hold true for these rabbits.

Professor Sidney Dickinson says: "The original pair might be responsible in five years for a progeny of over twenty millions. That the original score that were brought to the country have propagated after some such ratio, no one can doubt who has seen the enormous hordes that now devastate the land in certain districts. In all but the remoter sections the rabbits are now fairly under control; one rabbiter with a pack of dogs supervises stations where 100 were employed ten years ago. Millions have been killed by fencing in the water holes and dams during a dry season, whereby they died of thirst and 
lay in enormous piles against obstructions they had frantically and vainly striven to climb, and poisoned grain and fruit have killed myriads more. A fortune of $£ 25,000$ offered by the - New South Wales government still awaits the man who can invent some means of general destruction, and the knowledge of this fact has brought the various colonial governments some very original devices.

"Another great pest to the settlers is developing in the foxes, two of which were imported from Cumberland some years ago by a wealthy station owner, who thought that they might breed and give himself and friends an occasional day with hounds. His modest desires were soon met in the development of a race of foxes far surpassing the English variety in strength and aggressiveness, which not only devour many sheep, but out of pure depravity worry and kill ten times as many as they can eat. When to these plagues is added the ruin of thousands of acres from the spread of the thistle, which a canny Scot brought from the Highlands to keep alive in his breast the memory of Wallace and Bruce, and in New Zealand the blocking up of rivers by the English water eress, which in its new home grows a dozen feet in length and has to be dredged out to keep navigation open, it may be understood the colonials look with jaundiced eye upon suggestions of any further interference with Australian nature.

"Not to be outdone by foreign importations, the country itself has shown in the humble locust a nuisance quite as potent as rabbit, fox, or thistle. This bane of all men who pasture sheep on grass has not been much in evidence until within the last few years, when the great destruction of indigenous birds by the gun and by poisoned grain strewn for rabbits has facilitated its increase. The devastation caused by these insects last year was enormous, and befell a district a thousand miles long and two thousand miles wide. For days they passed in clouds that darkened the sky with the gloomy hue of an eclipse, while the ground was covered with crawling 
millions, devouring every green thing, and giving to the country the appearance of being carpeted with scales. It has been discovered, however, that before they attain their winged state they can easily be destroyed, and energetic measures will be taken against them throughout all the inhabited districts of Australia whenever they make another appearance." 


\section{CHAPTER XXXI}

\section{PARENT AND OFFSPRING}

317. Which plants and animals are to live. A casual ob. server, when looking at a forest, would say that many of the

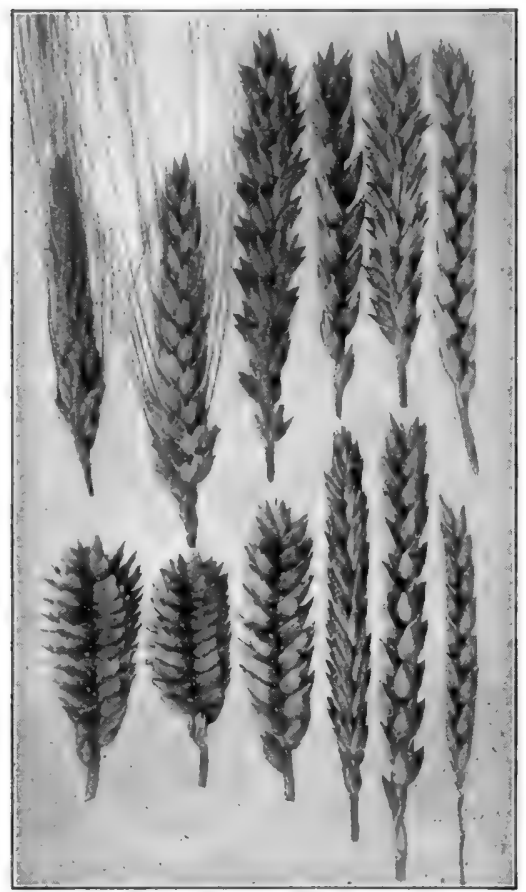

Fig. 133. Variation in wheat

These heads are taken from wheat that was grown by the Pima Indians. Note the wide differences in characters of the heads. The number of inferior heads is so great that the yield would be small. Photograph by R. M. Mear trees are alike. As soon as he looks closely and attempts to find two that are exactly alike, he finds himself in difficulty. It is exceedingly doubtful if any forest, however large, contains two trees which are exactly alike. It will be instructive to try to find two exactly like objects of the same kind, as leaves of an oak or maple tree, pebbles on the shore of a lake or bank of a stream, or chickens or pigs in a barnyard.

While we should have difficulty in finding like objects of the same kind, we should rarely fail to recognize the relationship of the same kind of objects. We can recognize oak trees, and most people can distinguish between red oaks, white naks, black 
oaks, etc. Even the descendants of a given set of parents bear such resemblances that we readily recognize their relationship. One family may have common characteristics that separate them from other families of children, but the different members of the family have distinctive characteristics.

The apparently opposed statements which follow are therefore true: individuals of the same kind are never exactly alike, but ordinarily these individuals have so many common characteristics that their relationships are readily seen.

318. The nature of variation. Individuals of the same kind may differ from one another in almost every feature of which they consist (fig. 133). If one selects the most widely different grains of corn that he can find on a single ear, he will usually be surprised at the variation. This is still better shown by selecting grains from different ears grown in different places. These are merely form and surface variations. Other kinds of variations in corn will be discussed later.

Equally great variations are found in other seeds. For instance, the seeds of the common ragweed usually have distinct spines upon the surface, but the number of spines varies. The form and surface of 100 seeds were studied. The table below shows the variation as found in the number of spines in these 100 seeds :

Number of spines,

Times occurring,

$$
\begin{aligned}
& 1,2,3,4,5,6,7,8,9 \\
& 1,3,7,9,25,37,25,12,1
\end{aligned}
$$

The common bur marigold has conspicuous yellow ray flowers. The number of these ray flowers varies, though this variation is often unnoticed. A count of 315 heads of this plant was made, and by means of this count the following table was derived:

$\begin{array}{ll}\text { Number of ray flowers, } & 3,4,5,6,7, \quad 8,9,10,11 \\ \text { Number of times occurring, } & 2,3,8,16,52,221,9,0,1\end{array}$

It is not only the form or the number of parts that varies, but the chemical composition. In connection with attempts to grow 
the best types of corn for the different needs of agrieulture and other inclustries, careful studies were made to determine the percentage of oil and of protein substances in corn.

It was found that in some of the ears the percentage of protein was as high as 12.54 per cent, while in other ears it was as low as 8.96 per cent. Likewise the oil content ranged from 5.39 per cent to 4.03 per cent.

319. Hybrids. One of the best breeds of cattle for the beef-producing sections of the United States is the Hereford

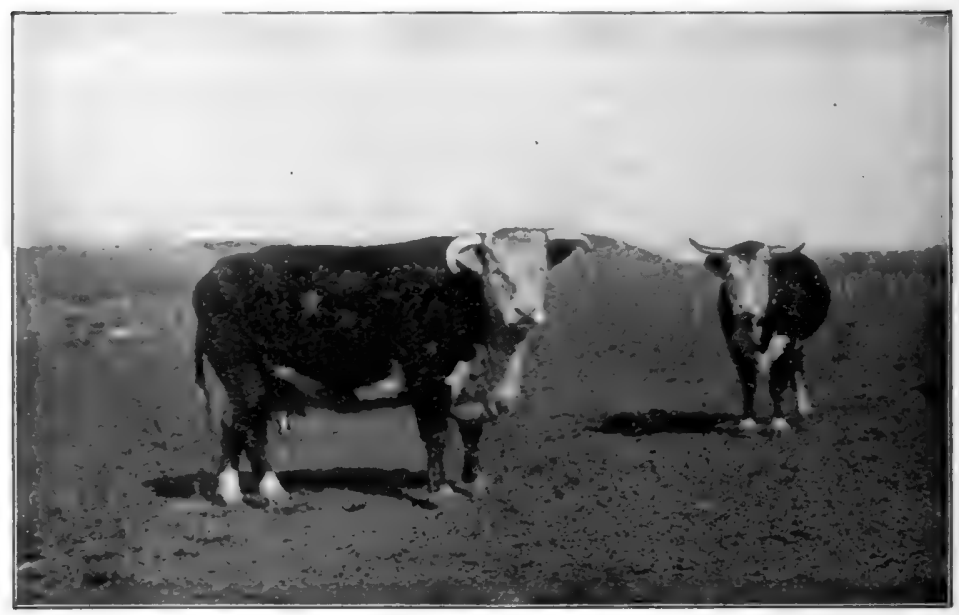

FIG. 134. Hereford cows

One of the breeds of domesticated cattle. Photograph by Robert K. Nabours

(fig. 134). In some parts of the country Herefords and other breeds of cattle have been seriously affected by a disease carried by the cattle tick, and the cattle industry has suffered greatly from this cause (sect. 115). The zebu, or Brahman bull, of India (fig. 135) is immune to the tick and is thus free from the disease which the tick carries. The zebu is not ordinarily regarded as being as good for beef production as our native cattle. It occurred to certain cattle growers to produce 
cattle by interbreeding Herefords and zebus, in the hope that the offspring might possess the desirable beef qualities of the IIereford with the tick immunity of the zebu. As a result of this experiment offspring were produced (fig. 136) showing various characteristics of the two kinds of parents. Offspring produced by crossbreeding are known as hybrids.

Some of the hybrid cattle produced as a result of the experiment just cited resemble the Hereford, some resemble the

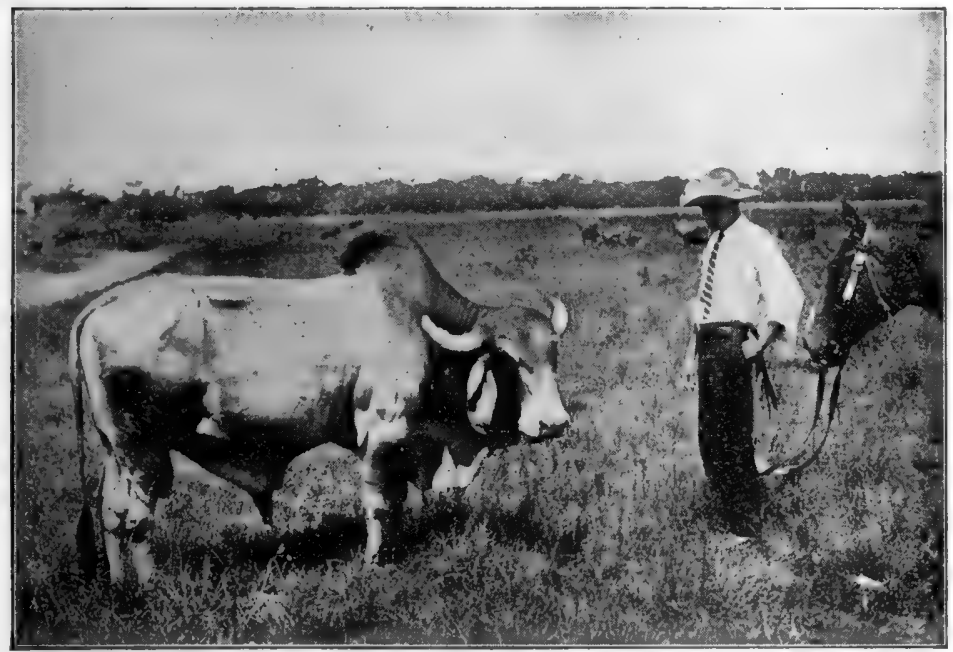

Fia. 135. A bull of the Brahman, or zebu, breed from India

The hump over the shoulders and the backward pointed horns are characteristic features of this animal. Photograph by Robert K. Nabours

zebu, and some bear partial resemblance to both kinds of parents. Some of the offspring retain the bodily form of the Hereford and the zebu's immunity to the cattle tick. Those individuals which retain these qualities are now being used as parents for the production of other cattle, with the expectation that this new hybrid breed will retain the desired qualities and thus become the solution of a serious practical problem. 
Among plants and animals many hybrids are constantly being produced. It is recognized that hybridization presents an important method of production of variations.

320. Natural and artificial selection. Whenever variations occur we may in a measure determine which variants shall have a chance to reproduce their kind. In the next generation variations will again appear and selection will again be necessary if we desire to perpetuate the type which has been selected.

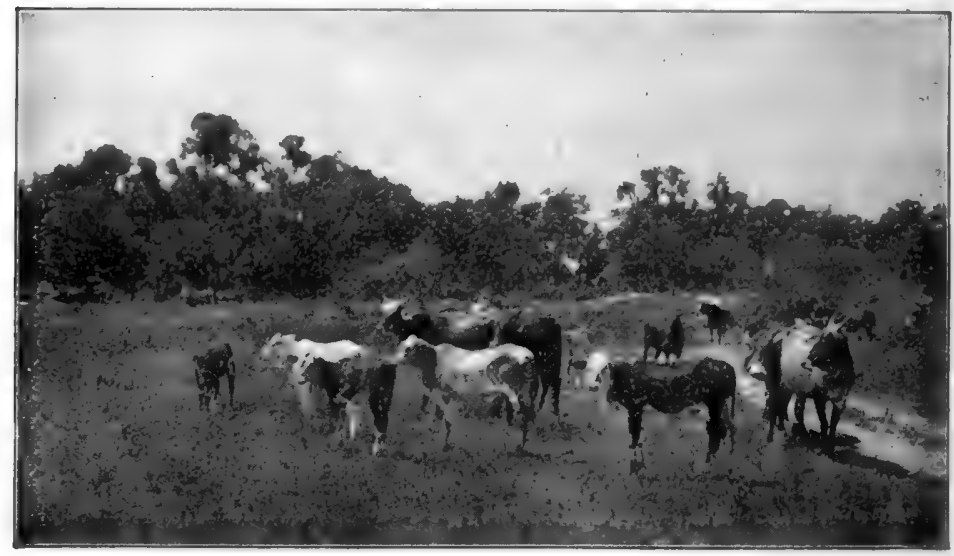

Fig. 136. Hybrids between a zebu and Hereford cattle

The humps and horns in some cases show relationship to the zebu, but coloring and general conformation of body are usually like those of the Hereford. Some of the hybrids, like the zebu, are free from the tick, which carries Texas fever. Photograph by Robert K. Nabours

It is possible to make a race of plants or animals less variable by selecting constantly for a certain type, and by eliminating the variations which do not conform to that type.

Man decides which of all the variations he desires for his own use and then tries to maintain these particular types and eliminate the others. This constitutes artificial selection. In open nature, through natural selection, those things that can live are the ones that do live. The animals of the extremely cold countries vary in the thickness and heat-retaining qualities 
of their coats of fur. They vary also in their fleetness in pursuit of food, in their ability to escape enemies, and in their physical endurance of the rigor of their environment. Those whose variations best fit them for their environment are usually the ones that live. The others die of hunger or of physical hardships, or by being caught and killed by their enemies. In succeeding generations, year after year, variations occur, and the animals that can endure the conditions of their environment are the ones that live.

321. Changes in environment. Any change in the environment affects the living things within it. Indeed, the changes in plant and animal life are in themselves fundamental changes in the environment, for plants and animals constitute a most important part of the environment. For example, when wolves, foxes, and rabbits occur in undisturbed nature in their usual numbers, since the wolves and foxes may feed upon rabbits when they can catch them, only those rabbits can live which can escape from, the wolves and foxes (and other enemies). If we suppose that there is an epidemic of disease which kills off all the wolves and foxes over a territory of 100 square miles, the environment for rabbits is greatly altered. Under such conditions many rabbits can live which could not live if the wolves and foxes were present in their usual numbers. It is evident that, with all the rabbits that are produced, with their many slight individual variations, normally only those can live that can escape from the wolves and foxes; but with wolves and foxes absent there is a much greater breadth of variation among rabbits that may now persist. Thus, the changed environment, so far as these factors are concerned, is favorable to the life of a larger number of rabbits.

But what do rabbits live upon? In one region in which rabbits live they eat in winter large quantities of buds from low shrubs (as young trees of sassafras, hawthorn, etc.). An unusual increase of rabbits thus greatly affects the environment 
for plants upon which rabbits feed. The supply of food may become exhausted, and starvation of the rabbits may result largely because of the success of the large number of rabbits in escaping the animals that prey upon them.

The environment changes, therefore, for wolves and foxes, for rabbits, and for the plants upon which rabbits feed, but these are only a small part of the factors that make up the natural environment in any region. The whole matter is extremely complex and is constantly changing. This constant change in the environment means constant change in the kinds of things that may live. Variants that can live in one environment may sometimes be unable to live in the same region when it has undergone extensive changes.

322. Results of natural selection. We have seen from our studies of overproduction and variation that many variable forms are introduced upon the earth, most of them failing to live to adult size and failing to perpetuate their kind. The living plants and animals now found are to be looked upon as the few that have persisted. Not only this, but natural selection is still going on, and we must not look upon the things now living as the final types of inhabitants of the earth. They are merely the results of nature's processes at this time, and nature is still working.

323. Artificial selection. Man selects those variations that give promise of being advantageous to him in some way. He tries to adjust the environment about these plants and animals so as to produce the best results. If he wishes to produce an animal that will furnish beef in large quantities, he selects and grows the variety which most nearly resembles his ideal. He then tries to create the most favorable environment by careful feeding, pasturing, and housing, and by warding off disease. In the same way sheep, swine, driving horses, corn, wheat, coffee, carnations, and roses are selected and grown under artificial conditions, and results are produced which are often very unlike those found in undisturbed nature. 
324. Progressive results of artificial selection. While we are still in ignorance of many factors that have to do with the differentiation of two types of plant from one ancestral stock, we have at hand a good many experiments that are instructive (fig. 137). A study of the accompanying tables based upon ten years of experimentation with coln breeding

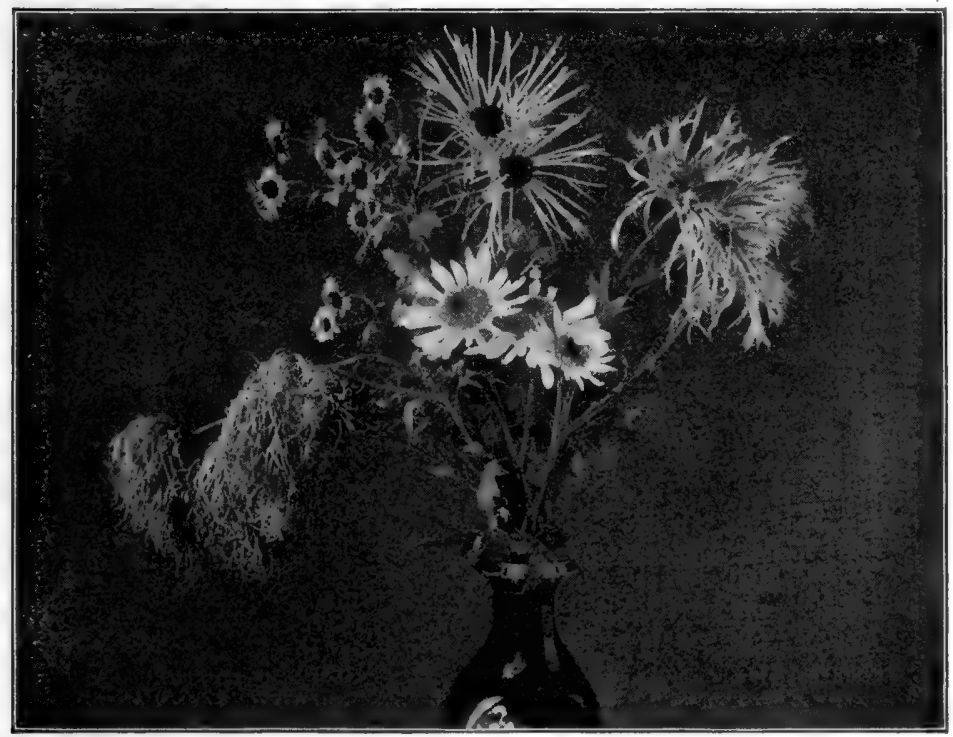

F1G. 137. Diversity of form produced by selection and breeding Five varieties of Chrysanthemum. All chrysanthemums have descended from a common ancestor similar to the small upper left-hand specimen

shows that by constantly eliminating the undesired variations and maintaining the desired variations it is possible to accentuate the selected characters. In studying the first of these tables note the gradual increase of the percentage of protein materials in one lot and the corresponding decrease in the other lot. For feeding purposes the corn with the largest amount of protein would be more valuable. 
Ten Generations of Corn which was bred for Increase and Decrease of Protein ${ }^{1}$

\begin{tabular}{|c|c|c|c|c|c|c|}
\hline \multirow[t]{2}{*}{ YEAR } & \multicolumn{2}{|c|}{$\begin{array}{c}\text { High-PRotein Plot; } \\
\text { AVERAge PER CeNt } \\
\text { Protetn }\end{array}$} & \multicolumn{2}{|c|}{$\begin{array}{l}\text { Low-Protein Plot } \\
\text { AVERAG PER CeNT } \\
\text { Protein }\end{array}$} & \multicolumn{2}{|c|}{$\begin{array}{l}\text { Per Cent of } \\
\text { Difference } \\
\text { Between Cropg }\end{array}$} \\
\hline & $\begin{array}{l}\text { In seed } \\
\text { planted }\end{array}$ & $\begin{array}{c}\text { In crop } \\
\text { harvested }\end{array}$ & $\begin{array}{l}\text { In seed } \\
\text { planted }\end{array}$ & $\begin{array}{c}\text { In crop } \\
\text { harvested }\end{array}$ & & \\
\hline 1896 & - & 10.92 & - & 10.92 & .00 & $\therefore$ \\
\hline 1897 & 12.54 & 11.10 & 8.96 & 10.55 & .55 & \\
\hline 1898 & 12.49 & 11.05 & 9.06 & 10.55 & .50 & \\
\hline 1899 & 13.06 & 11.46 & 8.45 & 9.86 & 1.60 & \\
\hline 1900 & 13.74 & 12.32 & 8.08 & 9.34 & 2.98 & \\
\hline 1901 & 14.78 & 14.12 & 7.58 & 10.04 & 4.08 & \\
\hline 1902 & 15.39 & 12.34 & 8.15 & 8.22 & 4.12 & \\
\hline 1903 & 14.30 & 13.04 & 6.93 & 8.62 & 4.42 &..$^{2}$ \\
\hline 1904 & 15.39 & 15.03 & 7.00 & 9.27 & 5.76 & $\hat{i}$ \\
\hline 1805 & 16.77 & 14.72 & 7.09 & 8.57 & 6.15 & $: ?$ \\
\hline 1906 & 16.30 & 14.26 & 7.21 & 8.64 & 5.62 & $\ldots:$ \\
\hline
\end{tabular}

For the manufacture of corn oil it is desirable to secure varieties of corn having a large proportion of oil. In the table on page 299 it will be possible to note the gradual separation of two races of corn which differ greatly in the proportion of oil present, though all have descended from the same original lot of corn. The figures at the top and in the margins represent percentages of oil ; the figures in the body of the table indicate the number of ears of the indicated composition.

It is likely that if all these samples of ears of corn had been left to grow side by side, no such differentiation of the two races would have developed. They have been separated from one another only by selection and perpetuation of the desired types and by elimination of the others.

325. The weakness of the artificially selected types. The plants and animals that have been developed by man artificially could not persist long in their present form if removed from the care of man. A corn field, if left from year to year,

1 Bulletin 128, Ill. Agr. Ex. Sta., 1908. 


\begin{tabular}{|c|c|c|c|c|c|c|c|c|c|c|c|}
\hline 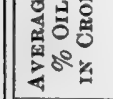 & \% & 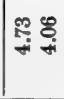 & 象 & 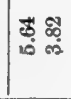 & 䑻点 & 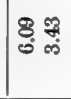 & F⿱ & 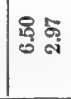 & 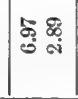 & 蛋 & 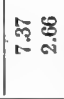 \\
\hline 098 & & & & & & & & & $1-1$ & $1+$ & 10 \\
\hline 968 & & & & & & & & & |a & 100 & | \\
\hline $00 \% 8$ & & & & & & & & & 10 & 10 & $\mid \infty$ \\
\hline 922 & & & & & & & & $1-$ & $1 \infty$ & 19 & 18 \\
\hline $0 g^{\prime} 2$ & & & & & & & & is & $\Phi$ & 1 & के \\
\hline 982 & & & & & $1-$ & $1-$ & $1-$ & 10 & $\infty$ & $\vec{\nabla}$ & 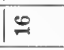 \\
\hline 002 & & & & & 19 & 10 & 10 & 19 & 19 & 129 & | \\
\hline $92 \%$ & & & $1-1$ & & $10^{\circ}$ & 19 & 19 & |न & 와 & 19 & 10 \\
\hline $0 \% 9$ & & & |ब & 10 & $\Phi$ & 18 & 10 & $\Phi$ & $\left.\right|^{\infty}$ & 10 & 10 \\
\hline 969 & & & |N & | 9 & $1 \%$ & |ี & $\Phi$ & I & 10 & |r & \\
\hline 009 & $1-1$ & & 10 & $\mid \approx$ & 19 & $1 \%$ & 19 & 19 & $1 \infty$ & & $1-$ \\
\hline $9 L 9$ & | & $1-$ & |क्ष & $\mid \vec{\Delta}$ & $\mid \infty$ & $\mid \Phi$ & 19 & 10 & & & \\
\hline $\operatorname{oss} s$ & 10 & 10 & | & कक्ष & 10 & 10 & 100 & $1-$ & & & \\
\hline 989 & 19 & 10 & 188 & $\mid \Phi$ & $1 \infty$ & $1 \infty$ & 10 & & & & \\
\hline 00.9 & | & | & 18 & 요 & $\mid-1$ & 10 & |N & & & & \\
\hline $\left.9 L^{\circ}\right\rangle$ & $1 \%$ & 920 & $\mathrm{~ms}^{-1}$ & |er & $1-1$ & & & & $1-$ & & \\
\hline $0 g^{\circ} \sigma$ & 7 & $\Leftrightarrow$ & $180^{\circ}$ & $\infty$ & $m$ & & & & & & \\
\hline 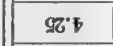 & 18 & igs & 109 & $1-\$$ & 0 & $=$ & & & & & \\
\hline $00^{\circ} \mathrm{T}$ & 19 & $\infty$ & $1+\overrightarrow{\text { का }}$ & $\mathscr{\infty}$ & 8 & $\infty$ & & & & & \\
\hline 928 & 17 & $\pi$ & $\overrightarrow{~ क े ~}$ & 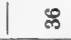 & 댐 & 8 & 20 & & & & \\
\hline 098 & & $\mid-\infty$ & $\theta$ & 앙 & 8 & $\%$ & $\infty$ & 10 & $*$ & & - \\
\hline $98 \%$ & & & $\infty$ & 10 & 잉 & के & 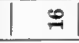 & ष्ष & 19 & -1 & \& \\
\hline $00^{\circ} \varepsilon$ & & & & $\infty$ & $\infty$ & 9 & 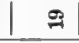 & 8 & $\vec{~}$ & 9 & $\Phi$ \\
\hline$S L Z$ & & & & -1 & $\infty$ & N & 感 & 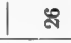 & \$ & $\overrightarrow{~ ह ै ~}$ & 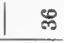 \\
\hline org & & & & & $I$ & & ${ }^{\circ}$ & $\infty$ & -1 & $g$ & के \\
\hline 967 & & & & & & & -1 & $=$ & $\infty$ & ส & 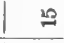 \\
\hline $00 \%$ & & & & & & & & & & $*$ & + \\
\hline $92 \pi$ & & & & & & & & & & - & \\
\hline 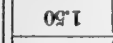 & & & & & & & & & & & - \\
\hline 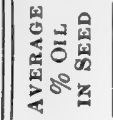 & & 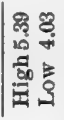 & 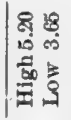 & 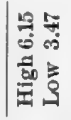 & 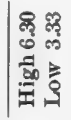 & 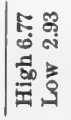 & 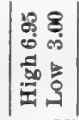 & 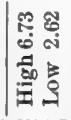 & 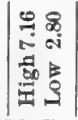 & 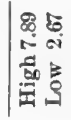 & 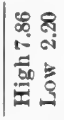 \\
\hline 草 & 参 & 鴱 & 急 & 密 & 然 & $\overrightarrow{\widetilde{\sigma}}$ & 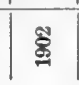 & 泃 & 䔍 & 票 & 单 \\
\hline
\end{tabular}


would probably, even in its second year, be more conspicuous for its weeds than for its corn. Farm animals, if left to shift for themselves, would doubtless, in most cases, soon cease to exist or would rapidly change their habits and appearance. A poultry yard, if deserted by man, would soon be cleared of chickens by marauding animals, by disease, or by starvation. A rose garden requires constant care to prevent its losing the high type of flower production desired by man. An apple orchard under relaxation of care very soon becomes infested by disease and reverts to relative non-productivity. Man's artificially selected types are in a condition of high tension, which is soon relaxed, partly or wholly, when man ceases to select and to care for his selected types.

326. Inheritance. Much that has been said bears more or less directly upon the topic of inheritance. "Heredity is the rule of persistence among organisms." It is an old saying that "like begets like," and while we know that organisms vary from one generation to another, we also know that they resemble one another with varying degrees of resemblance. We expect individual characteristics of parents to be more or less represented in the individual characteristics of offspring. Francis Galton studied in a large number of families the relations between the average height of the parents and the average height of the adult children, and some of these relations appear in the following table:

Average height of parents

72.5

71.5

70.5

69.5

68.5

67.5

66.5

65.5

64.5
Average height of children

71.4

69.9

69.5

68.6

68.0

67.6

67.1

66.8

65.6 
In no case is the average height of the children widely different from that of the parents. It is evident that children of tall parents are likely to be tall, though not averaging as tall as their parents, and that children of short parents are likely to be short, though not averaging as short as their parents. It must be understood that there may be exceptionally tall or exceptionally short chiliren in any family, and that such cases are included in the averages given.

Various other characteristics are inherited with the kind of definiteness that is shown above for height. It is often supposed that infectious diseases are inherited, but with the possible exception of a very few cases, this is not true. The claim that diseases are inherited gains apparent support from the fact that such a disease as tuberculosis may appear for several generations in the same family. In case of tuberculosis the offspring may inherit a weakened body, and although they do not really inherit the disease, they inherit a body so weakened that the disease readily gains a hold in it. Under these circumstances, constant association with those who have the disease may lead to infection.

327. Heredity and the future of the race. Few things contribute more to successful living than a sound and vigorous body, and such is a heritage of untold value. An unsound body is also a heritage, but a handicap heritage. We cannot emphasize too strongly the importance of making sure that no avoidable tendency to disease and no abnormally weakened bodies are passed on to succeeding generations. There are few tragedies more awful than that of being born into the world weighted down with a weakened body. Such bodies are given to innocent people because parents or society did not know enough or care enough to prevent the inheritance of things that make successful life hard, often well-nigh impossible, for the offspring. It is high time for the human race to recognize and use what is known of biological inheritance. We produce high types of corn and cattle because we want to make money 
from the product. What are we doing to make sure that the next generation of men and women shall be physically, intellectually, and morally as effective as the laws of heredity will enable us to make them?

328. Controlling human environment. No one of us can now determine what our own heredity shall be. That has been settled for us. We can decide, in a measure, what shall be the heredity of those to come after us. We can do much toward changing our environment so that defects in our own heredity may not lead to results so undesirable as might otherwise be.

A weakened body may often be strengthened by judicious care and exercise, so that a hereditary weakness may be almost or entirely overcome. We can curb a hereditary tendency until it is almost or quite inoperative. We can create for ourselves new and artificial environments which shall enable us to turn a harmful or worthless hereditary tendency into efficiency and a high type of usefulness. It is a heavy task to stem the tide of nature, and he who would do it must prepare for an effort in which some have failed and some have succeeded. It is worth the effort, for what is better than to turn weakness into efficiency? 


\section{INDEX}

(References to illustrations are indicated by asterisks accompanying page numbers. When an asterisk precedes the citation of a group of pages it means that several illustrations are included)

Absorption by plants, $234-240$

Agar, 81, 82

Air, 1*, 102

Air, composition of, 65,66

Air, compressibility of, $49,50,52$

Air, expansion of, 50-52

Air, expansion when heated, 10, 11*, 12,13

Air, how warmed, 10, 19, 20

Air, movements of, 140*

Air, properties of, *1-15

Air, structure of, 49-54

Air, water of, $* 21-27$

Air, weight of, *3-10

Air a mixture, 55,65

Air and combustion, *55-64

Air pressure, *4-10, 119, 121, 122, 129,130

Air pressure and altitude, 8*, 9*, 10

Air pressure and winds, $* 28-45$

Air pressure shown on weather maps, *29-45

Alcohol, 111, 135

Alcohol and evaporation, 111

Altitude and air pressure, *8-10

Altitude of sun, *16-18

Aluminum, 61, 135

Ammonia and cold storage, 111

Aneroid, 5*, 6, 8*

Animals as soil formers, 197, 200, 202,203

Anopheles, 98, 99*

Anti-cyclone, 35, 37, 38*

Antimony, 61

Argon, 65, 66

Arsenic, 61

Artificial selection, 294-297*, 298, 299

Ascent of water, 238, 239*

Assimilation, 251, 252, 259

Atmospheric pressure, *5-10, *28$45,119,121,122,129,130$
Atomic theory, 59,60

Atoms, 59, 60, 62-64, 66

Automobile, 10

Bacteria, *85-97, 156, 157, 225, 226

Bacteria, colonies of, $82 *$, 91*

Bacteria, distribution of, *88-97

Bacteria, photomicrographs of, $85^{*}$

Bacteria, useful, 87

Bacteria and decay, 86

Bacteria and disease, 87

Bacteria in cultivation, 87

Bacteria in water, 156,157

Bacteria of the air, 79-82*

Bacteria of the soil, 225, 226

Bacteria upon bread, 88, 89

Bacteriology, 85, 86

Balance of life, 285-289

Balloons, 133, 134

Barium, 61

Barograph, 5*, 8

Barometer, *5-8, 29-48, 129, 130

Barometer, aneroid, 5*, 6, 8*

Barometer, graduation of, 7*, 8*

Barometer, mercurial, 6*, 7*, 129, 130

Barometric readings, $* 29-48$

Bees, overproduction of, 283

Bicycle, 1, 10

Birds, reproduction of, 275, 276

Bismuth, 61

Bladder glass, 4*, 6

Blade of leaf, 69,70 *

Blizzard, 40

Blood poisoning, 87

Boiling, *104-108

Boiling and elevation, 106*

Boiling and melting, 108

Boron, 61

Brass, 135

Bread, in relation to bacteria, 88,89

Breathing, 268 
Bromine, 61

Bubonic plague, 101

Buoyancy, *132-135

Buoys, 152

Burning, of candle, $* 55-57,62-64$

Caisson, 2, 3*

Calcium, 61

Calms, belt of, 45

Canals, 147, 150, 151

Candle, $55-57,62,63$

Canning fruits, 86

Canoe, travel by, 149,150

Capillarity of soil, 207

Carbohydrates, 74, 75, 247, 248, 256

Carbohydrates, manufacture of, 74- 78

Carbon, 61, 63, 67, 74

Carbon dioxide, 63, 64* , 65, 68, 69, $74,81 *, 187,203,260,268$

Caves, 194

Cells, 71, 73*, 237*

Centigrade thermometer, 11, 12*

Cheese-making, 87

Chemical change, 60

Chimneys, 14

Chlorine, 61

Chlorophyll, 74-76, 253

Chloroplast, 73,78

Choke damp, 65

Cholera, 87

Chromium, 61

Chrysanthemum, 297*

Circulation, 257, 258*, 259, 267

Cities, origin of, 149,150

City block, a crowded, 89*

Clay, 200-202

Cleanliness and disease, 96, 97

Climatic influences of water, *136146

Clock, 180*

Clouds, 25*, 41

Coal, 135, 186, 187

Coal, energy in, 186, 187

Coal, formation of, 186*, 187

Cobalt, 61

Codfish, overproduction of, 283

Cold storage, 111-113

Cold waves, $37,38,39 *, 143 *, 144$

Cooling effects of evaporation, 109

Cooling of land and water, 142-144

Commercial relations of Great Lakes, $147,148,149 *-153$

Composition of foods, 242, 243

Compounds, 60, 62-64
Compressed air, 8*

Condensation of water vapor, 28$27,36, * 41-47$

Contaminated food, 265-267

Convection, 13*, 14

Copper, 61, 108, 135

Cork, 135

Corn, overproduction of, 281, 282

Corn, progressive breeding in, 297299

Corn, variation in, 290, 291, 296-299

Crops, value of, 233

Culex, 98*

Cyclones, *33-45

Dams, 130, 131*, 167*, 211*

Day, length of, 18, 19*

Death rate, $92 *, 93,155 *, 159 *, 162$

Decomposition, chemical, 60

Deforestation and erosion, $* 216-220$

Densities, table of, 135

Density, 134, 135

Dependent plants, $76 *, 77 *, * 82-85$

Desert-plant formations, 228*

Dew point, 24, 25, 26

Diastase, 248

Diffusion, $50,51,54$

Digestion, 248, 249, 256, 257

Dikes, 130

Diphtheria, 87

Disease, destruction by, 285

Disease and cleanliness, 96,97

Disease germs, $* 88-101$

Distillation, 107*, 108

Diving bell, 3

Dodder, 77*

Drainage, *205-214

Drainage, natural, 208

Drainage canal of Chicago, 83

Dry farming, 212, 213

Dunes, *221-223

Dust, 65, 79-82*

Earth, crust of, 66, *191-223

Earthworms and soil, 203

Ebony, 135

Efficiency of machines, 179

Electric power, 75

Electricity, 75

Elements, 60, 61

Elevation and air pressure $\$$ \%-10

Energy, 165-189

Energy, kinetic, 181

Energy, measurement of, 181

Energy, mechanical, *180-184 
Energy, potential, 181

Energy, source of, for plants, 75,76

Energy, transformations of, 181-189

Energy and life, 188, 189

Energy from sun, 187, 188

Environment, changes in, 295, 296

Environment, human, 302

Enzymes, 249, 256

Epidermis, 71, 73*

Equator, heat, 45

Erie canal, 150, 151

Erosion, 197, 198*, *215-223

Erosion and deposit, 220

Erosion and vegetation, 218*, 219*

Erosion by plants and animals, 197, 198*

Erosion by wind, 221*

Ether and evaporation, 111

Evaporation, 21, 109

Evaporation, rate of, 114*

Evaporation from plants, 115*, 116

Factory, plant compared to, 78

Fahrenheit thermometer, 11, 12*

Farm wells, 163*

Fermentation, 81, 82

Filtering plants, 160

Fire engine, 126

Fire extinguishers, 65

Flame, products of, $* 56-58,62-65$

Flame, structure of, $* 55-57$

Flea, and bubonic plague, 101

Floating objects, 133*

Flower, ${ }^{* 276-278}$

Fluid pressure, 130

Fluorine, 61

Food, purpose of, 262, 263

Food, transportation of, 247-249, 259

Food, variety of, 264, 265

Food in plants, 246-252

Food manufacture, *67-78

Food manufacture, relation of air to, $67-69$

Food storage, 249, 250*, 251

Food supply, 241-245

Football, 1, 6

Foot-pound, 177

Forecasting, weather, 46, 48

Formaldehyde, 86

Fort Dearborn, location of, 150

Forests and drainage, *216-220

Forests and erosion, *216-220

Fox, overproduction of, 288

Freezing, 103, 104, 108, 116, 117

Freezing mixtures, 116, 117
Freezing temperature, 12, 108, 104, 108

Freezing water, work by, 193*

Friction, 173, 174, 176

Frog, reproduction of, $273,274 *, 275$

Frost, action of, 193

Frost warnings, 48

Fruits and climate, 146

Furnaces, heating, 14

Galveston, hurricane in, 40*, 41

Gas, in candle flame, 56, 57*, 62-64

Gas pressure, 53

Gases, expansion of, 50,52

Gelatin, 81, 82

Generator for carbon dioxide, 64*

Germ diseases, 92-101

Glaciers, *195-197

Glass, 135

Gold, 61, 135

Grasslands, *229-232

Gravel, 201, 202

Grazing, 231, 232*

Great Lakes, *136-139, *143-153

Great Lakes, commercial relations of, $147,148,149 *-153$

Greenhouse, 20

Guard cells, 72, 73*

Harbor, relation to railroads, 151

Harbors, 151, 152

Havana, Cuba, healthfulness of, 96

Heat and molecular movement, 53

Heat as energy, *181-189

Heating of land and water, $* 140-142$

Heredity, 300-302

Hereford, 292*, 294*

High-pressure centers, *30-39

Hot waves, 37, 38, *137-139

House fly, 88, *93-96

House fly, carrying of bacteria by, 94*, 95*

House fly, disposal of, 95,96

House fly, life history of, $* 93-94$

Humidity, *21-27

Humidity, absolute, *22-27

Humidity, relative, *22-27

Humidity in cyclones, 36

Humidity in houses, 27

Humidity in United States, 26*, 27

Humus, 203

Hurricanes, 40*, 41

IIybrids, 292-294*

Hydraulic press, 126, 127*, 128

Hydrochloric acid, 64 
Hydrogen, 58-63, 68, 74

Hygienic aspects of nutrition, 262269

Hygienic conditions, 92*, 93*

Ice, 103-117

Ice cream, 117

Ice machines, 111, 112*

Illinois and Michigan Canal, 151

Indian pipe, $76^{*}$

Inheritance, 299-302

Iodine, 61

Iron, 61, 135, 142

Irrigation, *205-214

Isobars, *30-39

Isotherms, *30-39

Keokuk dam, 167*

Kerosene, use of with mosquitoes, 100

Lake breeze, *138-140

Lake climate, effects of, 146

Lakes, climatic influence of, $* 136$ 146

Land breeze, 140

Lawn sprinkler, 126

Lead, 61, 108, 135

Leaf, *68-74

Leaf, interior of, $72,73^{*}$

Leaf, structure of, *69-73

Leprosy, 87

Life in the soil, 224-226

Life-saving stations, 152, 153

Light, 75, 76, 185-188

Light as source of energy, 75,76

Lighthouse, 2*, 152

Limewater, 63

Liquids and molecular theory, 53,54

Lockjaw, 87

Low-pressure centers, *30-39

Lumbering, *229-232

Machines, *172-179, *183-186

Magnesium, 61

Malaria, cause of, 97

Mammals, reproduction of, 275, 276

Manganese, 61

Marble, 64

Mastication, 254-256, 263

Matter, states of, 103

Measurement of work, 177

Melting point, 108

Mercurial barometer, $6 *$, 7*

Mercury, 7, 61, 135

Mesophyll, 70, 73*
Metals, 61

Milk, 90, 91

Milk, bacteria in, 91*

Mistletoe, 84*

Mixtures of gases, 53,59

Moisture of air, 21-27, 36, 45, 46, 47*

Mold, 79-82, 87

Molecular theory, 52-54

Molecules, 52-54, 59, 60, 64, 66

Mont Blane, 105

Morning-glory, overproduction of, 281,282

Mosquitoes, destruction of, 99,100

Mosquitoes, kinds of, 100, 101

Mosquitoes, life history of, 97, 98*

Mosquitoes and malaria, *97-100

Mount Rainier, 9*, 106*, 195*

Mushrooms, 83*

Natural selection, 294, 296

Niagara Falls, work by, 165, 166*, 171*

Niagara River, 165, 166*, 171*

Nickel, 61

Night, length of, $18,19 *$

Nitrogen, $61,65,66,243-245$

Nitrogen, loss from soil, 243, 244

- Nitrogen, supply of, 245

Norther, 40

Nutrition, hygienic aspects of, 262269

Nutrition of animals, *253-261

Oak wood, 135

Ocean, 136, 146

Offspring and parent, *290-302

Osmometer, 235*

Osmosis, *234-238

Overproduction, 281- 284

Oxygen, 58-66, 68, 74, 187, 259, 260, 268

Palisade, 73*

Palmate leaf, 70*

Parasites, 83, 84*

Parent and offspring, *290-302

Pasteurization, 90, 92

Peach growing and climate, 146

Peanut seedling, 279*

Peat, 200, 202, 203

Perspiration, 113

Perspiratory glands, 118

Petiole of leaf, 69, 70*

Phosphorus, 61, 243

Photographic plate. is 
Photomicrographs of bacteria, 85*

Photosynthesis, 76-78

Pine wood, 135

Pinnate leaf, 70*

Plague, 87

Plant associations, 228*, 229*

Plant compared to factory, 78

Plant covering of the earth, *225-233

Plant food, raw materials, $67,68,74$, 78,203

Plant food, where made, 69

Plant formations, *227-229

Plants, reproduction of, $270-273$, *276-280

Plants as soil formers, 197, 198*, $200,202,203$

Platinum, 58, 61, 108, 135

Pneumatic tire, 1, 6, 10, 49

Pneumonia, 87

Pollution of water supply, *156-164

Pond scum, 271, 272*

Portages, 149*, 150, 151

Potassium, 61

Pressure, transmission of in liquids, *126-129

Pressure at faucets, 129

Pressure of liquids, *118-133

Protein manufacture, 242

Protoplasm, 73

Pulleys, mechanical advantage of, 176

Pulleys, use of, *173-176

Pumps, 119, 120*, 121, 122

Quito, Equador, 105

Rabbit, overproduction of, 287, 288

Rabbits, 295, 296

Ragweed, variation in, 291

Railways, $147,148,151$

Rainfall in United States, 45, 46, 47*

Raspberry, 279*

Reclamation of swamp lands, 213, 214

Refrigeration, 86

Refrigerators, 116

Reproduction, *270-280

Reservoirs, for water storage, 160

Respiration, 252, 260, 268

Rock of earth's crust, *191-199

Root hairs, 236*, 237*

Root structure, *236-238

Running water, work by, *165-168

Rural water supply, 162, 163*
Saliva, $255,256,263$

Salmon, overproduction of, 282,283

Sand, 200-202

Sand dune, *221-223

Sanitary canal, 151, 161, 162

Saprophytes, 83*

Saturation, water vapor, 21, 22

Sault Sainte Marie Canal, 147

Sea water, 135

Seasons, *16-20

Seasons, relation to sun, ${ }^{* 16}-18$

Sedimentation, *215-223

Selection, *292-299

Sewage disposal, *154-164

Sewers, 160, 161

Silicon, 61

Silt, 200-202

Silver, 61,135

Simple substances, 60,61

Siphon, 118, 119*

Sirocco, 38

Smoke, 14, 15, 63, 79, 80

Soda water, 65

Sodium, 61

Soil, *196-239

Soil, as water filter, 163

Soil, kinds of, 200

Soil, value of, 245

Soil moisture, distribution of, 205*

Soil particles, 202, 203, 205*

Soil water, *205-214

Soils and man, 226

Solids, and molecular theory, 53, 54

Soot, 63,79

Starch, composition of, $68,74,75$

Starch, decomposition of, $68 *$

Starch, digestion of, 248

States of matter, 103

Steam, *104-108

Steam engine, $75,183,184^{*}, 185-187$

Steel plants, location of, 148

Stegomyia, 100*, 101

Stipules, 69

Stomata, 72, 73*

Storm warnings, 48

Struggle for existence, 281-289

Submarines, 133, 134

Suez Canal, 147

Sugar as plant food, 74-77

Sulphur, 61, 108, 243

Summer residences and climate, 146

Sun, altitude of, *16-18

Sunflower, 72

Sun's rays, inclination of, 17*, 18* 
Swamp lands, reclamation of, 213, 214

Symbols, chemical, 60, 61

Tadpole, 274*, 275

Teakettle, 107

Teeth, 254*, 255*

Temperature, *187-146

Temperature, seasonal changes of, 16

Temperature in cyclones, 33, 34

Temperature of air, 5, *10-20

Temperature of soils, 206

Texas fever, 101, 292-294

Thermometers, 11, 12*, 110*

Thermometers, wet-bulb and drybulb, $110^{*}$

Thunderstorms, 41, 42

Tick, and cattle fever, 101, 292-294

Tillage and water, 207

Tin, 61, 135

Tire, pneumatic, $1,6,10,49$

Tornado, 35, 42*, 43*

Trade winds, 44*, 45

Transpiration, 115*, 116, 206, 207

Transplanting, 240

Transportation by water, 147-153

Tuberculosis, 87, 301

Tunnels, 3

Turbines, 168, 169

Typhoid, 87, 90, 92, 93, 155, 159

Typhoid, death rate from, 92, 93, 155*, 159*

Typhoid and flies, $* 93-96$

Vapor of water, 21-27, 36, 41-47, 66

Variation, 290*-292, 295-300

Vegetative reproduction, 279*, 280

Veins of leaf, $69,70^{*}$

Vinegar and bacteria, 87

Waste material of plants, 75

Water, and soil temperature, 206

Water, boiling point, 105*, 106*, 108

Water, climatic effects of, *136-146

Water, composition of, 58*, 59, 60
Water, dissolving rock, 194

Water, freezing point, 104, 108

Water, pressure of, $118-183$

Water, produced by flame, $57,68,62$

Water and erosion, $192-196$

Water and tillage, 207

Water motor, 126

Water power, *167-169

Water supply, and sewage disposal, *154-164

Water supply, sources of, 154, 158*, 162, 163*

Water supply of New York City, 158*

Water table, 208, 209*

Water used by crops, 206, 207

Water vapor, $21-27,36,41-47,66$, 103

Water wheels, 168*

Water-borne commerce, 147-153

Weather, *28-48

Weather Bureau, The United States, 46, 48, 137, 138

Weather forecasting, 46,48

West Indies' hurricanes, 41

Westerly winds, belt of, $44^{*}, 45$

Wheat, variation in, $290^{*}$

Wild plants, value of, *229-232

Wind, *28-48

Wind and erosion, 221*

Wind belts, 44*, 45

Winds, cyclonic, $* 33-35$

Winds, direction of, $* 33-35,44,45$

Winds, trade, 44*, 45

Winds, westerly, 44*, 45

Work, 165-189

Work accomplished by heat, 182184*

Yeasts, 81, 82, 270*, 271

Yeasts, fermentation by, 81*

Yellow fever, 100, 101

Zebu, 292, 293*, 294*

Zinc, 61, 135 



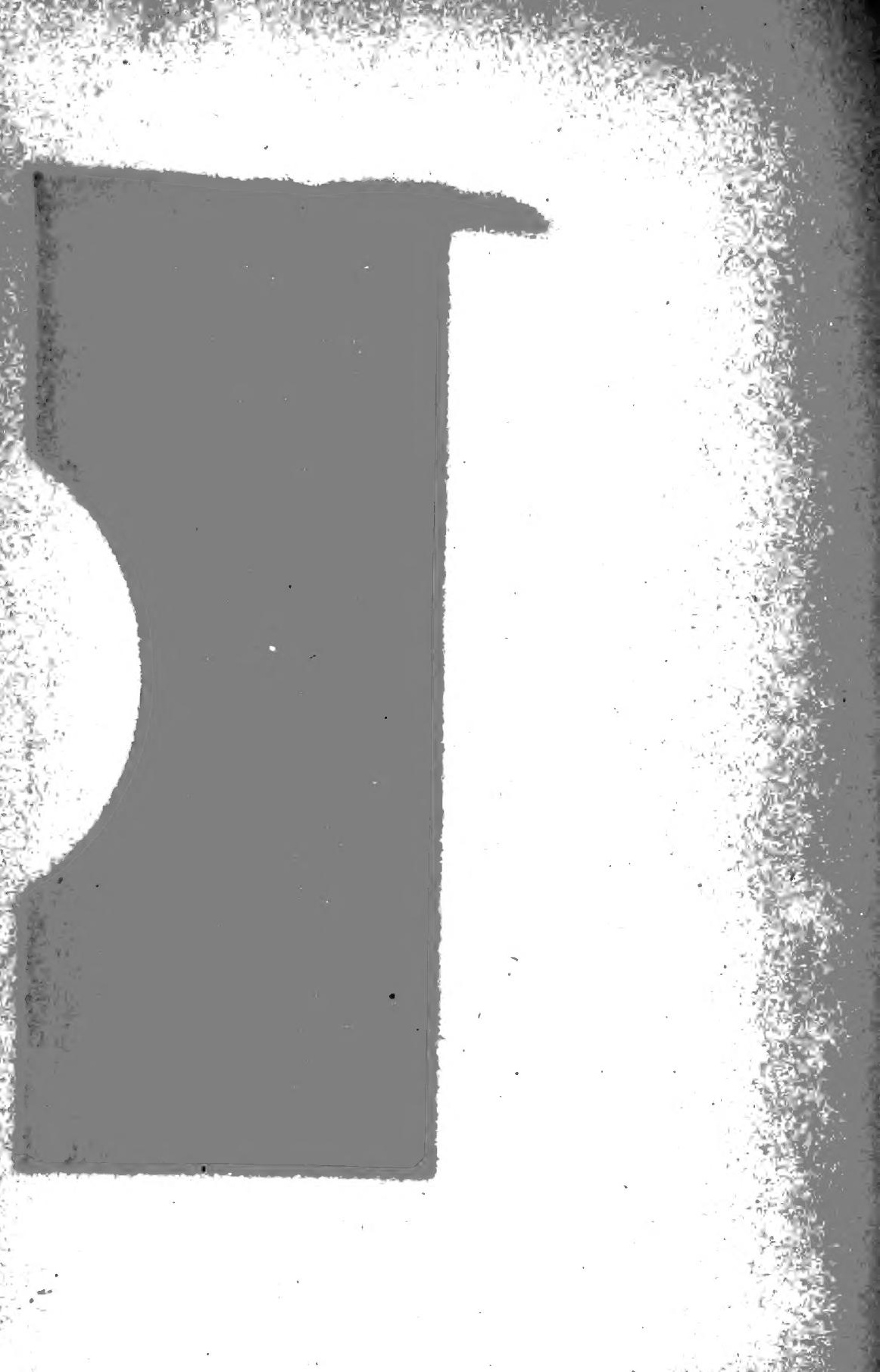




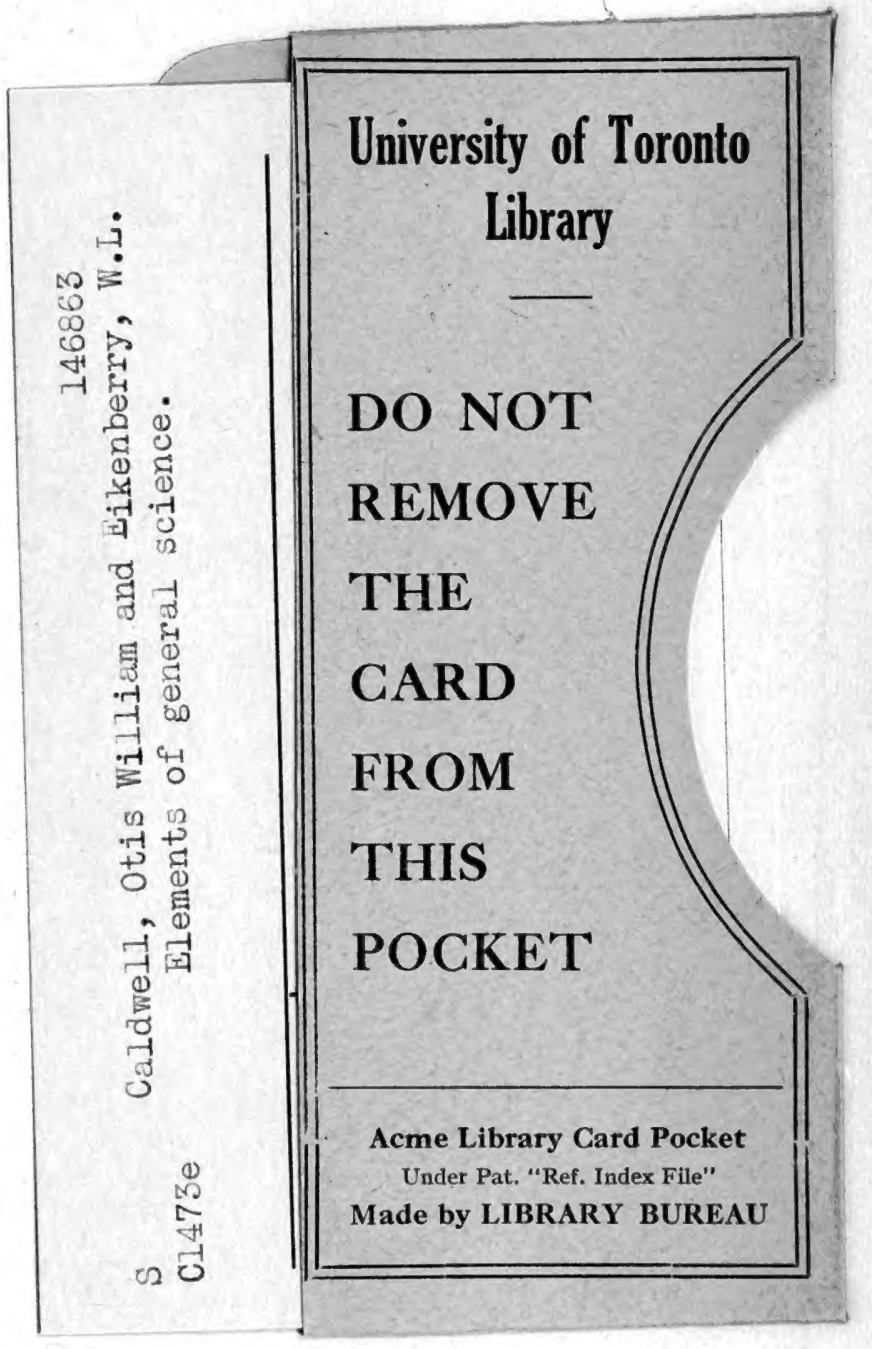


thitim

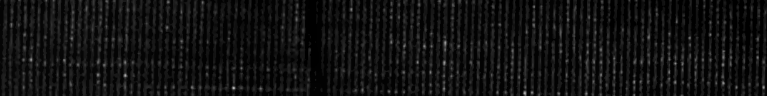

36.

(3)

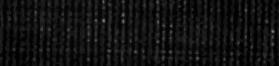

(6)

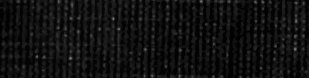

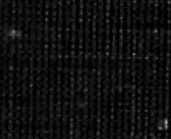

tos 